\title{
INSTITUTIONAL CHANGE PROCESSES IN NATIONAL TOURISM ADMINISTRATIONS: THE CASE OF SERVICIO NACIONAL DE TURISMO, CHILE
}

\author{
BY \\ César Alejandro Guala Catalán
}

A thesis submitted to the Victoria University of Wellington in fulfilment of the requirements for the degree of

Doctor of Philosophy in Tourism Management

Victoria University of Wellington

(2013) 


\begin{abstract}
Three decades after the creation of the Chilean national tourism administration - the Servicio Nacional de Turismo (Sernatur) - the government initiated a process of institutional change. In 2007, a bill was submitted to Parliament and in 2010 the bill was enacted (Act 20423). Act 20423 replaced the existing national tourism administration (NTA) with a new set of public organisations performing various roles in tourism. The act not only created a new structure but also modified the allocation of roles in tourism to different agencies thereby creating a new public institutional framework for tourism in Chile.
\end{abstract}

Although changes like those occurring in Chile have attracted some attention, such research tends to lack a broad perspective and fails to consider how and why processes of change occur and how changes in the general environment impact on the process. In order to address this broad perspective, this thesis concentrates on three research questions: what was the process that led to the creation of the new Chilean institutional framework for tourism, what were the factors that influenced and shaped the process, and how and why did the process and the factors influence the outcomes of the process. In this way, this research aims to provide a better understanding of how and why NTAs change over time.

To address this problem, a conceptual framework is developed from three separate bodies of literature: tourism organisations, the administration of the public sector, and tourism policymaking. The framework illustrates two critical aspects to investigate a process of change in NTAs: a spatial scale and a temporal scale. The first scale shows that the process of change occurs in, and is influenced by, a broad context composed of two sub-systems and multiple interrelated organisations. The second scale presents the process of change over time and shows that changes in the environmental conditions also influence the process.

The process of change and the influence of contextual factors are examined using an in-depth analysis of the relevant documentation. This method is complemented by in-depth semi-structured interviews with multiple stakeholders. In order to address 
the various aspects of the conceptual framework, a multi-phase approach is also adopted for the analysis of the data.

The research reveals that in democratic countries like Chile, institutional change occurs in the context of a legislative process. Three policy stages are suggested to operationalise the process: pre-legislative, policy window, and legislative. In each of these stages there are several components of a policy process: evaluations, agendas, formulation, decision making, and implementation. During the process of change these components overlap and a division into consecutive phases as proposed by the Policy Cycle Model cannot be operationalised. The thesis also shows that the process is influenced and shaped by several factors arising from environmental conditions and evaluation reports. Environmental conditions directly impact on the process and shape the focus and outcomes of evaluation reports. In turn, evaluation reports impact on the process by shaping the proposals discussed during the policy stages. This also challenges the Policy Cycle Model on the ground that evaluations are not part of a single phase and that these evaluations play different roles during the policy process. Finally, this thesis suggests that the outcomes of a process of institutional change in tourism are influenced by both the environmental conditions and the features of the process (consultation, participation, agreement, disagreement, power, negotiation, and acceptance). Variations in the environmental conditions influence the features of the policy process and in turn, changes in these features directly impact the outcomes of the process.

In summary, the analysis of the Chilean case reveals that processes of change in NTAs are directly influenced by the general environment in which these processes occur. This suggests that these processes are not isolated developments and therefore the general environment strongly influences the features and outcomes of the process. Hence, investigating the influence of these conditions is critical to explain how a process of change occurs and why particular outcomes result from the process. Variations in the environmental conditions impact on the features of the policy process so that changes in these features directly shape the outcomes of the process. 


\section{ACKNOWLEDGEMENTS}

I would like to say thank you to all my research participants. Without their involvement, this research could have not been possible. My deepest thanks to my principal supervisor, Professor Douglas G. Pearce. His guidance, patience and commitment were invaluable to reach this stage. Thank you for giving me the opportunity to start this journey and learn from you. I would also like to thank my second supervisor, Dr. Julia Albrecht. Her advice, empathy and support throughout these years made this a great learning process. Thank you to my wonderful parents and sister. Their commitment, dedication and endeavour have been an example for me to follow and an inspiration for whatever I do in life. This thesis is for them. To Steve; without your company and support this journey would have not been the same. This thesis is also for you. To Paola, Ximena, Carola, Fabiola, Christian, Aldo, Rocío, Max and many others friends from Chile; they were part of this dream from the very beginning and looked after me in spite of the distance. To my dear friends in New Zealand: Alf, Grant, Fraser, Harp, Shirley, Shane, Carlos, Ursula, Rodrigo, Begoña, Lili, Maggy, Phil, Regina, Daniel, Allan, Katja, Petra and many others. They were my family here for the last four years and will be always in my heart. To my good friend Huong, for her support and company during long sessions analysing data and writing up this thesis. To David Tecklin, Bronwen Golder, Deborah Collins and Emma Adcock for showing me New Zealand as the best place to carry out my $\mathrm{PhD}$. To Jan Stewart, for her great support with my English. To my $\mathrm{PhD}$ colleagues at the university: Rebecca Bednarek (NZ), Zanele Ndaba (South Africa), Lois Parkes (Jamaica), Heike Schänzel (Germany), Chootima Longjit (Thailand), Garoon Pongsart (Thailand), Tuan Ngoc Le (Vietam), Ina Reichenberger (Germany), Robert Capistrano (Phillipines) and Tibor Zsirmik (Hungary). I would also like to thank Sophia and Megan for their help during these years. Thanks to the owners and staff of Café Astoria. Working there gave me the opportunity to take a breath from my thesis, meeting new people and discovering a different facet of what living in New Zealand is. Last, but not the least, to New Zealand Aid (NZAID) for granting me the scholarship and allowing me to come to New Zealand. Without these four years of funds my life here would have been a struggle and this thesis hard to finish. To all of them and many other people I have met during these years, thank you very much. 


\section{TABLE OF CONTENTS}

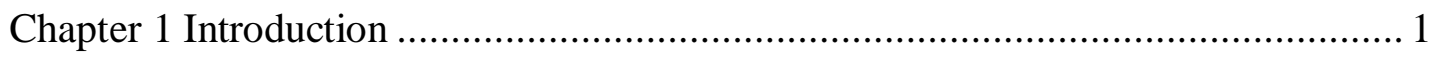

1.1 Why processes of change in national tourism administrations?................. 1

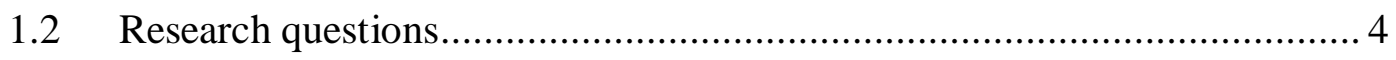

1.3 What is a process of institutional change in NTAs? ...............................6

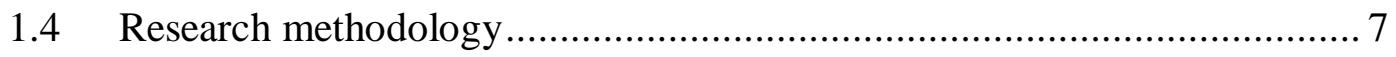

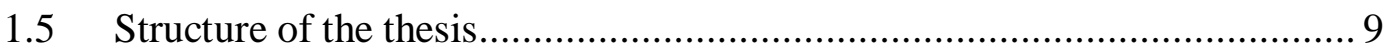

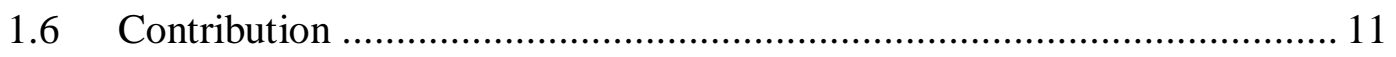

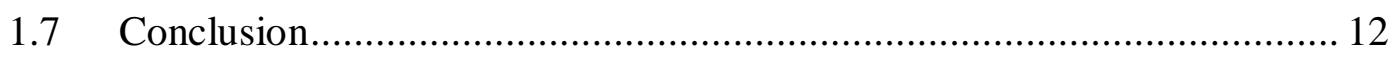

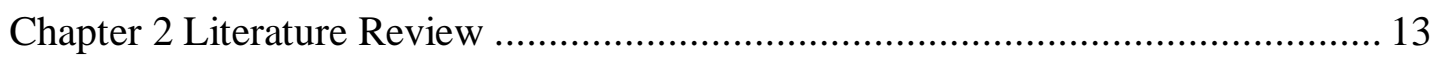

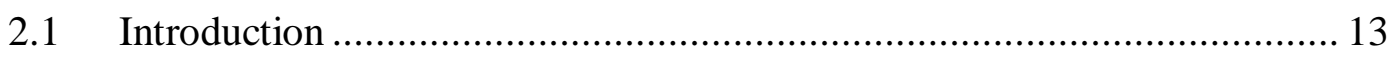

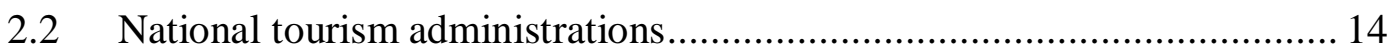

2.3 Tourism policy making: the Policy Cycle Model as an approach to explore institutional change processes in NTAs ............................................................. 18

2.3.1 The Policy Cycle Model. ................................................................ 19

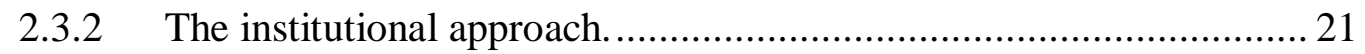

2.4 A conceptual framework to investigate the institutional change processes in Sernatur. 22

2.5 The public sector administration: an approach to explore NTAs .............. 27

2.5.1 New Public Management: a dominant approach for the public sector.27

2.5.2 Governance and Administrative reforms of the public sector.. 29

2.6 New elements for the interpretation of findings: An integrated conceptual framework to investigate the process of change in Sernatur ............................... 32

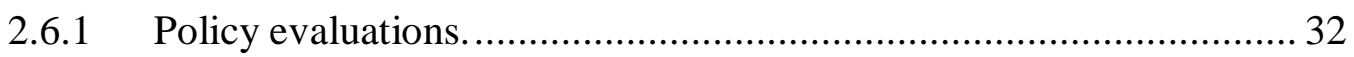

2.6.2 Policy agendas, formulation, and decision making. ........................ 33

2.6.3 An integrated framework to investigate the process of change in

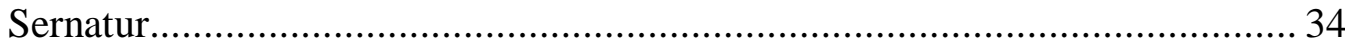

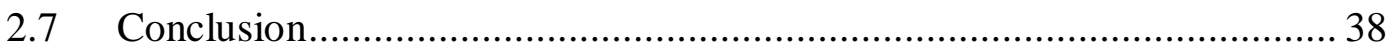

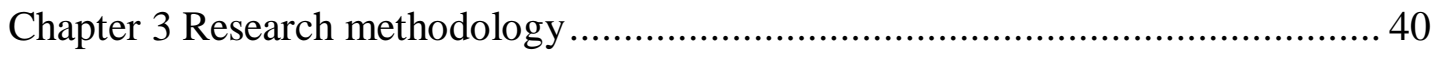

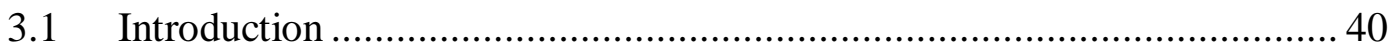

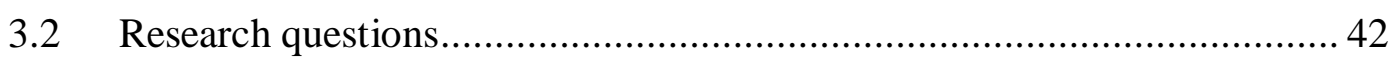

3.3 Methodological design: Qualitative case study, interpretive, and multi-

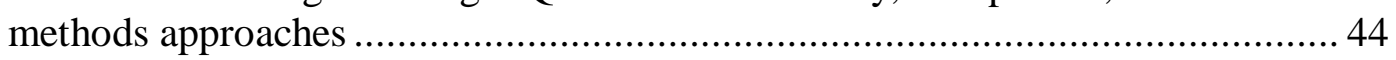

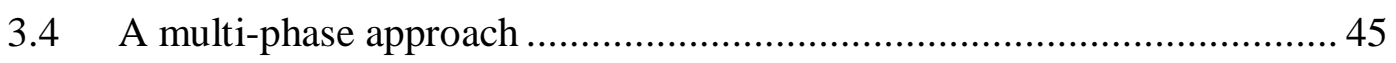

3.4.1 Phase I: Approaching the case..................................................... 45

3.4.2 Phase II: Immersion in the data................................................ 51

3.4.3 Phase III: Final data analysis and interpretation. ........................... 56 


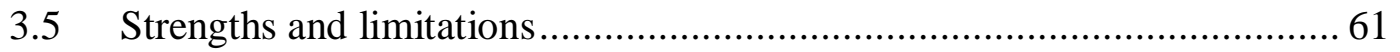

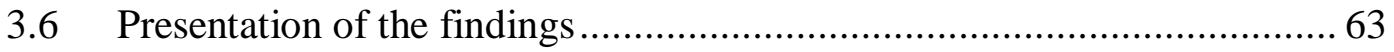

Chapter 4 Chile in the 2000s - environmental conditions and background information

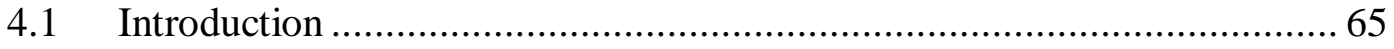

4.2 The Chilean political and administrative sub-system .............................6 66

4.2.1 The Executive branch: the government administration. ....................6 67

4.2.2 The Legislative branch............................................................ 73

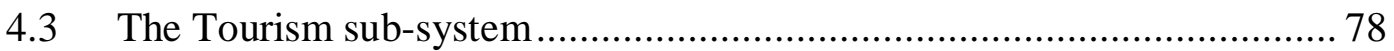

4.3.1 The tourism industry: an overview............................................ 78

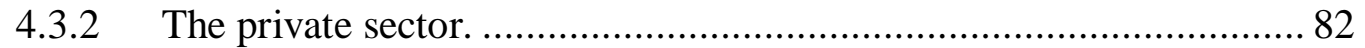

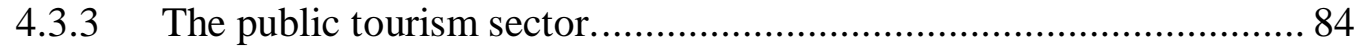

4.4 The Chilean NTA: Servicio Nacional de Turismo (Sernatur)................... 90

4.5 Environmental conditions in Chile during the last decade ...................... 93

Chapter 5 The process of institutional change in Sernatur .................................. 99

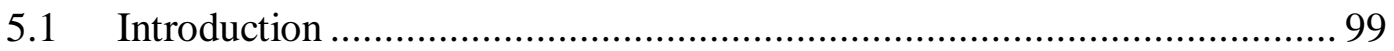

5.2 The process of change in Sernatur: An overview ................................ 100

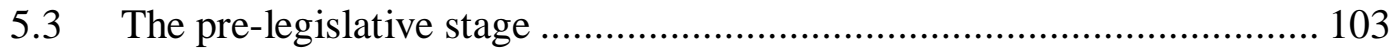

5.4 The policy window and the institutional agenda ................................. 107

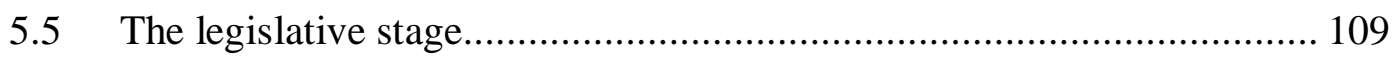

5.5.1 The decision agenda............................................................ 110

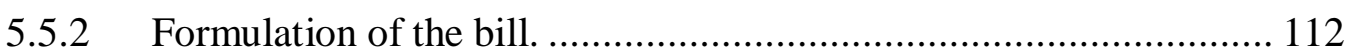

5.5.3 The decision making in Parliament. ................................................. 115

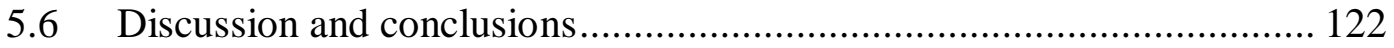

Chapter 6 The factors that influenced the process of change in Sernatur .............. 127

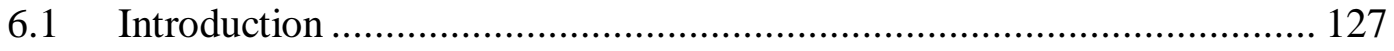

6.2 The evaluation reports: an overview ............................................. 131

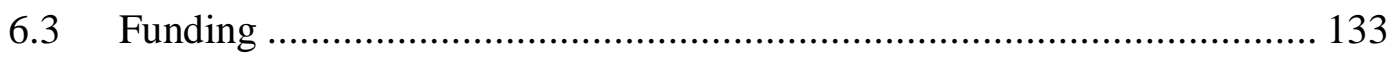

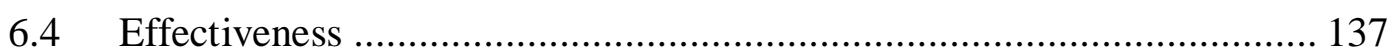

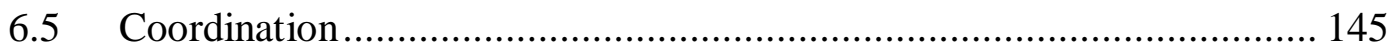

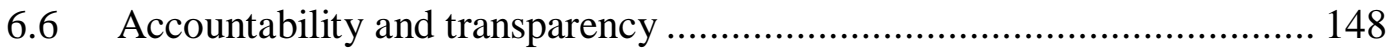

6.7 Discussion and Conclusions ............................................................... 152

Chapter 7 The outcomes of the process of change and the influence of the process

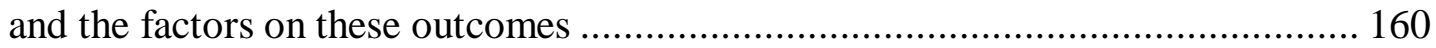

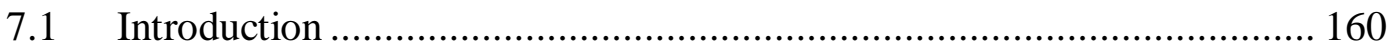

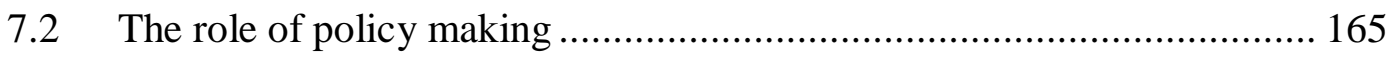

7.3 The role of marketing................................................................... 168 


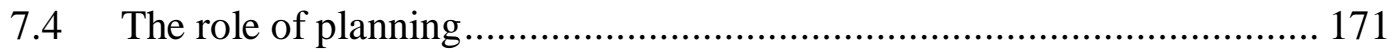

7.4.1 Tourism development in the SNASPE. ..................................... 172

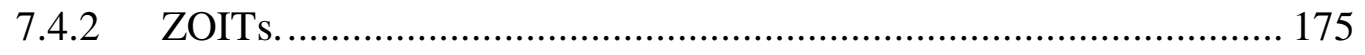

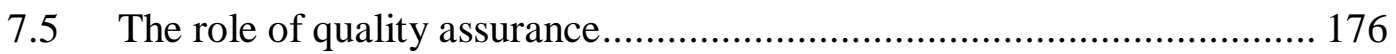

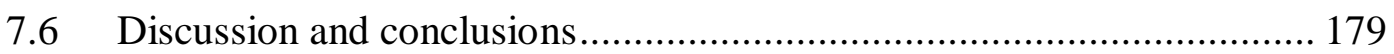

Chapter 8 Understanding processes of change in NTAs: How and why do these

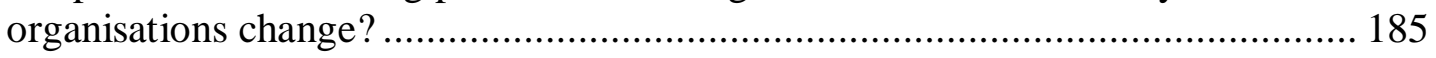

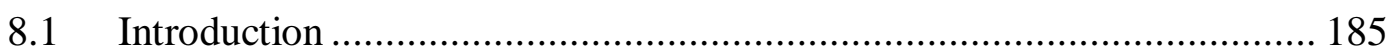

8.2 The lessons learnt from the process of change in Sernatur.................... 186

8.2.1 The processes of change in Sernatur. .......................................... 186

8.2.2 The factors that influenced and shaped the processes in Sernatur. ... 189

8.2.3 The influence of the process and the factors on Act 20423 ............ 193

8.3 How and why NTAs change over time. A generalised conceptual framework to investigate processes of change in NTAs ................................ 199

8.3.1 Processes of change in NTAs: how do these processes occur?........ 204

8.3.2 Why do NTAs change? The factors shaping a process of change. ... 207

8.3.3 Why particular outcomes result from a process of change? The influence of the process and the environmental conditions......................... 209

8.4 Implications and contributions of this research.................................... 211

8.5 Some reflections about this research .............................................. 215

8.6 Avenues for future research ...................................................... 217

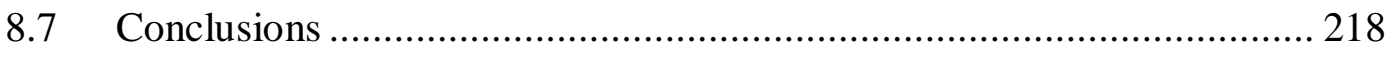

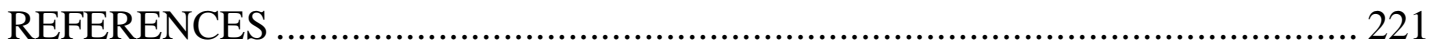

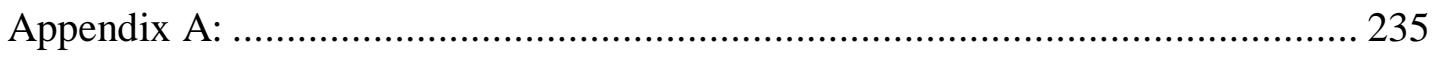

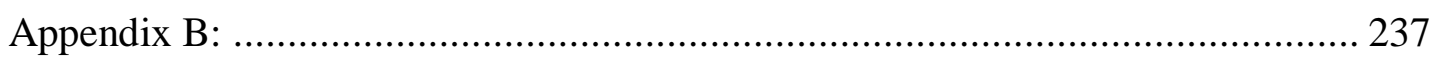

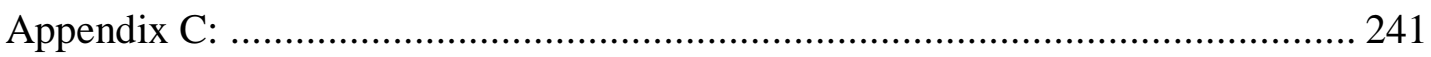

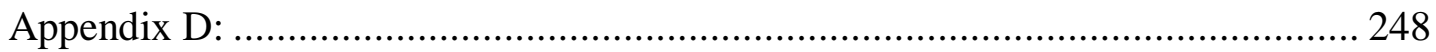

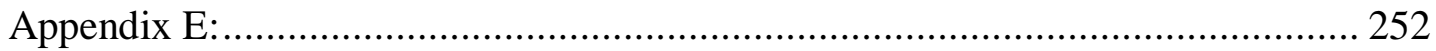

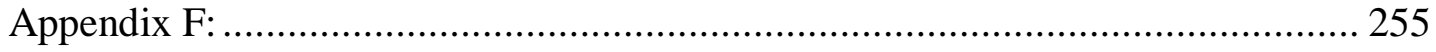




\section{List of Figures}

Figure 1.1: Institutional change in the Chilean framework for tourism 1

Figure 2.1: A conceptual framework for the inter-organisational analysis of tourism organisations.

Figure 2.2: The Policy Cycle Model....

Figure 2.3: A conceptual framework for the analysis of processes of change in NTAs

Figure 2.4: An integrated framework to investigate the process of change in Sernatur

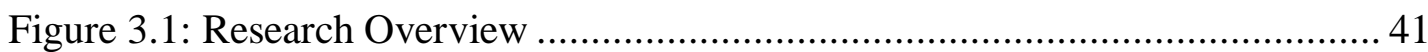

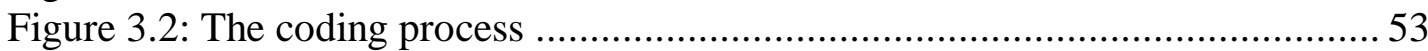

Figure 3.3: First analytical framework for the investigation of the process of change

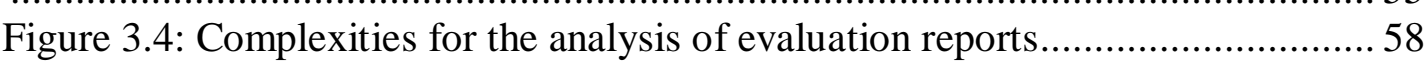

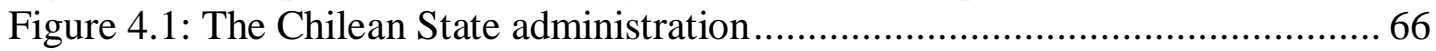

Figure 4.2: The legislative process in Chile ..................................................... 74

Figure 4.3: Inbound tourism and visitation in protected areas in Chile (2000-2010) 79

Figure 4.4: A comparison of priority tourism markets (2010-2010) ..................... 80

Figure 4.5: Contribution of the tourism sector to foreign exchange (period 2000-

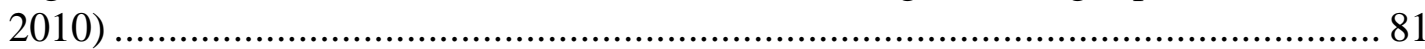

Figure 4.6: Public funds allocated to Sernatur and Tourism Chile (2000-2010) ...... 88

Figure 4.7: FNDR's funds allocated in tourism development by regional

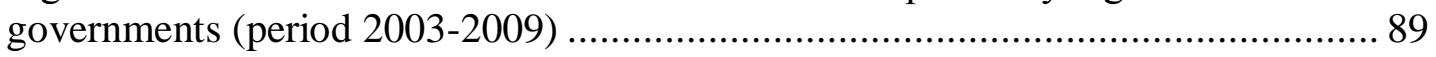

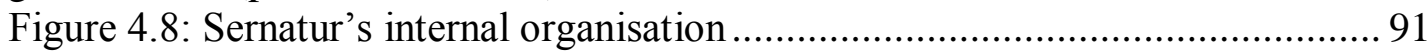

Figure 4.9: Environmental conditions underlying the process of change ................ 95

Figure 5.1: The process of change in Sernatur ............................................... 101

Figure 5.2: The legislative process for the tourism bill ..................................... 116

Figure 6.1: Types of evaluations identified in the Chilean case............................ 127

Figure 6.2: Content discussed during the process of change ............................. 129

Figure 6.3: Evaluation reports produced during the process of change................. 132

Figure 7.1: Features of the policy process: consultation, participation, agreement,

disagreement, negotiation, power, and acceptance ............................................ 161

Figure 7.2: A comparative analysis of the existing and resulting institutional

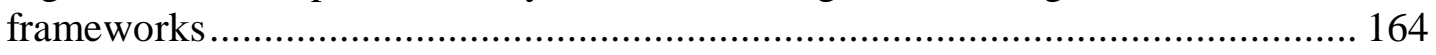

Figure 8.1: A generalised conceptual framework to investigate processes of change

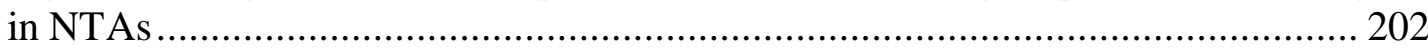




\section{List of Tables}

Table 3.1: Interview overview 47

Table 3.2: Analytical framework for the analysis of evaluation reports.................. 59

Table 4.1: Private organisations in tourism during the decade of the 2000s ........... 82

Table 4.2: Public organisations with roles in tourism during (period 2000-2010) ... 85

Table 5.1: Issues discussed during the pre-legislative stage (systemic agenda) ..... 105

Table 5.2: Issues agreed to be discussed in the bill (decision agenda) .................. 111

Table 5.3: Proposals discussed during the formulation of the bill ...................... 113

Table 5.4: Changes in the bill during the debate in Parliament ............................ 118

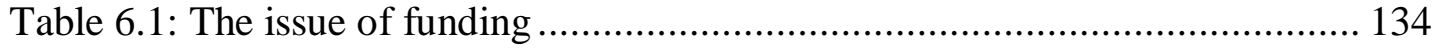

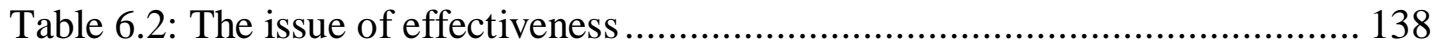

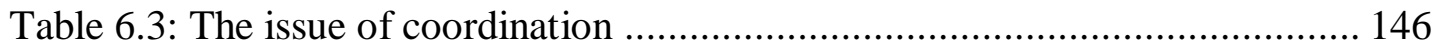

Table 6.4: The issues of accountability and transparency................................. 150 


\section{List of Acronyms}

\section{Spanish}

Achet

Achiga

C\&S

Conaf

Conama

Corfo

Consetur

Dipres

Fedetur

FNDR

Hoteleros Hoteleros de Chile

Hotelga

ndap

INE

ISO
Asociación Chilena de

Empresas de Turismo

Asociación Chilena de

Gastronomía

Boston Consulting Group

C\&S Soluziona Servicios

Profesionales

Corporación Nacional Forestal

Comisión Nacional del Medio

Ambiente

Corporación de Fomento a la

Producción

Consejo Superior de Turismo

Dirección de Presupuesto

Federación de Empresas de

Turismo de Chile

Fondo Nacional de Desarrollo

Regional

Federación Gremial de la

Industria Hotelera y

Gastronómica de Chile

Banco Inter Americano de

Desarrollo

Instituto Nacional de Desarrollo

Agropecuario

Instituto Nacional de

Estadísticas

International Organization for

Standardization

\section{English}

Chilean Association of Tourism

Companies

Chilean Association of

Gastronomy Companies

Boston Consulting Group

C\&S Soluziona Servicios

Profesionales

Forest Service

National Commission of

Environment

Economic Development Agency

Superior Council of Tourism

Budget Office

Chilean Federation of Tourism

National Fund of Regional

Development

Association of Hotel Companies

Association of Hotel and

Gastronomy companies

Inter American Development

Bank

National Institute of Agriculture development

National Institute of Statistics

International Organization for

Standardization 


\begin{tabular}{|c|c|c|}
\hline ITO & $\begin{array}{l}\text { Oficina Internacional de } \\
\text { Turismo }\end{array}$ & International Tourism Office \\
\hline Minecon & Ministerio de Economía & Ministry of Economy \\
\hline NPM & Nueva Gerencia Publica & New Public Management \\
\hline NTA & $\begin{array}{l}\text { Administración Nacional de } \\
\text { Turismo }\end{array}$ & National Tourism Administration \\
\hline NTO & $\begin{array}{l}\text { Organización Nacional de } \\
\text { Turismo }\end{array}$ & National Tourism Organisation \\
\hline OECD & $\begin{array}{l}\text { Organización para el Desarrollo } \\
\text { y la cooperación }\end{array}$ & $\begin{array}{l}\text { Organisation for Economic Co- } \\
\text { operation and Development } \\
\text { Public Administration }\end{array}$ \\
\hline $\mathbf{O O}$ & Oficina en el extranjero & Overseas Office \\
\hline PA & Administración publica & \\
\hline Sernatur & Servicio Nacional de Turismo & National Service of Tourism \\
\hline RTO & $\begin{array}{l}\text { Organización Regional de } \\
\text { Turismo }\end{array}$ & Regional Tourism Organisation \\
\hline Segpres & $\begin{array}{l}\text { Secretaria general de la } \\
\text { Presidencia }\end{array}$ & Secretary of the Presidency \\
\hline Sercotec & $\begin{array}{l}\text { Servicio de Cooperación } \\
\text { Técnica }\end{array}$ & Service of Technical Cooperation \\
\hline SNASPE & $\begin{array}{l}\text { Sistema Nacional de Áreas } \\
\text { Silvestres Protegidas del Estado }\end{array}$ & $\begin{array}{l}\text { National System of Protected } \\
\text { Areas }\end{array}$ \\
\hline Societur & $\begin{array}{l}\text { Sociedad Chilena de } \\
\text { Investigadores en Turismo }\end{array}$ & $\begin{array}{l}\text { Chilean Society of Tourism } \\
\text { Research }\end{array}$ \\
\hline UChile & Universidad de Chile & University of Chile \\
\hline UValparaiso & Universidad de Valparaíso & University of Valparaiso \\
\hline UNWTO & $\begin{array}{l}\text { Organización Mundial del } \\
\text { Turismo }\end{array}$ & $\begin{array}{l}\text { United Nations World Tourism } \\
\text { Organisation }\end{array}$ \\
\hline ZOIT & Zonas de Interés Turístico & $\begin{array}{l}\text { Zones of Interest for Tourism } \\
\text { Development }\end{array}$ \\
\hline
\end{tabular}




\section{Chapter 1 Introduction}

\subsection{Why processes of change in national tourism administrations?}

Three decades after the establishment of the Chilean national tourism administration (NTA) - the Servicio Nacional de Turismo (Sernatur) - the Chilean government introduced a bill to Parliament in 2007 in order to strengthen the public institutional framework for tourism. As a result, in 2010 Parliament passed the bill and enacted Act 20426 "that creates a new tourism institutional system for tourism development" (Ministerio de Economía Fomento y Reconstrucción, 2010). The act replaced the existing national tourism administration (NTA) and created a set of new public organisations responsible for tourism. The changes resulting from the enactment of Act 20423 are presented in Figure 1.1.

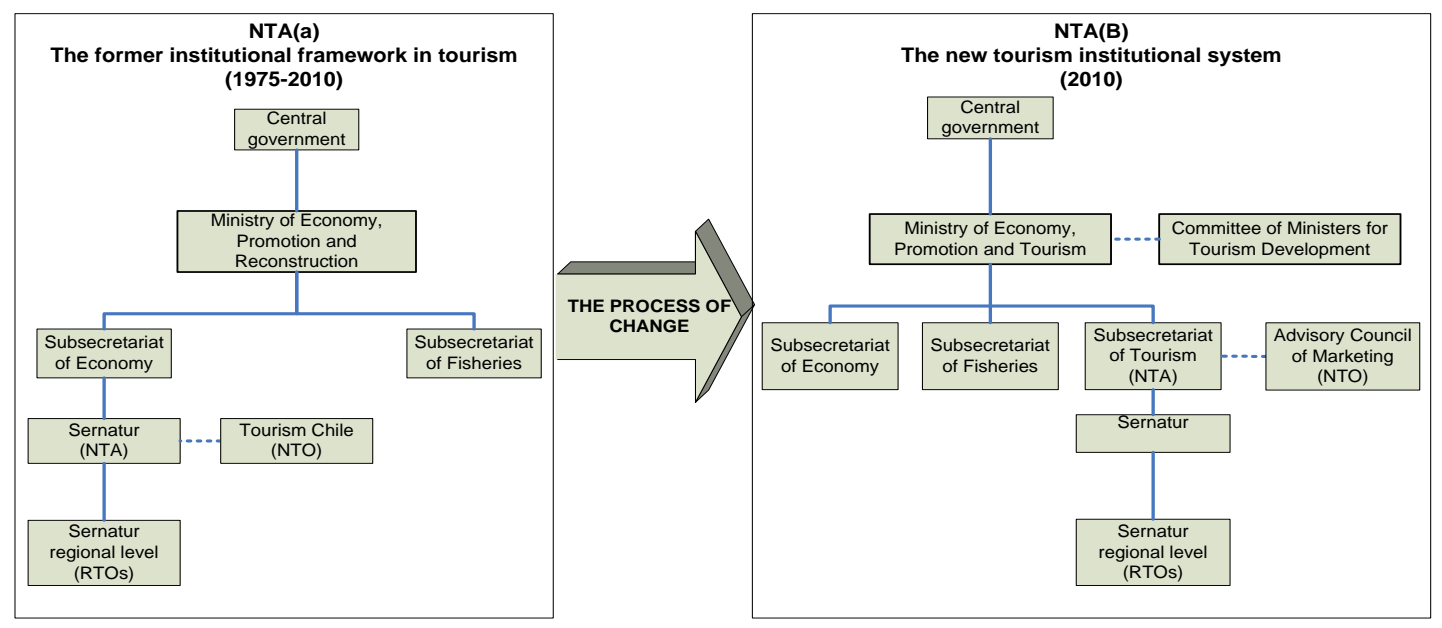

Figure 1.1: Institutional change in the Chilean framework for tourism

(Ministerio de Economía Fomento y Reconstrucción, 1975, 2010)

The figure shows the institutional framework that existed before Act 20423 (19752010). At the national level there was Sernatur as the NTA and Tourism Chile as the national tourism organisation (NTO). At the regional level there were branches of Sernatur (regional tourism organisations - RTOs). The NTA was a public service that depended on the Ministry of Economy, Promotion and Reconstruction (Minecon) and performed the roles of policy formulation, approval, and implementation (Ministerio de Economía Fomento y Reconstrucción, 1975). Other roles performed 
by the NTA were planning and quality assurance. The NTO (Tourism Chile) was an independent organisation created from matching funds between the public and private sectors and was in charge of formulating and implementing inbound marketing strategies (Ministerio de Economía Fomento y Reconstrucción, 1993).

As presented in Figure 1.1, Act 20423 created a new institutional framework for tourism (Ministerio de Economía Fomento y Reconstrucción, 2010). The new framework is composed of a new NTA (Subsecretariat of Tourism), a new NTO (Advisory Council of Marketing), an Inter-Ministerial Committee of Ministers for Tourism Coordination, and Sernatur. At the regional level there were no changes and Sernatur's regional branches were kept as RTOs. Hierarchically, the new NTA depends on the Ministry of Economy but - as shown in the figure - the name of the Ministry was changed to the Ministry of Economy, Promotion and Tourism. The enactment of the act also shifted the roles of agencies within the existing institutional framework. Now the subsecretariat formulates and evaluates policies, the Committee of Ministers approves, and Sernatur implements. A similar distribution of roles is adopted for marketing, planning and quality assurance. As noted here, the process of change in Chile went beyond a simple modification of the structure and roles of the NTA. Rather, the process created new public organisations with roles in tourism which prompted the emergence of a new "institutional system for tourism", the term used in this research for the outcome of the process in Chile.

This process of change occurred during a decade characterised by three critical aspects. First, during the 2000s the tourism industry experienced growth rates never seen before (see Chapter IV). Between 2001 and 2009 international arrivals increased from 1,760,000 to 2,749,000 (Sernatur, 2010), while the number of visitors to national parks also doubled from 1.063.000 to 2.056.000 (Conaf, 2011). The tourism industry also showed a positive performance in terms of its contribution to the economy. For instance, the contribution of the tourism sector to foreign currency almost doubled from US\$ 1,070 million in 2001 to US\$ 1,977 million in 2009 (Sernatur \& INE, 2010). Despite this steady growth, an evaluation conducted by the Inter American Development Bank (IADB) concluded that the country was still failing to realise its tourism potential (Inter American Development Bank, 2007b). 
A second aspect is the increasing commitment of the government to the tourism sector. Between 2002 and 2006 a series of strategies and plans was launched to strengthen the sector. These include the "National Tourism Agenda 2002-2005" (Sernatur, 2002), the "Chilean Tourism Policy" (Sernatur, 2005) and the "Tourism Action Plan 2006-2010" (Sernatur, 2006b). This commitment was also reflected in a growing number of public agencies implementing programmes in tourism. For instance, in 2007 the Chilean Economic Development Agency (Corfo) for the first time launched a programme orientated to directly fund and support the tourism sector (Corfo, 2010). Public funds allocated to tourism also grew. In 2001 Sernatur's budget was US\$ 7.6 million, while in 2009 this budget rose to US\$ 33.1 million (Dipres, 2000, 2008). As presented in Chapter IV, a similar trend occurred in the funds allocated to other public organisations at the national and regional levels.

A final aspect relates to the increasing adoption of the New Public Management approach (NPM) in the Chilean public sector (See Chapter II and IV). As briefly discussed in Chapter IV, the adoption of NPM rests on the neoliberal political economy model introduced during the 1980s' by General Augusto Pinochet's military government (1973-1989). In 1990, the Coalition of Parties for Democracy also known as "la Concertación" - won the presidential elections and Chile returned to democratic government. Pinochet's government and "la Concertación" negotiated a transition and agreed to maintain the political and economic model (Tecklin, Bauer, \& Prieto, 2011). For the next two decades, la Concertación was in power maintaining and strengthening the model. In 2003 a case of corruption inside the government was revealed and serious problems of governance, accountability and transparency in the public sector became evident. This triggered an agreement between political parties in order to address these problems and a process of administrative reform was conducted. As a result, and as discussed in Chapters II and IV, administrative reform was implemented in order to tackle key principles of the NPM approach, including governance, transparency, accountability, and performance measures (Lahera \& Cabezas, 2000; Olavarría, Navarrete, \& Figueroa, 2011; Waissbluth, 2005; Waissbluth \& Inostroza, 2007). 
In this scenario, the idea of reviewing the existing institutional framework gained political attention. In 2007 the central government submitted a bill to Parliament (El Mercurio, 2007a). The bill was debated between 2008 and 2009 (Cámara de Diputados de Chile, 2009c; Senado de la República de Chile, 2009c) and passed and enacted in 2010 (Act 20423) (Cámara de Diputados de Chile, 2010b).Although the dates when the bill was submitted and debated in Parliament are known, important aspects of the process have hitherto not been investigated; for instance, the broader process that included the formulation of the bill and other aspects such as when and why this process started and why a particular new institutional system resulted. In order to address these aspects, the next section introduces some critical research questions.

\subsection{Research questions}

In order to investigate the broader question and how and why NTAs change over time, the case of Sernatur is investigated through three principal research questions:

1) What was the process that led to the creation of the new Chilean institutional framework for tourism?

2) What were the factors that influenced and shaped the process?

3) How and why did the process, and the factors, influence the outcomes of the process?

Question one aims to establish the process that led to the creation of the new institutional system. In doing that, proposals of change structures and roles put forward during the process are also identified to support the analysis of research question three. Question two seeks to investigate the reasons that triggered and shaped the process. Wollmann (2007) suggests that evaluations may reveal the reasons triggering a policy process and help explain why the process occurred. Thus, evaluations of Sernatur and other organisations related to the existing institutional framework are analysed to identify and identify the factors that triggered the process of change. Because evaluations may also reflect the dominant environmental conditions underlying the process (Wollmann, 2007), the analysis of these evaluations also helps to explain how the general environment may have triggered and shaped the process of change in Sernatur. Finally, question three investigates why a particular institutional system resulted from the process of change. The 
proposals for structures and roles identified in question one are contrasted with the structure and roles contained in Act 20423. In this way, the researcher is able to identify what was included and what was omitted in the bill and to look for explanations of why this occurred. Explanation is sought by giving attention to the features of the policy process (i.e. consultation, participation, agreement, disagreement, negotiation, power, and acceptance) and the influence of the environmental conditions (Anastasiadou, 2008; Bramwell, 2006; Bramwell \& Meyer, 2007; Fallon, 2001; Pearce, 1990, 1992, 1996a, 1996b, 1997; Reed, 1997; Thomas \& Thomas, 2005, 2006).

As discussed in the next section, changes like the ones occurring in Sernatur have been increasingly studied in the literature on tourism organisations and policy making. However, this literature lacks a comprehensive perspective that investigates the process that leads to the changes and it also fails to consider adequately the environmental conditions which may change during the time in which the process occurs. Research investigating changes in the structure and roles of NTAs concludes that NTAs are dynamic organisations that change over time (Airey, 1984; Baum, 1994; Choy, 1993; Jeffries, 2001; Zhang, 2010). However, these studies mainly focus on describing changes in NTAs. Other research investigates the influence of the general environment on these changes (Dredge \& Jenkins, 2003; Hall, 2008; Pearce, 1992, 1996a, 1996b, 1997; Stevenson, Airey, \& Miller, 2008). For example, Pearce (1996a, 1996b, 1997) investigated the general environmental conditions in Sweden, Spain, and Belgium and concluded that changes in the NTAs result from variations in the political conditions. Despite this, research has failed to investigate changes in these conditions during the time in which the process occurs.

These streams of research show the lack of a comprehensive perspective mentioned above; that is, a perspective that integrates the process of change with an account of the factors influencing the process, the resultant outcomes, and the influence of changing environmental conditions during the time in which the process occurs. By adopting this comprehensive perspective to investigate the Chilean case, this thesis aims to provide a better understanding of the bigger questions of how and why NTAs change over time. 


\subsection{What is a process of institutional change in NTAs?}

A conceptual framework is developed from three separate bodies of literature: tourism organisations, the administration of the public sector, and tourism policymaking. First, the literature on tourism organisations and NTAs is investigated. This literature investigates changes in the structure and roles of NTAs but focuses on what the changes are and omits how and why these changes occur (Hall, 2008; Hall \& Jenkins, 1995; Kerr, 2003; Pearce, 1992, 1996a, 1996b, 1997). The model for the inter-organisational analysis of tourism organisations (Pearce, 1992, p. 18) may help the investigation of these omitted aspects. The model examines the relationships between different types of tourism organisations and highlights two critical elements that may apply in the analysis of processes of change in NTAs: the strong relationships between NTAs and other tourism organisations, and the influence of environmental conditions on the structures and roles of NTAs.

Because NTAs are central government bodies - and the process of change occurs in the public sector - the literature on the administration of the public sector is also reviewed. This literature offers the theoretical foundations to understand NTAs as public organisations and provides insights into the context in which processes of change occur. To address this literature, the dominant approaches of the administration of the public sector are considered: the New Public Management approach (NPM), administrative reform, and the global notion of governance. As

presented in Chapter II, the literature on these three approaches has been mostly addressed in the field of tourism policy making (Airey \& Chong, 2010; Moreno, 2008; Shone \& Memon, 2008).

The literature on tourism policy making is also analysed. This literature provides the basis to investigate processes of change in NTAs as policy processes. Research on tourism policy making suggests the use of the Policy Cycle Model to investigate a policy process (Pforr, 2001, p. 280). The model divides the process into a set of consecutive phases namely - evaluation, agenda setting, formulation, decision making, and implementation. In order to investigate these phases and the influence of the environmental conditions highlighted by Pearce's model (Pearce, 1992), the institutional approach is also adopted (Bevir, 2009). The institutional approach 
focuses on the analysis of both formal institutions (organisations) and the context in which these institutions exist, and emphasises the importance of contextual factors to explain changes in these organisations.

Based on the key elements of these three streams of research - that is, Pearce's model (1992), the Policy Cycle Model (Pforr, 2001), and the institutional approach (Bevir, 2009) - a conceptual framework to investigate the process of change in Sernatur is proposed (Figure 2.3). Despite the value of this conceptual framework for the research design, during the analysis of the data some challenges emerged and the division of the process of change into the phases suggested by the Policy Cycle Model could not be operationalised. To address this challenge, a new literature review on policy making was conducted and the process of change was operationalised in three major stages: pre-legislative, policy window, and legislative (Kingdon, 1995). As part of these stages, there are three major components of a policy process. First, there are multiple agendas. Second, there is formulation and decision making regarding these agendas and the selection of a particular course of action. Finally, there are multiple evaluations that influence the agendas and formulation and decision making (Birkland, 2007; Kingdon, 1995). Based on the new elements to investigate policy processes proposed by Birkland (2007) and Kingdon (1995), the conceptual framework was revisited and an integrated conceptual framework to investigate the case was developed (Figure 2.4). The conceptual and the integrated frameworks are examined in Chapter II and their implications for the research methodology are discussed in Chapter III.

\subsection{Research methodology}

Given the breadth of issues involved in addressing the research questions, this research adopts a qualitative interpretive case study approach (Creswell, 2007; Guba \& Lincoln, 1994; Putnam \& Pacanowsky, 1983; Yin, 2003). This approach enables the researcher to cross-check and interpret different points of view (stakeholder and evaluation reports) and to explain how and why the process of change occurs. A multi-method approach was employed for data collection (gathering documentation and semi-structured interviews) and a multi-phase approach adopted for data collection and analysis (Yin, 2003). 
Three major phases were undertaken in this research: I) First approach to the case, II) Immersion in the data, and III) Final data analysis and findings interpretation (see Figure 3.1). The first phase was carried out between March 2009 and October 2010. During this phase, the researcher conceptualised the study and developed a conceptual framework to investigate the process of change in Sernatur (Figure 2.3). Then, secondary information available on the internet was collected (i.e. official reports and news articles published in newspapers). Based on this data, between March and November 2009 milestones were identified and used to provisionally establish the process of change in Sernatur. For example, news articles highlighting the submission of the bill to Parliament were used to identify when the decision making in Parliament occurred. This information was cross checked with official memorandums of Parliament and the date of the official submission was identified. Between January and May 2010, secondary data was further analysed and used to refine the tools for data collection. At this point, the researcher produced a list of key documents to be gathered in the field, the set of questions contained in the semistructured interview, and a list with primary interview respondents. The semistructured interview addressed key aspects, including the characteristics of the structure and roles of the existing institutional framework, the characteristics of the new institutional system contained in Act 20423, the process that led to the changes in Sernatur, and the general environmental conditions underlying the process. Between June and October of that year, primary data was collected in Chile. Later, the interviews were transcribed and data was organised for analysis (November December 2010).

The second phase was conducted between January and December 2011. The phase started with the researcher's immersion in and familiarisation with the data collected in the field (Mehmetoglu \& Altinay, 2006). At this point, the emergence of a new element for the analysis - NPM - led to the literature review being extended. Based on the conceptual framework and the new body of literature on NPM, a first analysis of primary data was carried out. By using a coding technique for content analysis (Strauss \& Corbin, 1998) data was coded in themes, categories, sub-categories, and issues. During the analysis of this data a challenge emerged: some findings could not be explained by some features of the conceptual framework and the process of change in Sernatur could not to be operationalised based on the Policy Cycle Model. 
At this point the challenge was not the availability of data but the interpretation of this data in the light of the existing conceptual framework.

To face this challenge, a new literature review was conducted (Phase III). Based on this new literature the conceptual framework was revisited (Figure 2.3), an integrated framework to investigate the case was proposed (Figure 2.4), and further data analysis was carried out (January and July 2012). Conducting multiple literature reviews and revisiting the theoretical foundations as presented here is consistent with the systematic combining approach proposed by Dubois and Gadde (2002). The adoption of this approach is examined in detail in Chapter III. After data was interpreted, the findings were written up (August and December 2012).

Despite the additional literature and the emergence of new elements to investigate the case, the data collected in the field was sufficient for further analysis. This occurred because of the semi-structured design of the interviews. The interviews allowed the researcher to gather a wide range of information and, in turn, this wide range of data enabled the researcher to address the new elements emerging from the multiple literature reviews. Details of these phases are discussed in detail in Chapter III.

\subsection{Structure of the thesis}

This thesis consists of eight chapters. Chapter I has introduced the process of change in Sernatur, presented the research questions, situated the study in the context of the broader literature, and offered an overview of the research methodology. The contribution of this thesis is also discussed; that is, the adoption of a comprehensive perspective to investigate the process of change in Sernatur and in this way develop a better understanding of how and why NTAs in general may change over time.

Chapter II reviews the literature drawing on three major streams. Research on NTAs is investigated to understand the features and characteristics of this type of tourism organisation. Because NTAs are also public organisations, research on the administration of the public sector is also investigated. Finally, research on policy making and policy processes is examined to provide the context to investigate 
processes of change in NTAs. Drawing in these streams of research, the conceptual framework (Figure 2.3) and the integrated conceptual framework to investigate the process of change in Sernatur are also presented (Figure 2.4).

Chapter III addresses the research methodology. Three phases of literature review, data collection, and analysis are outlined and explained. The process for coding data and the analytical frameworks adopted for conducting the analysis are also presented. The chapter also discusses the challenges emerging during the analysis and the methodological implications of adopting a systematic combining approach.

Based on some elements of the integrated framework (Figure 2.4), Chapter IV provides background information about the context in which the process of change occurred. In particular, this chapter discusses the characteristics of the Chilean political administrative sub-system, the tourism sub-system, and Sernatur before the enactment of Act 20423. The general political and economic conditions during the 2000s (the period over which the institutional change occurred) are also investigated.

The next three chapters present the findings. Chapter V addresses the first research question and presents the process of change in Sernatur. Chapter VI investigates evaluations of the existing institutional framework and examines the dominant environmental conditions in Chile in order to identify and explore the factors that triggered and shaped the process (question two). The results of the process (question three) are investigated in Chapter VII. The chapter examines the process of change and its features, the reasons that triggered the process and the influence of the environmental conditions in order to explain why a particular institutional system resulted with a specific structure and roles.

Finally, in Chapter VIII the key findings are summarised in terms of the process of change in Sernatur and then discussed through the lens of the broader literature on tourism policy making. The chapter also provides a model to investigate processes of change in NTAs. In this way, the research aims to contribute to a better understanding of how and why institutional change in NTAs occurs. In this chapter, recommendations for further research are also presented. 


\subsection{Contribution}

As elaborated in Chapter II, research investigating changes in NTAs tends to focus on what these changes are and how these changes reflect the general environment in which NTAs change. In spite of this, existing research has largely neglected two aspects: the process that led to these changes (Hall, 2008; Hall \& Jenkins, 1995; Kerr, 2003; Pearce, 1992, 1996a, 1996b, 1997) and how changes in the environmental conditions during the time in which the process occur influence the process and its results (Hall, 2008; Hall \& Jenkins, 1995; Kerr, 2003; Pearce, 1992).

This thesis addresses these neglected aspects and emphasises the analysis of three major issues in the case study of Sernatur: a) what the process was that led to the changes; b) what factors influenced and shaped this process; and, c) how the outcomes of the process were influenced by both the features of the process and the environmental conditions. By investigating these questions in the Chilean case, the research aims to provide a better understanding of processes of change in NTAs and address the broader issue of how and why NTAs change.

A wide range of stakeholders were interviewed and a set of more than 50 documents were collected. All the key relevant stakeholders identified were interviewed and documents sought were collected, with the exception of a couple of persons and one particular report (See Chapter III). The detailed analysis of the Chilean case based on the rich body of data collected and analysed systematically with reference to frameworks drawn from multiple streams of literature and theories provides a very sound a comprehensive foundation for understanding the case and addressing the broader question of how and why NTAs change.

Building on the literature and the findings of the case study, a generalised conceptual framework is proposed for investigating processes of change in NTAs (Chapter VIII, Figure 8.1). The framework contributes to the literature in three main ways. First, the framework rests on four different streams of literature and theories which are brought together in order to address the neglected aspects of the literature mentioned above. Second, the framework provides a structure to investigate processes of change in other NTAs. The generalised conceptual framework emphasises the 
investigation of multiple elements of a process of change, namely stages, components and features of a policy process and the influence of a changing environment (see Chapter VIII). Finally, the framework aims to contribute from a methodological point of view. Because of the multiple elements of the framework, a wide range of data is required and multiple layers of analysis might be required. As discussed later in Chapter III, multiple phases of data analysis might be also required to address these complexities.

Finally, and as discussed in Chapter VIII, the analysis of the case also has practical implications for the Chilean tourism industry. For example, the findings presented here may allow the industry to have a better understanding of policy making in Chile and therefore, enable the industry to be better placed to monitor the implementation of Act 20423 or be involved in a new policy process.

\subsection{Conclusion}

This chapter has provided an introduction and overview of this thesis. As discussed above, changes such as the ones occurring in Chile have been investigated in recent years with special attention being given to what these changes are and how the general environment shapes the outcomes of a process. In spite of this, the research to date lacks a comprehensive perspective that helps explain how and why changes in NTAs occur. In order to address this comprehensive perspective, this chapter has emphasised the need to investigate both the process that leads to the changes and variations in the environmental conditions during the time in which the process occurs. This last aspect is critical because variations in these conditions influence the process and, in turn, the process influences and shapes the results. 


\section{Chapter 2 Literature Review}

\subsection{Introduction}

The literature on NTAs and policy processes provides the theoretical foundations to investigate the process of change in the Chilean NTA. Drawing on this literature, this chapter offers a conceptual framework to analyse the Chilean case. As elaborated in Chapter III, the conceptual framework directed the data collection, analysis, and interpretation. However, some components of the framework were found to be insufficient during data interpretation and further complementary literature was required. Then, the conceptual framework was revisited and an integrated framework to investigate the processes of change was proposed. As a consequence, this research has two frameworks: the conceptual framework developed during the research design and an integrated framework for data analysis. The methodological implications of this multiple literature review and conceptual frameworks are examined in detail in Chapter III.

During the research design, the literature review focused on two aspects: NTAs as tourism organisations and tourism policy making with emphasis on the Policy Cycle Model (Sections 2.2 and 2.3). This literature describes changes in the structure and roles of NTAs but largely omits the discussion of the process that led to these changes (Kerr, Barron, \& Wood, 2001; Pearce, 1992). Even where processes are investigated, the literature tends to be descriptive and ignores the influence of contextual factors to explain how and why these changes occur (Hall, 2008; Hall \& Jenkins, 1995; Kerr, 2003; Pearce, 1992). In some areas where these contextual factors are taken into account, another issue that the research ignores is changes in these factors over time (Hall, 2008; Pearce, 1992). In order to address these gaps in the literature, a conceptual framework for the analysis of the process of institutional change in Sernatur is proposed (Section 2.4).

A second review of the literature was conducted after data collection. Data collected in the field highlighted the existing NTA (Sernatur) as a public organisation strongly influenced by the features of the Chilean public sector. This data showed that 
dominant trends in the public sector - such as the adoption of the New Public Management Approach (NPM) - emerged as critical elements to explain the process of change in Chile. Although the notion of NTAs as public organisations and the influence of the public sector on NTAs were broadly addressed in the first literature review, a better understanding of the NPM approach was required. Thus, Section 2.5 reviews the literature on the NPM approach and administrative reforms of the public sector. As discussed in that section, research in NPM and administrative reform ignores NTAs as public organisations and omits the influence of changes in the public sector to explain changes in NTAs.

Finally, after the data analysis some findings regarding the process of change could not be adequately explained solely by the Policy Cycle Model. Therefore, a third review of the literature was required and new and complementary elements for analysis emerged to help the interpretation of findings (Section 2.6). In this section and based on these new elements - the conceptual framework was revisited and an integrated framework to examine processes of change in NTAs is proposed.

\subsection{National tourism administrations}

NTAs are part of the broader group of tourism entities called tourism organisations. Jeffries (2001) and Pearce (1992) define tourism organisations as bodies with roles and responsibilities in tourism development and promotion. Pearce (1992) identifies four kinds of tourism organisations: national tourism administrations (NTAs), national tourism organisations (NTOs), regional tourism organisations (RTOs), and local tourism organisations (LTOs). These organisations vary in level they are (from national to local) and also in the roles they perform. Among this group of organisations, NTAs and NTOs have gained the most attention in the literature. Pearce (1992), Jeffries (2001), and United Nations World Tourism Organisation (UNWTO) $(2005,2006)$ define NTAs as official agencies in charge of tourism development at the central level. The same authors also define NTOs as central bodies, but with roles in tourism inbound marketing. The UNWTO (2005, p.5) provides the official definition for NTA and NTO as follows: "NTA is a central public body with the administrative responsibility for tourism at the highest level, 
while NTO is an autonomous body of public, public-private or private status... with competence at national level for promoting inbound international tourism".

As noted in this definition, both organisations are placed at the national level but they differ in terms of their structures and roles. In terms of structure, NTAs are conceived as public organisations, while NTOs may assume different forms from public to private agencies. In terms of roles, NTAs are in charge of administrative responsibilities in tourism development (policy formulation, planning, control), while NTOs mainly perform the role of international marketing (Adamczyk, 2005; Jeffries, 2001; Pearce, 1992; United Nations World Tourism Organisation, 2005).

Despite the differences between the structure and roles of NTAs and NTOs, studies have not been consistent in using the terminology. For instance, an official report of the UNWTO (2006) aimed to examine the Chilean NTO but rather than describing Tourism Chile (NTO), the report focused on Sernatur (NTA). As noted in this example, research has explored marketing as a role of NTAs/NTOs. This lack of consistency is explained by Pearce (1992) who suggests that over the last decades NTAs have embraced functions that go beyond the simple issue of tourism administration, including operational roles such as marketing or research. As a consequence, NTOs have also assumed other functions such as research or product development and, in turn, the marketing function has also been allocated as a role of NTAs. In spite of these different perspectives to include marketing as a role of NTAs or NTOs - and in order to avoid this lack of consistency - this research project uses the definition of NTAs and NTOs as proposed by UNWTO (2005) and recognises inbound marketing as a role of NTOs.

Research exploring the structure and roles of NTAs has been conducted over the last three decades. Jeffries (2001) highlights that NTAs may adopt two forms: a single body, or a set of administrative bodies. Similarly, UNWTO (2005) identifies three different structures: agencies exclusively devoted to tourism (Ministry of Tourism), organisations incorporating several other branches related to tourism, and finally independent sections of a government structure (an executive body) in charge of tourism within a ministry. The last structure suggested by the UNWTO is, in fact, the structure adopted by Sernatur, a specialised body forming part of the Ministry of 
Economy (Ministerio de Economía Fomento y Reconstrucción, 1975). Details of Sernatur's structure are provided in Chapter IV.

Airey (1984), Baum (1994), Choy (1993), Jeffries (2001), Kerr et al. (2001), Pearce (1990, 1992, 1996a, 1996b, 1997) and UNWTO (1996), among others, classify the roles of NTAs in the areas of research, planning, development, regulation and cooperation. For example, Airey (1984) and Richter (1985) investigated these roles in the NTA of the United States of America and concluded that these roles were strongly influenced by the American political system (federalism).

The influence of the general environment on the characteristics of the structures and roles of NTAs have been also studied by Adamczyk (2005), Alipour and Kilic (2005), Choy (1993), Hall (2008), Jeffries (2001), Kerr et al. (2001), Meethan (1998) and Pearce (1990, 1992, 1996a, 1996b, 1997). Hall (2008) examines the involvement of governments with the tourism industry over the last six decades and shows how changes in this involvement have shifted the roles from direct intervention towards a more collaborative approach for tourism development. This is a critical aspect because these shifts may help explain how and why changes in the structures and roles of NTAs occur. A similar analysis is presented by Pearce (1992). He investigates tourism organisations in different countries and concludes that the features of these organisations reflect the general environment where they exist (governments' political and economic philosophies). Drawing on Hall (2008) and Pearce (1992), the examination of the general environment seems to be a critical factor to investigate with respect to changes in NTAs. According to Pearce (1992, 1996a, 1996b, 1997) these environmental conditions are composed of a set of political, policy, and economic factors that directly influences tourism organisations, including NTAs. In order to examine the influence of these factors on tourism organisations, Pearce proposes a framework that integrates concepts of tourism interorganisational analysis and environmental factors (Figure 2.1).

The starting point in Pearce's framework is the recognition of the tourism sector as a sub-system. The sub-system is composed of interrelated tourism organisations that are directly influenced by their environment. The framework recognises two scales: spatial and temporal. The first one shows tourism organisations placed at different 
levels, while the second offers a temporal perspective. Research carried out by Pearce (1996a, 1996b, 1997) uses the model and confirms the influence of the political environment on tourism organisations. For example, Pearce (1996a) examines tourism organisations in Belgium and concludes that changes in these organisations resulted from political changes implemented in the country after the Second World War. Later on, Kerr et al. (2001) describe Pearce's framework as the most widely known model to examine tourism organisations and use it to analyse changes in the Scottish NTA.

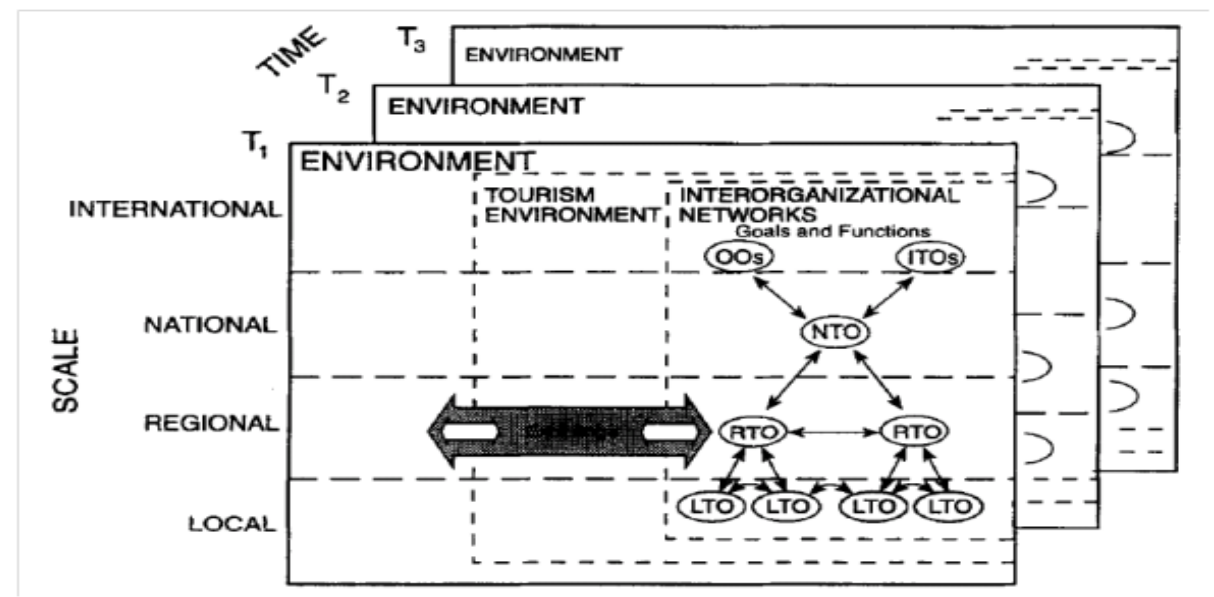

\section{Figure 2.1: A conceptual framework for the inter-organisational analysis of tourism organisations}

(Pearce, 1992, p. 18)

Although it investigates the broad range of tourism organisations, Pearce's framework raises two important issues for the analysis of institutional change processes in NTAs: the strong relationships between NTAs and other tourism organisations, and the influence of environmental conditions on changes in structures and roles of NTAs. The implications of these issues for the investigation of processes of change in NTAs are discussed in detail in Section 2.4.

In spite of Pearce's framework and the analysis conducted by this author, there is still a gap in the tourism literature investigating processes of change in NTAs. Most research has failed to use clear conceptual frameworks, it has adopted a descriptive perspective to explain changes in NTAs and ignores the influence of environmental conditions. Even in those cases where environmental conditions have been 
considered research has omitted the fact that these conditions may change over time directly influencing the process of change (Hall, 2008; Hall \& Jenkins, 1995; Kerr, 2003; Pearce, 1992).

This gap in the literature is not only at the global but also at the case level. In Chile, the literature on tourism is limited, while literature exploring the Chilean NTA scarcely exists. The Chilean literature on tourism is limited to publications produced in the Spanish language in two main sources: the journal "Gestión Turística" edited by Universidad Austral de Chile, and "Anales de Societur" edited by the Chilean Society of Tourism Research (Societur). In both cases, research papers are restricted to local case studies in areas of sustainable tourism, economy, planning, quality, marketing, and policy. The existing Chilean tourism literature in English is scarce and distributed among different fields whose findings have implications for the tourism sector. The number of articles directly related to tourism does not reach 20 and includes Blanco et al. (2007) who assess sustainable tourism in Chile; Tamborini (2005) who examines the roles of the state in tourism at the local level in southern Chile; and Sepulveda (2001) who looks at the economy of tourism in the country. Among these articles, none refers to tourism policy making at the central level or the public tourism institutional framework. The literature addressing the structure and roles of the Chilean NTA is even more limited and consists mainly of technical or official reports. Some reports examine Sernatur from a general perspective and as part of a broader analysis of the industry (Inter American Development Bank, 2007b; Sernatur, 2002, 2005, 2006b), while other reports particularly focus on the structure and roles of Sernatur (Boston Consulting Group, 2007; C\&S Soluziona Servicios Profesionales, 2004; P4 \& Tourism Resource Consultants, 2008; United Nations World Tourism Organisation, 2005, 2006; Universidad de Chile, 2007). As discussed in the following chapter, this stream of technical reports in Chile constitutes relevant inputs to analyse the case.

\subsection{Tourism policy making: the Policy Cycle Model as an approach to explore institutional change processes in NTAs}

This section presents the literature on policy making with emphasis on the Policy Cycle Model (Pforr, 2001) and the institutional approach to examine policy processes. The Policy Cycle Model provides a useful approach to divide a policy 
process in phases, while the institutional approach provides the lens through which the Policy Cycle Model is investigated. The broad concept of tourism policy provides the background for the investigation of the Policy Cycle Model and the institutional approach. Hall and Jenkins define tourism policy as "Whatever governments choose to do or not to do with respect to tourism" (Hall and Jenkins, 1995, p. 8). Two critical elements emerge in this definition. First, governments can either choose to do something to tackle a particular issue or do nothing. Second, if they have chosen to do something, governments need to identify and formulate alternatives to address the issue, choose one of these alternatives, and implement the selected one. The identification, formulation, selection, and implementation of one alternative suggest the notion of a process that consists of a set of consecutive phases. These phases are examined next.

\subsubsection{The Policy Cycle Model.}

In order to examine the phases of a policy process, the literature on policy making highlights the use of the Policy Cycle Model (Figure 2.2).
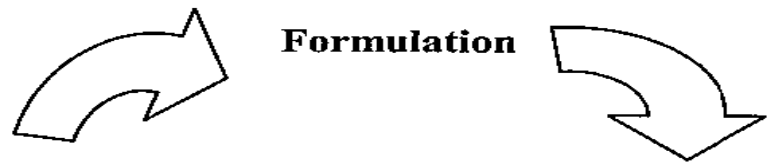

\section{Agenda Setting}

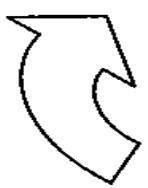

Evaluation \& Review
POLICY CYCLE

\section{Decision Making}

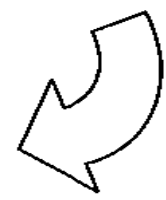

Implementation

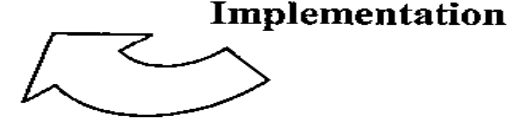

\section{Figure 2.2: The Policy Cycle Model}

(Pforr, 2001, p. 280)

Figure 2.2 shows that the Policy Cycle Model consists of five major phases (Pforr, 2001). The starting point is the phase of evaluation in which a particular problem is identified. Once the problem attracts public attention, the process moves towards the phase of the agenda setting in which the idea of identifying solutions to address the 
problem emerges. Later on, several alternatives to tackle the problem are identified and formulated (formulation) and then one or various alternatives are selected for implementation (decision making). At this last phase - and following the definition of tourism policy provided above - there is also a chance that none of the proposed alternatives is selected, keeping the status quo. In the case that a particular alternative is selected, it is implemented and later on evaluated. If the identified problem still persists, the policy is reformulated or changed and the process starts again.

Two different perspectives exist regarding to the validity of the Policy Cycle Model. On one hand, authors such as Sabatier (1999) and Bevir (2009) criticise the model on the grounds that a clear division in phases rarely happens and the boundaries of the phases are hard to operationalise. On the other hand, Pforr (2001) and Stevenson et al. (2008) argue that it is a useful analytical tool to understand policy processes and an appropriate way to simplify the process for its analysis. The literature indicates the validity of the model has been confirmed by a broad stream of tourism research. Pforr (2001) and Stevenson et al. (2008) investigate tourism policy changes by looking at the entire policy cycle; Pforr (2005, 2006), Reed (1997) and Thomas and Thomas $(2005,2006)$ research particular stages, including agenda setting and policy formulation; and finally Anastasiadou (2008) and Meethan (1998) study policy outcomes. In spite of the validity of the model highlighted by this stream of research, none of existing studies has used it to explore processes of institutional change in NTAs.

Research has examined the Policy Cycle Model in the light of different policy approaches. Bramwell and Meyer (2007), Dredge and Jenkins (2003), Pforr (2006), Scott et al. (2008), Timur and Getz (2008) and Varvasovszky and Brugha (2000) use stakeholder and network approaches to look at policy processes. By analysing policy actors' interests and influence, these authors research roles, motivations and positions of stakeholders in order to explain their relationships during the policy making process. In particular, Dredge (2006a, 2006b) and Dredge and Jenkins (2003) use the network approach to analyse policy networks in local tourism organisations, and Pforr (2006) maps stakeholders' communication, reputation, and cooperation in a particular phase of the policy process in Northern Australia. 
In spite of the value of these approaches, the literature highlights some limitations that may apply for exploring processes of change in NTAs. Ham and Hill (1984) consider that the network and stakeholder approaches say little about policy processes, while Stevenson et al. (2008) and Brugha and Varvasovszky (2000) argue that these approaches focus on stakeholders omitting the examination of the general environment as a key factor for the analysis. Because the analysis of changes in NTAs requires a broad perspective which considers the influence of environmental conditions as a key element, the limitations of the stakeholders and network approaches also apply for investigating processes of change in NTAs.

\subsubsection{The institutional approach.}

In order to tackle the limitations of the stakeholder and network approaches, Bevir (2009) suggests the use of the institutional approach. The institutional approach focuses on the analysis of both institutions and the context within which institutions exist. According to the author, institutions may be defined in two different ways: formal and informal. Formal institutions are formal organisations governed by written laws or rules (e.g. government departments), while informal institutions relate to organisations that lack written rules but exhibit patterns of behaviour (e.g. policy networks). Drawing on the concept of formal institutions, the institutional approach would allow the examination of the process of change in the Chilean case focussing on the organisations constituting the institutional framework, the rules governing these organisations and the general environment where these organisations exist.

Research using the institutional approach has been conducted by Dredge and Jenkins (2003), Shone and Memon (2008), Stevenson et al. (2008) and Tyler and Dinan (2001). These authors examine phases of the policy process and highlight the importance of exploring these processes in the context of their environment. Other authors combine the institutional approach with other perspectives. Treuren and Lane (2003) combine organisational, institutional, and network approaches to develop a theoretical framework for tourism policies; Anastasiadou (2008), Bramwell (2006), Fallon (2001), Stevenson et al. (2008), Tyler and Dinan (2001), and Vernon et al. (2005) analyse decision making based on the stakeholders' 
perspective and its social context by using multiple approaches; and finally Dredge (2006a), Pearce (1990, 1992, 1996a, 1996b, 1997), and Thomas and Thomas (2005, 2006) assume broader approaches in order to examine the influence of environmental conditions in policy processes and tourism organisations. Also drawing on the institutional approach - but focussing on stakeholders' relationships - Anastasiadou (2008), Bramwell (2006), Bramwell and Meyer (2007), Fallon (2001), Reed (1997), and Thomas and Thomas (2005, 2006) investigate power distribution in policy processes and highlight the importance of the general environment in order to explain this distribution. This last stream of research is particularly important because - as discussed in Chapter VII - the results of the process of change in Sernatur were strongly shaped by environmental conditions; these conditions influenced the features of the process (e.g. power), and these features, in turn, directly shaped the results of the process of change.

\subsection{A conceptual framework to investigate the institutional change processes in Sernatur}

Previous sections separately analysed the literature on NTAs and policy making in order to have a better understanding of processes of change in NTAs. That literature shows that this body of research has lacked a comprehensive perspective, omitting aspects such as why and how changes in NTAs occur and how these changes are influenced by environmental conditions. In order to address these aspects, Figure 2.3 proposes a conceptual framework to investigate the process of change in the Chilean NTA. The framework rests on the notion that NTAs are not isolated structures. Drawing on Pearce's model, the framework shows the relationships between NTAs and their environment: there is a broad system and two sub-systems which influence NTAs. At any particular period of time, there is a system that represents the general environment and the dominant political and economic factors in a particular country. As part of this system, there are two sub-systems: the administrative and the tourism sub-systems. The first is composed of public organisations related to the country's national administration (i.e. ministries, public agencies), and the second includes public and private organisations directly related to the tourism sector. Public tourism organisations include regional and local tourism organisations, while private tourism organisations include industry associations and academia, among others. 


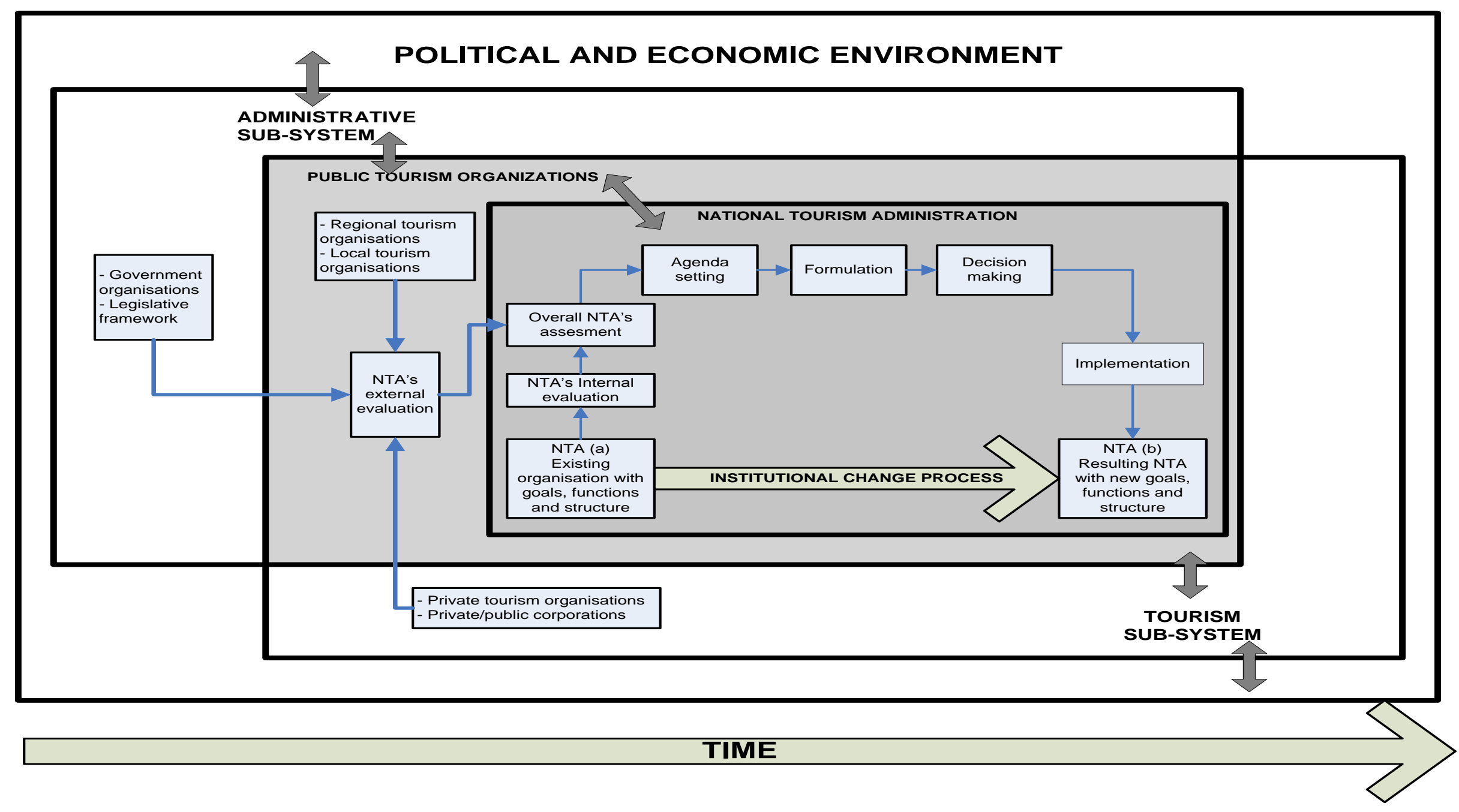

Figure 2.3: A conceptual framework for the analysis of processes of change in NTAs 
Because NTAs are located in both the administrative and tourism sub-systems, the framework shows an overlap between these two sub-systems in order to show that NTAs are public and tourism organisations. It is inside this overlap that NTAs are placed and where the process of the institutional change occurs.

The conceptual framework also uses the institutional approach to show NTAs as formal institutions that are influenced by broader systems and sub-systems. Based on this approach, Figure 2.3 shows arrows which connect the different features of the framework (the system, sub-systems and the process of institutional change). The political and economic environment influences the administrative and tourism subsystems, and simultaneously these sub-systems influence the process of change. Reciprocal relationships may also occur. For example, institutional change in NTAs may affect the administrative and tourism sub-system, and in turn may affect the general political and economic environment. These reciprocal relationships are a critical aspect discussed later in Chapter VII and help explain the results of the process of change in Sernatur.

The process of institutional change from $\operatorname{NTA}(a)$ to $\operatorname{NTA}(b)$ is also presented in the figure. NTA(a) represents the existing institutional framework at a particular place and time, while NTA(b) is the institutional framework resulting from a process of change. Based on the Policy Cycle Model, the conceptual framework shows the process of change in several phases. The starting point of the process of change is the evaluation phase, which provides the factors that triggered the change from NTA(a) to NTA(b). Wollmann (2007) identifies two types of evaluations: internal and external. Internal evaluations are conceived as self evaluations, while external evaluations are initiated and conducted by other organisations. In the context of the conceptual framework, internal evaluations of NTAs provide important information to identify and investigate the factors that triggered the change; however external evaluations coming from the organisations located in the administrative and tourism sub-systems are also relevant. These external evaluations provide some inputs to identify and examine these factors, but in addition, they also reflect the general environment where the process occurs (this is investigated in-depth in Chapter VI). 
After identifying the reasons that triggered the change, the policy process continues with the phases of agenda setting. Birkland (2007) defines agenda setting as the process by which a particular problem is identified, analysed and validated by the stakeholders in order to attract public attention. Thomas and Thomas (2005, 2006) studied this phase based on the stakeholders' motivations, their knowledge of the process, and the use of their mobilisation skills to influence the process. Following Thomas and Thomas, the analysis of the agenda should considers stakeholders' discourses to set and legitimise the need for change in the NTA and also how this discourse is transferred into a political agenda.

The next steps in the process are formulation and decision making. According to Sidney (2007), these two phases are closely related. The formulation phase focuses on identifying a set of possible solutions, while decision making addresses the adoption (or not) of any of the identified solutions. Reed (1997) provides a comprehensive analysis of these two phases that is useful to investigate processes of change in NTAs. By focusing on the local level, Reed (1997) identifies three policy arenas called developmental, allocational, and organisational. The developmental arena analyses the stakeholders' perspective in relation to economic development aims in a particular place; the allocational arena focuses on understanding the distribution of resources during the decision making process, and, finally, the organisational arena analyses roles and involvement of stakeholders during the phases of formulation and decision making. By considering each arena, Reed analyses actors' power relationships during the formulation and decision making phases and shows how actors mobilised and what tactics they used to influence these phases. The analysis conducted by Reed (1997) is useful to investigate the phases of formulation and decision making in processes of change in NTAs. For instance, the analysis of the formulation phase should explore actors' involvement to define alternatives for structures and roles of NTAs, while the decision making phase should investigate the tactics that stakeholders use to influence the results of the process of change. When the decision making phase has concluded, the institutional change process finishes with the implementation of a modified or new institutional framework (NTA b). 
The last feature of the conceptual framework is a temporal perspective. The institutional change process occurs over a particular period of time with specific environmental conditions. Because changes in these conditions might have occurred during the process, Figure 2.3 shows an arrow at the bottom which presents the process of institutional change through time. The arrow crosses the broad system, sub-systems, and the process of change as a way to highlight any important change in the environmental conditions while the process occurs.

The conceptual framework provides the theoretical foundations to explore the institutional change process in the Chilean NTA. In the case, the broad system is composed of the economic and political conditions in the country during the 2000s, which is the period over which the process of change occurred. In the administrative sub-system there are different organisations related to the Chilean public administration (ministers, government agencies, and Parliament). The tourism subsystem is composed of private organisations, such as the Superior Council of Tourism (CONCETUR), the Chilean Federation of Tourism Companies (FEDETUR), and the Chilean Association of Tourism Companies (ACHET). This sub-system also includes Tourism Chile due to the reason that the NTO was created as a public-private organisation. As part of both sub-systems - in the overlapped area of the framework - there are public tourism organisations including the NTA, regional tourism organisations, and a bigger group of local tourism organisations.

With reference to the process of change, the starting point of the framework to analyse the case requires identifying and explaining the factors that triggered the change. The analysis of the environmental conditions and internal and external evaluations of Sernatur help investigate these reasons. Several reports mentioned in section 2.2 provide these evaluations and constitute relevant inputs to explain the reasons triggering the process of change. After the examination of these reasons, the framework suggests analysis of the phases of agenda setting, formulation, decision making, and implementation. In this particular study, however, the phase of implementation is omitted due to the fact that the Tourism Act (Act 20423) was only implemented in 2011. Drawing on Anastasiadou (2008), Bramwell (2006), Bramwell and Meyer (2007), Fallon (2001), Reed (1997), and Thomas and Thomas (2005, 2006), the analysis of the phases of agenda setting, formulation, and decision making 
will be examined based on the distribution of power and the ability of stakeholders to influence the process. During the analysis special attention will be given to stakeholders' ability to influence the agenda of institutional change (agenda setting), power distribution and actors' involvement to define alternatives for the structure and roles of the NTA (formulation), and stakeholders mobilisation to influence the final decision (decision making). Finally, the dominant environmental conditions underlying the process will be also examined. These conditions include economic, political, and policy factors.

Despite the value of this conceptual framework, a preliminary analysis of data collected in the field showed that policy factors - such as the adoption of the NPM approach - strongly influenced the process of change in Sernatur. Thus, a new literature review on the administration of the public sector and the adoption of the NPM was required.

\subsection{The public sector administration: an approach to explore NTAs}

As discussed in the previous section, NTAs are not only tourism organisations but also national level public organisations. Therefore, studying NTAs also requires an examination of the literature on the administration of the public sector. In order to investigate this literature two main issues are explored: NPM as the dominant approach for the public sector, and administrative reforms conducted to implement the NPM approach. By tackling these issues, this section aims to identify how dominant approaches in the public sector may influence processes of change in NTAs.

\subsubsection{New Public Management: a dominant approach for the public sector.}

The general literature on the administration of the public sector highlights that the NPM approach appears late in the 1980s to address the increasing criticisms of the then dominant approach of Public Administration (PA). In order to understand the implications of the NPM for the public sector, the general concept of PA will be examined first. Hughes (2003) defines PA as the act of serving the public by public servants. According to this author, the approach rests on the concept of bureaucracy proposed by Weber and separates public policy and public administration into different spheres: politicians identify and decide policies while administrative public 
bodies implement these policies (Olavarría, 2007). Following Weber's notion of bureaucracy, PA relies on principles such as hierarchical structures, role distribution, and work specialisation to lead the public sector (Waissbluth, 2005). PA principles have been researched from different disciplines, including political science, economics, and management. For instance, political science highlights the influence of the political systems on the administration of the public sector (Peters \& Pierre, 2003).

Following Weber's notions of bureaucracy, the PA approach led the public sector over the last century (Hughes, 2003). However, late in the $20^{\text {th }}$ Century some criticism emerged triggering a shift from the traditional PA perspective towards the NPM approach (Barzelay, 2001; Bevir, 2009; Brudney, O'Toole, \& Rainey, 2000; Farazmand \& Pinkowski, 2007; Hughes, 2003; Olavarría, et al., 2011; Peters \& Pierre, 2003; Waissbluth \& Inostroza, 2007). These criticisms include low efficiency in the public sector, obsolete and rigid administrative structures, and lack of responsibility among public servants (Pedersen, Sehested, \& Sorensen, 2011). To face these criticisms - and drawing on neoliberal theory (Bevir, 2009) - the NPM approach emerged as a set of principles that advocates reducing the size of the state and promoting the implementation of private sector management principles among public agencies (Bevir, 2009; Jansson \& Parding, 2011; Pedersen, et al., 2011).

Several principles show the difference between PA and NPM. First, unlike PA, which considers mechanisms of command and control, NPM advocates the use of market based mechanisms for achieving efficiency (Pedersen, et al., 2011). Second, while PA sees citizens as beneficiaries of public services provided by the state, NMP places citizens in the centre of the public administration and considers citizens as customers that demand public goods and services (Hughes, 2003). Finally, PA places public servants' responsibility on policy implementation, while NPM makes public servants responsible for achieving results rather than being merely responsible for the implementation process (Hughes, 2003). In order to implement the principles addressed by NPM, a process of administrative reform in the public sector is required. As presented next, this reform has changed the organisation of the public sector and triggered the emergence of the concept of "good governance" (Jansson \& Parding, 2011). 


\subsubsection{Governance and Administrative reforms of the public sector.}

The substantial shifts in the practices of the public sector to address NPM cannot be implemented without conducting an administrative reform. Turner and Hulme (1997) define administrative reform as a planned change to public bureaucracies that attempts to achieve efficiency, accountability, and transparency. Furthermore, Olavarría, et al. (2011) describe administrative reform as a modernisation of the public sector focused on public structures and organisational processes to achieve efficiency. Waissbluth (2005) identifies two types of administrative reforms: the institutional and the substantial. On one hand, institutional reform focuses on organisations' performance, power, and articulation with regards to policies. In this context, an institutional reform advocates changes in rules and practices. On the other hand, substantial reform refers to the change in organisational arrangements, goals, and objectives of the public action. Normative changes or the creation of new public organisations - such as resulted from the enactment of the Tourism Act (Act 20423) - are examples of changes occurring as part of substantial reforms.

Over the last decades an increasing number of countries have conducted administrative reforms in the public sector (Barzelay, 2001; Bevir, 2009; Brudney, et al., 2000; Farazmand \& Pinkowski, 2007; Turner \& Hulme, 1997). For example, New Zealand and Australia were among the first to conduct these reforms during the 1980s. During the 1990s the Organisation for Economic Co-operation and Development (OECD) suggested the implementation of the NPM approach among its state members and, since then, administrative reforms have been increasingly implemented in different countries. The United States of America conducted administrative reforms during the 1990s (Barzelay, 2001) and Chile did so during the 2000s (Waissbluth \& Inostroza, 2007).

The changes resulting from reforms in the public sector shifted the approach of governments to govern the states and triggered the emergence of the concept of “good governance". This is highlighted by Bevir (2007, p. 7) who states that:

The term governance can be used specifically to describe changes in the nature and role of the state following the public-sector reforms of the 1980s and 1990s. Typically, these reforms are said to have led to a shift from a hierarchic 
bureaucracy toward a greater use of markets, quasi-markets... especially in the delivery of public services.

Most of the existing definitions of good governance consist of a list of reforms, practices, and outcomes that relates to the NPM approach. For instance, the World Bank (1994) defines good governance as a concept that embraces the principles of accountability, transparency and effectiveness in policy making. Bevir (2009, p.33) defines accountability as "giving a report of oneself", which implies public organisations giving account of their acts. Hughes (2003, citing Gore, 1993), defines transparency as a means to achieve legitimacy and credibility in decision making, while Bevir (2009) defines effectiveness as the results achieved by the public sector. In order to address these principles, NPM advocates disaggregating the public sector into administrative units (Hughes, 2003; Peters \& Pierre, 2003; Waissbluth \& Inostroza, 2007), budgeting against objectives, evaluation of results, management based on objectives, and performance measure (OECD, 1998).

The stream of literature examining the concepts of NPM, administrative reforms and governance is extensive (Barzelay, 2001; Bevir, 2007, 2009; Hughes, 2003; Pedersen, et al., 2011; Peters \& Pierre, 2003; Waters, 2011). At the case level there is also a stream of literature exploring these concepts, but in particular focussing on the administrative reform in the Chilean public sector (Lahera \& Cabezas, 2000; Olavarría, 2007; Olavarría, et al., 2011; Pliscoff, 2008; Waissbluth, 2005; Waissbluth \& Inostroza, 2007). As presented in the Chilean literature on administrative reform, NPM started to be slowly adopted by some public agencies late in the 1990s. In 2003 - after a case of corruption in the public sector became publicly known - political parties reached an agreement to conduct administrative reform, and the principles of the NPM started to be implemented in the entire public sector (Gobierno de Chile \& Congreso de Chile, 2003). The reform advocates the modernisation of the state in aspects such as public servants being selected on the basis of professional skills, performance measure, transparency and accountability.

In the tourism field, research addressing NPM, administrative reforms, and governance is relatively new. For example, Pearce (1992) examines changes in the New Zealand's tourism institutional framework and explains changes occurring over 
the 1980s as a result of the adoption of the NPM approach (deregulation of markets, reducing government intervention, and increase of accountability). With the exception of Pearce (1992), Airey and Chong (2010), Moreno (2008), Shone and Memon (2008), and Zhang (2010), who examine changes in tourism policies in the light of administrative reforms, most research has focused only on governance. Yüksel et al. (2005) study governance and examine the transference of authority and distribution of power, legitimacy, and accountability from the national to the local level in Turkey. Also focused on governance, Dinica (2009) investigates tourism governance for sustainable development, Wesley and Pforr (2010) examine governance of coastal tourism, and Hall (2011a) researches governance in sustainable tourism. There is also some tourism research developing conceptual frameworks to examine governance. Beaumont and Dredge (2010) analyse tourism governance by exploring three different networks at local level. Among other aspects, the authors highlight accountability and transparency as important principles for giving credibility and trust to any tourism policy process. Hall (2011b) develops a theoretical framework and proposes four types of governance to conceptualise tourism governance, while Dredge and Whitford (2011) propose a framework that integrates the range of actors involved in a policy process and the general economic, political, and social factors in order to examine governance. In spite of these recent advances in tourism research, none of them focuses on governance and processes of change in NTAs.

While at a global level there is some literature on NPM and tourism governance, at the case level almost no literature exists and the little that does is mostly addressed in some technical reports investigated in Chapter VI. In this context, the process of administrative reform conducted in the Chilean public sector provides critical elements to understand the process of change in Sernatur. As discussed later in Chapters VI and VII, the principles of the NPM approach and the notion of good governance strongly influenced the results of the process of change by promoting the adoption of transparency, accountability, and disaggregation of the tourism public sector in administrative units. 


\subsection{New elements for the interpretation of findings: An integrated conceptual framework to investigate the process of change in Sernatur}

During data analysis some of the findings were not able to be adequately explained through the lens of the Policy Cycle Model and a better understanding of policy processes was required. Thus, a third literature review was conducted with emphasis on four major components of the policy processes: policy evaluations, policy agendas, formulation, and decision making. Based on these components, the conceptual framework (Figure 2.3) was revisited and an integrated framework to investigate the processes of change in Sernatur was proposed (Figure 2.4).

\subsubsection{Policy evaluations.}

A new review of the literature on policy evaluations shows that besides the classification of evaluations as internal and external presented in Sections 2.3, evaluations may also vary depending on their objectives and the role they play in a policy process (Parsons, 1995; Sabatier, 2007; Wollmann, 2007). For Parsons (1995), evaluations aim to examine the results of policies in relation to the goals they are meant to achieve, while for Sabatier (2007) evaluations look to identify and assess alternatives during policy formulation.

Parsons and Sabatier's definitions illustrate two broader concepts presented in the literature: the analysis "of policy" and analysis "for policy" (Hill, 2005; Sabatier, 2007). Analysis of policies adopts a descriptive and analytical approach in order to evaluate policy contents, outcomes, or processes. In order to evaluate contents and outcomes evaluations assess policy performance, while in order to evaluate processes, evaluations examine how policy is made and shaped (Hill, 2005). Evaluations also may be carried out to conduct analysis for policies. This analysis relates to policy formulation (Sabatier, 2007) and aims to examine and evaluate alternatives to take decisions during policy formulation (Hill, 2005). Being aware of these different types of evaluations is critical to understanding and explaining the contents of evaluation reports. 
Another critical aspect is the notion of evaluation as a single phase proposed by the Policy Cycle Model. Jann and Wegrich (2007) and Sabatier (2007) stress that there is no convincing argument that evaluation is the engine of the policy process and remark that evaluations exist throughout the entire process. The idea that evaluations occur across the entire process is also presented by Parsons (1995, citing Palmedo, 1987). Parsons highlights that during agenda setting, evaluations are used to define the size and distribution of a policy problem; during the formulation, evaluations are used to identify alternative means for achieving solutions; during decision making there are political evaluations to accept a policy; and, finally, during implementation, evaluations are used as an analysis of the extent to which a programme achieves success. This influence of evaluations over the entire process of change is a critical aspect examined in Chapter VI.

\subsubsection{Policy agendas, formulation, and decision making.}

In order to complement the literature on policy processes presented in Section 2.3, a new literature review was also conducted with an emphasis on policy agendas, formulation, and decision making. Three different types of policy agendas may be identified: systemic, institutional, and decision agendas. The systemic agenda consists of a general list of issues that are commonly perceived by members of a community as meriting public attention (Birkland, 2007; Clark, 2004; Howlett \& Ramesh, 2003; Parsons, 1995; Princen, 2007). Parsons (1995) describes a set of steps that are useful to examine the creation and expansion of the systemic agenda. First, there is an initiator that triggers the creation of an issue or policy problem. At some point, this issue gains media attention. With this media interest, the issue also gains attention from the public and decision makers. According to Parsons, a key aspect in moving the systemic agenda is the way the issues are framed; for example, by redefining the same issue over and over again among different proposals. Once the decision makers' attention is gained, the issue moves from the systemic to the institutional agenda. Once a government has accepted that something needs to be done, it can be said that an issue has entered the institutional agenda (Howlett \& Ramesh, 2003). The institutional agenda refers to a narrowed list of issues that explicitly receives government consideration (Birkland, 2007; Clark, 2004; Howlett \& Ramesh, 2003; Parsons, 1995; Princen, 2007). Finally, the decision agenda relates to the selection of particular issues that the government puts forth for an active 
decision (Birkland, 2007). This agenda contains a fewer number of issues that are about to be acted upon by a governmental body, for example by a bill (Birkland, 2007; Clark, 2004; Howlett \& Ramesh, 2003; Parsons, 1995; Princen, 2007).

Once the decision agenda is set and the issues to be addressed by a policy are identified, it may be said that the formulation starts (Pforr, 2001, 2005, 2006). Formulation implies a process of crafting policy alternatives to address the issues of the decision agenda (Sidney, 2007). Once these alternatives have been formulated, they are approved or rejected in a process called decision making (Sidney, 2007). According to Pforr (2001), decision making relates to the final decision, to the adoption of a particular course of action that signals that the formulation has came to an end.

With reference to the process of change in Sernatur, the systemic agenda contains the issues defined by the tourism industry to strengthen the tourism sector; the institutional agenda relates to the formal recognition of the government that the tourism sector needs to be strengthened; and, finally, the decision agenda contains the issues that the government is open to including in the tourism bill. Drawing on the definitions of formulation and decision making provided in this section, formulation refers to the process of crafting the tourism bill before its submission to Parliament, while decision making refers to the parliamentary debate to pass the bill. The examination of these agendas and their influence on formulation and decision making of the tourism bill is critical to explaining how issues gained attention throughout the process of change in Sernatur and how and why certain ideas were included or rejected.

\subsubsection{An integrated framework to investigate the process of change in Sernatur.}

Because of the limited ability of the Policy Cycle Model to divide policy processes in phases, and based on the new elements of the literature presented in this section, another way to look at the process of change was required. Kingdon (1995) identifies the concept of policy window. The concept of policy window, which emerges from the notion of window of opportunity (Scodanibbio, 2011), is defined as a window that opens up at a specific time and for a specific policy (Kingdon, 1995). The policy 
window opens when three separate streams intersect: problem, policy, and politics (Clark, 2004; Howlett \& Ramesh, 2003; Kingdon, 1995). The problem stream represents the perception of a policy problem by the political community, the policy stream represents the solutions for a policy problem, and the politics stream represents political events such as a change of government (these streams are investigated in detail in Chapter V).

The concept of policy window suggested by Kingdon suggests that the window triggers the movement from one stage to another. As presented in Chapter I, any institutional change in the Chilean public sector requires a bill formulated by the Executive and passed in Parliament. The need to have a bill to conduct the institutional change in Sernatur means that the process of change occurred in the context of a legislative process. In this research this is called the legislative stage. Following Birkland (2007), legislative processes are usually preceded by long discussions that lead to the establishment of the agenda, formulation, and decision making. Therefore, a pre-legislative discussion also existed (pre-legislative stage). Drawing on the three stages mentioned above, the existing conceptual framework (Figure 2.3) was revisited and an integrated framework to investigate the processes of change in Sernatur was proposed (Figure 2.4).

Figure 2.4 considers three key elements contained in the original conceptual framework. There is a broad system composed of the dominant economic, political, and policy conditions underlying the process of change. As part of this system there are two sub-systems (administrative and tourism) composed of multiple public and tourism organisations. In the overlap area of these sub-systems there are public tourism organisations, including NTAs. It is in this overlap that the process of change occurs. Finally, the integrated framework also highlights the relationships between NTAs and their environment. There are mutual relationships between the features of the framework (the broader system, sub-systems, the NTA and the process of change), which are represented by arrows that connect these features. 


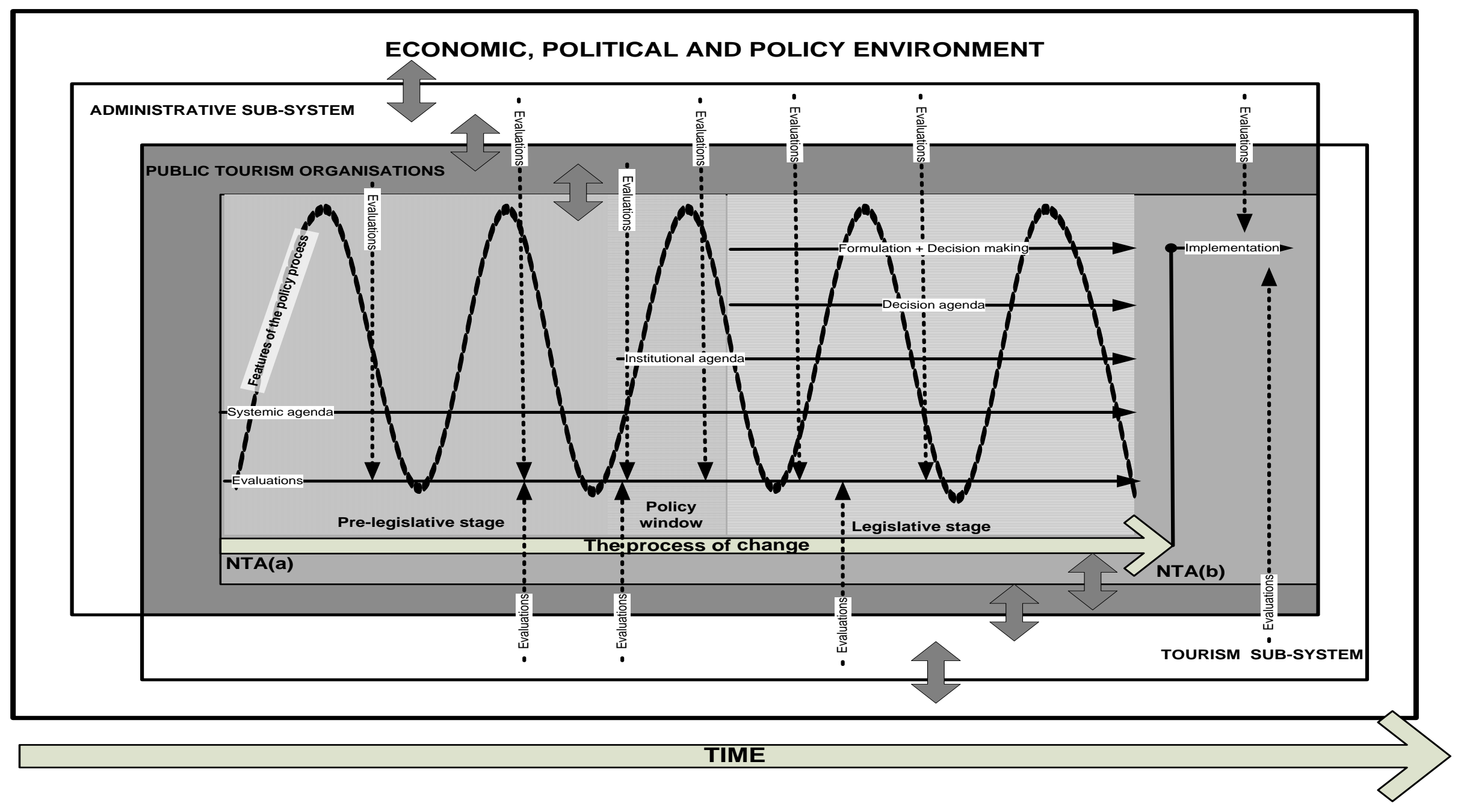

Figure 2.4: An integrated framework to investigate the process of change in Sernatur 
In spite of these common elements, the integrated framework challenges the use of the Policy Cycle Model and shows that the process of change occurs in three stages (pre-legislative, policy window, and legislative). As part of these stages, evaluation, agendas, formulation, decision making, and implementation exist as components of the policy process. These components help identify what issues are discussed during a policy process, and help investigate how these issues are debated and modified through the different stages of the process.

As noted in the figure, the components overlap and occur in parallel. For example, evaluations exist throughout the entire process and are conducted either as part of the process of change or in the general environment. The systemic agenda contains a broad discussion about a policy problem and emerges during the pre-legislative stage; the institutional agenda contains the intention of the government to tackle problems identified in the systemic agenda and emerges during the policy window; and, finally, the decision agenda includes a narrowed list of issues that emerges from the legislative stage. During the legislative stage, solutions to address the decision agenda are identified, formulated, and approved or rejected (formulation and decision making). Because formulation and decision making are closely related (Sidney, 2007), Figure 2.4 shows them together. Once a final decision is adopted, policy implementation begins.

Finally, the integrated framework also presents the features of the policy process as a key element for the analysis: participation, consultation, agreement, disagreement, negotiation, power, and acceptance. These features illustrate the mechanisms that stakeholders may use to influence and move the process forward (Thomas \& Thomas, 2005, 2006). Participation relates to the opportunity for members of a society to be involved in a policy process, whereas consultation is one of the mechanisms by which stakeholders are involved in the process (McLaverty, 2011). Agreement shows consensus amongst stakeholders regarding particular aspect of the process, while disagreement relates to lack of consensus (Bevir, 2009). Negotiation emerges as a mechanism for public policy dispute resolution (Blomgren, 2011). In the context of negotiation and lack of consensus, power relates to the ability of certain actors to impose their ideas and influence the process (Bramwell \& Meyer, 2007). Finally, in this research acceptance will be understood as the mechanisms by 
which less powerful actors face the imposition of power and aim to move the process forward. Chapter VII investigates the features described above in detail in order to explain how the process of change in Sernatur occurred and why particular outcomes resulted. In addition, Chapter VII addresses these features in a more general way and suggests their examination in processes of change in NTAs.

Although Anastasiadou (2008), Bramwell (2006), Bramwell and Meyer (2007), Fallon (2001), Reed (1997) and Thomas and Thomas (2005, 2006) investigate some of these features to analyse the results of policy processes(e.g. participation, negotiation and power), these features have not been used as explanatory factors to investigate processes of change in NTAs.

\subsection{Conclusion}

The literature discussed in this chapter shows that research has investigated changes in the structure and roles of NTAs but has largely neglected two critical aspects: the process that leads to the changes and the influence of contextual factors that explain how and why these changes occur. Furthermore, both the literature on tourism policy making and processes of change in NTAs have not considered other elements of the policy process. For example, the research described in Section 2.3 investigates the agenda setting phase but not the existence of different types of agendas as described in Section 2.6. That literature has also omitted the notion of policy windows to investigate what triggers the movement of the agendas and how these agendas move from the pre-legislative to the legislative stage. In addition, although power has been examined in an important stream of literature presented in Section 2.3, there has not yet been any consideration of the analysis of power and other features of the policy process as explanatory factors to investigate processes of institutional change in NTAs. In this context, the investigation of the institutional change process in Sernatur may help address these neglected aspects by tackling issues such as what the process was, how this process occurred, and why a particular outcome resulted from the process.

The integrated framework developed highlights important aspects of the literature to investigate these issues (Figure 2.4). As discussed in this chapter, evaluations and environmental conditions allow the researcher to identify the factors triggering the 
process of change and explain the results of the process. Evaluations and environmental conditions also provide information to examine the process itself: they may have influenced and shaped the different agendas, the formulation of the bill, and its decision making in Parliament. The examination of the policy agendas, formulation, and decision making is also relevant. The analysis of the systemic and institutional agendas provides information about how the idea to formulate the tourism bill emerged and how this idea gained attention inside the government; the formulation of the bill provides information about how the contents of the bill were identified (decision agenda) and how these contents were negotiated to be included in the bill; and finally, the decision making allows the examination of the debate and negotiation of the bill in Parliament.

By investigating these critical issues, this research aims to provide a comprehensive analysis of the case and address the broader question of how and why NTAs change over time. In order to present how these critical issues are addressed in this research, the next chapter discusses the research questions and the research methodology to examine the institutional change process in the Chilean NTA. 


\section{Chapter 3 Research methodology}

\subsection{Introduction}

The conceptual framework presented in Chapter II (Figure 2.3) provides the initial theoretical foundation for investigating the Chilean case. The framework suggests an examination of the process of change, the factors that shaped and influenced the process, the outcomes resulting from the process, and the influence of the environmental conditions. These critical elements are tackled by the research questions and in turn, the questions and the framework suggest the methods for data collection and analysis.

As mentioned in the previous chapter, in spite of the value of the conceptual framework some particular findings could not be adequately interpreted, notably the process of change in separate and clearly divided phases. Thus, two additional literature reviews were conducted, the conceptual framework was revisited, and an integrated framework (Figure 2.4) was proposed to investigate the process of change in Sernatur so that further analysis could be carried out. Dubois and Gadde (2002) define such multi phase literature reviews and data analysis as a research design called systematic combining. Systematic combining enables the researcher to move back and forth between empirical observation and theory. In doing that, the researcher expands his understanding of both empirical phenomena and theory and is able to provide a better explanation of the phenomenon under investigation. These multiple phases of literature review and data analysis are presented in Figure 3.1 and the implications for this research are examined in detail in Sections 3.4.

Figure 3.1 shows that a first literature review was conducted during the research design. The main elements found in this literature review helped form a conceptual framework and the main features of the framework supported the formulation of the research questions. Based on the research questions, the figure shows the methodology and the methods for data collection, analysis, and interpretation 


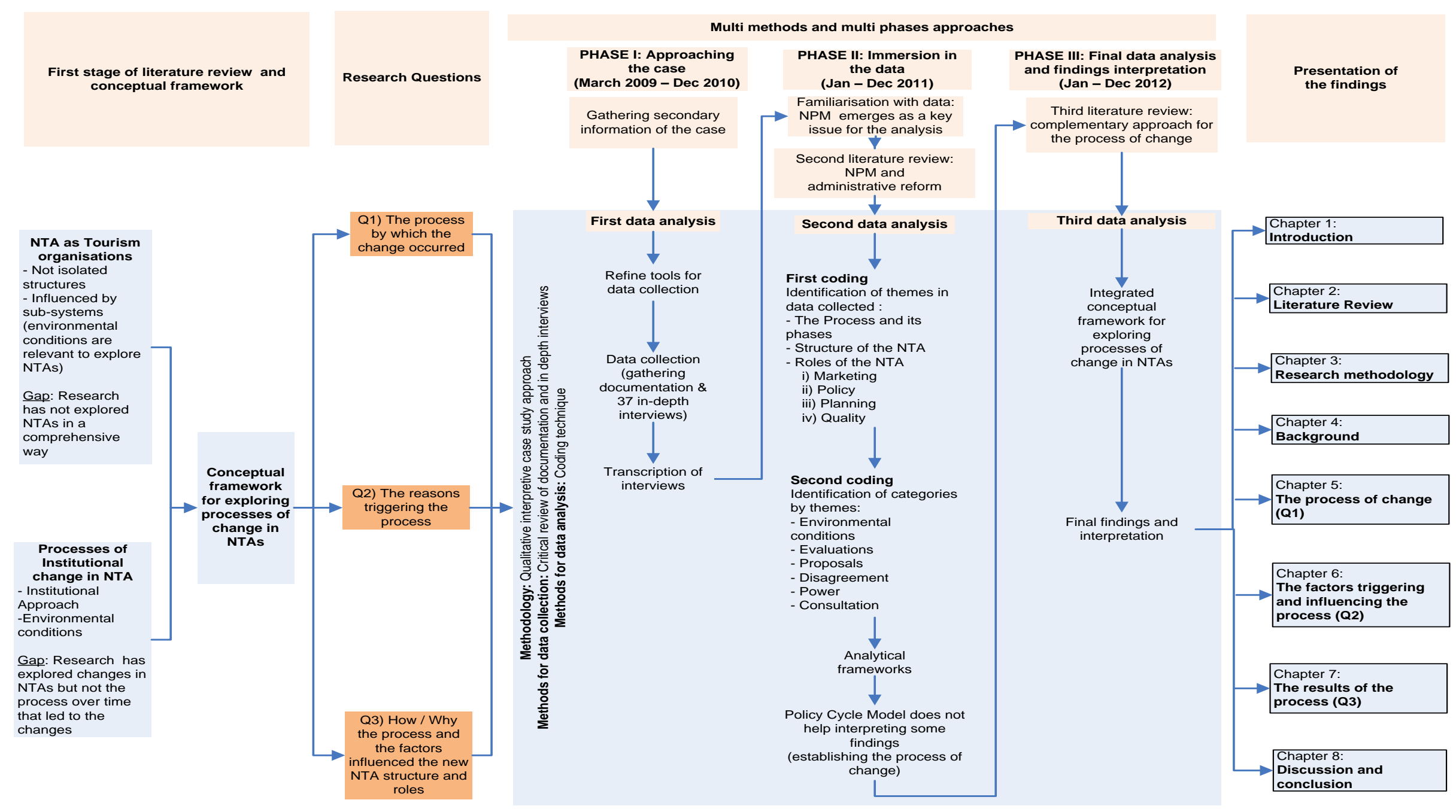

Figure 3.1: Research Overview 
A qualitative interpretive case study approach was adopted for investigating the process of change in the Chilean NTA. For data collection, a multi method approach was embraced (gathering related documentation and in-depth semi-structured interviews). Figure 3.1 shows that a multi-phase approach was adopted because data was collected, analysed, and interpreted in several phases. First, a set of secondary data was collected and analysed prior to the fieldwork. This analysis helped to develop a first approach to the case and to refine the semi-structured interview. The importance of the NPM approach emerged from the interviews conducted in the field. Because the literature on NPM was not investigated during the research design, a second literature review was required. Drawing on the conceptual framework and the new body of literature on NPM, a second phase of data analysis was carried out (Phase II). By using the coding technique for content analysis (Strauss \& Corbin, 1998), data was coded by themes which were individually explored for categories and sub-categories. Due to the fact that some findings were not able to be explained by some features of the framework, a third literature review was conducted (Phase III). During this phase, the conceptual framework (Figure 2.3) was revisited and the integrated framework (Figure 2.4) emerged as the basis on which further data analysis was undertaken and final interpretation of the findings was made.

In order to explore those aspects in detail, the next section elaborates on the research questions, Section 3.3 presents the methodology, Section 3.4 examines the methods for data collection and analysis, Section 3.5 shows the strengths and limitations of the methodology, and Section 3.6 presents the structure of the thesis.

\subsection{Research questions}

In order to tackle the elements emerging from the conceptual framework (Figure 2.3), this research explores the following key questions in the Chilean case:

1) What was the process that led to the creation of the new Chilean institutional framework for tourism?

2) What were the factors that influenced and shaped the process?

3) How and why did the process and the factors influence the outcomes of the process? 
Question one aims to establish and examine the process of change. The Policy Cycle Model presented in the conceptual framework (Figure 2.3), suggests that the process of change occurs in a set of consecutive phases. However, as discussed in Chapter II, the model has limitations in terms of operationalising these phases and therefore a new approach to investigate the process of change was proposed in Figure 2.4 (the integrated framework). Figure 2.4 shows that the process of change is divided into three major stages: pre-legislative, policy windows, and legislative stage. Therefore, question one aims to identify these stages and establish the process of change in Sernatur. Key milestones - such as critical events - were identified and used as breakpoints to distinguish these stages. These milestones were identified based on the main features of the literature described in Chapter II. For example, the literature highlights that a policy window is opened when three streams intersect (problem, policy, and politics). Thus, the identification of milestones that signal these three streams was required to identify when the policy window was opened. Figure 2.4 also shows that the components of a policy process (evaluation, multiple agendas, formulation, and decision making) existed as part of these three stages. For example, there was not a single phase of agenda setting as proposed by the Policy Cycle Model, but several overlapped agendas distributed over the three stages. Something similar occurred with formulation and decision making during the legislative stage. On account of this, milestones were also identified and used to establish when these components occurred (i.e. the announcement of the bill made by Bachelet to identify formulation or the announcement of the bill submission to Parliament to identify decision making).

Question two seeks to identify and investigate the factors that triggered and shaped the process. The integrated framework (Figures 2.4) shows that environmental conditions and evaluation reports could provide important information to address this question. As discussed in Section 2.6, there are different types of evaluations: internal/external; commissioned as part of the process or in the general environment; and conducted "for" or "of" policy analysis. While the first two types of evaluations may contain information about why the process of change started, the last type of evaluations (of/for policy analysis) may provide information about what solutions were proposed during the process and how evaluations influenced and shaped the debate during the formulation and debate of the bill in Parliament. 
Finally, question three attempts to explain the results of the process of change in Sernatur. In addressing this question, the analysis brings together the process of change and the factors investigated in question one and two. As presented in Figure 2.4, the features of the process are also investigated to explain why a particular outcome resulted from the process of change. Following Reed (1997) and Thomas and Thomas $(2005,2006)$ who investigate the tactics actors use to push forward their agendas in a policy process (e.g. negotiation and power), this question examines agreement, disagreement, acceptance, negotiation, and power as features of the policy process to explain the results of the process of change. As with the other two questions, the examination of the impact of environmental conditions on the process also emerges as a critical element.

\subsection{Methodological design: Qualitative case study, interpretive, and multi-methods approaches}

The methodology design has to enable the research to investigate critical aspects of the process of change in the Chilean NTA. On account of this, a qualitative case study approach is adopted to investigate the process of change in Sernatur. Creswell (2007), Marshall and Rossman (2006) and Yin (2003) define a qualitative case study as a research design in which one case or multiple cases are investigated in their specific social context. While the adoption of a qualitative case study approach is appropriate because of the research focus on the Chilean case, the approach also tackles an important aspect presented in the conceptual framework: the general context in which the process occurs. The qualitative case study approach rests on the notion that understanding social actions is useful to explore social phenomena and that these actions are influenced by the setting in which the actions occur (Guba \& Lincoln, 1994). Since the institutional change process in the Chilean NTA occurred in a broader political and economic environment, a qualitative case study allows the researcher to capture the influence of these environments on the process.

This research also adopts an interpretive approach. This approach was adopted because multiple data is required and multiple perspectives may emerge amongst stakeholders in order to explain what happened during the process of change. The interpretive approach aims for interpretation and explanation of the phenomenon 
under investigation. In particular, the approach centres on the study of meanings; the way individuals make sense of their world through their communication and behaviour (Putnam \& Pacanowsky, 1983). The use of the interpretive approach and its implications for data collection, analysis and interpretation are examined in detail in Section 3.4.

Finally, a multi-method approach was adopted to collect data. Because of the wide range of information required, the methods selected as more appropriated for data collection for this study were gathering documentation and conducting semistructured interviews. For instance, the factors that triggered and shaped the process were likely to be contained in official evaluation reports; however stakeholders' perspectives, gathered from interviews, were also required for a better understanding of these factors. The particularities of the methods for data collection and analysis are discussed next.

\subsection{A multi-phase approach}

A key aspect of this research design is the iterative nature of the research process. As presented in Figure 3.1, data was collected and analysed over several phases. During these phases, the literature was reviewed on multiple occasions in order to refine data analysis and interpretation of findings. As noted in the figure, three major phases were undertaken: I) approaching the case, II) immersion and first analysis, and III) final data analysis and interpretation.

\subsubsection{Phase I: Approaching the case.}

During the first phase, secondary data was collected and analysed to provisionally establish the institutional change process. This secondary data included consultancy and official reports, newspapers, and other resources presented in Appendix A. To establish the process, this data was analysed in order to look for milestones (critical events) that allow the identification of the phases of the process (e.g. presidential announcements of the bill). Milestones also included events occurring in the general environment that may have influenced the process (e.g. changes of government or ministers). Drawing on the main features of the Policy Cycle Model described in the literature, milestones were identified, systematised in a timeline, and used to identify 
the phases of the process and provisionally establish the process of change in Sernatur. For example, in 2001 several news reports highlighted that Sernatur was conducting a series of workshops to elaborate an agenda (El Mercurio, 2001a, 2001b). As explained in Chapter V, the workshops led to the National Tourism Agenda, which sets the basis for the process of change in Sernatur. In this case, these news reports were used to identify when the phase of agenda setting may have been initiated. A similar situation occurred with the phase of decision making. Several news reports highlighted that the government submitted a tourism bill to Parliament in November 2007 (El Mercurio, 2007a, 2007b; Radio Cooperativa, 2007). This set of news reports was cross checked with procedures of Parliament (Cámara de Diputados de Chile, 2008a), and both were used to identify when the phase of decision making in Parliament started.

\subsubsection{Refining tools for data collection.}

Secondary information was analysed further in order to refine tools for data collection. From this analysis, the researcher identified a set of documentation to be collected in the field and the analysis also helped to refine the semi-structured schedule. Background documents (secondary data) were first reviewed separately. By using a colour coding technique (Quinn, 2002), different alternatives for the structure and roles of the NTA were identified. From this analysis five broad themes emerged across all the background documents: structure of the NTA, role of policy making, marketing, planning, and tourism quality assurance. Then, a comparative analysis of each theme in the documents was conducted and the main aspects emerging from the analysis were summarised in tables and used as the basis to finalise the check-list of questions for the interviews.

The table containing the role of marketing is used to exemplify this analysis (Appendix B). The table shows an overview of the role of marketing before the bill was submitted to Parliament. The table also presents existing evaluation reports about this role. Since each document contained different proposals to address modifications in the role of marketing, the table identifies the document with a number: (1) shows the role contained in Act 1224 before the bill was passed (Ministerio de Economía Fomento y Reconstrucción, 1975), (2) presents the alternatives discussed (C\&S Soluziona Servicios Profesionales, 2004; Universidad 
de Chile, 2007), (3) shows the proposal submitted to Parliament (Gobierno de Chile \& Ministerio de Economia Fomento y Reconstruccion, 2007) and (4) shows the marketing role enacted by the Act (Ministerio de Economía Fomento y Reconstrucción, 2010). In order to compare the proposals contained in these documents, the table shows each proposal and identifies who was in charge of proposing, approving, and implementing marketing. Based on this analysis important questions emerged, including issues such as why it was necessary to change the roles of marketing; why there were changes between what was proposed in the bill and what was approved by the Act; how and why these differences occurred; and why a particular approach to address a change in the role of marketing was adopted. The emerging questions were included in the table and highlighted in red in order to be considered during the process of developing the checklist of questions. The same approach was conducted for the five themes identified. Drawing on this analysis a checklist of questions was produced (Appendix C) and then organised in seven sections as presented in Table 3.1.

\begin{tabular}{|l|l|}
\hline $\begin{array}{l}\text { A) Respondent's professional } \\
\text { background }\end{array}$ & $\begin{array}{l}\text { - Interviewee's professional background, position, role in the } \\
\text { agency and time working in the agency }\end{array}$ \\
\hline $\begin{array}{l}\text { B) Respondent's organisational } \\
\text { background }\end{array}$ & $\begin{array}{l}\text { - Characteristics of the organisation where the interviewee works } \\
\text { and the relation of the organisation to the tourism sector }\end{array}$ \\
\hline C) The Tourism Act & $\begin{array}{l}\text { - Overview of Act } 20423 \\
\text { - Milestone about when the process started } \\
\text { - The process of formulating the bill }\end{array}$ \\
\hline - The decision making in the congress \\
- Proposals discussed during the process
\end{tabular}

Table 3.1: Interview overview 
Sections (A) and (B) consider general information about the interviewee (professional and organisational background). Section (C) aims to obtain an overview of the process of change (the factors that triggered the process, the characteristics of the process and the resulting outcomes). The next section (Section D) focuses on the structure of the institutional framework for tourism. In particular, this section examines the existing framework contained in Act 1224, the proposals for the structure suggested during the process, the framework proposed by the tourism bill, and the framework resulting from the enactment of Act 20423. The intentions underlying this section were to identify the alternative structures discussed during the process, examine changes among these alternatives and look for explanations about why a particular structure resulted from the process. Section (E) focuses on environmental conditions that may have influenced the process. This section also includes the provisional timeline with the process developed at the beginning of the research. The idea here was to identify any new milestones that might help the researcher to have a more precise version of the process of change. The next set of questions (Section F) examines the four roles contained in Act 20423 - policy making, marketing, planning, and tourism quality. This section investigates the features of these roles before the bill was formulated, the factors that triggered changes in these roles, the alternatives discussed during the process, and why a particular approach was adopted to address these roles. Lastly, Section (G) contains final considerations including other issues the interviewee considered important to address, documents recommended to be reviewed, or the identification of additional actors to be interviewed.

\subsubsection{Data collection in the field.}

After gaining ethical approval from Pipitea Human Ethics Committee, data collection began. Based on the list of documents previously identified - and also the recommendations of interviewees - a set of documents was collected in the field (Appendix D). These documents included official and unofficial reports and consultancies produced by Sernatur, government agencies, universities, tourism federations, and the business sector. Parliamentary procedures regarding the discussion of the bill in Parliament were also collected. All the relevant documents sought were collected with the exception of one (the matrix document). The implication of this is explained later in Section 3.5. 
A provisional list of stakeholders prepared prior to the fieldwork was used as a guide to conduct a first set of interviews. These first interviews focused on people that certainly were involved with the process (e.g. Sernatur's director). This provisional list was discussed during interviews and a new list of actors was prepared. In the new list, some organisations were confirmed and others were omitted as they were not directly involved in the process. In turn, a new group of stakeholders that were not included in the first list also emerged (e.g. Budget Office - Dipres).

In total, 37 representative stakeholders were interviewed (Appendix E). This group included four Members of Parliament, a former Minister of Economy, several former national chiefs of public agencies, representatives of private sector tourism organisations, and Chilean researchers in tourism. The Members of Parliament were selected from the Chamber of Deputies, which is the Chamber where the bill was submitted and where the main changes to the bill were introduced. These deputies were selected because they were part of the Tourism Commission of the Chamber and also due to their high involvement with the bill. To guarantee that different political points of views were captured among these politicians, members were selected from the two main political coalitions: la Concertacion and la Alianza. The first one had majority in Parliament and represents the left-centre wing, while the second represents the right-centre one. The sample of interviewees also contains representatives of public agencies that have programmes in tourism and have a direct relationship to tourism development in the country (e.g. the Forestry Service Conaf). The tourism private sector was represented by the CEOs of national tourism associations in the hospitality, travel and accommodation sectors. Although private sector perspectives were mainly drawn from national tourism associations, a CEO of a local tourism association was also interviewed as a way to ensure that a local perspective was included. Finally, academic perspectives were also gathered as a way to complement the private and public sector perspectives.

All the stakeholders in the final list were interviewed, except for one Senator and a consultant (Mr. Marcelo Drago) who were unavailable. Former President Bachelet was not on the list but interviewing her would have been desirable due to the key role she played in the process. However, interviewing her was not possible because 
she was in New York in charge of the UN-Women Agency during the time data was collected.

The researcher's background in the Chilean tourism sector and his understanding of policy making in the country was critical to identifying this key group of stakeholders and gaining access to them. The researcher has a broad knowledge of the tourism sector, a field in which he has worked for about ten years. This facilitated identifying the core interviewees related to the industry. The researcher's work experience was also important in identifying politicians and decision makers. His last job in Chile was in environmental marine conservation policy making; this helped him to understand policy processes and identify key policy makers to be interviewed. This background and a networking strategy enabled the researcher to get access to relevant stakeholders and to gather documentation which had limited public access.

The researcher's background and knowledge of Chile also played a key role during data analysis and illustrates the adoption of the interpretive approach. Two examples may illustrate this. First, this background enabled the researcher to understand some institutional arrangements that are not formally established by any act and that were critical to investigate the process of change in Sernatur (i.e. the power of Dipres in the public sector). Second, in spite of this background, the researcher was not directly involved in the tourism industry for a couple of years before coming to New Zealand and also during the time he was conducting his $\mathrm{PhD}$. This distance gave him a better perspective and freedom for conducting the analysis of the case and depicting the process of change in the Chilean case.

The interviews were conducted in Spanish, the researcher's native language. This enabled him to address the semi structured nature of the interviews more readily, to follow up points in more detail and to capture new emerging issues. Conducting the interviews in Spanish also had practical implications for the interpretation of data. They are discussed in detail in Section 3.4.3.

Interviews were conducted face to face in Santiago and Valparaiso, where the central government and Parliament respectively are located. The interviews lasted about one 
and a half hours depending on the level of involvement of the interviewees with the process. There were some interviews that required two sessions due to the level of interviewee participation in the process. The interviews were audio recorded and notes were taken and used by the researcher to highlight and track important issues emerging from the discussion. All of the sections presented in Table 3.1 were addressed with each of the interviewees with the exception of Section F, which was only included depending on the interviewee's field of action. For instance, because the Forestry Service (Conaf) is the agency in charge of managing the National System of Protected Areas (SNASPE), interviews with Conaf representatives focused on the analysis of the role of planning (tourism development in national parks). The provisional timeline defined prior to the fieldwork was also discussed with the stakeholders. In this way, the identified milestones were validated and additional critical events were also identified.

The interviewees generally answered questions fully and openly, even on more sensitive issues. In 2010 there was a change of government and key interviewees directly involved to the process were no longer part of the government. Because these stakeholders were no longer in power, they were fairly candid about how and why the process of change in Sernatur occurred. Although sensitive issues emerged from the discussion (e.g. political disagreement) interviewees addressed these ideas and discussed them explicitly. When interviewees requested confidentiality and asked the researcher not to mention the source of the information, the relevant quotes included in the following chapters identify the interviewee as "anonymous". After data were collected in the field, interviews were transcribed verbatim to proceed with the analysis.

\subsubsection{Phase II: Immersion in the data.}

The second phase focused on the analysis of data collected in the field. This phase began with the familiarisation of the researcher with the data (Mehmetoglu \& Altinay, 2006). This enabled some first thoughts to emerge and allowed the researcher to notice new things emerging from the interviews. The manual transcription of the interviews, conducted by the researcher, helped the researcher to become familiarised with the data. While transcribing the interviews, the researcher noticed the emergence of new unanticipated elements addressed by most 
interviewees; they were the New Public Management approach (NPM) and the broader issue of governance. As these elements had not been addressed in the first literature review, the review of a new stream of literature was required prior the analysis of the data (i.e. the general idea of governance discussed in Section 2.5). After this second literature review, data was manually coded in order to look for themes and categories by using the coding technique for content analysis (Strauss \& Corbin, 1998; Yin, 2003).

\subsubsection{The coding process.}

The gathered documentation and the interview responses were analysed using a coding technique. The technique allowed the researcher to break down data into units of analysis and to then examine this data for broad themes, categories and subcategories (Stevenson, et al., 2008). Data was examined, segregated and grouped into broad topics (themes). Each theme was then explored separately to look for patterns (categories and sub-categories), which allowed the researcher to move from particular issues towards general topics for the analysis of the case (Borkan, 1999). The coding process consisted of several steps summarised in Figure 3.2.

Figure 3.2 shows how data was organised into themes, categories, and subcategories. As presented in the figure, the coding process was led by the critical elements presented in the conceptual framework (Figure 2.3), the research questions, and the new literature reviewed on NPM. These elements provided the basis for the identification of the themes and categories. As noted in Figure 3.2, six themes were identified: the process of change, the structure of the NTA, and the roles of policy making, marketing, planning, and quality assurance.

After that, a first cut coding was carried out. The coding was conducted manually by using a colour coding technique (Quinn, 2002; Tolish \& Davidson, 1999). First, the researcher read the interviews in order to look for information related to a particular theme. Once information was identified, data was colour coded. After this analysis, segments of text coming from different interviews were brought together into a particular theme and organised by using NVIVO. After reviewing the interviews, the researcher read the documents collected in the field. Using the same technique of colour coding, segments of text of the documents were identified and coded to a 
particular theme. Once data was disaggregated into themes, the next step was to organise the interviews and documents into themes by using folders.

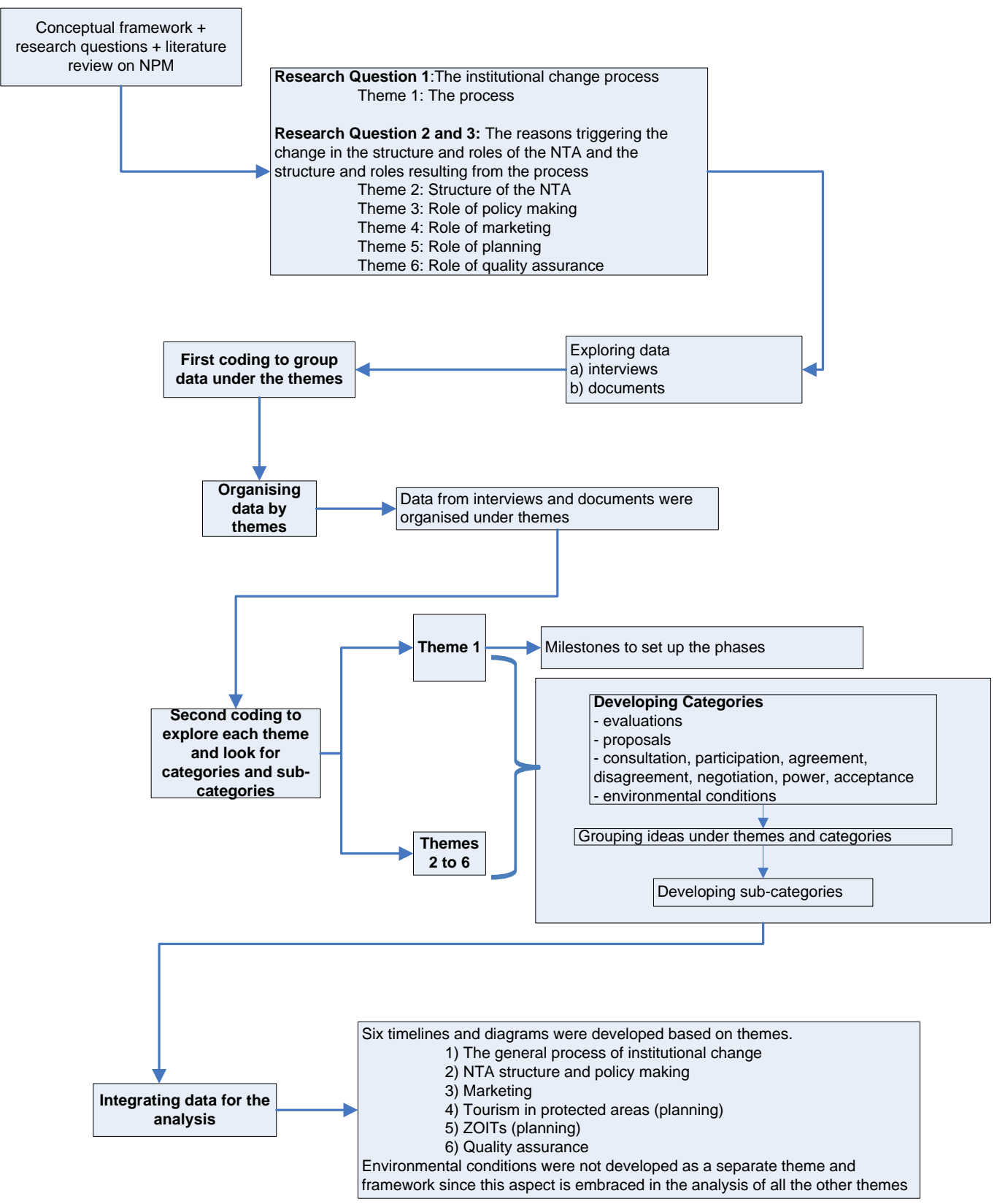

Figure 3.2: The coding process

Once data was organised by theme, a second cut coding was conducted. This second coding looked for milestones in order to establish the process of change and have an accurate version of the process developed in Phase I. As mentioned, critical events (milestones) that signal the start and final point of the phases of the Policy Cycle Model were identified and transferred to a chronological list of events (i.e. the 
submission of the bill to Parliament and its enactment to show the decision making phase). This second cut coding also aimed to identify categories. This was conducted separately theme by theme. Once again the conceptual framework (Figure 2.3), the research questions, and the literature on NPM provided the structure to explore each theme and identify categories. Evaluations and environmental conditions contained in the conceptual framework are expressed in categories with the same name. The category of "evaluation" provides the factors triggering and shaping the process of change, while "environmental conditions" shows the influence of external factors over the process and the outcomes. Other categories are "proposals", “disagreement", "negotiation", "power", and "acceptance” which helped to examine the features of the process of change. For example, proposals allowed the researcher to identify and explore what options were discussed during the process (formulation and parliamentary decision making), while disagreement, negotiation and power were used to interpret changes among proposals and explain the outcomes resulting from the process of change.

The next step was to develop sub-categories. Data grouped under a particular category contained many different issues. These issues were grouped into similar ideas and labelled with the name of a sub-category. The theme "role of marketing" and the category of "evaluation" are used to exemplify the identification of these sub-categories. The category of evaluation contains the factors that triggered changes in the role of marketing. In this example, interviewees and documentation highlighted the fact that Tourism Chile lacked representation of the tourism sector and also lacked mechanisms to show how decisions were made in the board of the NTO. Drawing on the literature on NPM, these ideas were grouped into the subcategory of "governance". This sub-category contained several issues, including coordination, funding, effectiveness, transparency, and accountability. Appendix F shows the themes, categories, sub-categories, and issues. As noted in the appendix, although "the process" is a theme by itself (Theme 1), the process is also considered as a category to explore themes 2 to 6 . This occurs because themes 2 to 6 (structure and roles of the NTA) were discussed in the context of the process. This double perspective of the process, as a theme but also as a category, allowed the researcher to examine the process of change and understand how the process influenced the outcome of the institutional change in Chile. 


\subsubsection{Data analysis.}

After the coding process, an analytical framework was developed in order to analyse each theme (Figure 3.3). The analytical framework is called "First analytical framework for the investigation of the process" because, as discussed later, a third data analysis was required and new analytical frameworks emerged.

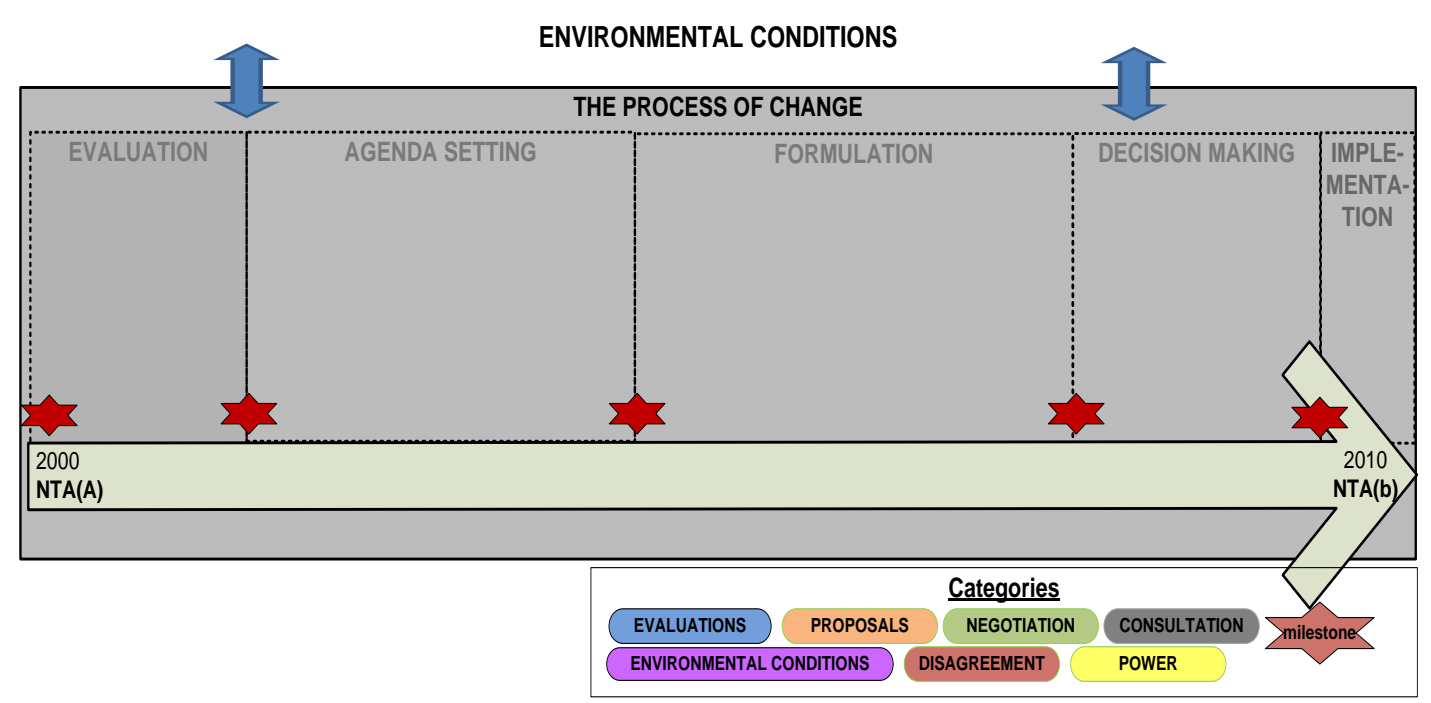

Figure 3.3: First analytical framework for the investigation of the process of change

The figure contains an arrow representing the timeline when the institutional change process occurred. The timeline shows the initial and the final points of the process. The starting point is presented by the existing NTA before the process occurred (NTA a), while the outcome of the process is presented by the NTA (b). The arrow with the timeline is inside a shaded box that contains the process of change. In the background of this shaded box, the phases of the institutional change process suggested by the Policy Cycle Model are presented (a set of clearly divided consecutive phases). Red stars show the milestones used to define the starting and final point of each phase. Categories and sub-categories were also brought into the analytical framework. By using coloured boxes, data related to each category and sub-category was allocated in the analytical framework. The category of evaluation, the sub-categories of governance, and the several issues contained as part of evaluations are used to exemplify this. Evaluation reports were identified and placed into the timeline in blue boxes. Each box contained the name of the evaluation and 
the year when it was conducted. As part of the box, relevant information contained in the evaluation was also included highlighting the name of sub-categories (e.g. governance) and issues (e.g. transparency and accountability).

The analytical framework allowed the researcher to link information from different sources, categories and sub-categories. By doing this, a comprehensive picture of each theme was achieved, including the identification of the factors that triggered the process of change, the identification of where changes in the structure and roles of the institutional framework emerged from, how $\operatorname{NTA}(b)$ evolved until it gained approval in Parliament, and how the environmental conditions influenced and shaped the process of change. In spite of the value of this analytical framework, data emerging from the case showed that a clear division of the process in phases hardly occurred. In fact, the phases of evaluation, agenda setting, and formulation did not have clear boundaries but, in fact, overlapped. Moreover, evaluations occurred during the whole institutional change process challenging the Policy Cycle Model and the conceptual framework (Figure 2.3). To address this limitation, and as mentioned at the beginning of this Chapter, a third and final data analysis was conducted.

\subsubsection{Phase III: Final data analysis and interpretation.}

At this phase a third literature review was conducted. Based on this new stream of literature, the conceptual framework (Figure 2.3) was revisited and an integrated framework for investigating the process of institutional change was proposed (Figure 2.4). This process of revisiting the research's theoretical foundations after data analysis and proposing complementary frameworks is defined by Dubois and Gadde (2002) as systematic combining. Systematic combining "is a non linear process of combining efforts with the ultimate goal of matching theory and reality" (Dubois \& Gadde, 2002, p. 556). The authors suggest that during the research process, the researcher needs to go back and forth between frameworks, data sources, and analysis in order to confront theory with the empirical world. While preliminary conceptual frameworks reflect theoretical preconceptions, frameworks developed after the analysis of data emerge to face and give explanation to what is discovered in the empirical fieldwork. Thus, systematic combining suggests that theoretical frameworks, empirical fieldwork, and case analysis evolve simultaneously during a 
research process as a result of the confrontation between theory and the empirical world. The integrated framework was used as the second analytical framework to investigate the process of change and employed to frame the findings presented in Chapters V to VII.

As presented in Figure 2.4, the process of change occurs in three main policy stages: pre-legislative, policy window and legislative. The figure shows that, while multiple agendas interact and evaluations exist across these three stages, formulation and decision making overlap as a single phase during the legislative stage. Based on this integrated approach, the researcher conducted the third data analysis. Because the analysis conducted in Phase II identified milestones to directly establish the phases of the Policy Cycle Model, at phase III the researcher revisited the data in order to identify milestones that signal the three policy stages. Similarly, the data was also revisited in order to identify milestones that indicate the three different types of agendas, evaluation, formulation, and decision making as proposed in Figure 2.4. For example, the literature highlights that the pre-legislative stage starts with a broad list of issues proposed by a sector. This list of issues is known as the systemic agenda (Birkland, 2007; Clark, 2004; Howlett \& Ramesh, 2003; Parsons, 1995; Princen, 2007). When the government embraces these issues - but also narrows them to a more limited list - it is said that the systemic agenda moves towards the institutional agenda (Howlett \& Ramesh, 2003). Therefore, milestones that signal these agendas were identified: these included the launch of the National Tourism Agenda by Sernatur in 2002 (systemic agenda), and the National Tourism Policy elaborated by the Ministry of Economy in 2005 (institutional agenda). This third analysis provided a better understating of policy processes and allowed the researcher to address the limitations of the Policy Cycle Model to establish the process of change (Chapter V).

After establishing the process of change, evaluation reports and environmental conditions were examined to investigate the factors triggering and shaping the process. At this phase a new challenge emerged, in particular for analysing the category of evaluation and the sub-category of governance. As mentioned above, the sub-category of governance was composed of several issues (coordination, funding, effectiveness, transparency, and accountability). The category "Governance" and its 
issues were addressed in most evaluations reports; however these reports varied depending on what particular issue of governance was examined and how these reports proposed to tackle these issues. For example, evaluation reports conducted during the pre-legislative mainly focused on funding, effectiveness, and coordination (C\&S Soluziona Servicios Profesionales, 2004; Chacon, 2002; Sernatur, 2002), while evaluations carried out during the legislative stages included other issues such as transparency and accountability (Boston Consulting Group, 2007; Inter American Development Bank, 2007b; Universidad de Chile, 2007). The way governance was addressed in the proposed solutions of these evaluation reports also differed. Reports conducted or commissioned by Sernatur proposed to strengthen Sernatur (C\&S Soluziona Servicios Profesionales, 2004), while Dipres proposed to modify the entire framework to guarantee the adoption of the NPM approach (Universidad de Chile, 2007). This is addressed in detail in Chapter VI.

Some of the themes, categories, sub-categories and issues were assessed simultaneously by several evaluation reports, which suggest that evaluations may have overlapped. The analysis of evaluation reports is even more complex because the issues are directly interconnected and also overlap (coordination may be either an issue or the cause of a problem affecting another issue). These complexities for the analysis of governance in evaluation reports are illustrated in Figure 3.4.

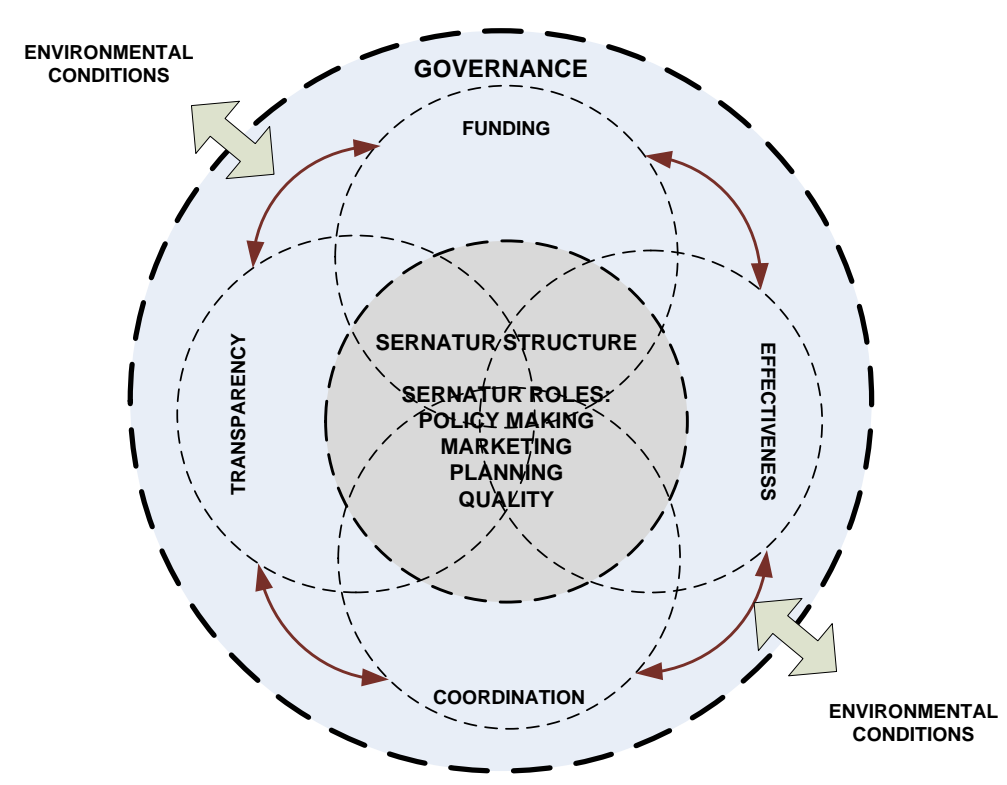

Figure 3.4: Complexities for the analysis of evaluation reports 
Figure 3.4 shows that governance is the broader sub-category that includes issues of funding, effectiveness, coordination, and transparency. These issues are used to analyse different themes (structure and roles). The figure also shows that funding, effectiveness, coordination, and transparency overlap during the analysis of the structure and roles of Sernatur. The interconnection between these issues is shown by red arrows. The figure also indicates that governance emerged as part of the environmental conditions underlying the process of change; for example, from the administrative reform in the public sector. Thus, the figure contains arrows that connect governance with the environmental conditions. In order to address these complexities for the analysis, an analytical framework was developed to analyse evaluation reports (Table 3.2).

\begin{tabular}{|c|c|c|c|c|c|}
\cline { 2 - 5 } \multicolumn{1}{c|}{} & \multicolumn{3}{c|}{ Problems } & \multirow{2}{*}{ Proposed solutions } \\
\cline { 2 - 6 } \multicolumn{1}{c|}{} & Theme & $\begin{array}{c}\text { Core } \\
\text { problem }\end{array}$ & Causes of the problem & Background cause & \\
\hline \multirow{3}{*}{ Issue } & Theme A & & & & \\
\cline { 2 - 6 } & Theme B & & & & \\
\cline { 2 - 6 } & Theme N & & & & \\
\hline
\end{tabular}

Table 3.2: Analytical framework for the analysis of evaluation reports

This analytical framework (Table 3.2) was used for the examination of the issues separately (funding, effectiveness, transparency, and accountability). For each issue the theme under examination is presented. Each theme is examined based on two major aspects - the identified problems and the proposed solutions to address these problems. Three aspects of the problems are presented in the table: these include the core problem, the causes of the problem, and the background causes. The core problem relates to the particular situation affecting an issue and theme; the cause of the problem refers to what in particular produces the core problem; and the background cause concerns the broader circumstances that lie at the root of the problem and its causes. The last column of the table shows the solutions proposed to address the problems. Although these proposed solutions are investigated in Chapter VI, an in-depth analysis of how and why some particular solutions were included in the tourism bill is conducted in Chapter VII. 
Analysis of the evaluation reports shows they generally agree on the identification of the problem; however they do not necessarily agree on the interpretation of the problem causes, the background causes, and the proposed solutions. As presented in Chapter VI, these differences occurred because two main different points of view existed: those of Sernatur and those of Dipres. These organisations interpreted the causes of the problem and the background causes in different ways and therefore developed different proposals to address these problems.

Althought information from documentation and interviews was consistent in most cases; some information contained contradictory points of view among the stakeholders. In order to embrace these different perspectives, these points of view were cross checked with documentation in order to establish the researcher's own interpretation. This suggests that in this research there are two layers of interpretation: the interpretation provided by the documentation and the interviewees about the case and the interpretation the researcher gives to the phenomena based on information emerging from the documentation and interviews. The different points of view regarding the role of marketing are used to exemplify these different layers of interpretation. When stakeholders were asked about the performance of Tourism Chile, some actors from the private sector had a positive evaluation while others argued problems of governance and accountability. To clarify these perspectives and interpret this data, information was cross checked with official evaluations of Tourism Chile. In that case these different perspectives - triangulated with documentation - allowed the researcher to identify points of disagreement and gain a better understanding of how to interpret the reports evaluating the NTO.

Different points of view not only existed amongst organisations but also on occasions within the same organisations. In these cases, these perspectives were addressed only when they had a direct implication to the process of change in Sernatur. For example different perspectives inside Conaf about its roles and internal structure had clear implications for the administration of the SNASPE and therefore for the tourism industry. They are briefly addressed in Chapter V and VII as explanatory factors to investigate the process of change in Sernatur but an in-depth analysis was not carried out because it exceeded the scope of this thesis. This also 
illustrates some of the trade-offs of this research in order to achieve a comprehensive perspective for the analysis of the case.

\subsection{Strengths and limitations}

The richness of the data collected is one of the main strengths of this research. The data collected was extensive and provided an excellent source of information to explore the case. Even when sensitive themes were addressed during the interviews (e.g. disagreement), interviewees addressed the questions and provided information. Gathering documentation was, in general, straight-forward, with the exception of some reports under revision that had not been officially published (e.g. Universidad Católica de Valparaiso, 2009). In most of these cases, the researcher was able to access these reports by using networking to contact people inside the government. The sample of stakeholders interviewed is representative of the national tourism industry and most of the actors included in the list were interviewed. Extra effort was required to contact public servant representatives because certain strategic public servants involved in the process were no longer part of government due to the change of government in 2010. Nevertheless, all public sector representatives included in the list of stakeholders were contacted and interviewed.

During the interviews, most information contained in the checklist of questions was gathered. Even though new elements for the analysis emerged after data collection (Phase II and III), a second round of fieldwork to collect data was not needed. This occurred because of the semi-structured nature of the interviews which gave the researcher the flexibility necessary to address new issues emerging during the interviewing process. The adoption of NPM in Chile is a good example of this. The checklist of questions did not have any particular question regarding the issues of NPM and administrative reform. When these issues emerged during the interviews, the researcher took notes and prompted some new questions in order to address how NPM and administrative reform in Chile may have influenced the process of change.

It is acknowledged that this research contains certain limitations. The sample considered a broad range of representative stakeholders; most of these perspectives were gathered at the national level. However, since the private tourism sector in 
Chile is highly fragmented there was a possibility that certain groups were not represented by these associations, particularly small tourism companies at the local level. To address this issue and obtain a local perspective, an interview with a representative of a local tourism association in Southern Chile was conducted. Although more than one local stakeholder's points of view would have provided more information, fragmentation of the sector and time-cost considerations did not allow more interviews with this group of stakeholders to be conducted.

Another limitation is the lack of access to one particular document identified by the interviewees as "the matrix document". This document strongly influenced the Bachelet programme of government in tourism and is, therefore, considered a key document to explain the policy window and the start of the legislative stage. Despite efforts to get access to this document, the document could not be found anywhere and this limited the researcher's ability to cross check interviewees' responses with the matrix document and in this way to confirm the influence of the document on Bachelet's programme. To address this limitation, the researcher asked the interviewees to recall the issues contained in the document and then these issues were cross checked with Bachelet's programme of government and the influence of the matrix document on Bachelet's programme was confirmed. This aspect is addressed in detail in Chapter VI.

Challenges also arose with implications for the findings presented in the following chapters. During the coding, the existence of information that crossed multiple aspects of the analysis needed to be coded into different themes and categories. This produced a larger amount of information to explore the themes, but in this way it was guaranteed that this information was always considered for the analysis. For example, "the process" emerged as a theme as well as a category to explore other themes such as the structure and the roles of the NTA. During data analysis certain challenges were also encountered, such as stakeholders' contradictory points of view. Drawing on the adopted interpretive approach, the stakeholders' interpretation of the case was used by the researcher as explanatory factors for the researcher's own interpretation. Therefore, by acknowledging these contradictory perspectives and by triangulating them with secondary data, the researcher used these points of view to explain and interpret the case. During data analysis, and in order to provide a 
comprehensive perspective a trade-off of details against the broad perspective desired was required. In spite of a wide range of available data, during the analysis some details indirectly related to the case were omitted.

\subsection{Presentation of the findings}

The findings were written up by using thick description (Stevenson, et al., 2008). In order to address the research questions and discuss these findings, this research is divided into four major chapters. In these chapters, italic font is used to differentiate interviewees from other sources (journal articles, books, or reports). In addition, quotations extracted from interviews are presented in separate paragraphs.

Drawing on the importance of the environmental conditions to examine the case, Chapter IV provides the general context within which the process of change occurred and presents the general environmental conditions in Chile during the 2000s.

Chapter V presents the process of change divided into the three stages shown in Figure 2.4 (pre-legislative, policy window, and legislative stages). The components of the policy process are presented as part of these stages (multiple agendas, evaluation, formulation, and decision making). The different policy agendas were established based on documentation and stakeholders' discourse about the need to change the structure and roles of Sernatur and how this discourse was being narrowed from the systemic to the decision agendas (Birkland, 2007; Clark, 2004; Howlett \& Ramesh, 2003; Parsons, 1995; Princen, 2007). The formulation of the bill was examined based on different alternatives of structures and roles for the NTA. Different consultancy reports were used to examine what was proposed during the formulation, and these were complemented with stakeholders' perspectives about actors' participation, power, and involvement to influence the formulation (Bramwell, 2006; Bramwell \& Meyer, 2007; Dredge, 2006a; Reed, 1997; Stevenson, et al., 2008). Finally, decision making relates to the debate of the tourism bill in Parliament. This phase was explored based on the analysis of documentation (i.e. parliamentary procedures), combined with stakeholders' perspectives about actor's involvement, and the use of power to influence the final decision (Bramwell, 2006; Bramwell \& Meyer, 2007; Dredge, 2006a; Reed, 1997; Stevenson, et al., 2008; 
Thomas \& Thomas, 2005, 2006). Drawing on Bramwell (2006) and Stevenson, et al. (2008), Chapter V also examines environmental conditions as an important aspect to investigate the process of change.

To address the second research question, Chapter VI presents the analysis of documentation and interviews in order to identify the factors that triggered and shaped the process of change. To examine these factors, the different types of evaluations presented in Chapter II are examined with regard to Sernatur and other related organisations forming the tourism institutional framework. These evaluations were complemented by the analysis of the stakeholders' perception of the existing structure and roles of the institutional framework before the enactment of Act 20423. In this chapter, the environmental conditions provided in Chapter IV are also considered and used as explanatory factors to investigate these evaluations.

In order to investigate research question three, Chapter VII examines the outcome of the process in the light of three elements - the influence of the environmental conditions, the process of change, and the factors triggering the process (Bramwell, 2006; Dredge \& Jenkins, 2003; Pearce, 1990, 1992, 1996a, 1996b, 1997; Stevenson, et al., 2008). By using these elements to examine Act 20423, the chapter aims to explain the outcome of the process, in particular why a specific structure and particular roles were approved and how the process and the factors influenced this outcome. Finally, Chapter VII brings together the findings emerging from Chapters IV to VII and discusses them in order to provide general understandings of processes of change in NTAs. 


\section{Chapter 4 Chile in the 2000s - environmental conditions and background information}

\subsection{Introduction}

The integrated conceptual framework developed to investigate the process of change in Sernatur (Figure 2.4) shows that the process occurred in the context of a broader environment. This broader environment is composed of the general political and economic conditions in Chile during the 2000s; the period in which the process of change in Sernatur occurred. As presented in Chapter II, this broader environment is composed of two sub-systems: the administrative and the tourism sub-systems. Thus, this chapter aims to set the scene for the case by examining the broader environment and the two sub-systems. The chapter incorporates data gathered from interviewees, which is referenced in italic font. The chapter also deals with a set of acts that define the structure and roles of the public sector organisations. Details of these acts are provided in Appendix D.

As described later, the environment in Chile during the decade 2000-2010 was characterised by a period of general economic and political stability (Szmulewicz, 2010). Two changes of government occurred during this period with direct implications for the process of change in Sernatur. In 2000, President Lagos came into office and announced the need to identify the limitations of the tourism sector. In 2006, President Bachelet came into office and announced a tourism bill to strengthen the tourism institutional framework (El Mercurio, 2006b, 2006d, 2006e, 2007b, 2008). During this period, reorganisation emerges as a major characteristic for both the administrative and tourism sub-systems. In 2006, a process of administrative reform was implemented prompting a change in the organisation of the public sector (Olavarría, 2007; Olavarría, et al., 2011; Pliscoff, 2008; Waissbluth, 2005; Waissbluth \& Inostroza, 2007). The private tourism sector also went through reorganisation: traditional private tourism organisations disappeared, others were merged, and new associations also emerged (Cybertur, 2009; El Mercurio, 2006c, 2009). In the context of this dynamic decade, the tourism industry showed rates of growth never seen before. 
This growth generated political attention around 2005 (Ferreiro, Iglesias, Rodríguez, Santelices, Szmulewicz, 2010) and two key issues emerged regarding the sector: these were the economic potential of tourism, and the weakness of the existing public institutional framework to tackle this potential (El Mercurio, 2005, 2006c, 2006d, 2006e, 2007b; Senado de la República de Chile, 2005a, 2005b; Sernatur, 2006a, 2007a, 2008a, 2010; Sernatur \& INE, 2008, 2009, 2010).

The broader environment and the political-administrative and tourism sub-systems presented in Figure 2.4 are used in this chapter to examine the context in which the process of change occurred. Section 4.2 provides an overview of the Chilean administrative sub-system, section 4.3 shows the characteristics of the tourism subsystem, section 4.4 examines the existing NTA before the process of change occurred, and, finally, Section 4.5 brings the most relevant environmental conditions together in order to set the scene to investigate the process of change in Sernatur.

\subsection{The Chilean political and administrative sub-system}

The Constitution of the Republic of Chile defines the Chilean political organisation as a Presidential Democratic Republic Regime (Gobierno de Chile, 2005a). In this regime, the President acts as the head of the State and the Government. The State is organised in three separate and independent branches presented in Figure 4.1: the Executive, the Legislature, and the Judiciary.

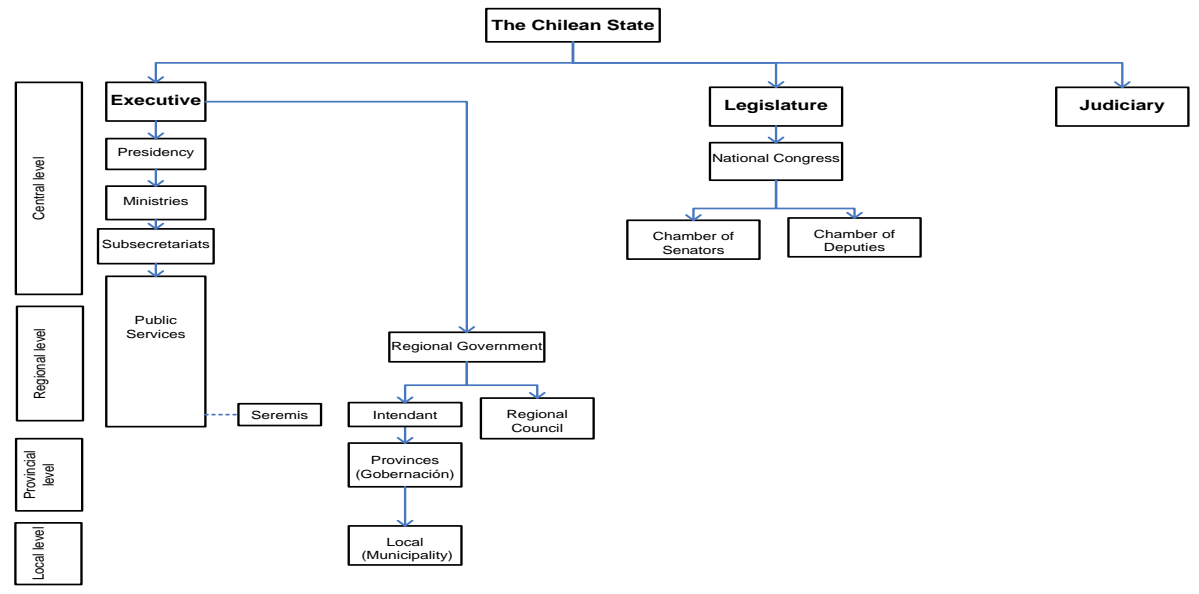

Figure 4.1: The Chilean State administration

(Government of Chile, 2009) 
Figure 4.1 shows that the Executive is composed of government organisations in charge of the country's administration at different levels, the Legislature is composed of the National Congress in charge of discussing and passing bills, and the Judiciary is composed of courts in charge of carrying out the judicial system. Because the Chilean NTA is a public organisation embodied in the public sector and also because the process of change occurred as a result of a legislative process the examination of the Executive and Legislative branches are examined next.

\subsubsection{The Executive branch: the government administration.}

The general administration of the country rests with the Executive. As shown in Figure 4.1, the administration of the country is conducted by organisations at different levels. At the central level - and led by the President - there are Ministries and Subsecretariats, while at the regional level there are Regional Governments and Regional Ministerial Secretariats (Seremis). Public Services, such as Sernatur, exist at both levels because their headquarters are placed at the national level but with representation at the regional level. At the lowest levels of the administration there are provincial governments and municipalities. Because the process of change was conducted at the central level but with direct implications for the regional level, this section examines the features of the central and regional administration.

\subsubsection{The central administration.}

Article 38 of the Constitution (Gobierno de Chile, 2005a) and Act 18575 (Gobierno de Chile, 1986) define the organisations comprising the central administration: The presidency, ministries, subsecretariats and public services. The presidency is led by the President. The President is elected for a term of four years. During the 2000s there were two presidential terms, Ricardo Lagos (1999-2006) and Michelle Bachelet (2006-2010), both from the same political coalition: Coalition of Parties for Democracy ("La Concertación”). After the presidency, ministries are the highest in the hierarchical organisation of the administration. Ministries deal with a particular area of the administration (i.e. health, education, economy), and are in charge of formulating their sector's national policy. In terms of structure, ministries are composed of one or more subsecretariats and several public services. Subsecretariats are administrative bodies in charge of the internal administration of ministries and advocate for policy implementation and evaluation. 
The bodies in charge of policy implementation are public services. Act 18575 (Gobierno de Chile, 1986) classifies public services in two categories: centralised and decentralised. Centralised public services operate under the general State legal status and budget, while decentralised public services operate under their own legal status and operational budget defined by the act that created the public service. Drawing on the decentralised category, public services may be classified as functional and/or territorial decentralised. Functional decentralisation refers to public services that are created to conduct a particular technical role; in this context, functional decentralised public services become specialised agencies in a particular theme. Territorial decentralisation occurs when public services establish regional offices at the regional level in order to implement plans and programmes. This classification is clearly visible in the Chilean NTA. Sernatur was created as a functional and territorial decentralised public agency, a specialised agency in tourism development with a central office in Santiago and several regional representations. Because there was not a specialised Subsecretariat of Tourism in charge of policy evaluation, this role was performed by Sernatur and the Subsecretariat of Economy. These characteristics of Sernatur are discussed in detail in Section 4.4.

\subsubsection{The regional administration.}

The structure of the central level administration is also reproduced at the regional level. Article 38 of the Constitution (Gobierno de Chile, 2005a) and the Constitutional Organic Act 19175 modified in 2005 (Gobierno de Chile, 1992, 2005a) provide the basis for the regional administration. As illustrated in Figure 4.1, the overall regional administration rests on a Regional Government. Regional governments are composed of an Intendant and a Regional Council. The Intendant is appointed by the President and acts as the head of the Regional Government, while the Council is composed of the Intendant and elected councillors. The Council is the main regional decision making body in charge of allocating funds assigned by the Central Government under the National Fund of Regional Development (FNDR). FNDR is an investment programme created by Act 19175 (Gobierno de Chile, 1992), which advocates for decentralisation by allocating funds to promote regional development in diverse areas such as tourism development. Even though the total FNDR budget received by the region is decided at the central level, the allocation of these funds at the regional level is the exclusive decision of regional councils. 
The administration at the regional level is also supported by Regional Ministerial Secretariats (Seremis) and public services. Seremis - which are administrative bodies that represent ministries - supervise policy implementation, while public services support policy implementation. In the structure of the public sector at this level there are multiple hierarchical dependences. Seremis depend on ministries and the Intendant, while public services depend on the national director of the public service, Seremis and the Intendant. This multiple hierarchical dependence illustrates the complex organisation of the public sector (highly centralised and hierarchical), which, in turn, has direct implications for the process of change in Sernatur. These implications are examined next.

\subsubsection{Implications of the government administration.}

The general administration of the country rests on a Presidential Regime defined by the Constitution. This means that the administrative power is concentrated in the President who delegates these powers to public organisations that compose the Chilean administration. Under the Constitution, the President appoints ministers, subsecretaries, and directors of public services for a presidential term. Although public organisation representatives (ministers, subsecretaries, and public services' directors) usually change when a presidential term finishes, public servants placed under the first line of the organisation direction should not be replaced after a change of government. However, in practice, political parties in government also replace and allocate new public servants based on political relationships. This has produced instability after a change of government and triggered cases of corruption. To address this problem - and after a case of corruption within the government was revealed in 2003 - the government and opposition parties agreed to the implementation of an administrative reform to the public sector (Waissbluth \& Inostroza, 2007). The reform advocates State modernisation based on the principles of the NPM approach, including the creation of an agency for recruiting public servants on merit and a performance measure system for the public sector (Gobierno de Chile \& Congreso de Chile, 2003).

The Presidential regime also allows the President to define priority sectors to be strengthened during a presidential term, which has a clear implication for the administration of the public sector. Priority sectors usually receive larger budgets 
and their representatives, such as ministers or subsecretaries, tend to attract more responsibilities and power in comparison with other representatives within the same hierarchy (Universidad de Chile, 2007).

Another key element of the Chilean public administration is its very hierarchical structure. At the top of the central level there are ministries as the main decision making bodies in charge of policy formulation, in the middle there are different organisations in charge of supervising implementation (subsecretariats), and at the bottom there are public services dealing with policy implementation. Although organisations created between 1973 and 1990 tend to concentrate roles and powers in the same agency, the trend underlying the creation of new agencies during the 2000s follows the idea of disaggregation of the public sector in administrative units. The concentration of roles in the same agency reflects the political scenario during the period of the Chilean dictatorship (1973-1990), while the allocation of roles among different agencies reflects the adoption of the NPM approach and the administrative reform mentioned above.

The adoption of the NPM approach followed the neoliberal political and economic model implemented by Pinochet's government during the 1980s'. The neoliberal model rests on economic arguments of state failure and free-market efficiency and conceives that the role of the state should be limited to establishing the conditions for free markets (Tecklin, et al., 2011). When Chile returned to democracy, Pinochet and "la Concertación" (the coalition of parties coming into office) agreed to maintain the model. La Concertación was in power for the next two decades and not only maintained the model but also strengthened it by adopting the NPM approach for the administration of the public sector (Tecklin, et al., 2011). When the case of corruption mentioned above was revealed, the government and opposition parties agreed to administrative reform in the public sector (Waissbluth \& Inostroza, 2007). The reform advocated State modernisation based on the principles the NPM approach and implemented private sector management principles among public agencies (Gobierno de Chile \& Congreso de Chile, 2003). The adoption of the NPM approach in the Chilean public sector and its influence on the process of change in Sernatur is a key element to be examined. This is analysed in depth in Chapters VI and VII. 
The administration is not only hierarchical but also highly centralised. As noted, the most important decision making bodies are concentrated at the central level, which triggers conflicts with organisations placed at the regional levels. For example, as described in Section 4.2.1, Seremis represent the ministries in the region but also support the Intendant. This aspect produces a double hierarchical dependence of Seremis and has triggered conflicts of authority between the central and regional administrations. In order to address the centralised nature of the administration, Act 19175 "For Regional Governments" was modified in 2005 in order to promote greater regional autonomy. One of these modifications allows regional governments to create public-private corporations to promote regional development in areas such as tourism. Although to date no regional corporations for tourism development have been created, it is important to have this modification in mind because the outcome resulting from the process of change (Act 20423) explicitly addresses this issue (Szmulewicz, 2010).

The fact that the public administration of the Chilean State is driven by multiple legal bodies is another relevant feature of the public sector. The entire public administration and its organisations are defined by the Constitution, acts, decrees, and other legislative bodies. In this context, modifications of structures and roles of these organisations require a decree from the President, while the creation of a new public organisation requires a bill formulated by the government and approved by Parliament (Gobierno de Chile, 2005a). As a consequence, the administration of the State is rigid and lacks the flexibility to change (Rodríguez, 2010). Because of this lack of flexibility, over the last three decades there has been an increasing trend to create organisations under the structures of councils, commissions, committees or foundations. The argument behind these structures is premised on the fact that because they are not defined in the Constitution - these organisations can be modified more readily.

The actor behind this trend is the Budget Office (Dipres), one of the most powerful organisations in the Chilean public sector. Dipres is in charge of designing, monitoring, and evaluating the annual budget for the entire public sector and also evaluating the efficiency of public organisations, policies, programmes, and projects (Dipres, 2011). Because of its role of monitoring efficiency, Dipres has historically 
opposed the creation of new public organisations (Zúñiga, 2010). Therefore, when the creation of a new agency is proposed, Dipres opposes this creation or suggests the creation of committees, councils, or commissions (Rodríguez, 2010). This trend has a clear implication for the analysis of the case because - as discussed in Chapters V and VII - Dipres strongly influenced the formulation of the tourism bill and used its power to push forward the creation of a technical secretariat as the new NTA.

The main features of the Chilean public administration (presidential system, hierarchical, centralised, and legislative driven) produce permanent conflict among organisations for achieving higher political status, triggering continuous demands for institutional changes. It is common that public services want to become subsecretariats, subsecretariats want to become ministries and ministries want to have more power from the President (Rodríguez, 2010). In fact - as discussed later on in Chapter VI - this demand for higher political status was one of the main arguments provided by Sernatur to start the process of institutional change.

Because of these demands, during presidential campaigns most candidates usually propose the creation of new public organisations. However, in most cases the creation of these organisations does not occur for several reasons: Dipres' opposition, changes in the government legislative agenda, or lack of agreement in Parliament. In turn, when new organisations have been created, they have mostly resulted from a simple change of name from some other existing entity. For instance, in 2004 the government created the Subsecretariat of Sport by changing the name of the existing National Institute of Sports. In this context, in 2005 candidate Bachelet announced the formulation of six bills to create two ministries and five subsecretariats (Bachelet, 2005). In 2010, when Bachelet's presidential term finished, just three bills had been passed: the creation of the Ministries of Environment and Energy and the Subsecretariat of Tourism. In the first two cases, existing organisations were converted into ministries, while the creation of the Subsecretariat of Tourism emerged as a completely new organisation.

The creation of the Ministries of Environment and Energy were sensitive issues that Dipres chose to support (Rodríguez, 2010); however, the creation of the Subsecretariat of Tourism was not a critical matter for the public sector and Dipres 
did not support its creation (Iglesias; Santelices, 2010). Therefore, the creation of the Subsecretariat of Tourism broke the trend of avoiding the creation of new public organisations and challenged Dipres' power. How and why this trend was broken are aspects examined in detail in Chapter VII. Because the creation of the Subsecretariat of Tourism resulted from a bill passed in Parliament, it is possible to suggest that an important part of the process of change occurred in the context of a legislative debate. In order to understand this legislative debate, the next section introduces the main features of the legislative process in Chile.

\subsubsection{The Legislative branch.}

The Legislature rests with the National Parliament whose structure and roles are defined by the Chilean Constitution (Gobierno de Chile, 2005a) and The Organic Constitutional Act 18918 (Gobierno de Chile, 2005b). The Parliament has a bicameral structure composed of the Chamber of Senators and the Chamber of Deputies. As part of each Chamber there are "select committees" composed of a number of Members of Parliament grouped around a particular theme (e.g. economy). The committees support the legislative process by conducting an in-depth analysis of bills before they are debated in the chambers' assembly. As presented in Act 18918, the legislative power rests with Parliament for formulating, debating, and approving bills. However, there are certain bills whose formulation and submission to Parliament are the exclusive responsibility of the Executive. This is the case of bills creating new public organisations, in which case the legislative power is vested in both the Government and Parliament (Gobierno de Chile, 2005a).

\subsubsection{The legislative process.}

The legislative process is long, complex, and composed of multiple steps that lead to the approval or rejection of a bill in Parliament. These steps are presented in Figure 4.2. 


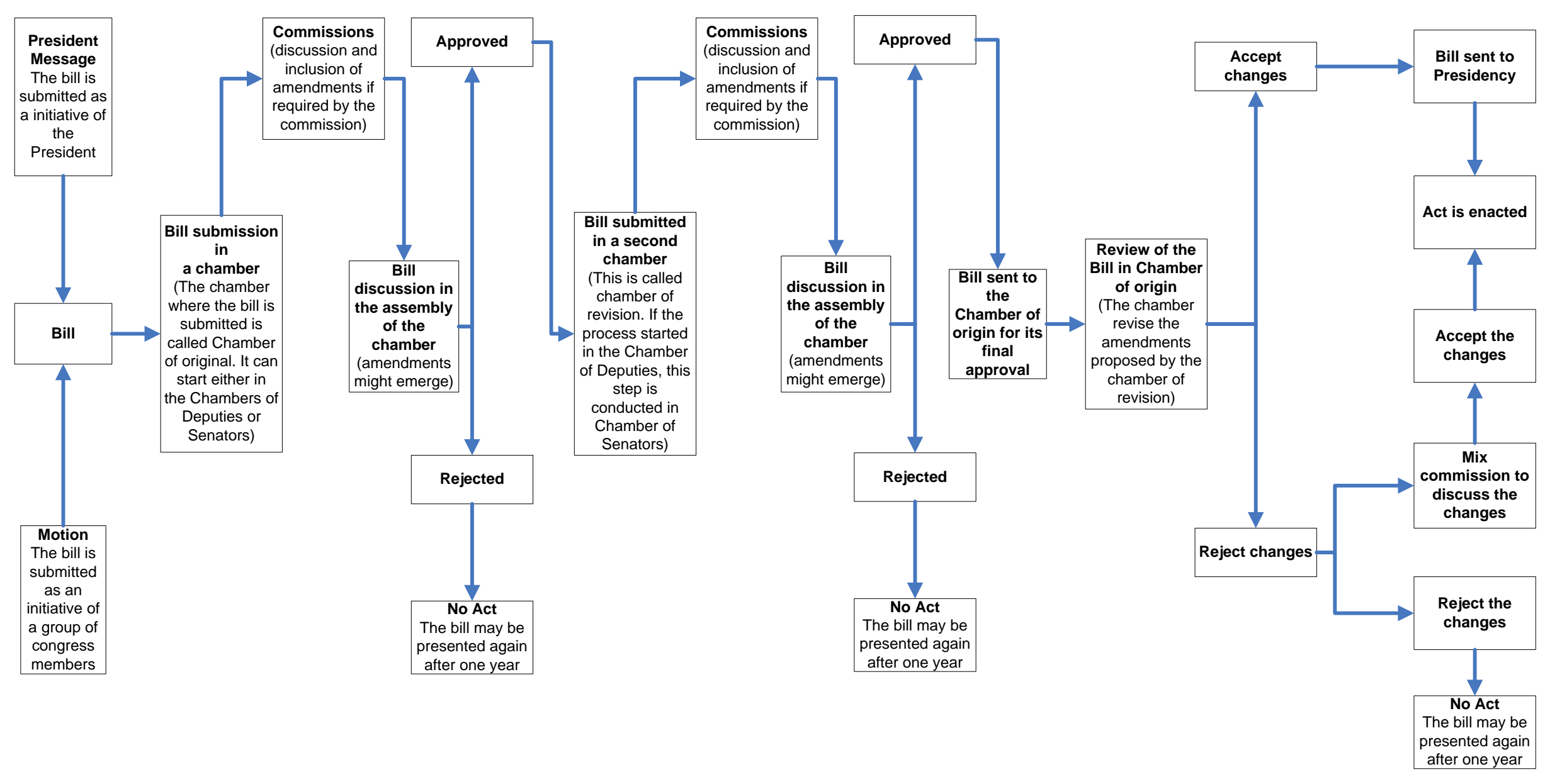

Figure 4.2: The legislative process in Chile

(Chamber of Deputies, 2010) 
The figure shows that bills may be formulated and submitted by the Executive (Message) or by a group of Senators or Deputies (Motion). The Constitution mentions that who formulates and submits a bill depends on the nature of the bill. The creation of a new public organisation is an exclusive preserve of the Executive and therefore bills to create new agencies must be formulated by the Executive and submitted as a "Message". In this case, the submitted bill must contain substantial aspects of the new organisation, including the new agency's structure, roles, and operational budget (Gobierno de Chile, 2005a).

In general, the submission of a bill may start in the Chamber of Senators or Deputies. The chamber where bills are submitted is called the "Chamber of Origin". Although the process may start in either of these chambers, Act 18918 establishes that there are certain types of bills whose submission is only possible in the Chamber of Deputies. This is the case of bills containing matters that affect the public sector administration and create new public agencies. Once submitted, the bill is briefly debated in the assembly of the "Chamber of Origin" in order to accept or reject the submission (first reading). This process is called "discussion in general". If the bill is accepted, it is sent to a "select committee" of the chamber. During the debate in the committee, the bill is examined in detail (part by part) and amendments may be proposed by the members of the committee. If the bill was submitted as a "Message", minor amendments may be directly submitted and approved by the committee in agreement with the Executive. However, changes that may affect substantial issues of the bill can only be submitted by the Executive.

After discussion in the committee, the bill is sent back to the assembly of the "Chamber of Origin" for a second debate (second reading). This part of the process is called "discussion in particular" because the bill is examined part by part. During this discussion new amendments may be suggested. In order to submit these amendments, agreement among congress members and approval from the Executive is also required. Once debated, the bill is voted. If it is approved, the bill is sent to the Chamber of Senators for debate, while if it is rejected the process finishes. In the context of the legislative process, the Chamber of Senators is called "Chamber of Revision". The process conducted in this chamber is similar to the process carried out in the "Chamber of Deputies". If the Senate approves the bill, it is sent back to 
the Chamber of Deputies who revises the bill in order to examine amendments submitted in the Senate. If changes are accepted, the bill is sent to the Constitutional Court and the Presidency Cabinet for its enactment. If changes are not accepted, a mixed commission is established between the two chambers in order to negotiate the changes and pass or reject the bill.

Finally, in order to make the process faster and ensure debate in parliament, the Executive can put Parliament under urgency. This is an exclusive power of the President in order to advance the debate of a bill that is considered strategic for the government's legislative agenda. There are three levels of urgency, which indicate that discussion and approval/rejection of a bill must be within thirty, ten or three days respectively (Gobierno de Chile, 2005b). As discussed in the next chapter, Bachelet used her power and put Parliament under urgency to pass the tourism bill.

\subsubsection{Implications of the legislative process.}

Two main considerations for the analysis of the process of change in Sernatur emerge from the legislative process described above: the active role of the Executive in formulating bills submitted as a "Message", and the role the Executive plays during the discussion in parliament.

The characteristics of the Chilean administrative system described in section 4.2.1 provide important insights for understanding the role of the Executive during the formulation of a bill. For example, the Presidential System of the Chilean administration suggests that the government legislative agenda and the formulation of a bill are strongly influenced by the President. As a consequence, "Messages" are sent to Parliament only when political commitment to a particular sector exists from the President. Under the centralised administrative structure of the country, the formulation of a bill is coordinated by the General Secretary of the Presidency (Segpres), which is the ministry in charge of submitting the bill and its amendments during the debate in Parliament. The hierarchical organisation of the administration also has implications for the formulation of a bill. The formulation involves actors from the ministries level only and consultation with other stakeholders is not compulsory. 
Once formulated, bills are only submitted after gaining approval of certain ministries placed at the top of the central level, such as the Ministry of Finances. During the governments of "la Concertación", the Ministry of Finances and its dependant Budget Office (Dipres) played a key role in policy formulation and evaluation. The Minister of Finances and Dipres' Director acted as the main advisory body to the Presidency, being in some cases even more influential and powerful than the Internal Affairs Minister who acts as the Prime Minister. Although Dipres' role in approving the submission of a bill is not defined by any act, the power gained by the agency has implied a tacit agreement inside the government in terms of involving Dipres during a bill formulation. If Dipres does not agree with some of the elements contained in the bill, particularly regarding financial issues, the formulation process may be stopped until agreement is achieved, whether with Dipres or based on an instruction from the President. The power that Dipres exercised during the formulation of the tourism bill was not an exception and is examined in detail in Chapters V and VII.

A second implication of the legislative process relates to the role the Executive plays during the legislative debate. Since bills creating new public organisations are submitted as "Messages", amendments suggested by Parliament are only possible on minor issues but not on substantial aspects. In fact, the Executive is the only branch with the power to change substantial aspects such as structure, roles, or budget contained in the bill. If Parliament considers that changes to these aspects are essential but the Executive decides not to submit these changes, the bill risks being rejected in Parliament. Thus, amendments on substantial aspects require negotiation between the Executive and Parliament in order to ensure the bill's approval.

Once submitted in Parliament, the legislative process is extremely complex and political commitment from the government is required to guarantee the approval of a bill. As noted in Figure 4.2, the legislative process contains several steps. At every single step the government is required to resolve doubts emerging from the debate and to negotiate amendments. Without adequate commitment to this, the process to pass the bill may last several years. Due to the presidential system of the Chilean administration, the commitment and involvement of the government in the process is influenced by the priority the President gives to a bill. In fact, there are bills that were submitted 20 years ago which are still in Parliament as a result of changes of 
government with different legislative agendas. The President's commitment is also reflected by the use of power to put Parliament under urgency. This reflects the interest and priority the President assigns to a particular bill and suggests that the bill under urgency is a priority in the government's legislative agenda.

\subsection{The Tourism sub-system}

As presented in the conceptual framework (Figure 2.3), NTAs are public entities but also form part of the tourism sub-system. This sub-system is composed of private and public tourism organisations directly involved with tourism development and also reflects the main features of the tourism industry over the decade when the process of change occurred. To investigate this sub-system, this section examines three major aspects: the state of the tourism sector in Chile during the 2000s, the organisations that make up the private tourism sector, and the organisations constituting the public tourism institutional framework.

\subsubsection{The tourism industry: an overview.}

The official Chilean tourism website emphasises the country's diversity of natural resources as the main attractions for visiting Chile (http://www.chile.travel). In order to highlight these natural values, during the 2000s the Chilean government conducted several marketing campaigns under the slogan "Chile: A Natural Inspiration" (Sernatur, 2010). The slogan - launched in 2002 and kept during the entire decade - aimed to highlight the country's natural values and show Chile as a pristine destination. In this context, from the beginning of the decade the tourism industry started to show growth rates never experienced before; between 2000 and 2010 inbound tourism and visitors to protected areas almost doubled, while tourism foreign exchange revenues tripled. Figure 4.3 presents inbound tourism and visitors to the SNASPE (National System of Protected Areas). 


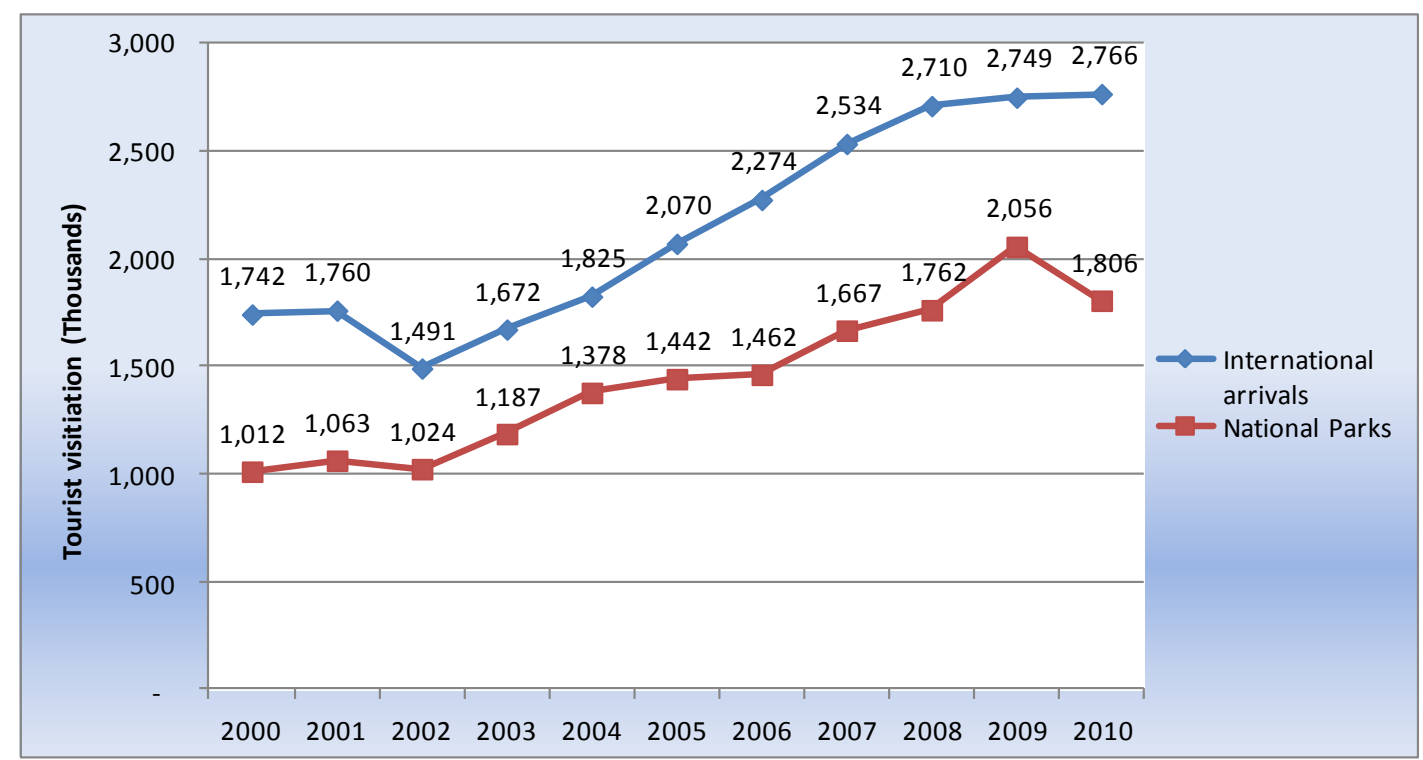

Figure 4.3: Inbound tourism and visitation in protected areas in Chile (20002010)

Source (Conaf, 2011; Sernatur, 2010)

Figure 4.3 shows that in both cases the number of tourists almost doubled. Inbound tourism increased from 1.7 million tourists in 2000 to 2.7 million in 2010 (Sernatur, 2001, 2010), while the number of visitors to protected areas rose from 1 to 2 million during the same period (Conaf, 2011). In the last case, the statistics seem to confirm the importance of natural attractions in the SNASPE for the tourism industry. Although the figure shows a steady increase in both cases, there are a couple of years where the trend was broken. For example, in 2002 the economic crisis in Argentina the main Chilean tourism market - triggered a fall in international tourists and the number of visitors to protected areas (Inter American Development Bank, 2007b). A second drop occurred in 2010, when the number of visitors to protected areas fell due to the Chilean earthquake that closed some of these areas.

The main tourism markets are typically neighbouring countries, particularly dominated by Argentina. Figure 4.4 compares the main markets between 2001 and 2010. 


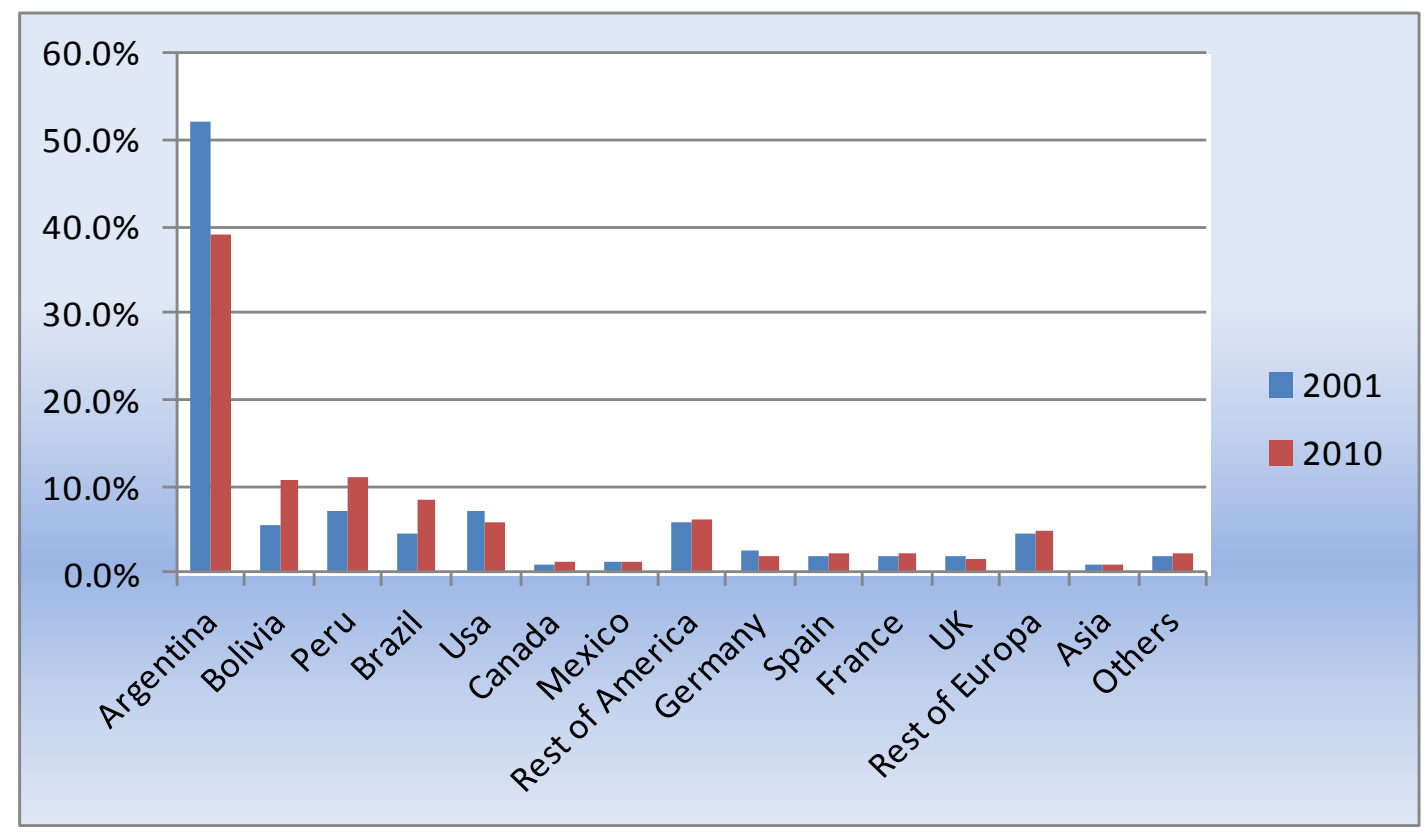

Figure 4.4: A comparison of priority tourism markets (2010-2010)

Source (Sernatur, 2002, 2010; Sernatur \& INE, 2010)

As noted in the figure, the long distance markets (North America and Europe) remain the same over the period. The difference occurs in the regional markets: Argentina falls while Peru, Bolivia, and Brazil rise. At the beginning of the decade $52 \%$ of inbound tourism was from Argentina; at the end of the decade the Argentinean market represented 39\% of the total inbound tourism. Conversely, Peru, Bolivia, and Brazil grew up from 17\% in 2001 to 30\% in 2010 (Inter American Development Bank, 2007b; Sernatur, 2002; Sernatur \& INE, 2010). This change might be explained as a result of the Argentinean crisis in 2002, which triggered the implementation of a strategy of market diversification (Inter American Development Bank, 2007b).

The growth of inbound tourism also expanded the contribution of the tourism sector to the economy, placing the industry as the fourth leading productive sector (Inter American Development Bank, 2007b). Figure 4.5 shows tourism foreign exchange revenues for the period 2000-2010. As noted in the figure, in 2000 the tourism industry contributed US\$800 million in foreign exchange revenues to the economy, while in 2010 this contribution rose to US\$ 2,039 million (Sernatur, 2010). Although 
there is a general increase, there is a drop in foreign exchange revenues in 2002, which is probably explained by the fall of the Argentinean market mentioned above.

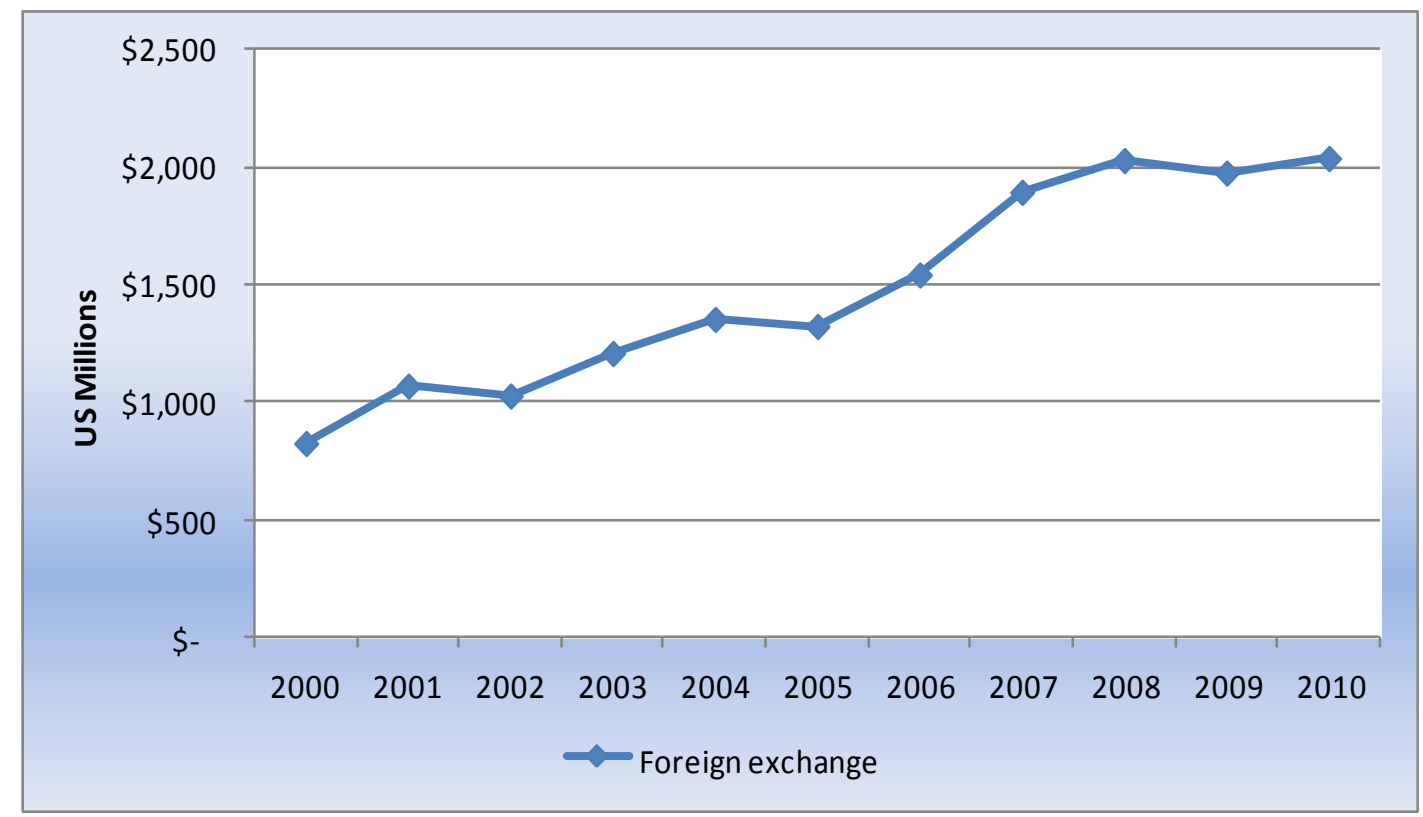

Figure 4.5: Contribution of the tourism sector to foreign exchange (period 20002010)

(Sernatur, 2010; Sernatur \& INE, 2010)

These statistics demonstrate that the 2000s were characterised by a growth that strengthened the tourism industry. Several factors may have driven this growth, including the international perception of Chile as a safe destination, the wide range of natural resources including protected areas in the SNASPE, and a growth of the tourism infrastructure (Inter American Development Bank, 2007b; Universidad de Chile, 2007). In spite of this development, during the decade the tourism sector still faced some important limitations (Boston Consulting Group, 2007; Inter American Development Bank, 2007b; Sernatur, 2002, 2006b). The tourism activity was highly seasonal, arrivals tended to be concentrated in five months of the year; there was little diversity of products and services; and, finally, these products and services were concentrated in three main destinations. Two reasons were identified to explain why limitations occurred; these were lack of competitiveness in the private sector, and weakness of the public institutional framework to coordinate the tourism industry (Boston Consulting Group, 2007; Inter American Development Bank, 2007b; P4 \& Tourism Resource Consultants, 2008). The main characteristics of the private and public sectors in tourism are examined next. 


\subsubsection{The private sector.}

The characteristics of the private sector provide important elements to understand the process of change and investigate how the sector was involved in the process. The tourism sector is composed of a diverse range of products and services, mainly provided by small family companies (Inter American Development Bank, 2007b). Because of the characteristics of these companies, there is a high level of informality; if companies are formally established, they lack integration to the value chain; the quality of the services they provide is low; and, finally, the sector is highly fragmented (Boston Consulting Group, 2007; Inter American Development Bank, 2007b; Organisation for Economic Co-operation and Development, 2010; P4 \& Tourism Resource Consultants, 2008). The fragmentation of the sector is also illustrated in the way the private sector is organised. As shown in Table 4.1, there are several private organisations and at different levels - national and local.

\begin{tabular}{|c|c|c|}
\hline & Name & Overview \\
\hline \multirow{4}{*}{ 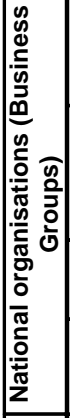 } & $\begin{array}{l}\text { Asociación Chilena de Empresas } \\
\text { de Turismo - ACHET }\end{array}$ & $\begin{array}{l}\text { Created in 1946, Achet groups private companies in the area of tour operators } \\
\text { and travel agencies ( } 130 \text { members). Achet aim to provide technical assistance to } \\
\text { its members and represent them to the public sector }\end{array}$ \\
\hline & $\begin{array}{l}\text { Asociación Gastronómica de Chile } \\
\text { - ACHIGA }\end{array}$ & $\begin{array}{l}\text { Created in 1980, Achiga groups private companies in the hospitality area, in } \\
\text { particular restaurants ( } 250 \text { members). Achiga aims to promote gastronomic } \\
\text { development and represent its members in negotiations and discussion with the } \\
\text { public sector }\end{array}$ \\
\hline & $\begin{array}{l}\text { Asociación Chilena de Líneas } \\
\text { Aéreas - ACHILA }\end{array}$ & $\begin{array}{l}\text { It was created in } 1997 \text { and represents the national and some of the international } \\
\text { airlines operating in Chile }\end{array}$ \\
\hline & Hoteleros de Chile - HOTELEROS & $\begin{array}{l}\text { Hoteleros was created in } 1993 \text { and groups hotel companies ( } 230 \text { members) } \\
\text { which represents around } 40 \% \text { of the hotel industry. Hoteleros aims to group the } \\
\text { sector for negotiations with the public and private sectors }\end{array}$ \\
\hline \multirow{3}{*}{ 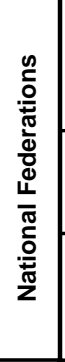 } & $\begin{array}{l}\text { Consejo Superior de Turismo - } \\
\text { CONSETUR }\end{array}$ & $\begin{array}{l}\text { Consetur was created in } 1993 \text { as part of the National Chamber of Commerce, } \\
\text { Services and Tourism. Consetur aims to coordinate tourism development by } \\
\text { facilitating communication between its members and public sector. Two tourism } \\
\text { associations are part of Consetur: Achila and Armasur }\end{array}$ \\
\hline & $\begin{array}{l}\text { Federación de Empresas de } \\
\text { Turismo - FEDETUR }\end{array}$ & $\begin{array}{l}\text { Fedetur was created in } 2009 \text { and is composed of private tourism companies and } \\
\text { organisations such as Achet, Hoteleros de Chile and Achiga. Fedetur aims to } \\
\text { group the private sector to promote tourism development with the public sector }\end{array}$ \\
\hline & $\begin{array}{l}\text { Federación Gremial de la Industria } \\
\text { Hotelera y Gastronómica de Chile }\end{array}$ & $\begin{array}{l}\text { It was created in } 1980 \text { and dissolved in } 2010 \text {, Hotelga was composed of ten } \\
\text { regional tourism organisations and two national organisations :Achiga and } \\
\text { Hoteleros. Its goals aimed to represent its members and promote tourism } \\
\text { development }\end{array}$ \\
\hline \multirow{2}{*}{ 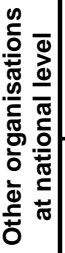 } & $\begin{array}{l}\text { Asociación Chilena de } \\
\text { Municipalidades Turísticas }\end{array}$ & $\begin{array}{l}\text { It was created in } 1992 \text { and groups } 185 \text { municipalities that have defined tourism } \\
\text { as a key sector for local development. The association aims to provide technical } \\
\text { assistance to its members and represent them to the public sector }\end{array}$ \\
\hline & $\begin{array}{l}\text { Sociedad Chilena de } \\
\text { Investigadores en Turismo - } \\
\text { SOCIETUR }\end{array}$ & $\begin{array}{l}\text { It was created in } 2007 \text { based on a scientific and academic goal, Societur groups } \\
\text { universities and researchers conducting investigation in tourism }\end{array}$ \\
\hline 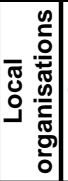 & Cámaras de Turismo & $\begin{array}{l}\text { Cámaras de Turismo (Tourism Chambers) are local organisations created to } \\
\text { group tourism companies. These organisations are part of the local Chamber of } \\
\text { Commerce. In some cases these local Chambers are or have been part of } \\
\text { Consetur }\end{array}$ \\
\hline
\end{tabular}

Table 4.1: Private organisations in tourism during the decade of the 2000s 
At the national level, three major types of organisations exist: a) business groups that represent private companies in particular areas (accommodation, hospitality, and travel agencies); b) federations that bring together business groups and private companies; and c) other organisations such as tourism research associations. At the local level there are tourism chambers (Cámaras de Turismo) that group tourism businesses at the municipal level (district).

As shown in the table, business groups exist to cluster companies that operate in similar areas of the industry (accommodation, gastronomy, and travel agencies). In most cases, these business groups are also part of a federation. Because of the Chilean legal definition of federation - whose businesses only can be members of one - there is a permanent tension between federations in order to attract members (García, $R, 2010$ ). As a consequence, the change of members from one federation to another causes some federations to become strengthened while others are weakened. This tension is illustrated by the creation of Fedetur in 2008. To create Fedetur, private companies and business groups belonging to existing federations had to be attracted. In this context, Achet left the Superior Council of Tourism (Consetur) in 2008 and the Association of Hotel Companies (Hoteleros) left the Association of Hotel and gastronomy Companies (Hotelga) in 2010. The creation of Fedetur, thus, caused the migration of members from existing federations and triggered a reorganisation of the private sector. As a result, in 2010 Consetur lost power due to the migration of members and the existing Hotelga was dissolved due to the lack of members (Arriagada, 2010). This fragmentation was also illustrated by conflicts inside the sector and the lack of a single and common position to address tourism development (Ferreiro, 2010). In 2006, a Chilean newspaper reported conflicts between Consetur's board and some of Consetur's members caused by the different agendas to address tourism development (El Mercurio, 2006c). This conflict triggered the creation of Fedetur and the migration of some of Consetur's members to the new federation.

Another feature of the private sector is the lack of representation inside business groups and federations. Groups and federations lack diversity of members (by size and geographical location) and the biggest companies tend to control the agendas of 
these groups and federations (Universidad de Chile, 2007). This lack of representation is partially illustrated in Table 4.1. For example, the Chilean Tourism Annual Report (Sernatur \& INE, 2010) identifies 1,246 travel agencies and tour operators in Chile; however, just 130 of them are members of Achet. A similar situation occurs with other business groups. The report identifies 3,256 restaurants, catering and food and beverage businesses but only 250 are part of the Chilean Association of Gastronomy Companies (Achiga). The diversity of private organisations and the lack of representation described here produce a complex and fragmented private sector. This fragmentation affects coordination across the entire sector, impeding a common position to negotiate with the public sector (Universidad de Chile, 2007), and affects the legitimacy of the industry to negotiate with the government (Inter American Development Bank, 2007b; Universidad de Chile, 2007). These features become key elements for investigating the process of change in Sernatur. As discussed later, this fragmentation may help explain the low involvement of the private sector during the process of change and its limited ability to influence the results of the process.

\subsubsection{The public tourism sector.}

Before the enactment of Act 20423, the public sector was composed of multiple organisations with direct and indirect relations with the tourism industry (e.g. Customs Service). Because of this wide range of organisations, this section just focuses on those with direct and relevant programs in tourism. Table 4.2 shows these organisations at the central and regional levels.

As observed in Table 4.2, at the central level there were several ministries. Among these ministries, the Ministry of Economy was the main body in charge of tourism development. The Ministry was composed of two subsecretariats: Economy and Fisheries. The Subsecretariat of Economy was in charge of supervising the implementation of tourism policies, strategies, and plans. Tourism Chile (the NTO) was also part of this group of organisations at the central level. Despite the fact that Tourism Chile was neither a ministry nor a committee or council, the NTO is presented in the table because of to its role of international marketing. 


\begin{tabular}{|c|c|c|}
\hline & Name & Role \\
\hline \multirow{6}{*}{ 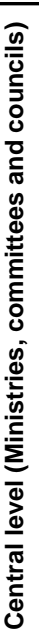 } & $\begin{array}{l}\text { Ministry of Economy, Promotion } \\
\text { and Reconstruction }\end{array}$ & $\begin{array}{l}\text { In charge of formulating policies related to competitiveness. The ministry focuses } \\
\text { on information technologies, fisheries and tourism. The ministry defines the } \\
\text { tourism policy supported by Sernatur }\end{array}$ \\
\hline & Ministry of National Lands & $\begin{array}{l}\text { In charge of formulating policies in public lands and managing these areas. } \\
\text { Since } 2003 \text {, the ministry implements a programme called "heritage routes". In } \\
\text { this programme, the ministry designs, implements and operates the routes }\end{array}$ \\
\hline & Ministry of Housing & $\begin{array}{l}\text { In charge of the housing policy, the Ministry has a key role in the process to } \\
\text { declare a ZOIT }\end{array}$ \\
\hline & $\begin{array}{l}\text { National Commission of } \\
\text { Environment - CONAMA }\end{array}$ & $\begin{array}{l}\text { In charge of the conservation and management of natural resources. Conama } \\
\text { plays a key role in the process to declare a ZOIT and also controlling } \\
\text { environmental impacts in areas declared as ZOIT }\end{array}$ \\
\hline & $\begin{array}{l}\text { Council of Ministers for Tourism } \\
\text { Development }\end{array}$ & $\begin{array}{l}\text { Created in } 2004 \text { by a presidential decree, the Council aims to coordinate the } \\
\text { public sector from the highest level of the public administration in order to } \\
\text { advance in tourism development }\end{array}$ \\
\hline & Tourism Chile & $\begin{array}{l}\text { Tourism Chile is the Chilean NTO. It is a public-private agency in charge of } \\
\text { conducting the tourism international marketing strategy. The budget of Tourism } \\
\text { Chile is created as a result of the partnership between public and private sector. } \\
\text { The public sector funds } 50 \% \text { of the marketing strategy and the other } 50 \% \text {, plus } \\
\text { operational costs are provided by the private sector }\end{array}$ \\
\hline \multirow{5}{*}{ 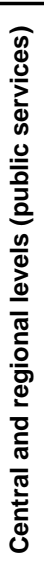 } & $\begin{array}{l}\text { National Tourism Board - } \\
\text { SERNATUR }\end{array}$ & $\begin{array}{l}\text { The Chilean NTA is a public service with headquarters at the central level and } \\
\text { multiple offices at the regional level. Sernatur is in charge of planning and } \\
\text { promoting tourism and conducts the roles of policy design and implementation }\end{array}$ \\
\hline & $\begin{array}{l}\text { Service of Technical Cooperation - } \\
\text { SERCOTEC }\end{array}$ & $\begin{array}{l}\text { Sercotec depends on the Ministry of Economy. Sercotec focuses on small } \\
\text { business by providing technical assistance and funding for the initiating or } \\
\text { strengthening small businesses }\end{array}$ \\
\hline & $\begin{array}{l}\text { National Institute of Agriculture } \\
\text { Development - INDAP }\end{array}$ & $\begin{array}{l}\text { Indap is part of the Ministry of Agriculture. Indap has a programme of "Rural } \\
\text { Tourism" that provides technical assistance, funds and loans for implementing } \\
\text { and strengthening rural tourism business }\end{array}$ \\
\hline & Forest Service - CONAF & $\begin{array}{l}\text { Conaf is a state owned private corporation managed by the Ministry of } \\
\text { Agriculture. Conaf is the agency in charge of managing the official protected } \\
\text { areas in Chile (SNASPE). The agency has a programme called "Ecotourism for } \\
\text { National Parks" and has conducted some call for bids to grant concessions } \\
\text { inside the parks for implementing projects }\end{array}$ \\
\hline & $\begin{array}{l}\text { Economic Development Agency - } \\
\text { CORFO }\end{array}$ & $\begin{array}{l}\text { Corfo is part of the Ministry of Economy. Corfo provide support in areas of } \\
\text { innovation and competitiveness (funds for research, project implementation, } \\
\text { market research, etc) }\end{array}$ \\
\hline 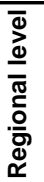 & Regional Governments & $\begin{array}{l}\text { Regional governments are in charge of managing the FNDR. Over the last } \\
\text { decade, several projects in tourism development for the regions has received } \\
\text { funds allocated by FNDR }\end{array}$ \\
\hline
\end{tabular}

Table 4.2: Public organisations with roles in tourism during (period 2000-2010)

The table also shows organisations placed at both the central and regional levels (public services). Sernatur (the NTA), is presented as part of these organisations because of its structure as s public service agency. The agency was in charge of designing and implementing the tourism national policy and also supported the Subsecretariat of Economy in policy evaluation (the main features of the structure and roles of Sernatur are examined in the next section). As noted in the figure, there were also other public services with programmes in tourism development. These programmes provided subsidies and loans to support investment, technical assistance and training (Inter American Development Bank, 2007b). Conaf is a good example of these public services. Conaf is the specialist body for protected areas and is the 
manager of the SNASPE. Because of the increasing growth of visitors to the SNASPE presented in Figure 4.3, during the 1990s and 2000s Conaf implemented a programme called "Ecotourism for National Parks". The programme consisted of a call for bids that aimed to grant concessions inside national parks to implement private tourism businesses (Conaf, 2004, 2007a, 2007b). Finally, the table shows regional governments at the regional level. As described in Section 4.2.1, regional governments administered the public sector at the regional level and are in charge of deciding the allocation of funds of FNDR in several areas, including tourism development.

The wide range of public organisations with roles in tourism development suggests the existence of a fragmented institutional framework for tourism. This fragmentation - combined with the centralised and hierarchical nature of the public sector - limited Sernatur's abilities to coordinate the public sector (Sernatur, 2002, 2005, 2006b). The implementation of the programme "Ecotourism in National Parks" mentioned above is a good example. Over the last two decades Conaf conducted four calls for bids to grant concessions. To do that, Conaf identified priority national parks to be part of the programme, called for bids, evaluated the received proposals, and granted concessions (Conaf, 2004). The programme was directly led and implemented by Conaf with very little involvement from Sernatur, triggering permanent tension between these two organisations (Inter American Development Bank, 2007b). To address this tension, in 2005 Conaf and Sernatur signed a Memorandum of Understanding (MOU) in order to guarantee Sernatur's involvement. The MOU consisted of a call for bids to grant tourism concessions inside a group of national parks identified by Sernatur and Conaf. In this MOU, Conaf was the main agency in charge of conducting the process and Sernatur provided technical assistance (Conaf, 2007a). However, after the implementation of the MOU no concessions were granted and the tension persisted (Bau, Galaz, Iglesias, Santelices, 2010).

The use of funds under FDNR is another example to show problems of coordination in the public sector. During the decade, increasing FNDR funds were allocated by regional governments for implementing regional marketing campaigns. However, these campaigns were not necessarily consistent with the national tourism marketing 
strategy. Because of this fragmented and uncoordinated institutional framework, President Lagos launched the Council of Ministers for Tourism Coordination in 2002. However, the Council met just a couple of times and no advances in coordination were achieved (C\&S Soluziona Servicios Profesionales, 2004; Universidad de Chile, 2007).

In the context of this fragmented and uncoordinated public institutional framework and the steady growth of the industry described in Section 4.3.1, the tourism sector increasingly gained attention in the public sector. The Ministry of Economy and Sernatur launched multiple documents highlighting the economic potential of the sector and the need to improve coordination. In 2002, Sernatur produced the National Tourism Agenda (Sernatur, 2002); in 2005, Sernatur and the Ministry of Economy released the National Tourism Policy (Sernatur, 2005); and, finally, in 2006, President Bachelet presented the Tourism Action Plan (Sernatur, 2006b).

In parallel, the tourism sector also gained attention from other public organisations within the Chilean administration. Two key milestones emerge to explain what may have triggered the attention of the public sector: the Boston Consulting Group (BCG) Report (Boston Consulting Group, 2007), and a technical aid project conducted by the IADB (Inter American Development Bank, 2007b). In 2005 the National Innovation Strategy was launched as a priority by President Lagos, and in 2006 the Commission for Innovation was created as a priority by President Bachelet. The Commission for Innovation commissioned the BCG to identify five priority areas for increasing Chilean innovation and competitiveness; one of these areas was tourism. Since innovation was a priority for President Bachelet, the results of the BCG report received the highest attention from political spheres, triggering the interest and commitment of the public sector to fund programmes in tourism development. In parallel, the IADB conducted a technical aid project that evaluated the tourism sector. This project resulted in a loan proposal request by the government in order to strengthen the tourism industry. The loan considered funds to review the structure and roles of Sernatur and implement changes in the existing tourism institutional framework. Although the loan was approved in 2010, the new government in power from 2010 did not take it up. 
The increasing attention from the public sector triggered the creation of new programmes in tourism and the allocation of bigger funds to strengthen the industry. During the decade, Sernatur launched several programmes: "Holidays for Seniors", "Secondary Students' Trips programme" and "Go Around Chile" (Inter American Development Bank, 2007b; Sernatur, 2010). These programmes received public funds by way of subsidies. The subsidies were transferred to tour operators and used to create low cost tours for seniors and students to promote domestic tourism (Inter American Development Bank, 2007b; Sernatur, 2010). In parallel, Sernatur and Corfo funded the creation a of a new quality assurance scheme, while Corfo created a subsidy to promote the implementation of the scheme among the private sector (Corfo, 2010; Sernatur, 2007b, 2010). Programmes like these were also created by the National Institute of Agriculture Development (Indap), National Commission of Indigenous Affairs (Conadi), Service of Technical Cooperation (Sercotec) and other public agencies, demonstrating the increasing attention received by the tourism industry.

The increasing allocation of funds in tourism was also visible in the budgets of Sernatur and Tourism Chile. Figure 4.6 shows public funds allocated to the NTA and NTO for the period 2000-2010.

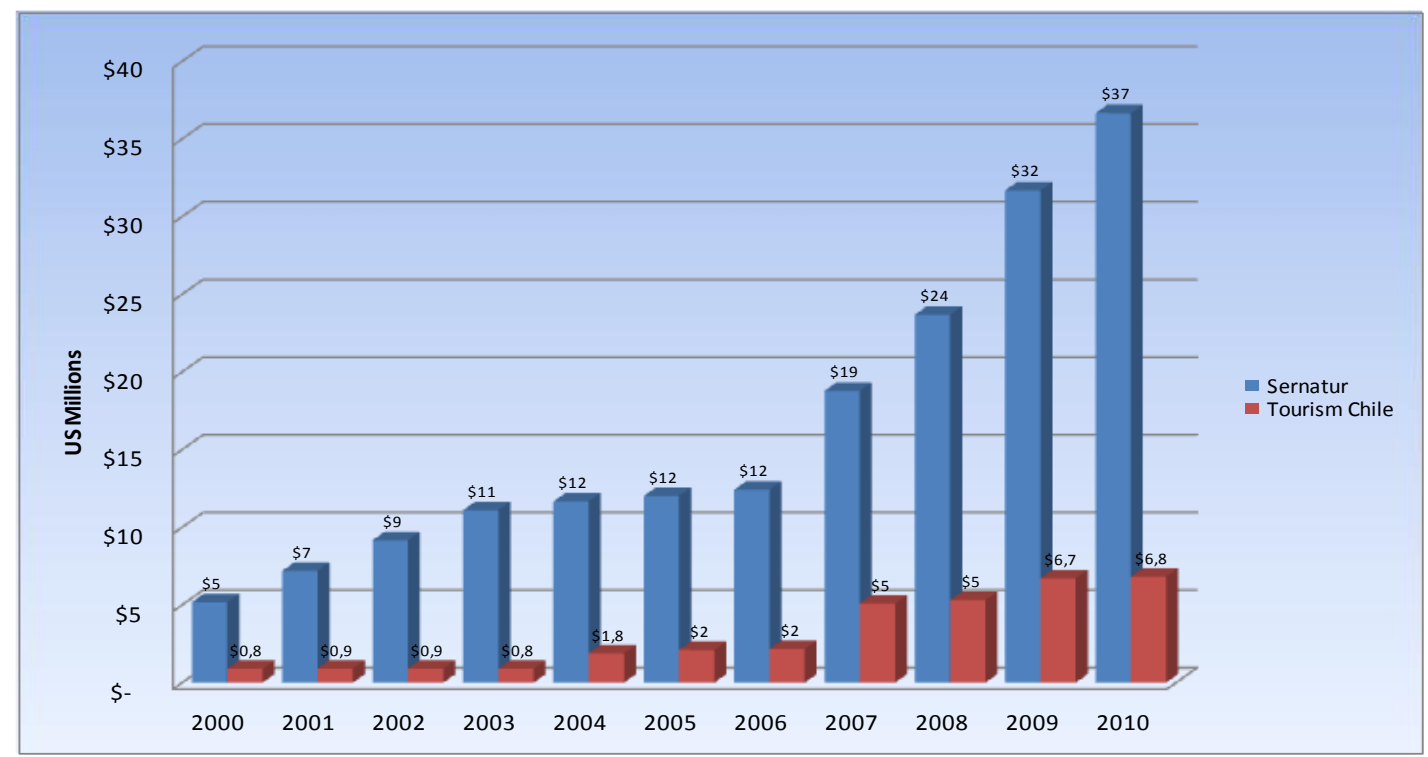

Figure 4.6: Public funds allocated to Sernatur and Tourism Chile (2000-2010)

(Dipres, 2000, 2001, 2002, 2003, 2004, 2005c, 2006, 2007, 2008, 2009) 
The graph shows a steady increase of funds allocated to Sernatur and Tourism Chile. In a decade, the budgets of these two organisations grew by $700 \%$. Although it is arguable if these budgets were enough, the fact is that from 2006 they tripled. The highest rise occurred from 2007 onwards, which coincides with the year when the BGC report was released. Because innovation was a priority for President Bachelet and due to the fact that tourism was one of the five sectors proposed by the BCG the increase in the budgets of Sernatur and Tourism Chile might have resulted from the priority given by the President to the sectors identified by the BCG. This presidential commitment may also explain higher political involvement from other public agencies. For example, in 2005 Corfo allocated US\$1 million for tourism development, while in 2008 the allocation rose to US\$15 million (Corfo, 2010).

Funds allocated to the tourism sector also grew at the regional level. As presented in Figure 4.7, public funds allocated by regional government rose from US $\$ 0.2$ million in 2003 to US\$4.4 million in 2009. From 2003 to 2005 funds rose from US 0.2 to 1.2 million; however the biggest rise occurred in 2006, when allocated funds reached US 4 million (Sernatur \& INE, 2010). As noted in the figure, in 2007 and 2008 regional governments allocate fewer funds, probably explained by the emergence of other priorities. In spite of this, during the second part of the decade, the allocation of funds in tourism increased significantly in comparison to the period 2003-2005.

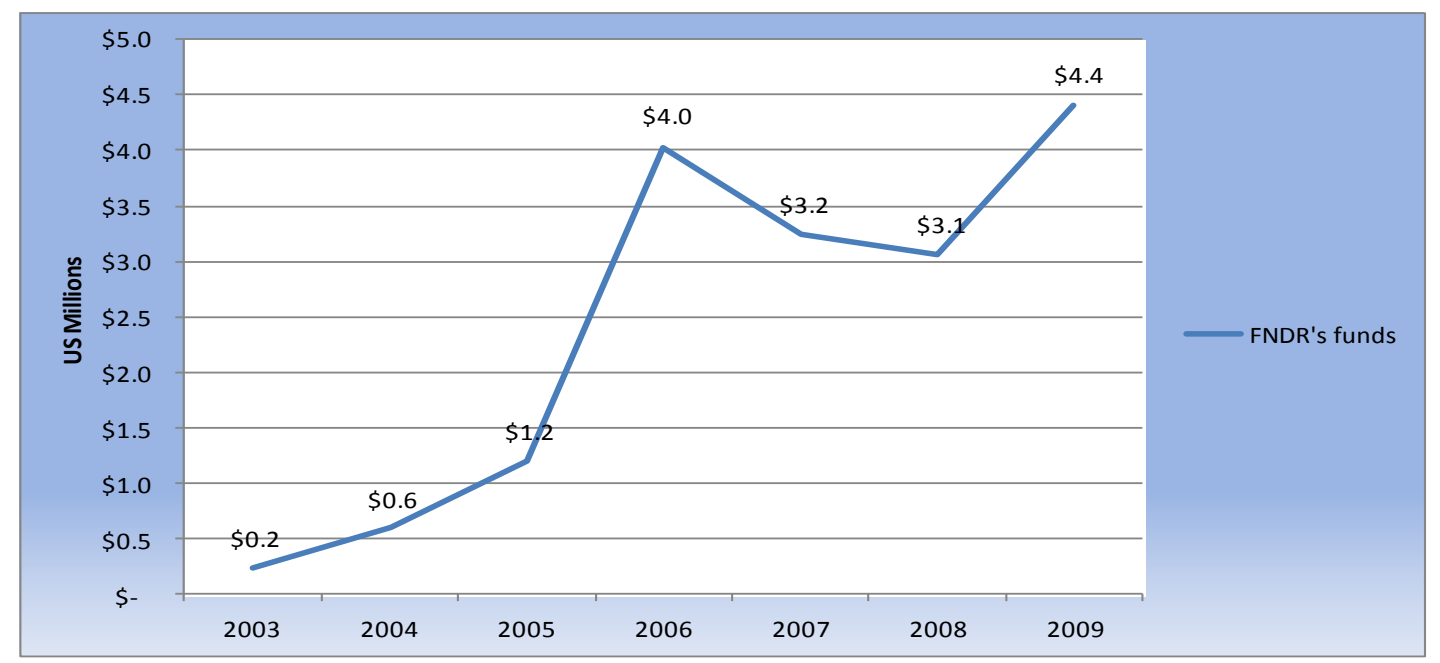

Figure 4.7: FNDR's funds allocated in tourism development by regional governments (period 2003-2009) 
The graphs presented in this section illustrate how the public sector increasingly committed to the tourism industry. Despite this greater allocation of funds, the main features of the public institutional framework for tourism did not change; it remained highly fragmented and lacked coordination. The reasons these features did not change may be explained by some of the characteristics of the Chilean administrative sub-system - hierarchical, centralised, and fragmented. As presented in Table 4.2, the structure of the NTA was a public service, which by definition is placed at the bottom of the administration of the central state. Because of the characteristics of the administrative sub-system, Sernatur was not able to coordinate other public organisations; even more so, considering that many of the organisations to be coordinated were higher up the hierarchy or had far bigger budgets. In order to investigate how Sernatur was part of the administration of the State and how the structure and roles of the NTA reflected the characteristics of the public sector, the next section investigates the structure and roles of Sernatur before Act 20423 was passed.

\subsection{The Chilean NTA: Servicio Nacional de Turismo (Sernatur)}

Sernatur was created in 1975 by Act 1225. In terms of structure, the agency was created as a functional decentralised public service: Sernatur was the only specialist tourism public organisation (functional decentralised) with headquarters centred at the national level and 15 offices at the regional level (territorial decentralised). As mentioned before, the NTA depended on the Ministry of Economy, Promotion and Reconstruction and was supervised by the Subsecretariat of Economy (Ministerio de Economía Fomento y Reconstrucción, 1975).

In terms of roles, the agency was in charge of researching, planning, promoting, coordinating, and marketing tourism development (Ministerio de Economía Fomento y Reconstrucción, 1975). The agency was also originally in charge of controlling the industry; however in 1980 this role was suppressed in accordance with a general trend in the public administration (Ministerio de Hacienda, 1980). The suppression of this role limited Sernatur's mechanisms to control tourism development, affecting for instance the implementation of the quality assurance system described in Section 4.3.2. Another important modification occurred in 1993. In that year Act 19255 was 
enacted in order to modify the role of Sernatur in international marketing. This act aimed to advance a private-public partnership scheme and allowed Sernatur to create and be part of private corporations for conducting international marketing. As a result, Tourism Chile was created the same year as a partnership between Sernatur and the private sector. In this scheme, the role of international marketing was transferred to Tourism Chile, while domestic marketing remained with Sernatur (Ministerio de Economía Fomento y Reconstrucción, 1993). This separation of marketing increased the problems of fragmentation of the institutional framework for tourism, causing greater problems of coordination and representation. This is a key element examined in detail in Chapter VI.

The internal organisation of Sernatur was defined by Act 1224 and Sernatur regulations with its subsequent amendments (Gobierno de Chile \& Ministerio de Economia Fomento y Reconstruccion, 2007; Ministerio de Economía Fomento y Reconstrucción, 1975, 1987, 1989, 1990, 1993, 2003, 2004, 2006, 2007). The organisation was divided into three areas that received the name of Sub Directions: Development, Regions, and Control. These areas are presented in Figure 4.8, which shows Sernatur's organisational chart just before the enactment of Act 20423.

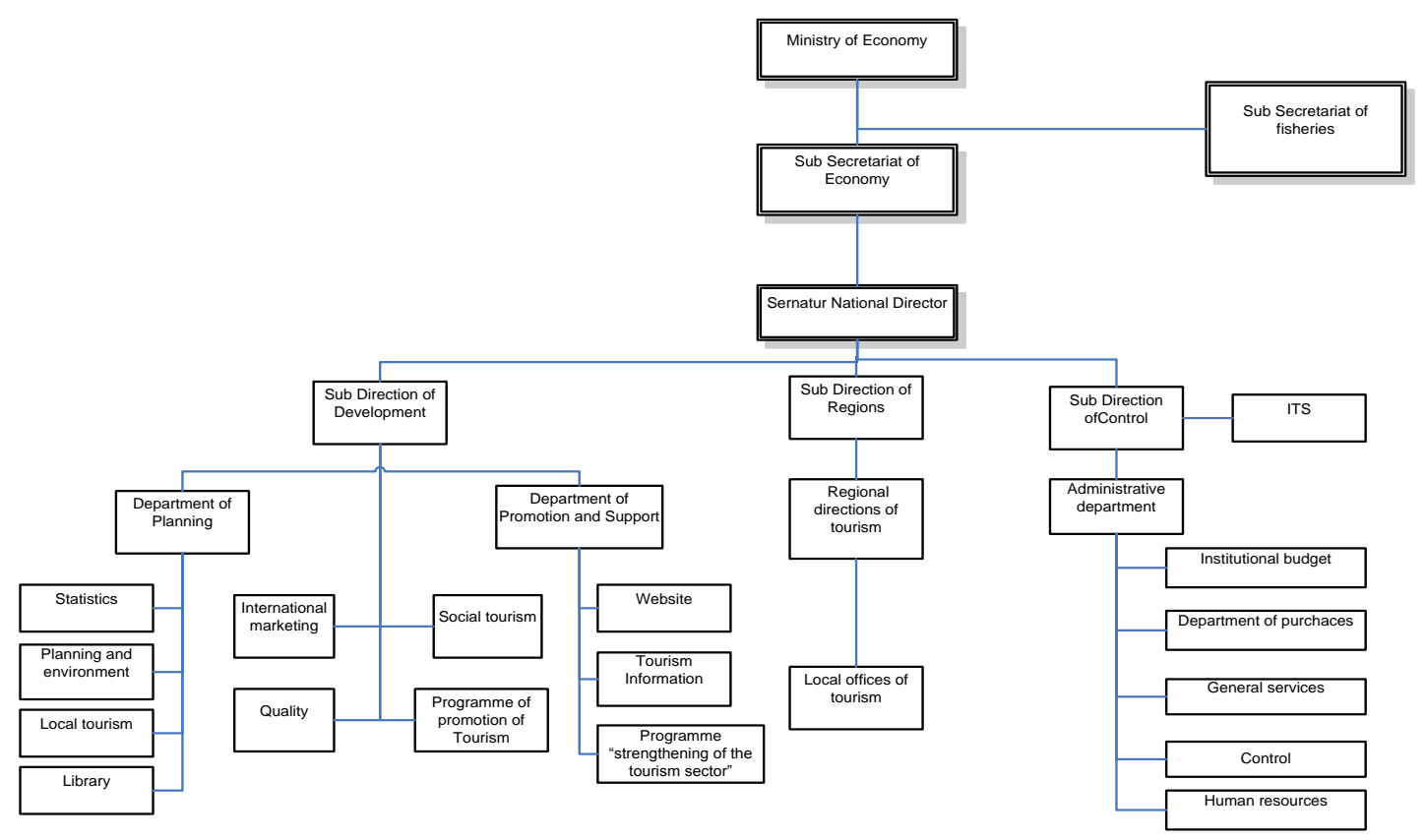

Figure 4.8: Sernatur's internal organisation

(Sernatur, 2010) 
The SubDirection of Development was in charge of tourism planning, domestic tourism and international marketing. Although international marketing was transferred to Tourism Chile, Sernatur created a programme to conduct domestic marketing and to collaborate with Tourism Chile in international marketing. The Sub Direction of Regions was in charge of leading Sernatur offices at the regional level, while the Sub Direction of Control was in charge of Sernatur's internal administration.

The peculiarities of the administration of the public sector described in Section 4.2 have clear implications for the organisation of Sernatur. Each sub-direction organised its roles in different departments and units. In order to face new challenges emerging in the tourism industry, over recent decades some new departments and units were created (e.g. the Department of Planning and its Unit of Planning and environment) (Rivas, 2010). Due to the legally driven nature of the Chilean public administration, the creation of new departments and units required legal modifications of Sernatur's regulation. However, in most cases this creation was only conducted by a Sernatur Director's decree causing the emergence of a de facto organisational structure (Gonzalez, Loader, 2010). This had a clear implication for the performance of new departments and units. Act 18575 establishes that the budget of a public organisation is allocated based on the staff composition and the internal organisation contained in the act that created the organisation (Gobierno de Chile, 1986). Due to the fact that new departments and units were created without modifying Sernatur's regulations, the newly created structures lacked the budget and staff to fulfil their roles. As a consequence, an inorganic structure unable to support the new challenges of the industry resulted.

The centralised and hierarchical characteristics of the public administration meant Sernatur lacked authority and power to coordinate the tourism industry. From the public sector perspective, the lack of authority of Sernatur was reflected, for instance, in Sernatur's low involvement in the programme "Ecotourism in National Parks". This lack of authority was also perceived inside the private sector, who highlighted the Sernatur's lack of resources and staff to coordinate the industry at the national and regional levels (Inter American Development Bank, 2007b). Despite the fact that Sernatur's budget rose from US\$5 to US\$37 million in a decade (Figure 
4.6), the perception of the private and public sectors about Sernatur did not change and the idea of an institutional change gained attention. These characteristics - plus the dynamics of the industry during the 2000s and the characteristics of the private tourism sector - are key elements not only to understanding why the process of change occurred but also the form and outcomes of the process. As presented in the integrated conceptual framework (Figure 2.4), these characteristics are represented by a set of factors forming part of the general environment in Chile during which the process of change occurred. The next section brings these factors together and sets the scene for establishing the process of change in Chapter V.

\subsection{Environmental conditions in Chile during the last decade}

Several environmental conditions directly or indirectly influenced the process of change in Sernatur. Figure 4.9 shows these conditions classified in political, policy, and economic factors (blue, green, and red respectively). Political factors include events such as the change of government; policy factors consider policy events or policy trends underlying the Chilean public sector; and economic factors include the features of the industry, illustrated, for example by tourism growth rates.

The figure shows several political factors. Due to the presidential nature of the Chilean political system, the interest of presidents in the tourism sector is a key factor that influenced the process of change in different ways. In 2001, one year after President Lagos came into office, Sernatur was commissioned to identify the problems and limitations of the tourism sector. To identify these problems, Sernatur conducted public-private workshops whose results were contained in the National Tourism Agenda (Sernatur, 2002). According to several interviewees, the National Tourism Agenda set the basis for the entire process of change (Alcayaga, Santelices, Szmulewicz, 2010). In 2005, during the presidential political campaign, Bachelet launched her programme of government (Bachelet, 2005). Strongly influenced by a Sernatur representative, the programme contained proposals to strengthen the sector including transforming Sernatur into a Subsecretariat of Tourism (Anonymous, 2010). As investigated later in Chapter V and VIII, the interest of these presidents is a key factor to understanding why and how the process of change in Sernatur occurred. 
The continuity given to the process by the former Sernatur director also emerged as a key political factor. Oscar Santelices was the director during two presidential terms. In 2006 - and despite the fact that Bachelet had previously announced that no one from the former administration would be in her cabinet - Santelices was confirmed in his position and became the only public service representative reconfirmed in Bachelet's first cabinet. Two reasons may have contributed to Santelices' confirmation as director of Sernatur: the positive evaluation performance of Santelices during the previous presidential term, and the need to give continuity to the process of strengthening Sernatur initiated during Lagos' presidential term (Iglesias, 2010). This confirmation gave continuity to the process and allowed Sernatur to put forward the idea of formulating a tourism bill (Arriagada, Iglesias, Meliboski, Santelices, 2010).

In 2006 Bachelet reshuffled her cabinet and the existing Minister of Economy was replaced by Alejandro Ferreiro. Although Bachelet announced the formulation of the tourism bill upon coming to office, the actual formulation only started after the appointment of Ferreiro. Towards the end of 2006, Ferreiro set up a commission between Minecon, Dipres, and Sernatur and the formulation of the bill began (Ferreiro, Iglesias, Rebolledo, Rodríguez, Santelices, Zúñiga, 2010). The power of Dipres described in Section 4.2 explains why Dipres was involved in this commission and represents a key political factor underlying the process of change. In 2008, just after the bill was submitted to Parliament, a cabinet reshuffle occurred and Alejandro Ferreiro was replaced by Hugo Lavados. This cabinet reshuffle prompted the appointment of the Sernatur sub-director (Sebastian Iglesias) as advisor of the minister, triggering a change in the allocation of power during the process. As presented later on in Chapter V and VII, Iglesias handled and negotiated the tourism bill in Parliament, influencing the debate in Parliament based on his own background from Sernatur. 
2000

\section{Change of Government
Lagos President \\ Change of Governm
Lagos President}
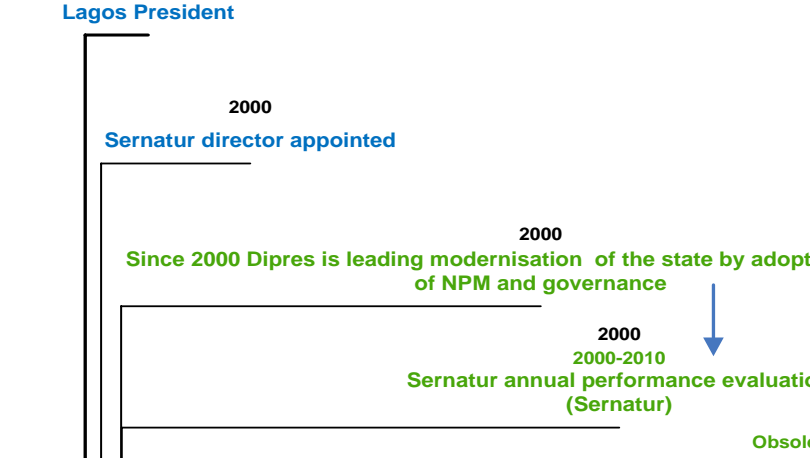

ENVIRONMENTAL CONDITIONS

2005
Bachelet's pro

05

2006

of

Bachelet Presid

2006

Sernatur director

Is confirmed

2006

Cabinet reshuffle Alejandro Ferreiro

2004 increasingly launches strategies to promote tourism in Snaspe 2004

ivate tourism sector

Fragmented priva

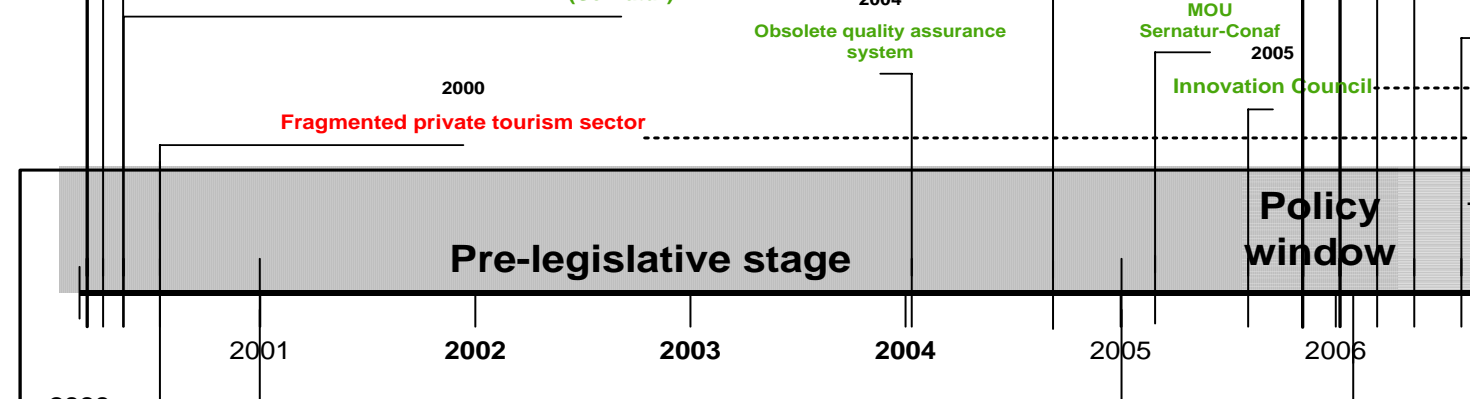

2000

2 2000 - 2010
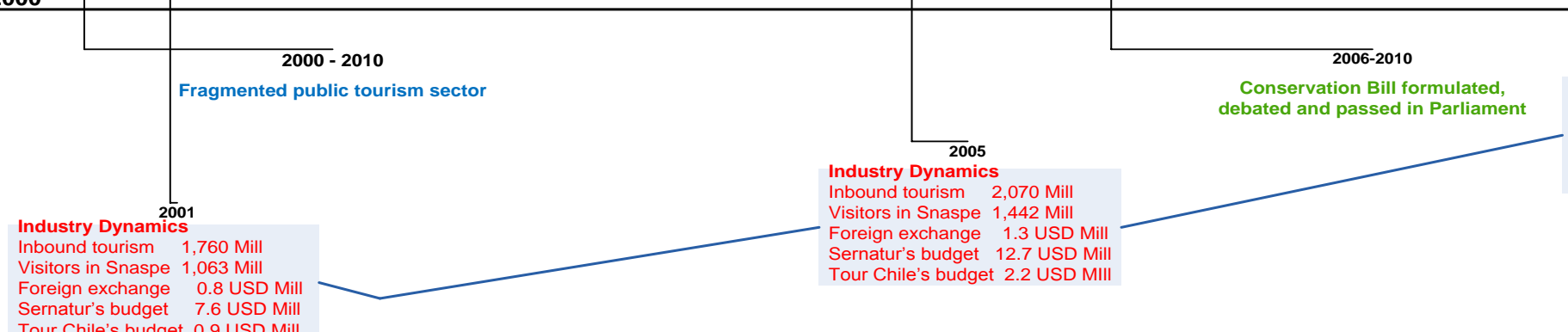

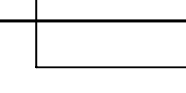

IADB

Loan proposal

echnical assistance

Research for

(IADB)

2007

BCG report

(Minecon/BCG)

ation of Fedetur

bill is formulated

Legislative stage

1007

Minister of Economy:

Hugo Lavados

Cabinet reshuffle

appointed as Lavados' adviso

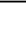


The administrative reform in the public sector to adopt NPM and the policy of innovation emerge as key policy factors. The administrative reform aimed to tackle key principles of the NPM approach, including governance, transparency, accountability, and performance measures (Lahera \& Cabezas, 2000; Olavarría, et al., 2011; Waissbluth, 2005; Waissbluth \& Inostroza, 2007). In order to advance the adoption of these principles, Dipres made it compulsory that from 2000 every public organisation must prepare internal evaluations to assess the fulfilment of these principles (Dipres, 2011). In addition, every year Dipres randomly selected some agencies or programmes for an in-depth organisational performance evaluation (comprehensive evaluations). In this context, from 2000 Sernatur conducted internal evaluations as part of the annual performance evaluations required by Dipres, while comprehensive evaluations were also carried out to evaluate Tourism Chile, a couple of Sernatur's programmes, and the National System of Protected Areas - SNASPE (Dipres, 2005a, 2005b). These evaluations were not commissioned or conducted specifically as part of the process of change in Sernatur; however their outcomes directly influenced the process by drawing the attention to the governance of the existing institutional framework (García, M, Rodríguez, Zúñiga, 2010). This is a critical aspect examined in detail in Chapter VI. The policy of innovation launched in 2005 also emerges as a key milestone to illustrate policy factors. As mentioned, the policy triggered the commission of the BCG report (2007). The BCG identified the tourism sector as a priority economic area and identified governance of the institutional framework as a key limitation to improving competitiveness.

Figure 4.9 also shows the involvement of Conaf in tourism development. As described in the previous section, during the 2000s Conaf actively promoted tourism development in the SNASPE by launching policy documents, calling for bids for granting concessions, and implementing the MOU with Sernatur. Finally, the formulation of the conservation bill (2006) also emerges as an important milestone illustrating policy factors. In parallel to the formulation of the tourism bill, the government formulated and submitted a bill to change the institutional framework of conservation (the conservation bill). The bill aimed to transfer the SNASPE from Conaf to the Ministry of Conservation, having direct implications for the tourism bill. These implications are examined in the next chapters. 
Figure 4.9 also shows economic factors illustrated by rates of tourism growth. Because of the steady growth of the industry described in Section 4.3, the tourism sector gained attention from the government who required a loan to the IADB in order to strengthen the tourism sector (Iglesias, 2010). The loan request prompted a technical aid project (Inter American Development Bank, 2007b) which legitimated the idea of formulating a tourism bill (Ferreiro, Iglesias, Santelices, 2010). This growth also influenced the results of the BCG study mentioned above. Because of the rapid growth of the industry in the 2000s, the BCG identified the tourism sector as one of the five sectors with more potential to advance competitiveness. Because competitiveness was a presidential priority, the results of the study gave visibility to the tourism sector in the public sector, sped up the formulation of the bill, and triggered the involvement of actors such as Dipres (Ferreiro, Rodríguez, 2010). The importance of the BCG report was particularly highlighted by the former Minister of Economy who stated:

Some environmental conditions stimulated the formulation of the bill... For example the policy of innovation and the BCG report highlighted the tourism sector as an economic area with potential to the economy. (Ferreiro, 2010)

These political, policy and economic factors occurred in the context of the complex and fragmented private and public sectors described in this chapter. During the decade the private sector underwent reorganisation, while the public sector faced administrative reform that aimed to increasingly adopt NPM. In this context, the idea of reinforcing Sernatur to strength the public tourism framework increasingly gained attention (Boston Consulting Group, 2007; C\&S Soluziona Servicios Profesionales, 2004; Sernatur, 2002, 2005, 2006b, 2006c; Universidad de Chile, 2007). As a result, in 2007 a tourism bill was submitted to Parliament for debate.

Although the date of submission is known, critical aspects have hitherto not been researched including how and why the idea of having a tourism bill gained attention, what the process to formulate the bill was, and how the debate in Parliament occurred. In order to examine these aspects, the integrated conceptual framework to investigate the process of change in Sernatur (Figure 2.4) shows that the process of change occurred in three different stages - the pre-legislative, policy window, and legislative stages. The features of the broader environment presented in this chapter 
help set the scene to investigate these stages. Drawing on these features, the next chapter aims to examine these stages and provide a comprehensive perspective about the process that led to the enactment of Act 20423 and the creation of a new tourism institutional framework (NTAb). 


\section{Chapter 5 The process of institutional change in Sernatur}

\subsection{Introduction}

The process of change in Sernatur could not be operationalised based on the set of consecutive phases suggested by the Policy Cycle Model. Therefore, and as discussed in Chapter II and III, the process was operationalised based on the integrated conceptual framework (Figure 2.4). The integrated framework suggests the existence of three stages: the pre-legislative, policy window, and legislative. As part of these stages there are the components of a policy process: multiple evaluations and agendas, which occur in parallel to the formulation and decision making of the bill.

To examine the process that led to the changes in Sernatur, Figure 2.4 shows the starting and the final points of the institutional change (NTAa and NTAb). As explained in Chapter I, the process of change not only modified the existing NTA but also the entire institutional framework for tourism. The new framework is composed of a Council of Ministers for Tourism, a Subsecretariat of Tourism (NTA), a Council of Marketing (NTO), and Sernatur. At the regional level, Sernatur branches are also kept as RTOs. The emergence of new and interrelated set of agencies suggests the idea that NTA(b) is a system of tourism organisations. This notion of a system for the new institutional framework is also presented in Act 20423, which is called the act "That Creates a New Institutional System" Hence, in this research $\operatorname{NTA}(b)$ will be also called a new institutional framework or a new institutional system.

The change in the structure of the institutional framework also resulted in changes in the roles of the agencies involved. The role of policy formulation was transferred from Sernatur to the Subsecretariat of Tourism; policy approval was transferred from the Ministry of Economy-Sernatur to the Committee of Ministers; marketing was reallocated from Tourism Chile to the Council; and, finally, Sernatur kept its role of implementation. Before examining how these particular changes occurred, the next section provides an overview of the entire process of change. 


\subsection{The process of change in Sernatur: An overview}

As discussed in Chapter IV, any institutional change in public organisations requires a bill formulated by the Executive and passed in Parliament. Since the process of change being analysed aimed to modify the structure and roles of the existing institutional framework for tourism, a bill was needed to carry out this change. In this context, after a change of government in 2006 the formulation of a tourism bill was announced (El Mercurio, 2006d, 2006e). In 2007 the bill was submitted to Parliament (Gobierno de Chile \& Ministerio de Economia Fomento y Reconstruccion, 2007), between 2008 and 2009 the bill was discussed (Cámara de Diputados de Chile, 2009c; Senado de la República de Chile, 2009c), and it was finally passed and enacted in 2010 (Cámara de Diputados de Chile, 2010b; Ministerio de Economía Fomento y Reconstrucción, 2010). As a result, in 2010 the government enacted Act 20423 "That Creates an Institutional System for Tourism Development” (Ministerio de Economía Fomento y Reconstrucción, 2010).

Drawing on Figure 2.4, the process of change in the case might be operationalised based on three major stages. The need to have a bill to carry out the institutional change in Sernatur means that the process of change occurred in the context of a legislative process (legislative stage). The legislative process officially starts with the inclusion of a bill in the government agenda: the President announces the formulation of a bill, the announcement begins the formulation, and then the bill is debated in Parliament. In terms of the literature, Birkland (2007) suggests that the legislative stage is, in general, preceded by long discussions that aim to set the agendas, which suggests that the process of change in Sernatur started before the announcement of the bill (i.e. in the pre-legislative stage). Between these two stages there is a transitional overlap called the policy window stage (Kingdon, 1995), which shows what triggered the movement from the pre-legislative to the legislative stage. These three stages in the process of change in Sernatur are presented in Figure 5.1. 


\section{ENVIRONMENTAL CONDITIONS}

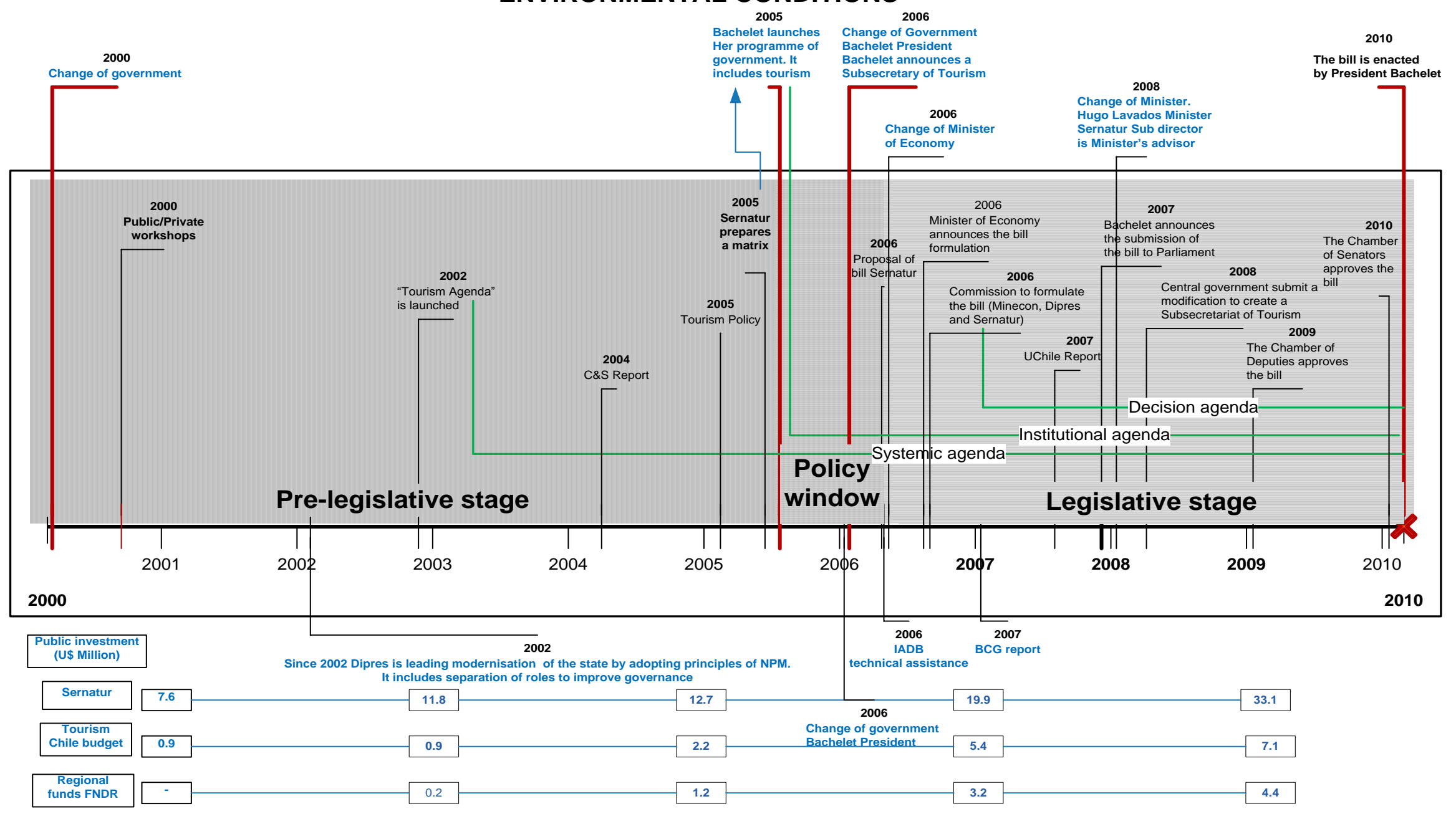

Figure 5.1: The process of change in Sernatur 
In Figure 5.1 red lines show the relevant milestones that were used as breakpoints to identify the stages. As part of these stages, milestones are also presented to identify the components of the policy process; that is, the multiple agendas (systemic, institutional and decision), the formulation of the bill and its decision making in Parliament. The different agendas are shown in green. As suggested by Birkland (2007), these agendas occur in parallel and overlap. The systemic agenda occurred during the pre-legislative stage but also extended into the legislative stage, overlapping with the other two agendas; the institutional emerged from the policy window and occurred during the legislative stage; and, finally, the decision agenda came about during the legislative stage. Milestones to examine evaluations are not presented because they are investigated in detail in Chapter VI. The figure also shows environmental conditions influencing the process (in blue).

The literature on policy stages and the components of a policy process helped to analyse data and identify milestones to operationalise the case. The pre-legislative stage started with the workshops conducted by Sernatur in 2001. These workshops triggered the enactment of the National Tourism Agenda, which signals the emergence of the systemic agenda (a list of issues identified by the tourism industry to strengthen the tourism sector). The pre-legislative stage concluded towards 2005 when candidate Bachelet launched her programme of government.

As discussed in Chapter II, the policy window is opened when three streams intersect. In this particular case, the increasing attention gained by the tourism sector (problem stream), a matrix document elaborated by Sernatur to strengthen Sernatur (policy stream) and the inclusion of this matrix document in the programme of the presidential candidate (political stream) intersected when Michele Bachelet came into office in 2006. Therefore, in this particular case political circumstances - the assumption of Bachelet as President - led to the establishment of the institutional agenda and opened the policy window.

The legislative stage started when Bachelet came into office and announced the formulation of a tourism bill. This announcement, combined with a cabinet reshuffle that changed the Minister of Economy in 2006, prompted the creation of a commission of representatives of Sernatur, the Ministry of Economy (Minecon), and 
the Budget Office (Dipres). The commission identified the contents of the tourism bill (decision agenda) and formulated the bill which was submitted to parliament in 2008 (formulation). Between 2008 and 2010 the bill was debated and passed in Parliament (decision making), and it was enacted towards the end of Bachelet's presidential term (February 2010).

In order to investigate the particularities of these stages, Sections 5.3 presents the pre-legislative stage and the systemic agenda, Section 5.4 shows the policy window and the institutional agenda, and Section 5.5 examines the legislative process, including the decision agenda, the formulation of the bill, and its decision making in Parliament. Finally, Section 5.6 discusses the main findings emerging from this chapter and presents the conclusions of the chapter.

\subsection{The pre-legislative stage}

The investigation of the systemic agenda is critical to understanding how the process of change started and how the pre-legislative stage occurred. In Figure 5.1, the systemic agenda is illustrated by a set of documents that highlighted the need to strengthen the tourism sector. These documents are identified in the shaded area of the pre-legislative stage.

The steps described by Parsons (1995) in Chapter II (Section 2.6.2) are used to examine the creation and expansion of the systemic agenda. Parsons suggests that there is an initiator that triggers the creation of an issue or policy problem. At some point, this issue gains media attention and interest from the public and decision makers. In the case of Sernatur, the systemic agenda was initiated in 2000, just after President Lagos came into office. The private sector that year called for the strengthening of the tourism sector - for example, by transforming Sernatur into a Subsecretariat of Tourism (El Mercurio, 2000b, 2000c). In response to private sector demands, President Lagos proposed several actions but declared that no institutional change in Sernatur was going to be conducted (El Mercurio, 2000a).

In September 2001, Lagos commissioned Sernatur to lead a series of workshops to identify priority issues to strengthen the sector. The workshops involved more than 100 stakeholders, including a broad range of representatives of public organisations 
with programmes in tourism and representatives of private tourism organisations (Sernatur, 2002). The workshops triggered the identification of a set of priority issues to strengthen the industry that are contained in a document called "Chile Tourist Country: Agenda 2002-2005" (Sernatur, 2002). This document is also known as the National Tourism Agenda. The document identifies 14 priority issues to strengthen the sector.

Towards the end of 2005, the list of issues proposed by the National Tourism Agenda was narrowed down and the number of priority issues was reduced from fourteen to five. These last issues were contained in a matrix document elaborated by Sernatur and included in the programme of government of Bachelet during the presidential campaign (Iglesias, 2010). As mentioned in Chapter III (Section 3.5), the "matrix document" could not be found anywhere, which limited the researcher's ability to confirm the influence of the document on Bachelet's programme of government. To address this limitation, interviewees were asked to recall the issues contained in the document and these issues were then cross checked with Bachelet's programme of government. In this way, the influence of the matrix document was confirmed.

In order to identify how the debate of the systemic agenda evolved and the 14 issues were reduced to five, it is necessary to identify what issues were discussed during the pre-legislate stage, and how and why some issues were selected and others omitted. Table 5.1 shows the issues addressed during the pre-legislative stage. The table presents four documents containing the priority issues discussed during this stage: the National Tourism Agenda (Sernatur, 2002), C\&S report (C\&S Soluziona Servicios Profesionales, 2004), the National Tourism Policy (Sernatur, 2005), and Michelle Bachelet's programme of government (Bachelet, 2005). This last document also illustrates the not found matrix document. The main issues contained in each document are also presented in the table. The issues that were consistently contained across the different documents are highlighted in green

The National Tourism Agenda generally addressed several issues related to the structure and roles of the existing institutional framework (Sernatur and Tourism Chile). In 2004, Minecon and Sernatur commissioned a study by C\&S. The study 
reviewed the organisational arrangements of Sernatur and proposed an alternative to strengthen these arrangements (C\&S Soluziona Servicios Profesionales, 2004). As described in the C\&S report, two alternative proposals were already identified by Sernatur and Minecon before conducting the study: to implement a major modification by formulating a tourism bill that changes the institutional framework, or to modify Act 1224 in terms of the structure and roles of Sernatur. The second alternative was adopted because President Lagos' presidential term was close to finishing and major modifications to the public institutional framework required more time to be formulated and discussed in Parliament. Therefore, C\&S focused on Act 1224 and only examined the issues of the National Tourism Agenda that were related to the contents of the Act. As presented in the table, these issues were the structure of Sernatur and the roles of coordination, marketing, planning (Zones of Interest for Tourism Development, ZOITs), and quality assurance. The other issues of the National Tourism Agenda were not addressed because they were not explicitly contained in Act 1224.

\begin{tabular}{|c|c|c|c|}
\hline $\begin{array}{l}\text { The national tourism agenda } \\
(2002)\end{array}$ & $\begin{array}{l}\text { C\&S Report } \\
\text { (2004) }\end{array}$ & $\begin{array}{l}\text { Tourism Policy } \\
\text { (2005) }\end{array}$ & $\begin{array}{c}\text { Michele Bachelet } \\
\text { programme of government } \\
(2005) \\
\end{array}$ \\
\hline Improve coordination & Improve coordination & Improve coordination & \\
\hline $\begin{array}{l}\text { Improve Sernatur institutional } \\
\text { arrangements }\end{array}$ & $\begin{array}{l}\text { Improve Sernatur institutional } \\
\text { arrangement }\end{array}$ & $\begin{array}{l}\text { Improve Sernatur } \\
\text { institutional arrangement }\end{array}$ & $\begin{array}{l}\text { Coordination and improve } \\
\text { Sernatur institutional } \\
\text { arrangement }\end{array}$ \\
\hline Increase marketing funds & Increase marketing funds & Increase marketing funds & $\begin{array}{l}\text { Increase marketing funds } \\
\text { and strengthen Tourism Chile }\end{array}$ \\
\hline $\begin{array}{l}\text { Zoits: increase the number of } \\
\text { declared ZOITs }\end{array}$ & $\begin{array}{l}\text { Zoits: increase the number of } \\
\text { declared ZOITs }\end{array}$ & $\begin{array}{l}\text { Zoits: increase the number of } \\
\text { declared ZOITs }\end{array}$ & \\
\hline $\begin{array}{l}\text { Quality: review the existing } \\
\text { system }\end{array}$ & $\begin{array}{l}\text { Quality: review the existing } \\
\text { system }\end{array}$ & $\begin{array}{l}\text { Quality: review the existing } \\
\text { system }\end{array}$ & $\begin{array}{l}\text { Quality: review the existing } \\
\text { system }\end{array}$ \\
\hline $\begin{array}{l}\text { Capture the value of protected } \\
\text { areas for tourism }\end{array}$ & & $\begin{array}{l}\text { Capture the value of } \\
\text { protected areas for tourism }\end{array}$ & \\
\hline \multicolumn{4}{|l|}{ Training and education } \\
\hline Information & & Information & Information \\
\hline Social tourism & & Social tourism & Social tourism \\
\hline \multicolumn{4}{|l|}{ Tourism investment } \\
\hline \multicolumn{4}{|l|}{$\begin{array}{l}\text { Formulate bills related to } \\
\text { tourism development }\end{array}$} \\
\hline \multicolumn{4}{|l|}{ Sustainability } \\
\hline \multicolumn{4}{|l|}{ Sendero de Chile } \\
\hline Strengthen Tourism Chile & & Strengthen Tourism Chile & \\
\hline
\end{tabular}

Table 5.1: Issues discussed during the pre-legislative stage (systemic agenda)

Based on some of the issues addressed by the National Tourism Agenda and the C\&S report, in 2005 President Lagos presented the National Tourism Policy (Sernatur, 2005). As noted in Table 5.1, the policy addressed nine of the fourteen 
issues suggested by the National Tourism Agenda. The issues omitted were not considered as they were not strategic enough to be part of the policy and therefore they should be addressed by government programmes (Iglesias, Santelices, 2010).

In December 2005 there was a presidential election. In November of that year Michelle Bachelet, the candidate who won the election, presented her programme of government. The programme contained five issues to tackle tourism development (Bachelet, 2005). As noted in Table 5.1, Bachelet's programme addressed several of the ideas contained in the National Tourism Agenda (Sernatur, 2002), the C\&S report (C\&S Soluziona Servicios Profesionales, 2004), and the Tourism Policy (Sernatur, 2005). In Bachelet's programme, the issue of coordination was addressed together with the institutional arrangement for Sernatur and marketing was addressed together with the strengthening of Tourism Chile (Bachelet, 2005). On the other hand, two issues were omitted in Bachelet's programme (tourism planning in ZOITs and tourism in protected areas). Once again, these issues were omitted on the ground that they were not strategic enough to be part of the selected group of issues contained in Bachelet's programme and therefore they should be a matter of government programmes to be addressed after the elecction (Iglesias, Santelices, 2010).

As highlighted by most interviewees, the National Tourism Agenda launched in 2002 is a critical milestone that set the systemic agenda and influenced the debate occurring during the entire pre-legislative stage (Iglesias, Rebolledo, 2010). As shown in the table, the priority issues that were commonly discussed in different proposals during this stage emerged from the National Tourism Agenda. Not only was the National Tourism Agenda relevant in setting the systemic agenda but it also had a direct influence on the institutional and decision agendas. In this regard one interviewee observed:

Since the National Tourism Agenda the issues were always the same... what changed over time were not the issues but the way these issues were addressed. (García, M, 2010)

The influence of the National Tourism Agenda on the institutional agenda becomes evident in the light of the literature discussed in Chapter II. As presented in Section 2.6.2, the systemic agenda is usually narrowed in order to move it higher up on the 
government agenda; in other words, to move issues from the systemic towards the institutional agenda (Parsons, 1995). According to Parsons, a key aspect in moving the systemic agenda is the way in which the issues are framed; for example, by defining and redefining the same issue over and over again among different proposals. Parson's suggestion is clearly presented in Table 5.1. The table shows that different proposals with similar issues were proposed by different documents over the entire pre-legislative stage. In this context, the National Tourism Agenda (Sernatur, 2002) set the basis for the discussion about strengthening the tourism sector. Among these issues, the C\&S report (C\&S Soluziona Servicios Profesionales, 2004) tackled the need change the internal organisation of Sernatur; the National Tourism Policy (Sernatur, 2005) addressed some of the issues of the National Tourism Agenda and the changes in Sernatur's institutional organisation; and, finally, Bachelet included five issues emerging from the Agenda into her programme of government in order to strengthen Sernatur (Bachelet, 2005).

\subsection{The policy window and the institutional agenda}

Once the decision makers' attention is gained, the issue moves from the systemic to the institutional agenda (Parsons, 1995). According to Kingdon (1995), this movement is usually triggered by critical events in the general political environment; for example, a change of government. These critical events move the agendas and open the policy window. In the case of the process of change in Sernatur, the programme of government of Bachelet and her election in 2006 are critical milestones that moved the agendas and opened the policy window.

As discussed in Chapter II, the policy window opens when three different streams (problem, policy and politics) intersect (Kingdon, 1995). In the case, different milestones presented in Figure 5.1 help identify the problem stream and illustrate how the tourism sector gained public attention. Towards 2005 the tourism industry kept growing. In this context, the industry argued that to sustain this growth it was necessary to strengthen the tourism sector (El Mercurio, 2005). That year, the private sector and Sernatur suggested transforming Sernatur into a Subsecretariat (El Mercurio, 2005), while in parallel a group of Members of Parliament asked the government to create a Ministry of Tourism (Senado de la República de Chile, 
2005a, 2005b). These events illustrate how towards 2005 the discourse about strengthening the sector was spread among different spheres and started to gain public attention (Iglesias, 2010).

The policy stream is represented by the matrix document mentioned in the previous section. With the tourism sector gaining public attention, the idea that legislative modifications to strengthen the NTA might occur sooner or later emerged in Sernatur (Iglesias, Rebolledo, 2010). In order to have a proposal in case a legislative process started, Sernatur elaborated this matrix document based on five priority issues emerging from the National Tourism Agenda (coordination, marketing, quality assurance, information and social tourism). The selection of these five issues is explained by an interviewee from Sernatur who stated:

Towards 2005 we had a matrix with five priority issues. We chose those five issues because to address them, we required legislative changes and political commitment...on the contrary, the other issues (those omitted) did not require legislative changes. (Iglesias, 2010)

Though the five issues addressed by the matrix did not progress toward a legislative discussion, toward the end 2005 a critical milestone emerged that signifies the political stream. Michelle Bachelet's programme of government tackled tourism development and included the five issues contained in the matrix document elaborated by Sernatur (Iglesias, Rebolledo, Santelices, 2010). As highlighted by some interviewees - who asked not to be identified - the inclusion of the matrix document in Bachelet's programme resulted from a direct intervention of Sernatur. This is presented in Figure 5.1 by an arrow that connects the matrix document with Bachelet's programme. An interviewee explains:

That occurred because we set up a commission that strongly influenced the part of the programme related to tourism. In fact, we wrote that part. We included the matrix document in Bachelet's programme; that is the reason why the programme included the tourism bill, the creation of a subsecretariat, etc. (Anonymous, 2010)

As mentioned before, the assumption of Bachelet as President led to the opening of the policy window and triggered the movement from the pre-legislative to the legislative stage. In the light of the literature on agenda setting, once a government has accepted that something needs to be done about a problem, it can be said that an issue has entered the institutional agenda (Howlett \& Ramesh, 2003). When Bachelet 
came into office in March 2006, the five issues of the matrix document became part of the government agenda and the institutional agenda emerged. The same year, Bachelet announced a bill to strengthen the tourism institutional framework (El Mercurio, 2006a, 2006e; La Tercera, 2006), so beginning the legislative stage.

\subsection{The legislative stage}

In March 2006 Bachelet announced the formulation of the tourism bill (La Nación, 2006; La Nación 2006a), officially signalling the beginning of the legislative stage. As discussed in Chapter IV, bills containing institutional change in public organisations can only be formulated and submitted to Parliament by the President (Gobierno de Chile, 1980) . Based on the centralised nature of the Chilean public administration, bills are formulated by the government bureaucracy (Ministers) and submitted to Parliament by the central office that manages the government legislative agenda (Secretary of the Presidency - Segpres). Because of the power of Dipres in the public sector, this agency plays a key role in formulating and approving the contents to be included in bills; in other words, Dipres plays a critical role in defining the decision agenda and formulation. Once in Parliament, bills are debated and approved/rejected in the Chambers of Deputies and Senators (Cámara de Diputados de Chile, 2010a).

As discussed in Chapter II, the components of a policy process overlap. The decision agenda is hard to separate from formulation and in turn, formulation usually overlaps with decision making (Sabatier, 2007; Sidney, 2007). As presented next, the decision agenda in this case occurred in parallel with the formulation of the bill, and because the bill submitted to Parliament was still being drafted and modified during its parliamentary debate, formulation also overlapped with decision making. To tackle these overlaps, and as a way to depict the legislative stage, in this research the decision agenda is presented as the process to define the issues to be included in the bill, formulation relates to the process of drafting the contents of the bill, and decision making explicitly focuses on the debate of the bill in Parliament. 


\subsubsection{The decision agenda.}

Birkland (2007) suggests that decision agendas emerge from the interaction of multiple agendas during a policy process. According to several interviewees, the formulation of the tourism bill rested on a set of priority issues negotiated between Minecon, Dipres, and Sernatur. In this case, the involvement of new agencies (Minecon and Dipres) brought other parallel agendas into the process, influencing the decision agenda.

Figure 5.1 shows several milestones occurring in 2006 that influenced and shaped the decision agenda. In July, the Minister of Economy (Ingrid Antonijevic) announced the formulation of a bill to transform Sernatur into a Subsecretariat (El Mercurio, 2006e). In this context, Sernatur formulated a draft bill (Sernatur, 2006c), which was ready to gain approval from the Minister of Economy towards the middle of that year (Iglesias, Rebolledo, 2010). Following the Chilean legislative process, this draft bill needed to be approved by the Ministry of Economy and Dipres prior to submission to Parliament. However in July, Bachelet reshuffled her cabinet and the existing Minister was replaced by Alejandro Ferreiro (El Mercurio, 2006b). Thus, additional time was required because the new minister needed to be informed about the bill (Iglesias, Rebolledo, Santelices, 2010). A few months later, the formulation of the bill was announced once again by the recently appointed Minister Ferreiro and President Bachelet (La Estrella de Iquique, 2006; La Nación 2006b).

These multiple announcements - and the fact that a bill contained the creation of a subsecretariat - drew the attention of Dipres which usually avoids the creation of new public organisations. Minister Ferreiro - conscious of the importance of involving Dipres during the formulation to guarantee the bill's submission - set up a commission composed of Sernatur, Minecon, and Dipres to support the formulation of the bill (Ferreiro, 2010). The importance of Dipres' involvement was illustrated by a Dipres representative:

When the ministries formulate bills without Dipres' involvement and we receive these bills to be reviewed, we usually archive and put them in a drawer. In the case of this bill, we got involved after a public speech of the President; she announced that a bill was going to be formulated for the tourism sector. This triggered our involvement. (Rodríguez, 2010) 
The establishment of this commission between Sernatur, Minecon and Dipres prompted the decision agenda. In contrast to the former Minister of Economy, who allocated the responsibility of formulating the bill to Sernatur, the new Minister decided to lead the process (Iglesias, Rebolledo, 2010). Once the commission was set up, Sernatur's representatives proposed to use the draft bill formulated previously. Because Minecon and Dipres were not involved in the formulation of that draft, these organisations did not accept Sernatur's proposal and suggested starting over by identifying key issues (Iglesias, Rebolledo, Rodríguez, Zúñiga, 2010). The identification of these key issues represented the decision agenda in the case. In order to examine how these issues were identified, it is necessary to examine what issues were proposed, who proposed them, what issues were included in the bill and how agreement was achieved on the selection of these issues. Table 5.2 shows that Sernatur proposed a list of issues to be negotiated with Dipres and Minecon. Some of them were accepted (in green) and others rejected.

\begin{tabular}{|c|c|c|c|}
\hline $\begin{array}{c}\text { Proposal of Bill formulated by } \\
\text { Sernatur (2006) }\end{array}$ & Sernatur & Minecon & Dipres \\
\hline $\begin{array}{l}\text { Coordination: Improve } \\
\text { coordination inside the } \\
\text { government }\end{array}$ & $\sqrt{ }$ & $\checkmark$ & $\checkmark$ \\
\hline $\begin{array}{l}\text { Structure of the institutional } \\
\text { framework: Review the existing } \\
\text { public institutional arrangement }\end{array}$ & $\sqrt{ }$ & $\checkmark$ & $\checkmark$ \\
\hline 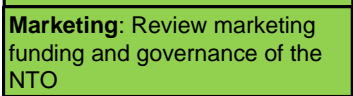 & $\checkmark$ & $\checkmark$ & $\checkmark$ \\
\hline $\begin{array}{l}\text { Quality: Implement a new } \\
\text { quality system based on a } \\
\text { certification scheme }\end{array}$ & $\checkmark$ & - & - \\
\hline Zoits: Increase declared ZOITs & $\sqrt{ }$ & $=$ & - \\
\hline \begin{tabular}{|l}
$\begin{array}{l}\text { Protected areas: Promote the } \\
\text { use of national parks in tourism }\end{array}$ \\
\end{tabular} & $\sqrt{ }$ & - & - \\
\hline Training and education & $\nabla$ & $\bar{X}$ & $\bar{X}$ \\
\hline Information & $\nabla$ & $\mathrm{x}$ & $\mathrm{x}$ \\
\hline Social Tourism & $\sqrt{ }$ & $x$ & $x$ \\
\hline National Fund for Tourism & $\checkmark$ & $x$ & $x$ \\
\hline Small business & $\sqrt{ }$ & $\mathrm{X}$ & $X$ \\
\hline
\end{tabular}

Table 5.2: Issues agreed to be discussed in the bill (decision agenda)

Table 5.2 shows that six issues were agreed between Sernatur, Minecon, and Dipres. Of these six issues, there was immediate agreement to address coordination, structure of the institutional framework, and marketing. Sernatur proposed these issues and Dipres and Minecon considered them as critical elements to tackle market failures in tourism (Rodríguez, Zúñiga, 2010). The other three issues (ZOITs, 
tourism in protected areas and quality assurance) were considered by Dipres as less relevant. In spite of this, Dipres accepted their inclusion as a result of the negotiation with Sernatur.

At this stage Sernatur also decided to include the issues of ZOIT and tourism in protected areas. During the policy window Sernatur omitted the inclusion of these issues on the grounds that they were matters of government programmes. However, evaluations conducted after 2005 conclude the lack of implementation of ZOITs and the limited results of the MOU with Conaf. Thus, Sernatur argued that legal modifications were required to address these issues and proposed to include them in the bill. This shows how evaluation reports may influence and shape the process and is discussed in detail in Chapters VI and VII.

The table also shows issues proposed by Sernatur emerging from the draft bill and that were not accepted by Minecon and Dipres (training and education, information, social tourism, and small business). These issues were omitted on the grounds that they could be better addressed by a programme (Rodríguez, Zúñiga, 2010). Dipres also opposed the creation of a National Fund. The creation of the fund by an act makes the allocation of funds compulsory without possibilities of modification, an issue described in Chapter IV as going against Dipres' policy (Iglesias, 2010).

\subsubsection{Formulation of the bill.}

Once the issues of the decision agenda were identified, the commission discussed alternatives in order to address the issues and draft the alternatives into sections and clauses for the bill. In doing that, Sernatur, Minecon, and Dipres differed in some of the proposed alternatives and disagreement emerged (Ferreiro, Iglesias, Rodríguez, Zúñiga, 2010). To tackle this disagreement, Minecon commissioned a study by the Universidad de Chile (UChile), but Sernatur did not accept the proposals contained in the study and disagreement persisted. In order to understand what caused disagreement and how it was tackled during the formulation of the bill, it is necessary to examine the alternatives discussed (Table 5.3). In the table, the issues and proposals resulting in disagreement are shown in orange (institutional framework, policy making and marketing). 
Table 5.3 shows the alternatives proposed by Sernatur, Minecon-Dipres, the proposals suggested by UChile, and the proposals included in the bill. As presented in the table, Sernatur proposed to address the structure and the roles of policy making and marketing by strengthening the existing institutional framework while Minecon and Dipres argued that a comprehensive modification to the framework was needed, including the creation of a new NTA and NTO. Because of the disagreement, the Minister commissioned the UChile study (Universidad de Chile, 2007). The study aimed to provide an external view and propose alternatives to address the issues under disagreement (Ferreiro, Iglesias, Zúñiga, 2010). The UChile study adopted a similar approach to Minecon and Dipres; thus, Sernatur opposed what UChile proposed (Santelices, 2010). In turn, Sernatur kept its proposal of strengthening the existing framework and used the BCG report (Boston Consulting Group, 2007) to support its argument (Rebolledo, Santelices, 2010).

\begin{tabular}{|c|c|c|c|}
\hline $\begin{array}{c}\text { Bill formulated by Sernatur } \\
\text { (Sernatur's position during the } \\
\text { formulation) }\end{array}$ & $\begin{array}{l}\text { Dipres and Minecon } \\
\text { Positions during the formulation }\end{array}$ & $\begin{array}{l}\text { U Chile report } \\
\text { (UChile, 2007) }\end{array}$ & $\begin{array}{c}\text { Submitted Bill } \\
\text { (Chilean Parliament, 2007) }\end{array}$ \\
\hline $\begin{array}{l}\text { Coordination } \\
\text { Focus on strengthening policy roles } \\
\text { of the existing organisations: }\end{array}$ & $\begin{array}{l}\text { Coordination } \\
\text { Focus on modifying the allocation of } \\
\text { policy roles among different } \\
\text { agencies: }\end{array}$ & $\begin{array}{l}\text { Coordination: } \\
\text { Focus on modifying the allocation } \\
\text { of policy roles among different } \\
\text { agencies (NPM): }\end{array}$ & $\begin{array}{l}\text { Coordination } \\
\text { Focus on modifying the allocation of } \\
\text { policy roles among different } \\
\text { agencies: }\end{array}$ \\
\hline $\begin{array}{l}\text { - To create a Commission of } \\
\text { Ministers for tourism development }\end{array}$ & $\begin{array}{l}\text { - To create a council of Ministers for } \\
\text { tourism development }\end{array}$ & $\begin{array}{l}\text { - To create a council of Ministers } \\
\text { for tourism development }\end{array}$ & $\begin{array}{l}\text { - To create a council of Ministers for } \\
\text { tourism development }\end{array}$ \\
\hline $\begin{array}{l}\text { Institutional framework } \\
\text { Focus on Sernatur's institutional } \\
\text { arrangement: } \\
\text { - Sernatur's Director raised to } \\
\text { the position of Subsecretary }\end{array}$ & \begin{tabular}{|l|} 
Institutional framework \\
Focus on the adoption of modern \\
public management principles: \\
\\
- Separation of roles among policy \\
formulation, implementation and \\
evaluation among different agencies \\
- A technical secretary is created \\
(new NTA) and led by a technical \\
secretary
\end{tabular} & $\begin{array}{l}\text { Institutional framework } \\
\text { Focus on the adoption of NPM: } \\
\text { - Separation of roles among policy } \\
\text { formulation, implementation and } \\
\text { evaluation among different } \\
\text { agencies. A technical secretary } \\
\text { (new NTA) is created and led by a } \\
\text { technical secretary. A second } \\
\text { consultancy report suggests a } \\
\text { technical secretary (new NTA) but } \\
\text { led by a secretary with position of } \\
\text { Subsecretary }\end{array}$ & $\begin{array}{l}\text { Institutional framework } \\
\text { Focus on the adoption of modern } \\
\text { public management principles: } \\
\\
\text { - To separate roles among policy } \\
\text { formulation, implementation and } \\
\text { evaluation among different } \\
\text { agencies. A technical secretary } \\
\text { (new NTA) is led by a secretary with } \\
\text { position of Subsecretary }\end{array}$ \\
\hline $\begin{array}{l}\text { Marketing } \\
\text { Focus on strengthening the existing } \\
\text { NTO: } \\
\text { - To create a foundation for } \\
\text { implementing marketing actions } \\
\text { - When it was not accepted by } \\
\text { Dipres, Sernatur proposed to } \\
\text { strengthen Tourism Chile }\end{array}$ & $\begin{array}{l}\text { Marketing } \\
\text { Focus on the adoption of modern } \\
\text { public management principles: } \\
\text { - A new NTO (a private-public } \\
\text { committee for marketing) }\end{array}$ & $\begin{array}{l}\text { Marketing } \\
\text { Focus on NPM: } \\
\text { - A new NTO (a private-public } \\
\text { committee for marketing) }\end{array}$ & $\begin{array}{l}\text { Marketing } \\
\text { Focus on the adoption of modern } \\
\text { public management principles: } \\
\text { - A new NTO (a private-public } \\
\text { committee for marketing) }\end{array}$ \\
\hline $\begin{array}{l}\text { Zoits } \\
\text { - To increase declared ZOITs }\end{array}$ & & \begin{tabular}{|l|} 
Zoits \\
- To implement a cluster approach \\
to declare ZOITs
\end{tabular} & $\begin{array}{l}\text { Zoits: } \\
\text { - To align ZOITs declaration into the } \\
\text { General Act of Urbanisms }\end{array}$ \\
\hline $\begin{array}{l}\text { Quality } \\
\text { - To implement a new quality } \\
\text { system based on a certification } \\
\text { scheme }\end{array}$ & & $\begin{array}{l}\text { Quality } \\
\text { - To implement a new quality } \\
\text { system based on a certification } \\
\text { scheme }\end{array}$ & $\begin{array}{l}\text { Quality } \\
\text { - To implement a new quality } \\
\text { system based on a certification } \\
\text { scheme } \\
\text { - To include in the system tourist } \\
\text { rights and security standards for } \\
\text { tourist }\end{array}$ \\
\hline \begin{tabular}{|l|} 
Protected areas \\
- To strengthen Sernatur and Conaf \\
alliance to promote tourism in \\
national parks
\end{tabular} & & $\begin{array}{l}\text { Protected areas: To elaborate } \\
\text { management plans for tourism } \\
\text { development in protected areas }\end{array}$ & $\begin{array}{l}\text { Protected areas } \\
\text { - To create a new programme to } \\
\text { promote tourism in protected areas } \\
\text { in charge of the Ministry of Public } \\
\text { Lands }\end{array}$ \\
\hline
\end{tabular}

Table 5.3: Proposals discussed during the formulation of the bill 
No agreement was reached at this stage and Sernatur proposed to ask for external support from someone who was acknowledged as an expert. This expert was $\mathrm{Mr}$. Marcelo Drago, who suggested a new review of the six issues originally agreed by Sernatur, Minecon, and Dipres (Table 5.2). The issues were discussed again and no agreement was achieved after more than one year of discussion (Santelices, 2010). The different perspectives between Sernatur and Minecon-Dipres and the disagreement inside the commission were highlighted by some representatives of these organisations:

We spent two years formulating the bill. It was a long discussion with Dipres. Dipres did not want to create a Subsecretariat. There was also a long discussion with Dipres regarding Tourism Chile, Dipres wanted to bring back marketing to the government... we were stuck. (Santelices, 2010)

There were conflicts... It seems that Sernatur just wanted to create a Ministry of Tourism and appointed Sernatur's director as the Minister. They actually would have been happy by creating a bill that says "create the ministry of tourism and appoint the Subsecretary”. Regarding marketing, Sernatur never saw a conflict in terms that Tourism Chile was capturing public funds.... marketing is a public good and therefore we wanted it back to the government. (Rodríguez, 2010)

As examined in Chapter VI, the different points of view between Sernatur and Minecon-Dipres emerged due to different perspectives to explain what the problems in the institutional framework were. These different perspectives triggered permanent disagreement during the legislative stage. Towards the end of 2007 no agreement was achieved and Dipres used its power to push forward its proposal and influence the contents of the bill (Iglesias, Rebolledo, Szmulewicz, 2010).

Besides disagreement, another key feature during the formulation of the bill was the lack of consultation. This may be explained because the Chilean Constitution does not explicitly mention consultation as a step in formulation. The commission leading the formulation conducted one on one meetings with some stakeholders in order to improve the understanding of a particular theme; for example, Conaf (Zúñiga, 2010). However, most public and private stakeholders were not involved with the formulation and they did not see the bill until it was submitted to Parliament (Bau, García, M, Martinez, Martinez, Szmulewicz, 2010). 
This lack of consultation triggered another disagreement, in this case between Conaf and Sernatur/Minecon (Bau, Diaz, Galaz, Iglesias, Lazo, Rebolledo, 2010). This disagreement resulted from the treatment the bill gave to the issue of "planning tourism in protected areas". As shown in Table 5.3, the bill submitted to Parliament creates a new programme for promoting tourism in protected areas. The new programme is implemented by the Ministry of Public Lands and replaces the one implemented by Conaf. Even more importantly, the bill completely ignored Conaf as the agency in charge of the SNASPE (Bau, Lazo, Martinez, 2010). The reason why this occurred is analysed in Chapter VI. When Segpres called on all the ministers involved with the bill to sign it for submission, Conaf's director advised the Minister of Agriculture not to sign the bill. Thus, the Minister refused to sign it and asked for more discussion inside the government (Bau, Galaz, Iglesias, 2010). No agreement was achieved and the president instructed the minister to sign the bill for submission. In compensation, Segpres' minister proposed to the Minister of Agriculture that any modification could be discussed in Parliament (Bau, 2010). This conflict is illustrated by the Conaf's former director who stated:

I warned the Minister of Agriculture not to sign the bill; suddenly the President publically announced the bill submission. We could not do anything; we are just a technical agency, the political role rested with Segpres and the ministers. At the end Segpres offered us to review and change the bill in Parliament. (Bau, 2010)

After signing, the bill was submitted. According to proceedings of the Chamber of Deputies, the bill was submitted to Parliament in January 2008 (Cámara de Diputados de Chile, 2010c). The submission of the bill in Parliament is a key milestone that shows the end of the formulation of the bill by the government and signifies the start of its debate in Parliament.

\subsubsection{The decision making in Parliament.}

The decision making in Parliament occurred in the context of the Chilean legislative process described in Chapter IV. Figure 5.2 shows in green the steps followed by the tourism bill in Parliament. 


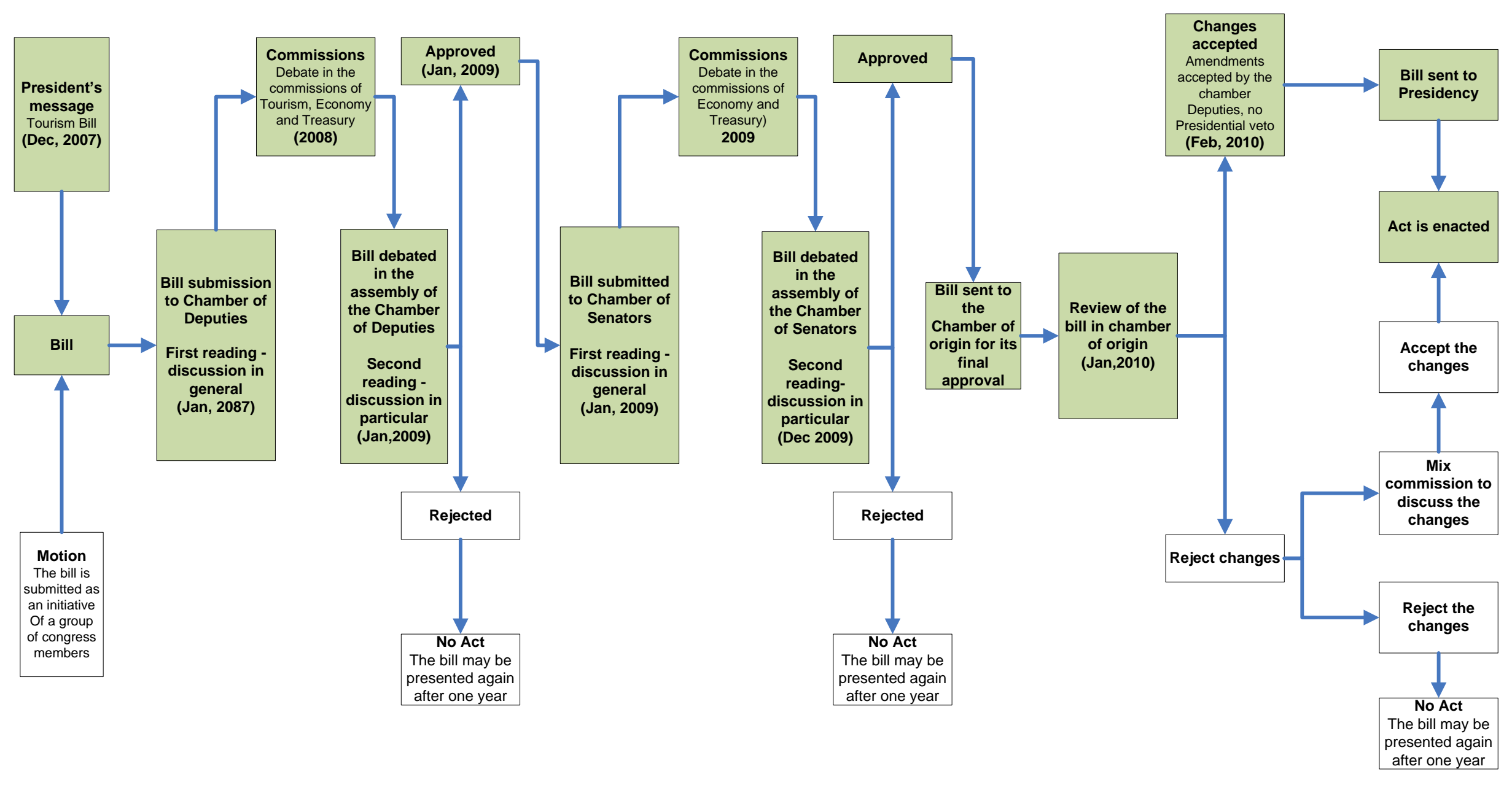

Figure 5.2: The legislative process for the tourism bill 
In January 2008 the Chamber of Deputies conducted the first reading of the bill and agreed to debate it (Cámara de Diputados de Chile, 2010c). The same month, the bill was sent to the Commission of Tourism of the chamber. The debate in the commission lasted for the rest of the year (Cámara de Diputados de Chile, 2009b). Towards the end of 2008, the bill was also reviewed by the Commissions of Economy and Treasury (Cámara de Diputados de Chile, 2009a).

In January 2009, reports from these commissions were presented to the assembly of the Chamber of Deputies. The reports recommended approving the bill but with modifications. After that, the chamber conducted the second reading, voted the bill part by part, and approved the bill with modifications (Cámara de Diputados de Chile, 2008a, 2008b). Then, the bill was sent to the Chamber of Senators (Cámara de Diputados de Chile, 2010c). The debate in the Chamber of Senators followed similar steps to that the Chamber of Deputies. The first reading took place in April 2009 and then the bill was reviewed by the Commissions of Economy and Treasury. In December 2009 and January 2010 the second reading was conducted and the bill was approved with modifications (Senado de la República de Chile, 2009a, 2009b, 2009d, 2009e, 2009f). Once the Chamber of Deputies and the Government agreed to the changes made by the Senate, the bill was sent back to Segpres for its enactment (Cámara de Diputados de Chile, 2010c).

Therefore, as a result of the debate in both chambers, the bill was approved with modifications. In order to investigate what exactly these modifications were and why and how these changes emerged, the different versions of the bill debated in parliament are examined next. These versions are presented in Table 5.4, which shows in red the parts of the bill that changed as a result of the debate. The table shows three different versions of the bill: the bill submitted to Parliament, the version approved by the Chamber of Deputies and the bill approved by the Senate. These versions contain six broad sections related to the structure and roles of the institutional framework: I) structure, II) coordination, III) marketing, IV) ZOITs, V) tourism in protected areas, and VI) tourism quality assurance. Since both ZOITs and the promotion of tourism in protected areas are matters of the role of planning, in the future these issues will be addressed together. 
As noted in the table, changes mainly occurred regarding the structure of the framework and the roles of coordination, marketing, and quality assurance. Among these modified issues, the one that faced the most changes was the structure of the proposed NTA.

\begin{tabular}{|c|c|c|}
\hline $\begin{array}{c}\text { Submitted bill } \\
\text { (Chamber of Deputies, 2007) }\end{array}$ & $\begin{array}{l}\text { Bill passed in Chamber of Deputies } \\
\text { (Chamber of Deputies, 2010) }\end{array}$ & $\begin{array}{l}\text { Bill passed in Chamber of Senators } \\
\text { (Chamber of Senators, 2010) }\end{array}$ \\
\hline $\begin{array}{l}\text { Structure } \\
\text { New institutional framework. A } \\
\text { technical secretary is created as the } \\
\text { new NTA. The NTA is led by a } \\
\text { secretary with position of } \\
\text { Subsecretary }\end{array}$ & \begin{tabular}{|l|} 
Structure \\
New institutional framework. A \\
Subsecretariat of Tourism is created as \\
the new NTA
\end{tabular} & $\begin{array}{l}\text { Structure } \\
\text { New institutional framework. A } \\
\text { Subsecretariat of Tourism is created as } \\
\text { the new NTA. The Ministry of Economy, } \\
\text { Promotion and Reconstruction is } \\
\text { replaced by Ministry of Economy, } \\
\text { Promotion and Tourism }\end{array}$ \\
\hline $\begin{array}{l}\text { Coordination } \\
\text { Council of Ministers for tourism } \\
\text { development }\end{array}$ & $\begin{array}{l}\text { Coordination } \\
\text { Committee of Ministers for tourism } \\
\text { development }\end{array}$ & $\begin{array}{l}\text { Coordination } \\
\text { Committee of Ministers for tourism } \\
\text { development }\end{array}$ \\
\hline $\begin{array}{l}\text { Marketing } \\
\text { Public-private advisory committee of } \\
\text { marketing. Sernatur must leave } \\
\text { Tourism Chile within one year after } \\
\text { the Act is enacted }\end{array}$ & $\begin{array}{l}\text { Marketing } \\
\text { Public-private advisory council of } \\
\text { marketing. Sernatur must leave Tourism } \\
\text { Chile within one year after the Act is } \\
\text { enacted } \\
\text { Regional governments may be part of } \\
\text { corporations to promote tourism }\end{array}$ & $\begin{array}{l}\text { Marketing } \\
\text { Public-private advisory council of } \\
\text { marketing. Sernatur must leave Tourism } \\
\text { Chile within two years after the Act is } \\
\text { enacted } \\
\text { Regional governments may be part of } \\
\text { corporations to promote tourism }\end{array}$ \\
\hline $\begin{array}{l}\text { ZOITs } \\
\text { To align the process to declare ZOITs } \\
\text { with the Act of Urbanism }\end{array}$ & $\begin{array}{l}\text { ZOITs } \\
\text { To align the process to declare ZOITs } \\
\text { with the Act of Urbanism }\end{array}$ & $\begin{array}{l}\text { ZOITs } \\
\text { To align the process to declare ZOITs with } \\
\text { the Act of Urbanism }\end{array}$ \\
\hline $\begin{array}{l}\text { Protected areas } \\
\text { Concessional programme managed } \\
\text { by Ministry of Public Lands }\end{array}$ & $\begin{array}{l}\text { Protected areas } \\
\text { Concessional programme managed by } \\
\text { Ministry of Public Lands }\end{array}$ & $\begin{array}{l}\text { Protected areas } \\
\text { Concessional programme managed by } \\
\text { Ministry of Public Lands }\end{array}$ \\
\hline $\begin{array}{l}\text { Quality assurance } \\
\text { New quality system. It contains } \\
\text { - Quality certification } \\
\text { - Security certification } \\
\text { - Two quality labels (quality-security) } \\
\text { - Tourist rights }\end{array}$ & $\begin{array}{l}\text { Quality assurance } \\
\text { New quality system. It contains } \\
\text { - Quality certification } \\
\text { - Security standards } \\
\text { - One quality label } \\
\text { - Tourist rights }\end{array}$ & $\begin{array}{l}\text { Quality assurance } \\
\text { New quality system. It contains } \\
\text { - Quality certification } \\
\text { - Security certification compulsory for } \\
\text { adventure tourism } \\
\text { - One quality labels } \\
\text { - Tourist rights. Fines were increased }\end{array}$ \\
\hline
\end{tabular}

\section{Table 5.4: Changes in the bill during the debate in Parliament}

During the debate in the Commission of Tourism of the Chamber of Deputies, the deputies belonging to the commission presented to the Minister of Economy their disagreement about the proposed structure (technical secretariat) and asked him to change the bill in order to create a Subsecretariat. Because this change can only be submitted by the Executive, in a meeting with the Minister of Economy and his advisor, the deputies informed the government that the bill would be rejected if changes were not submitted (De Urresti, Goic, Iglesias, Rebolledo, Recondo, Santelices, 2010). The argument given was that the proposed structure would not tackle the problem of the power of the NTA to coordinate the sector and, therefore, 
the proposal would not strengthen the tourism industry. As a Member of Parliament stated:

The creation of a technical secretariat was not a good idea; we did not want to have more Ministers without desks. If we are going to approve a modification, it must have been a real modification... we stopped the discussion and told the Minister that we were not going to approve it if it's not modified toward a higher hierarchical structure...The ministry was on the horns of the dilemma. (Goic, 2012)

The Minister agreed to the condition imposed by the commission and started negotiation inside the government. An important milestone occurring just before the debate of the bill in Parliament is critical to explain why the minister accepted this condition. The general government cabinet reshuffle conducted by Bachelet in January 2008 resulted in the appointments of Hugo Lavados as the new Minister of Economy (El Mercurio, 2008) and the former Sernatur sub-director (Sebastian Iglesias) as the minister's advisor. In his new role, Iglesias gained power to influence both the debate of the bill in Parliament and the support of the new minister to create a subsecretariat (Iglesias, Rebolledo, Santelices, Szmulewicz, Zúñiga, 2010). Since the new minister was not involved in the formulation of the bill, he did not have a problem addressing this change (Iglesias, 2010).

In order to submit this amendment, the creation of a subsecretariat, negotiation with Dipres - which never agreed to the creation of the subsecretariat - was needed (Iglesias, Rebolledo, Rodríguez, Santelices, 2010). Thus, this negotiation was complex. Iglesias lobbied inside the government to change the bill and create the subsecretariat, but Dipres opposed this creation (Iglesias, Rodríguez, 2010). Because there was no agreement at this level, the discussion moved towards the Ministers of Economy and Treasury, but once again agreement was not achieved. Because disagreement persisted, President Bachelet exercised her power to resolve the disagreement and commissioned the submission of an amendment to create the Subsecretariat of Tourism (Iglesias, Rebolledo, Santelices, 2010). This negotiation was illustrated by the former Sernatur Sub-Director and advisor to the minister:

Once I got to my office I called someone at Dipres and told him that we were going to submit a modification to create a Subsecretariat. Since this modification did not change the budget contained in the bill, the change did not require Dipres' approval... we had a very hard discussion and at the end I just hung up the phone. Then the conflict moved towards the Ministry of 
Economy and Treasury, who had the same discussion with no agreement... At the end the President instructed the creation of the Subsecretariat. (Iglesias, 2010)

After the amendment was submitted and the existing technical secretariat was replaced by a Subsecretariat of Tourism, the bill was debated and passed by the Commission of Tourism and the Assembly of the Chamber of Deputies. As presented in Table 5.4, the debate in the Senate resulted in a new change emerging related to the structure of the institutional framework: the name of the Ministry of Economy, Promotion and Reconstruction was changed to become the Ministry of Economy, Promotion and Tourism. The idea underlying this proposal was to strengthen the position of the Minister of Economy as Minister of Tourism.

Table 5.4 shows that other changes also occurred. There was a change in the use of the nomenclature "committee" and "council" due to a semantic reason. "Committee" was adopted for the group of Ministers for coordination because this word is more suitable for groups advocating coordination. In turn, "council" was adopted for the public private marketing group due to the advisory nature of the new NTO. A change also occurred for the role of marketing. The submitted bill mentions that Sernatur must leave Tourism Chile in the space of one year; however the approved version of the bill authorised Sernatur to be part of the NTO for a further year. The reason why this change occurred is the lobbying conducted by Tourism Chile in the Senate (this lobby is examined later). The role of quality assurance was also affected by some modifications. Although there were some changes in the Chamber of Deputies, relevant modifications to this role occurred as a result of the debate in the Senate. As presented in the table, the security standards became compulsory for adventure tourism companies and the limits of fines for companies that did not reach the standards were increased. With the exception of these changes and other minor modifications, the bill approved by Parliament practically remained the same.

A distinctive feature of the debate in Parliament was the level of participation of relevant stakeholders. Unlike the formulation of the bill, during the debate in Parliament there was a broad consultation with multiple stakeholders. During 2008 the Commission of Tourism of the Chamber of Deputies invited a large number of representatives of the private sector (Recondo, Goic, 2010). Due to the fragmented 
nature of the private sector and the lack of a common representative of the industry described in Chapter IV, the commission invited representatives of multiple organisations. As presented in proceedings of the commission, some of these organisations were Achet, Hotelga, Consetur, Hoteleros, and Achiga (Chapter IV). The public sector was also invited, but was mainly represented by Conaf (Cámara de Diputados de Chile, 2009b). In the context of this consultation, deputies also organised nationwide workshops (De Urresti, Goic, Recondo, 2010). One of the most important regional consultations was the "Tourism National Forum" organised by Societur and the Chamber of Deputies (Cámara de Diputados de Chile, 2009b). After the forum, Societur submitted to Parliament a document with a set of suggestions to modify the bill (Sociedad Chilena de Investigadores en Turismo, 2008). However, none of these changes was addressed by the different versions of the bill.

During the debate in the Senate there was also consultation, but it was more limited. The private sector was invited to some sessions of the Commission of Economy. At this point, the private sector was mainly represented by Consetur and the recently created Fedetur (Senado de la República de Chile, 2009f). Consetur unsuccessfully lobbied to modify the labour code and to make the labour regime in tourism more flexible (García, R, García, M, 2010); while in parallel, Fedetur lobbied for changing the marketing scheme proposed in the bill. Fedetur suggested eliminating the entire part of the bill containing the creation of the Council of Marketing (Arriagada, Yunis, 2010). Since this part was not eliminated, Fedetur successfully lobbied to keep Tourism Chile for a longer time as a strategy to gain time and promote changes to the bill after enactment (Arriagada, 2010). As a result, Sernatur can still be part of Tourism Chile for two years after the enactment of the bill.

Finally, the presidential nature of the Chilean administration discussed in Chapter IV and the commitment of Bachelet to the tourism bill became evident during the debate in Parliament. As described in Chapter IV, the President is able to strongly influence the legislative debate by putting Parliament under urgency. Throughout the debate of the tourism bill in Parliament, the Chambers of Deputies and Senators were put under urgency several times. During the last part of the debate (in the Senate), Parliament was put under "extreme urgency" for immediate debate to pass or reject 
the bill (Cámara de Diputados de Chile, 2010c). As a consequence, the bill was passed three days after the "urgency" was submitted. This approval started to signal the end of debate in Parliament. In February 2010 - just a month before Bachelet's presidential term finished - the bill was enacted (Cámara de Diputados de Chile, 2010c). The enactment of the bill signalled the end of the legislative stage and the start of implementation. As mentioned in Chapter I, the implementation of the bill exceeds the scope of this research.

\subsection{Discussion and conclusions}

Drawing on the integrated conceptual framework (Figure 2.4), this chapter has presented the institutional change process in Sernatur. Figure 5.1 shows that three major stages might be identified: pre-legislative, policy window, and legislative. The pre-legislative stage contains the general discussion in the industry about the need to strength the tourism sector, while the legislative stage involves the formulation and passing of the bill in Parliament. Between these two stages there is an overlap called the policy window. The window shows the movement from the pre-legislative stage to the legislative stage and is portrayed by a change of government in 2006.

As part of these stages, the components of the policy process existed: evaluation, agenda setting, formulation, and decision making. As presented throughout this chapter, the boundaries of these components are not as clear as the Policy Cycle Model suggests and these components overlap. As also presented here, there was no single agenda setting phase; on the contrary, multiple agendas overlapped during the entire process of change. A similar situation occurred with formulation and decision making. This may be explained because during the debate of the bill in Parliament, the bill was further amended and modified. This confirms Sabatier's position (2007) that it is hard to separate the components of a policy process into the phases proposed by the Policy Cycle Model. Milestones were identified to operationalise these stages and policy components. The milestones were critical events that allowed the researcher to identify the stages and recognise when the multiple agendas, formulation, and decision making occurred. 
Three different agendas were recognised: systemic, institutional, and decision. The systemic agenda represents the priority issues identified by the industry. This agenda emerged as a result of the public-private workshops led by Sernatur in 2001 and the National Tourism Agenda launched in 2002 (Sernatur, 2010). The institutional agenda reflects the decision of the government to include the formulation of the tourism bill into the government legislative agenda. The inclusion of some issues of the National Tourism Agenda in Bachelet's programme of government and Bachelet's election in 2006 shows the movement from the systemic to the institutional agenda. Finally, the decision agenda contains the issues the government decided to include in the bill. The establishment of a commission in charge of formulating the bill prompted the decision agenda and the actual formulation.

When Bachelet came into office in 2006, the formulation of the bill became part of the government legislative agenda. This milestone opened the policy window and triggered the start of the legislative stage. At this stage, new stakeholders emerged to be involved with the process of change (Minecon and Dipres). Drawing on a list of issues proposed by Sernatur, negotiation between Minecon, Dipres, and Sernatur took place to identify the issues to be included in the bill (decision agenda). These issues were the structure of a new tourism system, roles of policy making, marketing, planning (ZOITs and tourism in protected areas), and tourism quality. Having identified the decision agenda, Sernatur, Minecon, and Dipres identified proposals to address these five issues in the contents of the bill. However, these organisations had different proposals and disagreement emerged.

Despite the fact that negotiations were conducted, at the end of the formulation Dipres imposed its power and strongly influenced the contents of the bill. As discussed in this chapter, Sernatur proposed a list of issues to be part of the decision agenda; however Dipres did not validate the list and negotiated a narrowed list of issues. The narrowed list contained issues emerging from the National Tourism Agenda (2002). This confirms two aspects highlighted in the literature of policy agendas: first, the influence of the systemic agenda on the institutional and decision agendas, and second, that these three agendas overlap during the legislative stage. 
The fact that Dipres accepted/rejected the issues suggested by Sernatur shows the power of Dipres to influence and set the decision agenda. The involvement and power of Dipres is also critical for the formulation of the bill. During the prelegislative and legislative stages Sernatur proposed strengthening the existing institutional framework; however during the legislative stage Dipres emerged with a new proposal and suggested a modification to the entire institutional framework. Dipres' interest in addressing the NPM approach for the public sector helps explain this new proposal. For example, the allocation of policy roles among different agencies advances the disaggregation of the public sector into administrative units; while the creation of an advisory council for marketing gives transparency and accountability to the allocation of public funds for tourism marketing. In order to address the proposal of Dipres, a new institutional framework was required. This suggests that in this case the new framework is a result of the implementation of new roles. This last aspect is discussed in detail in Chapter VII. Dipres' involvement also may suggest that the institutional change in the tourism sector was not an isolated process and was driven by the processes of administrative reform described in Chapters II and IV. In this context, Dipres may have influenced the process of change in Sernatur in order to address the adoption of NMP in the tourism public sector.

Once in Parliament, the bill was debated and modified in the context of the legislative process described by the Chilean Constitution. It was during the debate of the bill in Parliament that the bill underwent most of the changes, including the creation of a Subsecretariat of Tourism. Against Dipres' position of avoiding the creation of subsecretariats, the Subsecretariat of Tourism was created in 2010, essentially challenging the power of Dipres. The reasons why this situation occurred were partially illustrated in this chapter: a change of Minister of Economy in 2008 and the appointment of the Sernatur sub-director as the minister's advisor who lobbied the bill in Parliament. These political appointments changed the distribution of power during the debate in Parliament and allowed Sernatur to have a better margin of negotiation with Dipres. Two other reasons also exist to explain how Dipres' power was challenged - the general agreement in Parliament to create a subsecretariat, and the president's commitment to the tourism bill. In Parliament there was a general consensus about the need to create a subsecretariat rather than a 
technical secretariat. This agreement allowed the Commission of Tourism of the Chamber of Deputies to threaten the government with rejecting the bill if the subsecretariat was not created. This threat would not have been effective without Bachelet's commitment to the bill. Every time when disagreement existed and the bill was stopped, Bachelet used her powers to advance the submission and debate of the bill in Parliament. In this context, when Parliament asked for the creation of the subsecretariat, the President instructed an amendment to the bill and the new NTA was created.

Another key feature of the entire process is the uneven participation and consultation of relevant stakeholders through the different stages. The private sector played a key role in defining the systemic agenda, in particular by being involved in the formulation of the National Tourism Agenda in 2002. However, the involvement of the sector tended to disappear throughout the process. Towards the end of the prelegislative stage, the systemic agenda was basically promoted by Sernatur and the private sector was not an active actor. During the legislative stage - in particular during the formulation of the bill - private sector involvement practically did not exist. This involvement partially changed during the parliamentary decision making. A similar situation occurred with the involvement of the public sector. The involvement of these two sectors is critical to examine the features of the policy process but also the results of the process of change. For instance, although the private sector was highly involved during the debate in Parliament, the sector was not able to influence the bill in aspects considered as critical. The fragmented nature of the private sector may have affected its ability to influence the bill in Parliament and explain its unsuccessful lobbying. This is depth investigated in more depth in Chapter VII.

The milestones presented in this chapter helped the identification of the stages and components of the process of change. However, these milestones just signal what started the process, opened the policy window, and prompted the formulation and debate of the bill in Parliament. Therefore, a more comprehensive understanding of what factors triggered and shaped the process is required. For example, the process of change probably would not have started if the tourism sector had not shown the dynamic rates of growth in inbound tourism, foreign exchange revenue, and public 
investment described in Chapter IV. Neither would the process have occurred without the commitment of President Bachelet to the bill combined with the general consensus about the weakness of the existing tourism institutional framework. In light of the integrated conceptual framework (Figure 2.4), these factors emanate from environmental conditions underlying the process and from several evaluative reports related to the existing institutional framework. On account of this, the next chapter examines these conditions and reports with particular emphasis on the reports. By doing this, Chapter VI aims to identify and analyse the factors that triggered and shaped the process of change in Sernatur. 


\section{Chapter 6 The factors that influenced the process of change in Sernatur}

\subsection{Introduction}

This chapter investigates the factors that influenced and shaped that process of change in Sernatur. The integrated conceptual framework (Figure 2.4) shows that the process may be influenced by factors emanating from two sources: policy evaluations contained in evaluation reports and the general environment in which the process occurs. Policy evaluations are defined as an analytical tools and procedures that play a key role in assisting a policy process (Wollmann, 2007). For example, as discussed later, evaluations might either assess policy outcomes or support policy formulation. Environmental conditions may also influence the process. For example, policy factors emanating from environmental conditions (e.g. the New Public Management approach - NPM) may influence the discussion during the process but these conditions may also influence the focus and outcomes of some evaluation reports. Thus, the environmental conditions presented in Chapter IV are examined to investigate their impact on evaluation reports. As discussed later, more than 20 evaluation reports were identified in this case. This large number of reports was generated because evaluations were conducted by multiple agencies, in different contexts and with different goals. In order to systematise and investigate this large number of reports, Figure 6.1 shows that three types of evaluations might be identified.

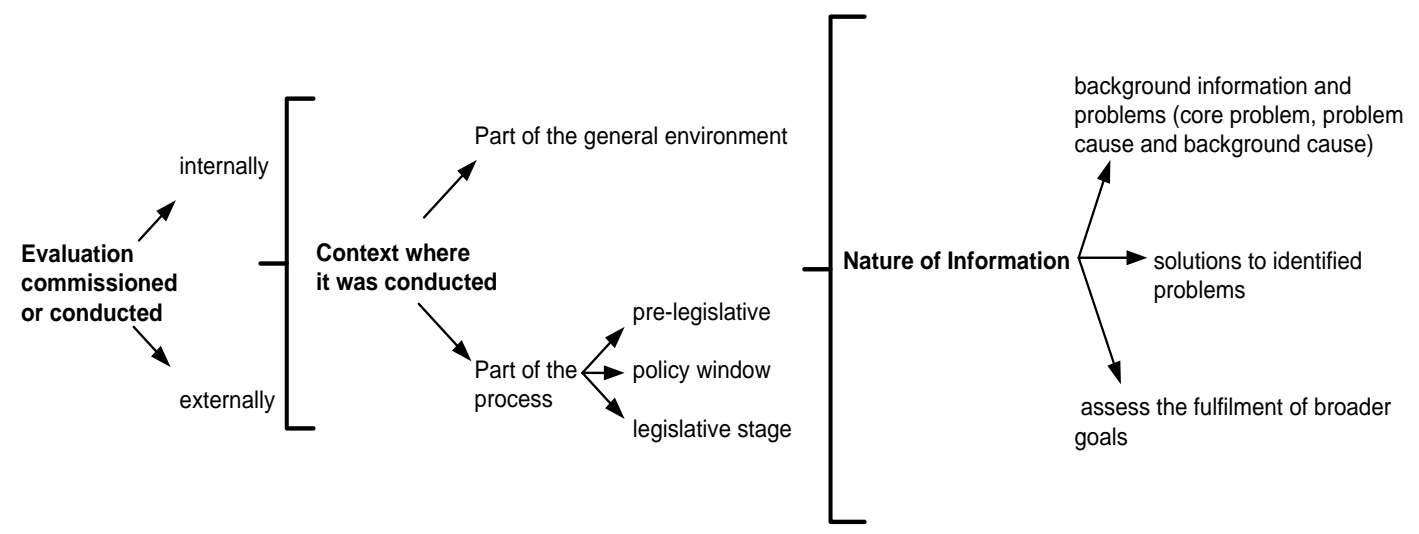

Figure 6.1: Types of evaluations identified in the Chilean case 
Figure 6.1 shows that evaluations may be classified depending on who commissioned them. Internal evaluations are self evaluations - in this case conducted by Sernatur - while external evaluations are initiated and conducted by other organisations (e.g. Budget Office - Dipres). Evaluations may also vary depending on the context in which they are carried out. Evaluations may be undertaken either in the broader environment or as part of the institutional change process. The evaluation of Tourism Chile conducted by Dipres (Dipres, 2005a) is a useful example of an evaluation occurring in the broader environment. Although this evaluation was not conducted to assist the process of change in Sernatur, some of its outcomes were used by Dipres during the formulation of the bill. Evaluations were also carried out as part of the institutional change process and conducted during the three policy stages (pre-legislative, policy window, and legislative). For example in 2007 - during the legislative stage - UChile conducted an evaluation commissioned by the Ministry of Economy (Minecon) and Dipres to support the formulation of the bill. Finally, Figure 6.1 shows that evaluations also varied depending on the type of information they provided. Some of these evaluations provided background information on the industry and identified problems in the tourism sector; others contained proposals with solutions to address the identified problems; and, finally, others provided information related to the assessment of a broader goal (e.g. the assessment of the adoption of NPM).

The analysis conducted in this chapter shows a clear interconnection between the different types of evaluations and suggests that a single classification (one category only) is not possible. Evaluations (internal or external) were conducted either as part of the general environment or in a particular stage of the process and, at the same time, provided diverse information (background, proposals, or assessment of a broader goal). For example, internal and external evaluations carried out during the pre-legislative stage provided background information on the tourism sector but also identified problems and proposed solutions to address these problems. In turn, evaluations conducted during the legislative stage focused on identifying alternatives to address these problems. 
Using the methods of data analysis presented in Chapter III, this chapter presents an in-depth analysis of the evaluation reports. Evaluations were coded into categories to investigate the factors that triggered and influenced the process of change. As presented in Figure 6.2, during the analysis of these evaluations, the researcher looked for broad themes, subcategories and issues.

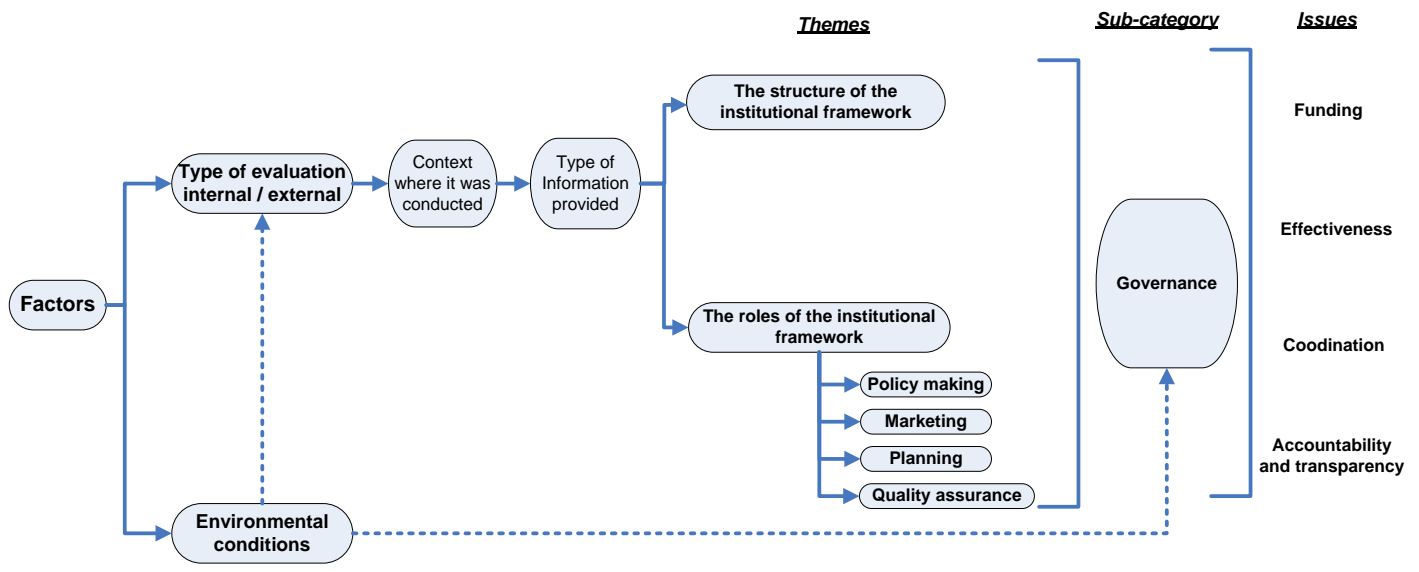

Figure 6.2: Content discussed during the process of change

Figure 6.2 shows that regardless of the type of evaluation, five broad themes may be identified in evaluation reports: the structure of the institutional framework and the roles of policy making, marketing, planning and quality assurance. As presented in the figure, one general subcategory emerged from the analysis: governance. Within this sub-category four issues emerged: funding, effectiveness, coordination and transparency/accountability. Funding relates to the allocation of funds to the different parts of the institutional framework; effectiveness examines results achieved by the organisations involved; coordination refers to the ability of Sernatur to coordinate the framework; and, finally, transparency and accountability relate to the ideas of participation, representation, transparent policy making, and accountable actions (Bevir, 2009). The themes, sub-category, and issues presented above were simultaneously addressed in most of the identified evaluation reports, which confirms the complexities of the analysis discussed in Chapter III. For example, the UChile report (2007) looked at the structure of the NTA and the roles of policy making and marketing with emphasis on the issues of funding, coordination, effectiveness, and accountability. Some of these themes and issues were also addressed by the BCG (2007) and IADB (2007b) reports. 
Although most of them addressed the sub-category of governance, these reports differed in two aspects: the particular aspect of governance, and the solutions proposed to tackle problems of governance. For example, evaluations conducted during the pre-legislative stage mainly focused on funding, effectiveness, and coordination, while evaluations carried out during the legislative stage gave more emphasis to transparency/accountability. The proposed solutions to issues of governance also varied. Evaluations conducted during the pre-legislative stage proposed to strengthen Sernatur, while evaluations conducted during the legislative stage proposed to modify the entire framework to guarantee the adoption of the NPM approach. These differences in how the pre-legislative and legislative stages addressed governance issues occurred because of a critical factor highlighted at the end of Chapter V, the power of Dipres during the legislative stage. Dipres brought the adoption of the NPM approach as an important element for the discussion and directly influenced the focus of some evaluations conducted at this stage (Rodríguez, Santelices, Szmulewicz, 2010). In this case, the interest of Dipres in the NPM approach is a key factor that shaped the contents and outcomes of some evaluations and also influenced the contents discussed during the formulation of the bill. Because the adoption of the NPM is a policy factor existing in the general environment, Figure 6.2 contains arrows that connect these conditions with the evaluation reports and the issues of governance.

To deal with the analysis of these evaluations, the issues of funding, effectiveness, coordination, and transparency/accountability are used. Because of the nature of governance as a sub-category, governance is examined during the analysis of these four issues. A similar situation occurs with environmental conditions. For the analysis of each issue, the analytical framework provided in Chapter III (Table 3.2) is used to identify themes, problems, and proposed solutions related to a particular issue. Because differences may exist between evaluations investigating a similar issue, evaluation reports were crossed checked with interviewees' responses To present the analysis of the evaluations, Section 6.2 provides an overview of the identified evaluations; Section 6.3 investigates funding; Section 6.4 looks at effectiveness, Section 6.5 examines coordination; and Section 6.6 explores accountability and transparency. Finally, Section 6.7 provides a general discussion of the findings emerging from this chapter. 


\subsection{The evaluation reports: an overview}

Figure 6.3 provides an overview of the evaluation reports. In the figure, these reports are classified based on the types of evaluations presented at the beginning of this chapter. In order to differentiate internal and external evaluations the figure identifies the agencies commissioning or conducting them. The figure also shows the evaluations in black and blue to distinguish those conducted as part of the process from those conducted in the general environment respectively. Because evaluation reports overlap in terms of providing information on several issues simultaneously, the type of information each evaluation provides is not presented in the figure.

During the pre-legislative stage (2000-2005) there were several evaluations conducted as part of the process of change: a diagnosis of the tourism industry commissioned by Parliament (Chacon, 2002), the National Tourism Agenda (Sernatur, 2002), the C\&S report (C\&S Soluziona Servicios Profesionales, 2004), and the National Tourism Policy (Sernatur, 2005). With the exception of the C\&S report - which mainly focused on the structure of the framework - the rest of these evaluations examined the structure of the framework and the roles of policy making, marketing, quality assurance, and planning. During this stage other evaluations were also conducted as part of the general environment; these included the evaluations of Tourism Chile and the National System of Protected Areas (SNASPE) conducted by Dipres in the context of the administrative reform to adopt NPM. In the figure, the evaluations resulting from this reform are connected by an arrow. In parallel, Conaf (the Forest Service) also conducted some evaluations of its concession programme for tourism development in the SNASPE.

Figure 6.3 shows that evaluations were also conducted (2006-2010). One of these was the UChile report (2007) which examined the structure and roles of the institutional framework in order to support the process of formulation of the bill. In the general environment there were also some evaluations. In 2006 and 2008 two documents evaluated the effectiveness of the Zones of Interests for Tourism Development (ZOITs) as a planning tool (Sernatur, 2006d, 2008b). 


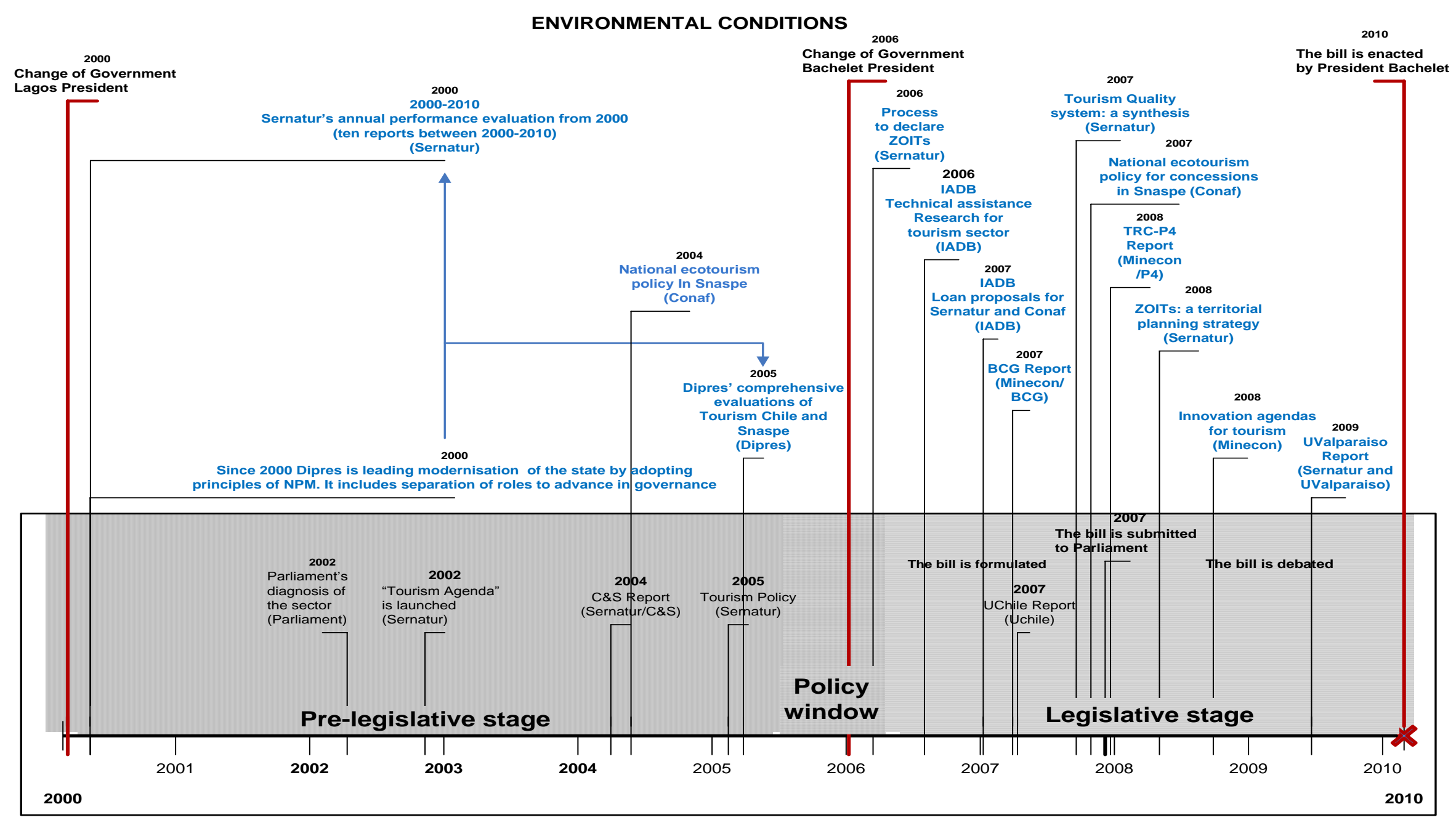

Figure 6.3: Evaluation reports produced during the process of change 
In 2006 and 2007 the IADB and the BCG reports evaluated the industry and the structure and roles of the institutional framework for tourism (Boston Consulting Group, 2007; Inter American Development Bank, 2007b). In parallel, Sernatur launched an evaluation of the existing quality assurance system (Sernatur, 2007b) and Conaf evaluated the results of its concession programme to promote tourism development in the SNASPE (Conaf, 2007a). In 2008 Minecon launched two new studies containing evaluations of the sector: the TRC-P4 report (P4 \& Tourism Resource Consultants, 2008) and the Innovation Agendas for Tourism Destinations (InnovaChile Corfo, 2007). Finally, in 2009 Sernatur and UValparaiso conducted an evaluation of Sernatur's structure and proposed strategies in case the tourism bill was enacted (Universidad Católica de Valparaíso, 2009). Although evaluations conducted after 2008 were not commissioned directly to support the formulation of the bill, they may have directly influenced the debate of the bill in Parliament. The evaluations presented here addressed several issues: funding, effectiveness, coordination, and transparency/accountability. These issues are examined next.

\subsection{Funding}

Funding relates to the allocation of funds to promote tourism development. Evaluations conducted during the process examined this issue with regard to themes structure, marketing, and planning (Table 6.1). Structure was examined based on the allocation of funds to Sernatur for its operation and programme implementation; marketing was analysed in terms of the allocation of funds to Tourism Chile for the implementation of marketing strategies; and planning was analysed based on the funds received by Conaf to promote tourism development in the SNASPE.

Table 6.1 shows that one common core problem emerged across the three themes: the low allocation of funds by the central government to Sernatur (structure), Tourism Chile (marketing), and the SNASPE (planning) (Dipres, 2005a, 2005b; Sernatur, 2002, 2005). In spite of the significant jump in the budgets of these organisations presented in Figure 4.6, evaluations produced towards the end of the decade still identified the limited allocation of funds as a problem (Boston Consulting Group, 2007; Inter American Development Bank, 2007a, 2007b; P4 \& Tourism Resource Consultants, 2008; Universidad Católica de Valparaíso, 2009). 


\begin{tabular}{|c|c|c|c|c|c|}
\hline \multirow[b]{2}{*}{ Issue } & \multirow[b]{2}{*}{ Theme } & \multicolumn{3}{|c|}{ Problems } & \multirow[b]{2}{*}{ Proposed solutions } \\
\hline & & Core Problem & Causes of the problem & Background causes & \\
\hline \multirow{3}{*}{ Funding } & Structure & $\begin{array}{l}\text { Lack of funds for the } \\
\text { operation of Sernatur and } \\
\text { the implementation of } \\
\text { programmes }\end{array}$ & $\begin{array}{l}\text { - Low political commitment from the central } \\
\text { government to allocate funds (Sernatur) } \\
\text { - Limited Sernatur skills to capture more } \\
\text { funds from Dipres (Dipres) }\end{array}$ & $\begin{array}{l}\text { - Sernatur's weak hierarchical position inside the } \\
\text { central government to capture more funds (Sernatur) } \\
\text { - Problem of the institutional framework design of } \\
\text { Act } 1224 \text { (Dipres) }\end{array}$ & $\begin{array}{l}\text { - Transform Sernatur in a subsecretariat (Sernatur) } \\
\text { and create of a marketing fund } \\
\text { - Modify the entire framework. Create a new NTA } \\
\text { and strengthen Sernatur as the implementation } \\
\text { agency (Dipres) }\end{array}$ \\
\hline & $\begin{array}{l}\text { Role of } \\
\text { marketing }\end{array}$ & $\begin{array}{l}\text { Lack of funds for the } \\
\text { implementation of marketing } \\
\text { strategies by Tourism Chile }\end{array}$ & $\begin{array}{l}\text { - Low political commitment from the central } \\
\text { government to allocate funds (Sernatur) } \\
\text { - Matching fund scheme was limiting the } \\
\text { government to increase the budget } \\
\text { (Sernatur and Dipres) }\end{array}$ & $\begin{array}{l}\text { - Sernatur's weak hierarchical position inside the } \\
\text { central government to capture more funds (Sernatur) } \\
\text { - Problem of the institutional framework because of } \\
\text { Act } 19255 \text { (Dipres and Sernatur) }\end{array}$ & $\begin{array}{l}\text { - Transform Sernatur in a subsecretariat and } \\
\text { create a foundation to guarantee permanent funds } \\
\text { (Sernatur) } \\
\text { - Replace the existing NTO by a council of } \\
\text { marketing (Dipres) }\end{array}$ \\
\hline & $\begin{array}{l}\text { Role of } \\
\text { planning }\end{array}$ & $\begin{array}{l}\text { Lack of funds for tourism } \\
\text { development in the SNASPE. } \\
\text { It may limit tourism } \\
\text { development in these areas }\end{array}$ & $\begin{array}{l}\text { - Conaf's ability to capture funds for } \\
\text { managing the SNASPE, which may affect } \\
\text { tourism development }\end{array}$ & $\begin{array}{l}\text {-Problem of design in the Institutional framework for } \\
\text { conservation (Conaf and Dipres) }\end{array}$ & $\begin{array}{l}\text { - Improve the concession system } \\
\text { (Conaf and Dipres) }\end{array}$ \\
\hline
\end{tabular}

Table 6.1: The issue of funding 
Regarding the structure of the NTA and the role of marketing, Sernatur and Minecon-Dipres agreed the lack of funding for Sernatur and Tourism Chile was a core problem but they differed over the causes of the problem, the background causes, and proposed solutions. In 2002 Sernatur argued that the cause of the problem was the weak commitment from the government (Sernatur, 2002). In 2008 this situation remained and the World Economic Forum ranked Chile in the $106^{\text {th }}$ position among 130 countries highlighting weak government commitment to tourism (Blanke \& Chiesa, 2008). This low priority was also argued in reports such as BCG (2007), Chacon (2002), C\&S (2004), P4 \& Tourism Resource Consultants (2008), Sernatur (2002, 2005, 2006b) and Universidad Católica de Valparaíso (2009). This lack of support was also highlighted by the former Minister of Economy who stated:

Sernatur was pretty ignored inside the ministry, I realised that when I became Minister. There was not connection, no commitment from the Ministry of Economy towards Sernatur. (Ferreiro, 2010)

Based on the evaluation of Tourism Chile (Dipres, 2005a) and the UChile report (Universidad de Chile, 2007), Minecon-Dipres provided a different cause of the problem. They argued that the low allocation of funds had nothing to do with political commitment and suggested that organisational weakness of Sernatur and Tourism Chile limited these organisations' abilities to capture more funds (Rodríguez, Zúñiga, 2010). This was exemplified by a Minecon representative, who mentioned in relation to Sernatur:

Look at the budget and the pool of programmes Sernatur implemented. What Sernatur has implemented is very limited in comparison with the programmes that a public service in charge of a sector should implement... this is why Sernatur has this limited budget. (Zúñiga, 2010)

According to these organisations, the background causes also differed. Sernatur argued that the there was a problem of governance in Act 1224: the weak hierarchical position of the NTA inside the government affected the ability of the NTA to capture more funds for Sernatur and Tourism Chile. In turn, Minecon-Dipres argued that the background cause was a failure in the institutional design of Acts 1224 and 19255. According to Dipres-Minecon, Act 1224 did not embrace the principles of the NPM, which affected Sernatur's organisation and ability to capture public funds. A similar situation occurred with Act 19255 that created Tourism Chile from matching funds from Sernatur and the private sector. The position of Dipres 
was in line with different reports highlighting that as the public funds were growing, the private sector was having problems providing the matching $50 \%$ of the fund (Boston Consulting Group, 2007; Dipres, 2005a). This limited the government's willingness to increase the budget and therefore limited the allocation of public funds to Tourism Chile. This was illustrated by a Consetur representative:

Although the private sector agreed with the scheme of public-private cooperation, we did not agree the percentages of contribution defined by Act 19255. What might have happened if the government decided to allocate USD 100 million? It would be impossible for us to allocate another 100 millions. (García, R, 2010)

In order to tackle these problems Sernatur and Minecon-Dipres proposed different solutions. Sernatur proposed strengthening the NTA by transforming it into a subsecretariat: it was argued that this would give Sernatur more political status and improve its powers to capture more public funds. In addition, Sernatur proposed the creation of a fund for marketing to guarantee permanent and increasing funds for Tourism Chile (Sernatur, 2006c). Because the creation of the fund was not accepted by Dipres during the formulation of the bill, Sernatur proposed to strengthen Tourism Chile (Iglesias, Rebolledo, Rodríguez, 2010). In turn, Dipres suggested that a modification to the entire framework was required, including the creation of a new NTA (Technical Secretariat) and NTO (Council of Marketing). In this way, these organisations would be in a better position to capture public funds.

A weak allocation of funds was also identified as a core problem for planning, particularly for promoting tourism development in the SNASPE. An evaluation conducted by Dipres in 2005 concluded that the investment of Conaf in the SNASPE was less than $1 \%$ of its budget (Dipres, 2005b). Several evaluation reports concluded that the cause of this problem was Conaf's inability to capture and manage more funds(Dipres, 2005b; Inter American Development Bank, 2007a). According to these reports, the background cause behind the problem was a broader problem of governance in both the institutional design of Conaf and the institutional framework for environmental conservation. As explained in Chapter IV, Conaf is a state-owned corporation charged with carrying out public roles. In spite of receiving funds from the central government, Conaf may capture funds from other sources to manage the SNASPE. The weakness of the institutional design of Conaf and its position in the 
institutional framework for conservation limited Conaf's ability to capture more funds and fulfil its roles in the SNASPE (Boston Consulting Group, 2007). Sernatur, Minecon, and Dipres agreed on the diagnosis as the background cause and proposed the creation of a new programme to grant concessions in the SNASPE. In this proposal, however, identification of who would implement the programme was omitted. This occurred because, in parallel, the government submitted the conservation bill. This bill aimed to create a Ministry of Environment and transfer the SNASPE from Conaf to the new Ministry of Environment (Chapter IV). As it was unclear who would be in charge of the SNASPE, when Sernatur and Minecon proposed the new concession programme, they opted not to identify which agency would be in charge of the new programme.

\subsection{Effectiveness}

Effectiveness relates to the ability of Sernatur, Tourism Chile, and other organisations related to the tourism sector to achieve results. The main aspects of effectiveness emerging from evaluation reports are presented in Table 6.2.

The first theme presented in the table relates to Sernatur's ability to make policy. The evaluation reports identified a common core problem: the lack of tourism policies. During the pre-legislative stage the C\&S report (2004) and Sernatur (2002) highlighted this problem. As a result, the National Tourism Policy was created in 2005. In spite of this new policy, during the legislative stage the lack of tourism policies remained problematic (Boston Consulting Group, 2007; Universidad de Chile, 2007). This was highlighted by the former Minister of Economy:

It is a shame... but the great tourism development we had over the last decade resulted in spite of the policy rather than thanks to the policy. (Ferreiro, 2010)

According to Sernatur and Minecon-Dipres, the causes of the problem rested on Sernatur's insufficient human resources and technical capacity to tackle policy formulation (Boston Consulting Group, 2007; Inter American Development Bank, 2007b; P4 \& Tourism Resource Consultants, 2008; Sernatur, 2006b; Universidad Católica de Valparaíso, 2009; Universidad de Chile, 2007). 


\begin{tabular}{|c|c|c|c|c|c|}
\hline \multirow[b]{2}{*}{ Issue } & \multirow[b]{2}{*}{ Theme } & \multicolumn{3}{|c|}{ Problems } & \multirow[b]{2}{*}{ Proposed solutions } \\
\hline & & Core Problem & Causes of the problem & Background causes & \\
\hline \multirow{4}{*}{ Efficiency } & $\begin{array}{c}\text { Structure \& } \\
\text { Role of } \\
\text { policy } \\
\text { making }\end{array}$ & \begin{tabular}{|l|} 
Lack of tourism policies \\
(Sernatur/Dipres)
\end{tabular} & $\begin{array}{l}\text { - Lack of staff and skills in Sernatur to address } \\
\text { policy formulation, implementation and } \\
\text { evaluation (Sernatur) } \\
\text { - Sernatur has neglected its role of policy } \\
\text { formulation (Dipres) }\end{array}$ & $\begin{array}{l}\text { - Obsolescence of Sernatur's internal organisation } \\
\text { defined by Act } 1224 \text { (Sernatur) } \\
\\
\text { - Problem of the institutional framework design } \\
\text { Contained in Act 1224. i.e. separation of roles (Dipres) }\end{array}$ & $\begin{array}{l}\text { - Transform Sernatur in a Subsecretariat } \\
\text { and strengthening Sernatur internal organisation } \\
\text { (Sernatur) } \\
\text { - The creation of a new institutional framework } \\
\text { (Dipres) }\end{array}$ \\
\hline & $\begin{array}{c}\text { Role of } \\
\text { marketing }\end{array}$ & $\begin{array}{l}\text { - Low positioning of } \\
\text { the brand Chile } \\
\text { (Sernatur) } \\
\text { - Unknown impact of } \\
\text { implemented marketing } \\
\text { programmes (Dipres) }\end{array}$ & $\begin{array}{l}\text { - Fragmented marketing strategies: too many } \\
\text { public organisations and funds allocated in } \\
\text { marketing without a single brand (Sernatur) } \\
\text { - Lack of measure indicators to evaluate } \\
\text { performance, outcomes and results (Dipres) }\end{array}$ & $\begin{array}{l}\text { - Fragmented nature of the Chilean public sector } \\
\text { (Sernatur) } \\
\text { - Problem of the institutional framework design } \\
\text { contained in Act } 1224 \text { and } 19255 \text {. No adoption of } \\
\text { principles of NPM of outcome evaluation (Dipres) }\end{array}$ & $\begin{array}{l}\text { - Greater involvement of Sernatur with other public } \\
\text { organisations implementing marketing campaigns } \\
\text { (Sernatur) } \\
\text { - Creation of a new NTO to replace Tourism Chile } \\
\text { (Dipres) }\end{array}$ \\
\hline & $\begin{array}{l}\text { Role of } \\
\text { planning }\end{array}$ & \begin{tabular}{|l|} 
ZOIT \\
- ZOITs are declared \\
but never implemented \\
(Sernatur) \\
\\
SNASPE \\
- Lack of tourism \\
facilities in the \\
SNASPE \\
(Sernatur, Dipres)
\end{tabular} & $\begin{array}{l}\text { - No management plans were formulated } \\
\text { (Sernatur) } \\
\text { - No involvement of municipalities in the process } \\
\text { (Sernatur) } \\
\text { - Low levels of investment in the SNASPE } \\
\text { (Conaf, Sernatur) }\end{array}$ & $\begin{array}{l}\text { - Obsolete powers and roles of Sernatur defined } \\
\text { by Act } 1224 \text { ( Sernatur lack of mechanisms to } \\
\text { guarantee the formulation of the plan) (Sernatur) } \\
\text { - DFL } 485 \text { does not recognise ZOITs plans (Sernatur) } \\
\text { - Conflicts created by the application of Act } 19300 \\
\text { (Sernatur) } \\
\text { - Weak institutional framework for conservation } \\
\text { (Conaf) } \\
\text { - Conaf's concession programme to promote tourism } \\
\text { development does not work. It is bureaucrat, is slow } \\
\text { and with too much procedures (Sernatur) }\end{array}$ & $\begin{array}{l}\text { - Align the process to declare and implement ZOITs } \\
\text { to the General Urbanism Act (DFL 485) (Sernatur) } \\
\text { - Strengthen the existing concession system (Conaf) } \\
\text { - Create a new concession system (Sernatur) }\end{array}$ \\
\hline & $\begin{array}{c}\text { Role of } \\
\text { quality } \\
\text { assurance }\end{array}$ & $\begin{array}{l}\text { - Low private sector } \\
\text { competitiveness } \\
\text { (Sernatur, Dipres) }\end{array}$ & $\begin{array}{l}\text { - Low adoption of the existing quality } \\
\text { assurance standards by the private sector } \\
\text { (Sernatur, Dipres) }\end{array}$ & $\begin{array}{l}\text { - The existing scheme was created in } 1975 \\
\text { and was obsolete }\end{array}$ & $\begin{array}{l}\text { - Adopt the recently created programme of } \\
\text { quality assurance based on ISO standards and } \\
\text { certification as the official system (Sernatur) }\end{array}$ \\
\hline
\end{tabular}

Table 6.2: The issue of effectiveness 
In spite of the consensus about the core problem and its causes, Sernatur and Minecon-Dipres differed over the background causes. Sernatur argued that the obsolescence of its internal organisation - defined by Act 1224 in 1975 - caused the lack of staff and technical capacities and therefore did not allow the NTA to embrace policy formulation (C\&S Soluziona Servicios Profesionales, 2004; Sernatur, 2002, 2005, 2006b). Minecon-Dipres suggested that the background cause was primarily a failure of design in the entire tourism institutional framework. The framework was old and did not embrace principles of the NPM approach (Universidad de Chile, 2007). According to Dipres, even if more policies had been formulated the problem of effectiveness might have persisted because of a more structural problem: Sernatur did not tackle policy formulation from a perspective that addressed the principles of the NPM approach. This position is illustrated by a representative of Dipres:

In the context of the modernisation of the state, Dipres promoted policy formulation from a perspective that tackles market failures. Sernatur never had this vision and kept asking for funds to directly implement programmes rather than for formulating policies... so at the end you can see that much of Sernatur's budget had funds for these kind of things rather than to design policies to tackle market failures...Sernatur never saw itself conducting this role. (Rodríguez, 2010)

Because of these different perspectives about background causes the proposed solutions also varied. Sernatur proposed to reorganise the NTA internally and strengthen the agency by transforming it into a subsecretariat. It would give Sernatur more political power to tackle policy formulation (Sernatur, 2006c). In turn, Dipres suggested the modification of the entire framework. Based on the principle of disaggregation of the public sector in administrative units, Dipres proposed the allocation of policy roles amongst different agencies. This would require the creation of a new NTA in charge of policy formulation and evaluation and the reorganisation of Sernatur as the implementation agency (Universidad de Chile, 2007).

The second theme presented in Table 6.2 is marketing. Two different core problems were identified by Sernatur and Dipres. For Sernatur, the core problem was the weak positioning of the brand "Chile" (Sernatur, 2002). According to the NTA, the causes of the problem lay with the fragmentation of marketing strategies: there were multiple public organisations at the central and regional levels conducting parallel and uncoordinated marketing campaigns (C\&S Soluziona Servicios Profesionales, 
2004; P4 \& Tourism Resource Consultants, 2008). According to Sernatur, the background cause in this case rested with Act 1224. The act did not allocate enough power to Sernatur to enable it to organise and coordinate the public sector, thereby limiting Sernatur's ability to coordinate multiple and fragmented marketing strategies (Iglesias; Santelices, 2010). For Dipres, the core problem was the unknown impact of the campaigns implemented by Tourism Chile (Boston Consulting Group, 2007; Universidad de Chile, 2007). Several reports identified this problem and concluded that it was caused by the lack of Sernatur's monitoring of Tourism Chile's outcomes (C\&S Soluziona Servicios Profesionales, 2004; Dipres, 2005a). Dipres (2005a) evaluated Tourism Chile and concluded that, despite the fact that inbound tourism and foreign exchange had grown, there was no clear evidence that this growth resulted from the implementation of marketing campaigns. Once again, Dipres suggested that the background cause lay with a deficient design of the entire institutional framework: Acts 1224 and 19255 did not address the NPM principle of indicator measures and outcomes evaluation (Universidad de Chile, 2007). In order to address these problems, Sernatur proposed strengthening the NTA to improve its marketing skills and the creation of the marketing foundation in charge of coordinating marketing campaigns (Sernatur, 2006c). Because the foundation was not accepted by Dipres, Sernatur proposed to strengthen Tourism Chile. In turn, Dipres proposed the creation of a new NTO funded entirely by the government and based on the principles of the NPM approach, including outcome evaluations.

The third theme presented in Table 6.2 is planning. One of the core problems presented in the table is the lack of implementation of ZOITs. Act 1224 defines ZOITs as a planning mechanism to identify, plan, and protect areas with high values for tourism development. A decree from Sernatur was necessary to declare a ZOIT. Once declared, Sernatur conducted a process of territorial planning by formulating a management plan (Ministerio de Economía Fomento y Reconstrucción, 1975). Reports prepared during the pre-legislative stage highlighted that between 1975 and 2002 only five ZOITs were declared (C\&S Soluziona Servicios Profesionales, 2004; Sernatur, 2002). To address this low level of declaration, from 2004 Sernatur identified new ZOITs and towards 2008 ten new zones were declared (Sernatur, 2008b). Despite the increasing number of declarations, during the legislative stage 
different evaluations highlighted that these ZOITs were never implemented and that a lack of planning persisted (Boston Consulting Group, 2007; Universidad Católica de Valparaíso, 2009; Universidad de Chile, 2007).

Two causes of this problem of implementation were identified and agreed on by Sernatur, Minecon, and Dipres. First, the management plans were never formulated by Sernatur (Sernatur, 2006d, 2008b; Universidad de Chile, 2007), and second, the municipalities where plans for ZOITs were to be implemented were never involved (Sernatur, 2006d, 2008b). These organisations also agreed on the background cause: a broader problem of governance in several acts related to the process to declare a ZOIT. Act 1224 established that in order to formulate the plan, Sernatur should have coordinated the public sector. Due to the lack of powers of Sernatur described in section 6.2, the NTA was not able to coordinate the sector and therefore to formulate the plans (Boston Consulting Group, 2007; Universidad de Chile, 2007). Nor did Act 1224 consider involving municipalities in the process, which also limited the implementation of the plan (C\&S Soluziona Servicios Profesionales, 2004; Sernatur, 2006d, 2008b).

There was also a problem of governance with DFL 458 "Urbanism Act". According to the legally driven nature of the Chilean public sector, ZOIT management plans should be aligned with the official mechanism of planning defined by DFL 458 . However, ZOIT management plans were not recognised as an official mechanism by the Urbanism Act and, therefore, the plans were not legally binding (Sernatur, 2006d, 2008b; Universidad de Chile, 2007). Finally, Act 19300 "Basis of the Environment" was also identified as a background cause (Plumer, Rebolledo, Rivas, 2010). Because the aim of the ZOITs was to protect areas with relevant tourism resources, Act 19300 defines them as areas under official protection. Due to this definition, Act 19300 makes an environmental evaluation compulsory for any project planned inside a ZOIT. This implied a high level of bureaucracy for gaining approval for the implementation of tourism projects and even blocked tourism development inside certain ZOITs (Gonzales, Loader, Rivas, 2010). In order to address the lack of implementation of ZOITs, Sernatur originally proposed to involve municipalities in the process (C\&S Soluziona Servicios Profesionales, 2004; Sernatur, 2002, 2006c). However, after an evaluation conducted in 2006 (Sernatur, 2006d) during the 
formulation of the bill Sernatur proposed to align management plans for ZOITs with DFL 458. Although this proposal addressed the relation between Act 1224 and DFL 458, the relation between the first act and Act 19300 was not tackled during the formulation of the bill as it was presumed that the conservation bill being formulated in parallel should have addressed this aspect (Iglesias, 2010).

A second core problem related to planning is also presented in Table 6.2: the lack of tourism development in the SNASPE. Several reports suggested that this problem was caused by low levels of public and private investment inside protected areas (Conaf, 2004, 2007a, 2007b; Dipres, 2005b; P4 \& Tourism Resource Consultants, 2008; Sernatur, 2002, 2005, 2006b; Universidad de Chile, 2007). As described in Chapter IV, during the 1990s Conaf launched a concession programme to attract private investment in tourism facilities and address low public investment. Since the late 1990s four calls for bids were launched; the last one based on a MOU between Conaf and Sernatur. Towards the end of the 2000s low investment in the SNASPE persisted and protected areas were still very poor in tourism facilities (Boston Consulting Group, 2007; Conaf, 2007a; Universidad de Chile, 2007). In this case, Conaf and Sernatur differed in identifying the background causes. Conaf argued that the weakness of the institutional framework for conservation - in particular Conaf's organisational arrangement - was the background cause of this lack of development. This weakness was illustrated by the Conaf's institutional arrangement (a stateowned private organisation that operates with public funds) and also by the dichotomous nature of the roles of the agency (Conaf was in charge of forestry and conservation at the same time). This weakness affected the ability of the agency to promote tourism development in the SNASPE and thus to implement the concession system (Dipres, 2005b; Inter American Development Bank, 2007a). This was explained by the Conaf's former director:

We had a weak system of concessions for ecotourism - sure, I have to acknowledge it - but you have to recognise that it was the reflection of this very confusing Conaf institutional framework ... The limited number of concessions granted reflect the weakness of the institutional framework and Conaf's limitations. (Bau, 2010)

In contrast to Conaf's position, Sernatur argued that that the primary background cause was the weakness of Conaf's concession system (Boston Consulting Group, 
2007; Universidad de Chile, 2007). The results of the MOU signed between Sernatur and Conaf in 2005 to grant concessions in national parks helps explain Sernatur's view. The process to grant concessions was complex and the programme did not work as expected: Sernatur was not really involved, the process was hampered by Conaf's administrative problems, and the problem of low level of tourism development in the SNASPE persisted (Bau, Galaz, Lazo, Santelices, 2010). As explained by an interviewee from Conaf, at the end of the process only one concession was granted and the relationship between Conaf and Sernatur was seriously damaged:

Santelices (Sernatur Director) had a meeting with Catalina (Conaf Director) because they did not agree on the way the MOU was implemented. At the regional level there were fights among Sernatur and Conaf staff, it was chaos. We finally decided to close this concession programme. (Galaz, 2010)

Because of these differences between Conaf and Sernatur, the proposed solutions also varied. Conaf proposed to strengthen the existing concession programme and include it in the conservation bill under formulation. In turn - and because of the results of the MOU with Conaf - Sernatur suggested the creation of a new programme allocated to a different agency. In particular, Sernatur proposed that the Ministry of Public Lands should manage the programme; the implementation should be decided later, after the enactment of the conservation bill.

Finally, Table 6.2 shows that a lack of effectiveness also existed in terms of quality assurance. One core problem was identified: low private sector competitiveness (Sernatur, 2002, 2005, 2006b, 2007b). According to several reports, the cause of this problem lay with the industry's low levels of adoption of the existing quality assurance system (Boston Consulting Group, 2007; C\&S Soluziona Servicios Profesionales, 2004; Gobierno de Chile \& Ministerio de Economia Fomento y Reconstruccion, 2007; Inter American Development Bank, 2007b; P4 \& Tourism Resource Consultants, 2008; Sernatur, 2002, 2005, 2006b, 2006c, 2007b; Universidad de Chile, 2007). The system consisted of two elements: voluntary registration with Sernatur and a classification and qualification scheme. Although the system was voluntary, it was compulsory for accommodation providers (Ministerio de Economía Fomento y Reconstrucción, 1975). As discussed in Chapter IV, the system was created in 1975 with an important command and control emphasis. 
However during the $1980 \mathrm{~s}$ - and following a general trend in the entire Chilean public administration - the role of control in Sernatur was suppressed and Sernatur's powers to ensure the adoption of the system were eliminated (Ministerio de Hacienda, 1980). As a consequence, from the 1990s Sernatur did not control the implementation of the system and the number of registered companies steadily dropped, including accommodation providers for whom the registration was compulsory.

Evaluations conducted by IADB (2007b) and Sernatur (2005) show that in 2005 only $25 \%$ of the accommodation providers in Chile were registered with Sernatur, creating a serious problem of competitiveness. This situation was highlighted by the head of the quality assurance programme of Sernatur, who stated:

During 20 years we have classified 385 providers throughout the country, there were no incentives to be part of the system. (Loader, 2010)

Once again, the background cause was perceived to be the obsolete Act 1224 which contained the quality assurance system (Boston Consulting Group, 2007; Inter American Development Bank, 2007b; P4 \& Tourism Resource Consultants, 2008; Sernatur, 2002, 2005, 2007b). Evaluation reports concluded that the act and the system were obsolete and therefore the tourism market was extremely unregulated. In this context, from 2002 a new certification programme emerged to advance competitiveness and regulation. The new programme adopts standards of the International Organization for Standardization (ISO) in order to embrace internationally recognised quality measures; the programme considers voluntary certification as a market based mechanism of control rather than a command and control approach; although being voluntary, the certification becomes compulsory for adventure tourism in order to control activities that risk tourists' safety; and finally, the certification grants a label to certified companies and contains incentive and rewards to attract private companies to be certified. Because of the legally driven nature of the Chilean public sector, this new programme lacked legitimacy because it was not enacted by any act. Therefore, during the formulation of the bill Sernatur proposed to include the new programme as part of the tourism bill in order to implement it as the official quality assurance system. This was agreed to by Minecon-Dipres and the new scheme was included in the tourism bill. 


\subsection{Coordination}

Coordination relates to the abilities of Sernatur to bring together the different actors constituting the institutional framework for tourism. Table 6.3 shows that evaluations looked at coordination in the structure of the NTA and the roles of policy making, marketing, and planning.

Regarding the structure of the NTA and the role of policy making, coordination relates to the ability of Sernatur to organise the public sector for making policy (Universidad de Chile, 2007). Evaluation reports identified the lack of coordination within the government as the core problem and suggested that the cause of this problem was a lack of Sernatur leadership (C\&S Soluziona Servicios Profesionales, 2004; P4 \& Tourism Resource Consultants, 2008; Sernatur, 2002, 2005, 2006b; Universidad Católica de Valparaíso, 2009). This lack of leadership was highlighted by the Former Minister of Economy who stated:

When I took over as Minister I realised Sernatur was not considered inside the Ministry, there was no articulation with other public agencies...even though a council was created in 2002 to advance coordination, no major progress existed and the problems of coordination persisted. (Ferreiro, 2010)

Different background causes were identified by Sernatur and Minecon-Dipres. Sernatur suggested that Act 1224 did not allocate enough power to the NTA to tackle coordination (Sernatur, 2002) and therefore the NTA lacked a hierarchical position and powers as a decision making body (Sernatur, 2002, 2005, 2006b). This lack of a political body prompted the creation of the Council of Minister for Tourism in 2002 (C\&S Soluziona Servicios Profesionales, 2004). However, the Council only met a few times and the problem of coordination persisted (Inter American Development Bank, 2007b; Sernatur, 2005, 2006b, 2006c). In turn, Dipres-Minecon argued that the background cause was the centralised and hierarchical nature of the Chilean public sector. In line with Dipres, several reports concluded that the problem of coordination was inherent in the main characteristics of the public sector (centralised and hierarchical) and suggested that these characteristics - plus Sernatur's organisational weaknesses - were the background cause of the lack of coordination (Boston Consulting Group, 2007; P4 \& Tourism Resource Consultants, 2008; Universidad de Chile, 2007). 


\begin{tabular}{|c|c|c|c|c|c|}
\hline & & \multicolumn{3}{|c|}{ Problems } & \multirow[b]{2}{*}{ Proposed solutions } \\
\hline Issue & Theme & Core problem & Causes of the problem & Background causes & \\
\hline \multirow{3}{*}{ Coordination } & $\begin{array}{l}\text { Structure \& } \\
\text { Role of } \\
\text { policy } \\
\text { making }\end{array}$ & $\begin{array}{l}\text { Uncoordinated tourism } \\
\text { development } \\
\text { (Sernatur, Dipres) }\end{array}$ & $\begin{array}{l}\text { - Sernatur lacks leadership to coordinate the } \\
\text { public sector (Sernatur, Dipres) }\end{array}$ & $\begin{array}{l}\text { - Obsolescence of Act 122. The act does not allocate } \\
\text { powers to Sernatur in order to coordinate } \\
\text { the sector (Sernatur) } \\
\text { - Centralised and fragmented public sector (Dipres) }\end{array}$ & $\begin{array}{l}\text { - Create a Committee of Ministers for Tourism and } \\
\text { transform Sernatur into a subsecretariat (Sernatur) } \\
\text { - Create a technical secretariat whose } \\
\text { representative has position of subsecretary (Dipres) }\end{array}$ \\
\hline & $\begin{array}{l}\text { Role of } \\
\text { marketing }\end{array}$ & $\begin{array}{l}\text { Uncoordinated marketing } \\
\text { design implementation } \\
\text { (Dipres) }\end{array}$ & $\begin{array}{l}\text { - Fragmentation in tourism marketing (domestic } \\
\text { and international marketing are conducted by } \\
\text { different agencies) (Dipres) } \\
\text { - Fragmented international marketing campaigns } \\
\text { (Dipres) }\end{array}$ & $\begin{array}{l}\text { - Obsolescence of Act } 1224 \text { and failures in the } \\
\text { design of Act } 19255 \text { (Dipres) } \\
\text { - The fragmented nature of the public sector } \\
\text { (Dipres) }\end{array}$ & $\begin{array}{l}\text { - Create a Marketing Foundation (Sernatur) } \\
\text { - Create a Council of Marketing (Dipres) }\end{array}$ \\
\hline & $\begin{array}{l}\text { Role of } \\
\text { planning }\end{array}$ & $\begin{array}{l}\text { Lack of coordination during } \\
\text { the process for declaring } \\
\text { and implementing ZOITs } \\
\text { (Sernatur) }\end{array}$ & $\begin{array}{l}\text { - Sernatur cannot coordinate the planning } \\
\text { process (Sernatur) }\end{array}$ & $\begin{array}{l}\text { - Obsolescence of Act } 1224 \text { in the context of a } \\
\text { hierarchical public sector (Sernatur) }\end{array}$ & $\begin{array}{l}\text { - Align ZOIT with DFL 485. The Committee of } \\
\text { Ministers for Tourism declare ZOITs and the } \\
\text { Subsecretariat of Tourism coordinate formulation } \\
\text { and implementation (Sernatur) }\end{array}$ \\
\hline
\end{tabular}

Table 6.3: The issue of coordination 
Consistent with these different points of view, Sernatur and Dipres also had different proposals to address the problems. To tackle the lack of a hierarchical and political body, Sernatur proposed the creation of a Committee of Ministers for Tourism and the transformation of the NTA into a Subsecretariat (Sernatur, 2006c). The strategy behind these proposals was to legitimate the council already created in 2002 and allocate more political power to Sernatur based on its new structure of Subsecretariat (Santelices, 2010). Dipres agreed with the creation of a committee but suggested the creation of a Technical Secretariat as a new NTA to replace Sernatur. To address political power, the Secretariat should be placed in the Ministry of Economy and its representative should have the position of Subsecretary.

A core problem of coordination also existed with marketing: lack of coordination in marketing design and implementation (Boston Consulting Group, 2007). According to several reports, the cause of the problem lay with the fragmentation of marketing described in Section 6.2 (Boston Consulting Group, 2007; P4 \& Tourism Resource Consultants, 2008; Sernatur, 2002; Universidad de Chile, 2007). This lack of coordination was highlighted by a Member of Parliament who stated:

It was big mess, there were different organisations conducting campaigns: the ministers of Foreign Affairs, Education, Economy and others... but nobody coordinated it. (De Urresti, 2010)

Once again the background causes were seen to lie with Acts 1224 and 19255. Sernatur argued that Act 1224 did not allocate enough powers to the NTA to coordinate marketing (Iglesias, Rebolledo, Santelices, 2010), while Dipres suggested a problem of design in both acts. According to Dipres, these acts allocated the roles of domestic and international marketing to different organisations (Sernatur and Tourism Chile), which increased the existing problems of fragmentation and made marketing even more uncoordinated (Universidad de Chile, 2007). In order to address these problems - and because Dipres had not accepted the creation of the foundation mentioned in section 6.2 - during the formulation of the bill Sernatur proposed strengthening Tourism Chile. Unlike Sernatur, Dipres proposed to replace Tourism Chile with a Council of Marketing which would be in charge of domestic and international marketing and placed at the highest political level to guarantee coordination. 
Finally, Table 6.3 shows that lack of coordination also existed with planning. One core problem was identified: lack of coordination for the formulation of ZOIT management plans. Sernatur's lack of power to coordinate the formulation of the plans, and the obsolete Act 1224 which was not aligned with the existing planning mechanisms (DFL 485) were identified as the cause of the problem and the background cause respectively (Boston Consulting Group, 2007; C\&S Soluziona Servicios Profesionales, 2004; Sernatur, 2006d, 2008b; Universidad de Chile, 2007). To address this problem, Sernatur proposed a new process to declare and implement ZOITs which should be aligned to DFL 485 . Because Sernatur lacked the ability to influence and coordinate organisations placed at higher hierarchical levels, the new process is led by the Committee of Ministers for Tourism Development in order to guarantee coordination (García, M, Rebolledo, Rivas, Santelices, 2010). Dipres, who considered this issue a technical matter, agreed with the idea of aligning the declaration of ZOITs to DFL 485.

\subsection{Accountability and transparency}

Accountability and transparency refer to the ability of an organisation to give account of its results and be transparent in its decisions (Bevir, 2009; Hughes, 2003). Table 6.4 shows that accountability and transparency applied to the theme marketing and with reference to Sernatur and Tourism Chile. As discussed next, these two issues were generally addressed by several evaluation reports (C\&S Soluziona Servicios Profesionales, 2004; Dipres, 2005a; Sernatur, 2006a, 2007a, 2008a; Universidad de Chile, 2007).

Table 6.4 shows that a core problem of lack of transparency in Sernatur was identified by Minecon-Dipres. Act 19255 establishes that Tourism Chile needs to submit projects to Sernatur in order to receive public funds. Once Sernatur approves these projects, the funds are transferred to Tourism Chile for implementation (Ministerio de Economía Fomento y Reconstrucción, 1993). An evaluation conducted by Dipres (2005a) concluded that Sernatur's criteria to approve these projects were not clear enough (core problem). According to Dipres, the cause of this problem was the lack of procedural guidelines to support the approval and transfer of funds. Therefore, in 2006 Sernatur developed these guidelines (Ministerio de 
Economía Fomento y Reconstrucción, 2006) and gradually implemented them (Sernatur, 2006a, 2007a, 2008a).

A problem of transparency was also identified in Tourism Chile. Three core problems were identified by Dipres. First, there was a lack of information about how Tourism Chile's board selected priority markets and decided the allocation of funds in these markets (Dipres, 2005a). According to Dipres, the cause of this problem was the lack of an annual plan that gave account of the decisions of the board. Several interviewees suggested that this problem was more critical because private company representatives were in a majority on the board and had direct access to decision making. Therefore, a conflict of interest may have resulted as the interests of these companies may have induced decisions about priority markets and allocation of funds (García, M, Rebolledo, Szmulewicz, 2010). This was highlighted by a representative of Achiga, who mentioned:

We were part of Tourism Chile but we left it, we never knew how decisions in the board were made. (De la Fuente, 2010)

Act 19255 and the Tourism Chile's bylaws allowed Tourism Chile to commission external agencies to design and implement marketing campaigns. In this context a second core problem in Tourism Chile emerged: the lack of transparency in the procedure by which Tourism Chile commissioned these agencies (Dipres, 2005a; Universidad de Chile, 2007). This lack of transparency was also highlighted by a Sernatur representative who mentioned that on several occasions the NTO was not able to explain certain procedures and was asked to reimburse public funds. This lack of transparency was also commented on by a former Tourism Chile staff member who observed:

There was increasing doubt cast on the way Tourism Chile used public funds: about the correct and honest use of these funds. (Rebolledo, 2010) 


\begin{tabular}{|c|c|c|c|c|c|}
\hline \multirow[b]{2}{*}{ Issue } & \multirow[b]{2}{*}{ Theme } & \multicolumn{3}{|c|}{ Problems } & \multirow[b]{2}{*}{ Proposed solutions } \\
\hline & & Core Problem & Causes of the problem & Background causes & \\
\hline $\begin{array}{l}\text { Accountability } \\
\text { and } \\
\text { transparency }\end{array}$ & $\begin{array}{l}\text { Role of } \\
\text { Marketing }\end{array}$ & $\begin{array}{l}\text { In Sernatur } \\
\text { - Unclear criteria for approving } \\
\text { projects and transferring funds } \\
\text { to Tourism Chile (Dipres) } \\
\text { In Tourism Chile: } \\
\text { - Lack of information about how } \\
\text { funds are allocated on priority } \\
\text { markets (Dipres) } \\
\text { - Lack of information about } \\
\text { expenditures in campaigns (Dipres) } \\
\text { - There was no clarity about how } \\
\text { payments in kind made by the } \\
\text { private sector were measured }\end{array}$ & $\begin{array}{l}\text { - Sernatur does not have a guideline with } \\
\text { procedures to approve project presented by } \\
\text { Tourism Chile and transfer funds (Dipres) } \\
\text { - Lack of Tourism Chile annual plan (Dipres) } \\
\text { - Lack of mechanisms in Sernatur for } \\
\text { monitoring Tourism Chile expenses (Dipres) } \\
\text { - Lack of criteria to measure payments in } \\
\text { kind (Dipres) }\end{array}$ & $\begin{array}{l}\text { - Acts } 19255 \text { and } 1225 \text { that do } \\
\text { not address principles of NPM to } \\
\text { tackle accountability and } \\
\text { transparency } \\
\text { - Different perspectives to conduct } \\
\text { organisational management }\end{array}$ & $\begin{array}{l}\text { To strengthen Tourism Chile by: } \\
\text { - creating mechanisms for } \\
\text { transparency and accountability } \\
\text { - Incorporating new members } \\
\text { - Increasing control on Tourism } \\
\text { Chile } \\
\text { (Sernatur) } \\
\\
\text { To create a new NTO (Council of } \\
\text { marketing) that guarantee: } \\
\text { - mechanisms of transparency and } \\
\text { accountability } \\
\text { - participation of all relevant private } \\
\text { sector organisations } \\
\text { (Dipres) }\end{array}$ \\
\hline
\end{tabular}

Table 6.4: The issues of accountability and transparency 
According to Dipres (2005a), the cause of this problem lay with the lack of procedures and mechanisms in Sernatur for monitoring how the funds were spent after being allocated. Dipres argued that Sernatur did not provide the NTO with a clear mechanism to conduct calls for bids and therefore the NTO adopted its own procedure. For Tourism Chile's representative and the former Sernatur director, this problem did not exist. They suggested that if it occurred it was the exception (Moll, Santelices, 2010). The current CEO of Fedetur concurred with this position:

Dipres might have found some contracts for commissioning external agencies whose process of calls for bids was not clear, but if it occurred, it might have been an exception. (Yunis, 2010)

The third core problem of transparency in Tourism Chile relates to the contributions of the NTO to matching funds. Act 19255 establishes that Tourism Chile can contribute to the fund either by cash or payments in kind. Payment in kind may consist of hotel rooms or air tickets being provided and recognised as part of the matching fund (Ministerio de Economía Fomento y Reconstrucción, 1993). According to several interviewees, the core problem was the private sector increasingly contributed with payments in kind without clear criteria to measure nonmonetary contributions. The increasing amount of public funds allocated to Tourism Chile during the 2000s was identified as the cause of the problem. The NTO was unable to meet its contribution to the matching fund with cash and therefore increased its contribution by rising payments with unclear criteria to measure these payments. This was highlighted in a Dipres evaluation of Tourism Chile as follows: "The percentage of cash is too low in relation to the payments in kind, especially in air tickets... despite the fact that important discounts might exist, this contribution is valued based on market prices without even considering discounts" (Dipres, 2005, p.72).

According to Dipres, the obsolete Acts 1224 and 19255 are the background causes behind all the problems of transparency in Sernatur and Tourism Chile. These acts did not address the NPM principles of accountability and transparency and therefore Sernatur did not have mechanisms to provide checks and balances to the NTO. For Sernatur and Tourism Chile, however, these problems did not exist and they suggested that the Dipres' view was biased by a different perspective of 
organisational management (NPM). In this regard, Tourism Chile's former CEO argued that - in the interest of faster decision making - the private sector does not necessarily adopt the same bureaucratic procedures as the public sector. This may have influenced the view of Dipres about the lack of transparency in Tourism Chile:

Dipres investigated us for two years... when I became Tourism Chile CEO, Dipres did not want to approve the allocation of more funds until we were able to explain certain procedures... The problem was that Dipres' questions were related to administrative procedures. For example, they could not understand why I needed to pay six months in advance for going to a trade market; sure, in the public sector you pay after a service is provided but the private sector does not necessarily do the same... my answer in that case was simple and technical: I can pay closer to the date of the fair, but I cannot guarantee to have a good space in the fair if I do not pay in advance... in the private sector we are used to moving faster. (Moll, 2010)

To address the problems of accountability and transparency Dipres proposed the creation of a new NTO. They proposed that to guarantee accountability and transparency the new NTO should be entirely funded by the government, decisions should be made by the public sector in consultation with the private sector, and the board should be composed of industry association representatives rather than private companies. Because these problems did not exist for Sernatur and Tourism Chile, these two organisations suggested strengthening Tourism Chile and modifying the NTO's bylaws in order to tackle any possible problems of transparency. As discussed in the next chapter, Dipres imposed its power and during the formulation of the bill pushed forward the creation of a new NTO. During the formulation of the bill Dipres not only pushed forward its proposal to replace the NTO but also some of the other proposals described in this chapter. As discussed in Chapter VII, Dipres strongly influenced the content of the tourism bill, which confirms the critical role that Dipres played in the process of change in Sernatur.

\subsection{Discussion and Conclusions}

This chapter has investigated evaluation reports with implications for the existing tourism institutional framework (NTA a). As discussed here, the environmental conditions underlying the process may strongly influence these evaluations and in turn, evaluation may directly influence and shape the process of change. For instance, the change of government in 2000 triggered the identification of the 
limitations of the tourism industry in order to improve tourism development. This explains why evaluation reports conducted over this stage mainly focused on identifying these limitations. The change of government in 2006 triggered the formulation of the tourism bill; hence evaluation conducted at this stage aimed to provide solutions to address the identified problems and support the formulation of the bill. The reform of the public sector to address NPM also emerges as a relevant environmental condition that influences the interpretation of evaluation reports. The reform was put forward by Dipres and advocated improved governance and effectiveness in the public sector. This explains why evaluation reports conducted or commissioned by Dipres focused on governance, transparency, and accountability.

Drawing on the type of evaluations presented in Figure 6.1, a large body of internal and external evaluations of Sernatur and other related public agencies was analysed. Some of these evaluations were conducted in the general environment (Dipres, 2005a, 2005b; Inter American Development Bank, 2007a, 2007b; P4 \& Tourism Resource Consultants, 2008), while others were carried out as part of the process of change. In this last case evaluations were conducted during the entire institutional change process which confirms Parsons' (1995) and Sabatier's (2007) argument that evaluations exist across the entire policy process. For example, the National Tourism Agenda (Sernatur, 2002) gave public visibility to the failures in the tourism framework and triggered the pre-legislative stage and the systemic agenda. The National Tourism Policy and the Tourism Action Plan (Sernatur, 2005, 2006b) also evaluated the framework and identified failures; because these evaluations were supported by Minecon, they triggered a discussion inside the government and the agreement to tackle these failures (institutional agenda).

Other reports, such as BCG (2007) gave more political visibility to the sector, strengthened the idea of formulating a tourism bill and supported the opening of the policy window. The former Minister of Economy highlighted the importance of the BCG report and suggested that this report contributed to the tourism bill gaining momentum at the highest political level. Evaluations were also commissioned during the legislative stage. For example, the UChile report (2007) was commissioned by Minecon-Dipres to establish their position during the formulation of the bill and negotiate the decision agenda with Sernatur. Finally, reports also existed during 
decision making and influenced the debate in Parliament (e.g. Universidad Católica de Valparaíso, 2009). Reports also varied depending on the type of information they provided. Evaluation reports, such as the National Tourism Agenda (Sernatur, 2002), identified problems in the institutional framework with the ultimate goal of establishing a baseline of the tourism sector. Other reports - such as the BCG (2007), the National Tourism Policy (Sernatur, 2005), and UChile (2007) evaluated the institutional framework but in those cases, evaluations were used to identify and propose solutions to address the identified problems. A third stream of reports provided information to fulfil a broader goal, which is the case of Dipres evaluations to assess organisational performance based on the NPM approach.

The evaluation reports examined the structure and roles of the institutional framework (themes) and explored four interconnected issues: funding, effectiveness, coordination, and accountability. The analysis conducted in this chapter suggests that the focus of the evaluations varied depending on who commissioned them. For example, evaluations conducted by Sernatur focused on the issue of funding while evaluations conducted by Dipres emphasised transparency and accountability. This is particularly important because an understanding of who commissioned and what drove the evaluations is critical for interpreting the evaluation focus and results. For the analysis of these issues and themes, four aspects were examined: the core problems, the causes of the problems, the background causes and the proposed solutions. Evaluations conducted or commissioned by Sernatur and Dipres usually differed in what was identified as the core problems and the causes of the problems. Sernatur, Minecon, and Dipres generally agreed that the broader issue of governance was the background cause behind these problems. However, these organisations illustrated governance in different ways. Sernatur suggested that the problem of governance lay with the obsolete Act 1224, while Dipres identified a failure in the entire institutional framework. Evaluation reports commissioned or conducted by Sernatur illustrated the obsolescence of Act 1224 in three aspects. The first aspect is the lack of a political body with powers to coordinate the sector. The lack of a strong political body resulted because the structure of Sernatur was created as a centralised public service depending directly on the Ministry of Economy (Ministerio de Economía Fomento y Reconstrucción, 1975). It implied that the NTA was placed at the bottom of the hierarchy of central government, which emerges as critical 
considering the centralised and hierarchical nature of the Chilean public sector (Chapter IV). According to Sernatur, this administrative position affected Sernatur's political power and caused problems in funding, effectiveness, and coordination with regard to its roles of policy making, marketing, planning and quality (C\&S Soluziona Servicios Profesionales, 2004; Sernatur, 2002, 2005, 2006b). This was stated by a Member of Parliament:

It was generally agreed in the industry, even here in the Chamber and among deputies of different parties. Sernatur was completely obsolete as a public organisation, it was required to give Sernatur a higher political position, a higher political weight inside the government. (Goic, 2010)

A second aspect used by Sernatur to illustrate the problem of governance was Sernatur's outdated internal organisation (Inter American Development Bank, 2007b; Sernatur, 2006b). The structure of Sernatur and its internal organisation were defined in 1975. In spite of minor changes carried out during the 1980s and 1990s, the structure had remained the same for three decades. The number of Sernatur staff was also defined in 1975. Although some changes occurred toward the end of the 1990s, the staff composition was not enough for Sernatur to tackle its roles (C\&S Soluziona Servicios Profesionales, 2004; Universidad de Chile, 2007). Finally, Sernatur also illustrated the problem of governance by the lack of connection between the roles defined by Act 1224 and the roles that the NTA should have (Inter American Development Bank, 2007b). During the last decades new acts were enacted with direct implications for the tourism sector. These new acts also implied new roles for Sernatur; however no modifications to Act 1224 were made and Sernatur was unable to address these new roles. The issue of planning, particularly with respect to ZOITs, clearly illustrates this. During the 1990s, Act 19300 "Bases for the Environment" was enacted. The act considers that Sernatur must provide a technical report in order to approve or reject studies of environmental impact in areas declared as ZOITs. However, this role was never contained in Act 1224 and therefore Sernatur did not have the staff and skills to prepare these reports. This was highlighted by the former Sernatur director who stated:

Sernatur had a set of roles that were out of context, for example Sernatur could have declared public holidays. Can you figure Sernatur declaring public holidays? It could have been a mess. This shows you that Sernatur had lots of powers, however many of them were useful in other contexts, in the context of the 1970s when tourism was a recreational activity rather than an economic sector. (Santelices, 2010) 
In contrast to Sernatur's perspective, Dipres argued that the problem of governance was illustrated by a failure in the design of the entire public institutional framework: Act 1224 concentrated policy roles in the same agency (Sernatur) and Act 19255 allowed Sernatur to be part of Tourism Chile under a scheme that created problems of effectiveness, accountability, and transparency (Universidad de Chile, 2007). Act 1224 defined the structure of Sernatur and allocated the roles of policy formulation, implementation, and evaluation to the same agency. According to Dipres, this did not embrace the principle of disaggregation of administrative units in the public sector and affected Sernatur's ability to make policy effectively (Boston Consulting Group, 2007; Universidad de Chile, 2007). This was illustrated by a Minecon representative:

There was a problem of institutional design; there was nobody in charge of policy design. We needed to separate the policy roles and create a body in charge of policy formulation and evaluation different to Sernatur. That was the way to move forward policy making and address governance and efficiency. (Zúñiga, 2010)

An interviewee from Sernatur also highlighted this situation and suggested that the concentration of powers reflected the political context when the NTA was created: Sernatur was created under a period of dictatorship which reproduced the ideology of the regime in terms of concentrating powers rather than desegregating them (Plumer, 2010).

According to Minecon-Dipres the problem of governance was also illustrated by Act 19255 and the creation of Tourism Chile as the NTO. Three issues affecting governance resulted from the implementation of Act 19255. First, the private sector was inadequately represented in the NTO. This lack of representation could be a result of demanding criteria required for private companies to become members of Tourism Chile. These criteria included being able to pay memberships and having high quality services defined as "exportable tourism services". According to Dipres, the payment of membership fees limited smaller companies' ability to become part of the NTO, while the use of the concept of "exportable tourism services" promoted the incorporation of the biggest companies to the detriment of the smallest (Dipres, 2005a). 
This problem of representation was highlighted at the central level by the former Minister of Economy:

Tourism Chile was not composed of the industry association representatives, it was conformed of the private companies with more power to be there. (Ferreiro, 2010)

At the regional level this perception also existed and a regional tourism organisation's representative commented:

It was like a club composed of the tourism biggest companies... As a region we were never represented by Tourism Chile and its campaigns overseas, even though some of the funds for these campaigns came from the government. (Figueroa, 2010)

A problem of representation also existed on the board of the NTO. The board consisted of representatives of Sernatur and the private companies who were members of Tourism Chile. Until 2005, Sernatur had just one representative on the board. After the evaluation conducted by Dipres in 2005, four new representatives from Sernatur were included as a condition imposed by Dipres to transfer funds to Tourism Chile (Sernatur, 2008a). In the case of the private sector, its representatives were selected based on the contribution that individual private companies made to the matching fund. As a result, companies with larger contributions had more representatives on the board (Boston Consulting Group, 2007; SCL Econometrics S.A, 2008; Universidad de Chile, 2007). Finally, different reports also concluded that the funds were "captured" by the biggest companies in the NTO (Boston Consulting Group, 2007; Universidad de Chile, 2007). As the board was composed of private stakeholders rather than industry association's representatives, decision making tended to be monopolised by the bigger companies who decided marketing strategies in their own interests. Minecon-Dipres agreed with this argument and suggested that the "capture" resulted from the matching fund scheme proposed by Act 19255. In particular, it was suggested that marketing is a public good and as such marketing strategies should not be funded or decided by private companies (Boston Consulting Group, 2007; SCL Econometrics S.A, 2008; Universidad de Chile, 2007). This was even illustrated by a Tourism Chile member in an evaluation reports: "The objective of Tourism Chile is promoting Chile overseas... however there is a contradiction because Tourism Chile also has to represent its members, so 
in international campaigns does Tourism Chile represent the country or its members?" (SCL Econometrics S.A, 2008, p. 22).

Although this problem of capture did not exist for the former Sernatur director, for the sub-director of the NTA capture did occur which suggests that no common position existed even inside Sernatur. In this regard the sub-director stated:

There was a perception that the biggest companies' members of Tourism Chile were capturing public funds for their own interests. Although I think the problem existed, I think the problem was not the capture itself... for me, the problem was that the incentives were put just to attract these big companies to be part of Tourism Chile. (Iglesias, 2010)

These different perspectives demonstrate the lack of a single and common position. This also helps explain how interviewees' responses were cross checked with evaluation reports in order to have a better interpretation of the factors influencing the process of change.

As emphasised in this chapter, the discussion during the process was strongly influenced by the broader issue of governance and its principles of accountability, transparency, performance measure, and disaggregation of administrative units in the public sector. Because this broader issue directly relates to the reform in the public sector put forward by Dipres, it is also possible to suggest that governance emerges as a key environmental condition underlying and influencing the process of change in Sernatur. As also noted, different proposals emerged due to the differences between Sernatur and Dipres regarding governance.

During the formulation of the bill, and based on the idea that a stronger hierarchical position would imply stronger political power, Sernatur proposed strengthening Sernatur by transforming the NTA into a Subsecretariat (Sernatur, 2006c). This would allow Sernatur to reorganise the agency to address funding, effectiveness, and coordination for the roles of policy making, planning, and quality assurance. To tackle the problems of representation and transparency in Tourism Chile - and because the creation of a marketing foundation was not accepted by Dipres Sernatur proposed a reorganisation and strengthening of Tourism Chile as the NTO (Sernatur, 2006c). In contrast, and drawing on the NPM approach, Minecon and 
Dipres suggested the allocation of policy roles among different organisations, which implied the creation of a separate and specialised agency in charge of policy formulation and budgeting: the technical secretariat as the NTA (Universidad de Chile, 2007). To address the problem of governance in the NTO, Minecon-Dipres suggested the creation of a new NTO to replace Tourism Chile. In order to address transparency, Dipres proposed that the board of the new NTO would include private sector representatives, but, unlike the Tourism Chile scheme, the board should be composed of tourism association representatives rather than those from private companies. In addition, and in order to avoid the problems of capture of funds, Dipres suggested that the NTO would be entirely funded by the government.

As presented in the next chapter, Act 20423 partially incorporated the proposals of Sernatur and Dipres. Thus, the next chapter investigates how and why certain proposals were omitted from or incorporated into the act and why particular outcomes resulted from the process. In the light of the integrated conceptual framework (Figure 2.4) the investigation of these outcomes requires examining two critical aspects: the process itself and the factors influencing the process. Those aspects are examined next. 


\section{Chapter 7 The outcomes of the process of change and the influence of the process and the factors on these outcomes}

\subsection{Introduction}

As shown in Figure 1.1, the process of change in the case not only led to changes in the NTA (Sernatur) but also created a set of new organisations performing roles in tourism - the new institutional system for tourism development. Following the conceptual framework (Figure 2.4), the investigation of these results requires consideration of two interrelated elements examined in the previous chapters: the process of change and the influence of the environmental conditions. The features of the policy process discussed in Chapter II are used to investigate the influence of the process of change and the environmental conditions on Act 20423. As discussed in Section 2.6.3, these features are consultation, participation, disagreement, negotiation, power, and acceptance. Consultation and participation were uneven and tended to concentrate at the beginning of the pre-legislative stage (systemic agenda) and towards the end of the legislative stage (debate in Parliament). In turn, disagreement, negotiation, use of power, and acceptance emerged as a consequence of the greater involvement of Minecon (Ministry of Economy) and Dipres (Budget Office) during the legislative stage. As discussed in the previous chapters, at the legislative stage there were two opposing perspectives to address the process of change. Sernatur advocated for changes in the structure of the NTA to tackle problems in the roles, while Minecon and Dipres proposed changes in the roles to address problems in the structure. These different perspectives triggered disagreement and Sernatur and Minecon-Dipres negotiated to put forward their proposals. In this negotiation, Dipres imposed its power and pushed forward its proposals to be included in Act 20423. In turn, during the formulation of the bill Sernatur accepted this imposition but continued lobbying for changes to the bill in Parliament. A change in the distribution of power during the debate of the bill in Parliament gave Sernatur a better margin to negotiate and successfully lobby for these changes. As presented here, these features varied during the time with direct impact on the process. This is presented in Figure 7.1 and examined next. 


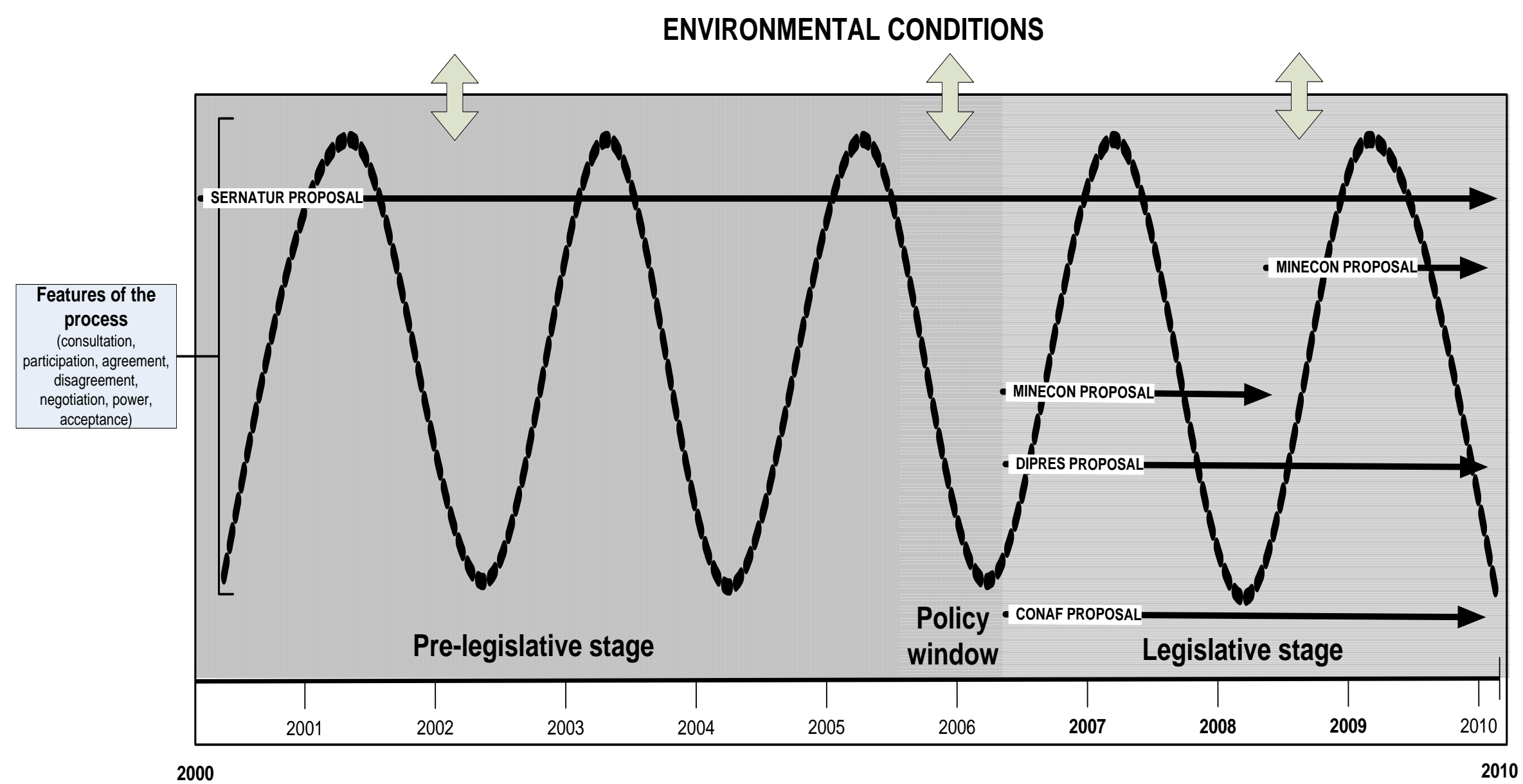

Figure 7.1: Features of the policy process: consultation, participation, agreement, disagreement, negotiation, power, and acceptance 
Figure 7.1 shows the stages of the process that led to the changes in Sernatur (prelegislative, policy window, and legislative stages). The figure presents the features of the policy process (dashed line) and shows that the balance and nature of these features vary during the process of change. During the pre-legislative stage there was consultation and participation. Towards the end of this stage and during the policy window, consultation and participation tended to disappear. Consultation and participation emerged once again during the legislative stage, although at this stage these features were concentrated during the debate of the bill in Parliament.

The main agencies involved in the process were Sernatur, Minecon, Dipres and Conaf (the Forest Service). Sernatur was involved throughout the entire process while Dipres, Minecon, and Conaf became involved during the legislative stage. These organisations agreed there was a problem of governance in the institutional framework; however some of their proposals for addressing this problem differed and disagreement emerged. To tackle disagreement negotiation was conducted and the organisations used different tactics to influence the process (power and acceptance). As discussed in Chapter II, and drawing on Bramwell (2006), Bramwell and Meyer (2007), Dredge (2006a), Reed (1997), and Thomas and Thomas (2005, 2006), the features of negotiation, power, and acceptance show how these organisations mobilised to influence decisions and what tactics they used to push forward their proposals

During the entire process of change, Sernatur's proposals focused exclusively on the structure and roles of the NTA and transforming Sernatur into a Subsecretariat (C\&S Soluziona Servicios Profesionales, 2004; Sernatur, 2002, 2005, 2006b, 2006c). The argument underlying this proposal was that a change in the structure was required to tackle problems in the roles of Sernatur. As there were no other agencies involved during the pre-legislative and policy window stages, there was no disagreement at this point. During the legislative stage - that is, once Dipres became involved in the process of change - this agency proposed the examination not only of the NTA but also of the other organisations composing the tourism institutional framework (Iglesias, Rebolledo, Rodríguez, Zúñiga, 2010). This occurred because of the evaluations Dipres had of Tourism Chile and Conaf (Dipres, 2005a, 2005b), which concluded that problems in the roles of these organisations directly affected the 
performance of the NTA and the entire tourism framework. Therefore, Dipres proposed to change the roles in the framework and suggested that any change in the structure should be a result of major changes to the roles. In addition, and because of Dipres' advocacy of the New Public Management approach (NPM) and the principle of disaggregation of the public sector in administrative units, Dipres proposed the allocation of roles to separate agencies. The proposal of Dipres was embraced by Minecon and an alliance between these organisations emerged. Because of this alliance to address a similar proposal, Figure 7.1 places the Dipres' proposal closer to that of Minecon.

The proposal of Minecon-Dipres was not accepted by Sernatur and disagreement emerged. To address this disagreement, Minecon commissioned the Universidad de Chile study to negotiate with Sernatur (Ferreiro, 2010). Sernatur did not accept the results of the study arguing that it was strongly influenced by Dipres and disagreement persisted (Iglesias, Rebolledo, Santelices, 2010). At this point Sernatur, being aware of the power of Dipres, accepted the proposal of Dipres to change the roles of the framework and separate policy roles but insisted on the creation of a Subsecretariat of Tourism. The Subsecretariat was not accepted by Dipres and disagreement persisted. Hence Marcelo Drago - the person mentioned in Chapter V as an expert acknowledged by all parties - was commissioned to support the negotiation. At this point, Dipres once again imposed its power and Sernatur had no option but accept the proposal of Dipres (Iglesias, Rebolledo, 2010). This shows that when disagreement existed, the selection of particular proposals did not result from negotiated agreement of the parties but was based on the imposition of the power of Dipres and acceptance by the less powerful organisation.

In 2007 the bill was submitted for debate in Parliament (Cámara de Diputados de Chile, 2008a). As this point - and as a result of the political appointment of the Sernatur sub-director as the advisor to the Minister of Economy - during the debate in Parliament Minecon became an ally of Sernatur. This new alliance is presented in Figure 7.1 by now placing Minecon's proposal closer to Sernatur's. This new alliance triggered changes to the bill and once again there was disagreement, negotiation and the use of power. As discussed later, Sernatur/Minecon challenged Dipres' power and pushed forward the creation of a Subsecretariat of Tourism 
(Iglesias, Rodríguez, Rebolledo, Santelices, 2010). Dipres did not accept the change and President Bachelet resolved the issue in favour of the creation of the Subsecretariat (Iglesias, Rebolledo, Santelices, 2010). Later on the bill was amended, discussed, and passed in the Chambers of Deputies and Senators (Cámara de Diputados de Chile, 2009c; Senado de la República de Chile, 2009a, 2009b). Two political factors are critical to explain the changes occurring in Parliament. The political appointment of the Sernatur sub-director changed the dynamics of power between Sernatur, Dipres, and Minecon. Minecon now supported Sernatur and strengthened the position of the NTA to negotiate changes in the bill and pushed forward the creation of the Subsecretariat. This appointment was complemented by the commitment of President Bachelet to the bill. Because of the involvement of the Sernatur Sub-director in the formulation of Bachelet's programme of government described in Chapter V, the amendments imposed by the President were strongly influenced by Sernatur's former sub-director.

As discussed in this Chapter, Dipres influenced the formulation of the bill while Sernatur influenced the debate in Parliament. Because the bill mostly addressed the proposal of Dipres (a change in the roles of the institutional framework), the next sections present the analysis based on the roles of policy making, marketing, planning, and quality assurance. Figure 7.2 will be used to support the analysis of these roles. The figure presents the organisations composing the existing and the resulting institutional frameworks. As noted in the figure, these organisations perform different policy functions: approval, design, and implementation.

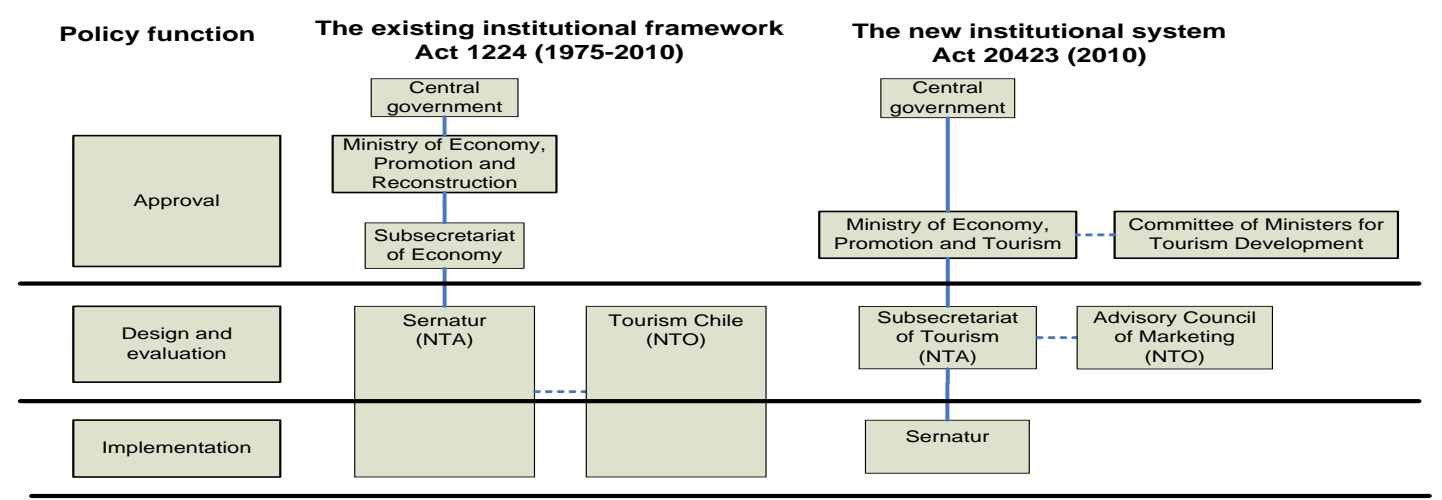

Figure 7.2: A comparative analysis of the existing and resulting institutional frameworks 


\subsection{The role of policy making}

As presented in Figure 7.2, Act 1224 established that the Ministry of Economy was in charge of policy approval and Sernatur concentrated the roles of policy formulation, evaluation, and implementation (Ministerio de Economía Fomento y Reconstrucción, 1975). After the tourism bill was enacted, policy roles were allocated among different agencies triggering the creation of a new institutional system. The new system consists of a Subsecretariat of Tourism (NTA) in charge of policy formulation and evaluation, a Committee of Ministers for Tourism Development in charge of policy approval, and Sernatur in charge of implementation (Ministerio de Economía Fomento y Reconstrucción, 2010).

Evaluations conducted during the process help explain how and why these changes emerged. Evaluation reports conducted or commissioned by Sernatur and MineconDipres coincided in allocating policy approval and implementation to a Committee of Ministers and Sernatur respectively; however these reports differed regarding policy formulation and evaluation. As discussed in Chapter VI, Sernatur proposed keeping policy formulation and evaluation in the same agency but Minecon-Dipres suggested allocating these roles to a separate agency (Iglesias, Rebolledo, Rodríguez, Santelices, Zúñiga, 2010). During the formulation of the bill, these opposing proposals caused disagreement between Minecon-Dipres and Sernatur and triggered the study by UChile. Strongly influenced by Dipres, UChile suggested a change in the entire institutional framework and proposed the creation of a technical secretariat in charge of policy formulation/evaluation, a Committee of Ministers in charge of coordination and policy approval, and Sernatur in charge of policy implementation (Universidad de Chile, 2007). Being aware of the power of Dipres, Sernatur's representatives accepted the proposal of UChile but suggested that if a new NTA was going to be created, that agency should be a subsecretariat. Because of its traditional lack of interest in creating new public agencies Dipres did not accept the creation of the subsecretariat, so disagreement and negotiation persisted (Iglesias, Rebolledo, Santelices, 2010).

As a result of the involvement of Marcelo Drago during the negotiation a proposal that partially met the interests of Sernatur and Dipres emerged: the creation of a new 
NTA (technical secretary) whose representative has the position of subsecretary (Iglesias, Rebolledo, 2010). Sernatur accepted the creation of a technical secretary being aware that changes might be achieved during the debate in Parliament (Iglesias, Santelices, 2010). In turn, Minecon-Dipres accepted the creation of the position of subsecretary arguing that the bill would be rejected if this position at least was not created. This last point was illustrated by a Minecon representative who stated:

UChile proposed that the technical secretariat was led by a technical secretary... to be honest, if we did not propose at least improving the political position of the secretariat representative and create the position of subsecretary, the bill was not even going to be submitted. (Zúñiga, 2010)

The bill submitted to Parliament mostly addressed the structure of the NTA and the roles of policy making proposed by Dipres (Iglesias, Ferreiro, Rebolledo, Santelices, Szmulewicz, Zúñiga, 2010). Several evaluation reports and policy and political factors are useful to explain why this occurred. Evaluations conducted by Dipres highlighted the limited skills of Sernatur to address policy formulation. Therefore, the creation of a new NTA was required. If a new NTA was going to be created, the new structure should address the principle of disaggregation of administrative units put forward by Dipres, in particular because under the existing framework Sernatur concentrated all the policy roles. Because of the lack of interest of Dipres in creating new public organisations, Dipres proposed the creation of a technical secretariat rather than a subsecretariat. Finally, the power of Dipres in the public sector - plus the greater involvement of the agency during the formulation of the bill - allowed Dipres to influence the formulation of the bill and put forward its proposal (Iglesias, Rebolledo, Rodríguez, Santelices, Zúñiga, 2010). The influence and power of Dipres was highlighted by the former Minister of Economy:

Dipres has been reluctant to create new public organisations... Dipres was never interested in creating a Subsecretariat; during the formulation they blocked us. I remember that the creation of a technical secretariat was an imposition of Dipres, they wanted to separate roles. (Ferreiro, 2010)

Towards the end of 2007 the bill was submitted to Parliament. When the Commission of Tourism of the Chamber of Deputies threatened to reject the bill if the technical secretariat was not replaced by a subsecretariat, Minecon negotiated inside the government to amend the bill (De Urresti, Goic, Iglesias, Recondo, 2010). 
Because there was not agreement between Sernatur/Minecon and Dipres, President Bachelet used her power and instructed the amendment to create the Subsecretariat (Iglesias, Rebolledo, Santelices, 2010). The bill was later passed in the Chambers of Deputies and Senators. At this point the name Ministry of Economy, Promotion and Reconstruction was replaced by the Ministry of Economy, Promotion and Tourism. This change was suggested by members of the Chamber of Senators and largely accepted as noted in the procedures of the Chamber (Senado de la República de Chile, 2009a, 2009b). Although the change may seem cosmetic, it can mean important changes in terms of political commitment if the Minister assumes his role as leader of the tourism sector (Plumer, 2010).

Several political factors help explain the creation of the subsecretariat. The power of the Sernatur sub-director in his position of advisor allowed him to handle the bill in Parliament and be directly involved in the negotiation with the Members of Parliament. In this context, the lobby conducted by Minecon/Sernatur to create the Subsecretariat was much easier (Iglesias, Rebolledo, Santelices, Szmulewicz, 2010). In parallel, the members of the Commission of Tourism agreed that the technical secretariat was not the best solution to tackle the structure of the NTA (De Urresti, Goic, Recondo, 2010). Using the hierarchical and legally driven nature of the public sector as the main argument, the commission opposed the creation of the technical secretariat on the grounds that existing secretariats lacked power and influence in the public sector (Goic, 2010). As mentioned by several interviewees, the importance of the creation of the subsecretariat in spite of Dipres' opposition lies in the fact that Sernatur challenged the power of Dipres (Arriagada, Iglesias, Ferreiro, García, M, Rebolledo, Santelices, Szmulewicz, 2010). This was highlighted by the former Minister of Economy:

A Dipres representative told me: Bachelet programme has the creation of seven Subsecretariats; if we create them it will drive us crazy. Even though the creation of this Subsecretariat (of tourism) makes sense, we are not going to create it because if we do it we will have to create the others. (Ferreiro, 2010)

Although the power of Dipres was challenged, a Dipres representative argued that this challenge did not occur and that the creation of a subsecretariat was always a possibility. In fact, this representative argued that for Dipres a Subsecretariat of Tourism was a feasible structure but - because of the interest of the President in the 
tourism bill - Dipres proposed to create a technical secretariat to have a margin of negotiation in case the bill was amended in Parliament. According to this Dipres' representative:

The technical secretariat emerged from Dipres as a way to negotiate. We knew that the bill could have even ended with the creation of a separate Ministry; in fact the President liked the idea of a Ministry of Tourism... Because you know that after any bill is submitted to Parliament everyone keeps playing the game (Minecon and Sernatur talked to Members of Parliament, Members of Parliament threatened the government, etc.) during the discussion in Parliament we said ok, we will give you a subsecretariat but don't ask us for anymore. This is the game, permanent negotiation. (Rodríguez, 2010)

\subsection{The role of marketing}

Figure 7.2 shows that the existing NTO was Tourism Chile. Tourism Chile was created from matching funds from the public and private sectors and charged with marketing approval, formulation, and implementation. Due to the NTO's focus on international marketing, the roles of domestic marketing were conducted by Sernatur. As a result of the process of change, Act 20423 created the public-private Advisory Council of Marketing as the new NTO. The new agency is in charge of both international and domestic marketing. The changes in the NTO were also driven by Dipres' proposal of disaggregating the public sector into administrative units. The Council is in charge of formulation and evaluation of marketing strategies, the Committee of Ministers approves these strategies, and finally Sernatur implements them.

During the pre-legislative stage Sernatur proposed strengthening the structure of Tourism Chile (C\&S Soluziona Servicios Profesionales, 2004; Sernatur, 2002, 2005). As discussed in Chapter IV, during the policy window stage Sernatur proposed transforming Tourism Chile into a foundation for marketing (Sernatur, 2006c). During the legislative stage - in particular during the formulation of the bill - Sernatur proposed the creation of this foundation but Minecon-Dipres did not accept it (Iglesias, Rebolledo, 2010). In turn, Minecon-Dipres suggested the allocation of marketing roles to separate agencies. In this case, and as with the role of policy making, the proposals suggested by Sernatur and Minecon-Dipres differed in one critical aspect. Sernatur directly focused on changes in the structure of the 
NTO, while Dipres focused on changes in the allocation of roles. These different proposals led to disagreement between Sernatur and Minecon-Dipres and negotiation started (Ferreiro, Iglesias, Montes, Rebolledo, Santelices, Zúñiga, 2010). During this negotiation, the results contained in the BCG and UChile reports increased the differences between Sernatur and Minecon-Dipres. The reports highlighted problems of governance, transparency, and accountability in Tourism Chile. Because Dipres had already identified the same problems (Dipres, 2005a), these reports strengthened the position of Dipres in that major change in the roles of marketing was required. As a consequence, agreement was never achieved (Iglesias, Rebolledo, Rodríguez, Santelices, Zúñiga, 2010) and Dipres imposed its power to push forward its proposal (Iglesias, Rebolledo, Rodríguez, 2010).

Several factors help explain the creation of the new NTO. Once again Dipres' power in the public sector is a critical political factor. Dipres put forward its proposal and the changes in marketing were primarily addressed from the point of view of Dipres. The NPM approach and the principle of disaggregation of administrative units also emerge as key policy factors to explain these changes. Dipres advocated the allocation of marketing approval, formulation, and implementation to separate agencies. In doing that, Dipres proposed a strong NTO be in charge of marketing formulation and evaluation. The characteristics of the new NTO were also influenced and shaped by evaluation reports conducted by Minecon-Dipres. As discussed in Chapter VI, these reports identified problems of representation in Tourism Chile, a capture of public funds by the private sector, and finally the fact that the private sector composing Tourism Chile was unable to meet the matching fund. Because of these evaluations, Minecon and Dipres advocated the creation of a new NTO. As stated by the former Minister of Economy:

Dipres did not like Tourism Chile, never did ... there was a problem in there, so we directly proposed that change. (Ferreiro, 2010)

To address the problems identified in these evaluations, Dipres proposed a new NTO composed of representatives of private tourism organisations as a way of guaranteeing representation. Arguing that marketing is a public good that should not be captured by a group, Minecon-Dipres put forward the creation of a council to be led by the State. Thus, the council brings back the roles of marketing approval, 
formulation, and implementation to the State under the argument that the marketing, as a public good, must be provided and controlled by the government (Zúñiga, 2010). In this scheme, the public sector defines the priorities of marketing and private companies are not able to capture public funds for their own interest. Finally, Act 20423 established that marketing is wholly funded by the state.

During the debate in Parliament, in particular during the consultation with the private and academic sectors, there were no criticisms regarding the new NTO even though a Tourism Chile representative also attended the sessions (Cámara de Diputados de Chile, 2008a, 2009b). This agreement changed after the National Tourism Forum (Chapter V) when private sector members of Tourism Chile manifested their disagreement with the creation of the council and asked the government to change the bill (Sociedad Chilena de Investigadores en Turismo, 2008). In spite of this request, the bill was discussed and passed in the Chamber of Deputies without changes. During the debate in the Senate, Tourism Chile was better organised and once again manifested its disagreement with the bill (Arriagada, Magniani, Moll, Rebolledo, 2010). At this point Tourism Chile - represented by the recently created Fedetur - lobbied to keep Tourism Chile as the NTO (Arriagada, Yunis, 2010). This proposal was not embraced by the Chamber and at the end Fedetur achieved just one change: Sernatur could still be part of Tourism Chile for two years after the enactment of the bill under the same scheme existing before the enactment of the bill. This was described by a member of Tourism Chile who stated:

We proposed to delete the entire part of the bill containing the council ... however Dipres pressured in parliament to keep this part. (Arriagada, 2010)

Several factors explain the disagreement and the lack of changes during the debate in Parliament. The lack of involvement of the private sector with the commission in charge of formulating the bill explains the disagreement over Tourism Chile in Parliament. Interviewees who are members of Tourism Chile emphasised that because of this lack of involvement, they learnt the contents of the bill just after its submission to Parliament (Arriagada, García, R, Magnani, Meliboski, Moll, 2010). This lack of involvement was also highlighted by a Member of Parliament:

The structure of marketing does not emerge from a consensus between the private and the public sector... this model (the structure of the NTO) did not 
emerge from the public sector in consultation with the private sector ... this model was just thought from the top. (Recondo, 2010)

In spite of the disagreement over Tourism Chile and the lobby conducted by Fedetur to change the bill in Parliament, the bill was enacted in 2010 with no major changes. The fragmented nature of the private sector and the power of Dipres are key factors that explain this. During the consultation conducted in Parliament one part of the private sector - the one forming part of Tourism Chile - disagreed with the bill and demanded maintaining Tourism Chile as the NTO. However, another part of the private sector which was not part of the NTO supported the creation of the council (Cámara de Diputados de Chile, 2009a, 2009b). In this context, negotiating any change in Parliament was complex due to the lack of a single demand (Recondo, 2010). This fragmentation was described by a Member of Parliament:

The private sector was never organised, this was a problem during the debate in Parliament... there was no single counterpart to negotiate with. (Recondo, 2010)

Although in the Chamber of Senators Fedetur lobbied for changes in the bill, these changes did not occur because of the power of Dipres to limit any change (Arriagada; Rodríguez, 2010). This power was highlighted by a Dipres representative who mentioned:

There was a conflict regarding marketing, I remember that during the formulation we agreed the change with Sernatur (the creation of the council) and suddenly in Parliament a change was requested... there was some lobbying and some companies lobbied in Parliament, with Santelices (Sernatur director) to change the council... we were firm and did not accept it. (Rodríguez, 2010)

This power was also acknowledged by the Sernatur sub-director, who stated:

I think we were a bit soft in this negotiation and Tourism Chile should have been kept... In 2010, when the bill was almost ready to be enacted, I remember saying that the bill still needed some discussion in this regard but Dipres did not accept any other change. (Iglesias, 2010)

\subsection{The role of planning}

The role of planning involves tourism development in both the National System of Protected Areas (SNASPE) and Zones of Interests for Tourism Development (ZOITs). Unlike the roles of policy making and marketing, the role of planning 
contained in Act 20423 was strongly influenced by Sernatur. Dipres argued that planning was a technical aspect of tourism and supported the proposals suggested by Sernatur (Rodríguez, 2010). Therefore, Sernatur and Minecon led the formulation of the bill and negotiated with Conaf when there was disagreement.

\subsubsection{Tourism development in the SNASPE.}

Act 1224 did not consider Sernatur's involvement in tourism development in the SNASPE. The agency in charge of this role was Conaf who implemented a programme of concessions in national parks. Act 20423 contains two important changes. The act explicitly addresses the involvement of the Subsecretariat of Tourism and creates a new programme of concessions allocated to the Ministry of Public Lands. Drawing on the proposal of Dipres for allocating roles to separate agencies, the new concession programme considers that the Subsecretariat proposes priority protected areas for implementing the programme, the Committee of Ministers approves these areas, and Sernatur supports the implementation.

An examination of the proposals discussed during the process is useful to explain where the creation of the new programme emerged from. During the pre-legislative stage and the policy window Sernatur proposed strengthening the concession programme of Conaf (Sernatur, 2002, 2005, 2006c). This proposal also included giving Sernatur a greater involvement in the process to grant concessions. During the formulation of the bill Sernatur changed its proposal and suggested the creation of a new programme allocated to a different organisation (Iglesias, Rebolledo, 2010). By highlighting the limited performance of Conaf in implementing its programme, Sernatur convinced Minecon and Dipres about the creation of a new concession programme. When the bill was ready to be submitted to Parliament, Conaf learnt about this change and opposed the creation of the new programme, which triggered the disagreement with Sernatur and Minecon described in Chapter V. Once in Parliament, Conaf's union lobbied to have the bill changed. In the Chamber of Deputies, the union asked for the elimination of the entire part containing tourism development in the SNASPE (Organizaciones Sindicales de Conaf, 2008). This proposal was not accepted and the bill was passed on the first reading. During the debate in the Chamber of Senators Conaf's union changed its proposal and 
demanded an amendment of the bill in order to reallocate the concession programme to Conaf. This proposal was not accepted either and the bill was passed and enacted without modifications.

The growth of visitors to the SNASPE described in Chapter IV emerges as a key economic factor to explain why tourism development in the SNASPE was included in the bill. This rapid growth showed the importance of the protected areas for the tourism industry and called the attention of Sernatur to the SNASPE. Because Sernatur was not involved in the concession programme of Conaf, Sernatur's representatives saw in the tourism bill an opportunity to modify the concession programme and guarantee the involvement of the NTA. Despite the fact that Sernatur originally proposed strengthening the programme of Conaf, evaluation reports and the results of the MOU presented in Chapter IV help to explain why a new concession programme was finally created. Drawing on these evaluations and the limited results of the MOU signed with Conaf, Sernatur proposed the creation of a new concession programme allocated to the Ministry of Public Lands. The allocation of the programme to this ministry resulted because - from the administrative point of view - the legal property of the SNASPE belongs to this ministry (Galaz, Rodríguez, Santelices, 2010).

The lack of involvement of Conaf during the formulation of the bill is a key factor to explain why disagreement existed before the submission of the bill. Conaf's representatives were invited to a couple of sessions to present the features of its concession programme; however these representatives did not have the chance to influence the formulation of the bill and were informed about the creation of the new programme just before the submission of the bill (Bau, Galaz, Martinez, 2010). This was explained by a Conaf representative:

Conaf was not part of the formulation of the bill, so we couldn't do anything... in fact, when the bill was ready to be submitted and we realised about this part of the bill (the creation of the new programme), the decision of the executive was already taken. (Galaz, 2010)

In spite of the opposition of Conaf to submit the bill and the lobbying conducted with Segpres (Secretary of the Presidency) to stop the submission, the bill was submitted to Parliament towards the end of 2007. Once again power emerges as a 
key political factor to explain how disagreement was tackled and why the bill was submitted. When the bill was stopped at Segpres, the Minister of Economy used his power and lobbied Bachelet for the submission of the bill (Iglesias, 2010). As explained in Chapter V, Bachelet used her power and announced the submission of the bill in the press (El Mercurio, 2007b; Radio Cooperativa, 2007) forcing Segpres to submit it (Rebolledo, 2010). The was commented on by the Minister of Economy:

There were lots of difficulties with Conaf... this was hard... It seems like Conaf did not want to lose the control of the parks...it was hard to move the bill forward. (Ferreiro, 2010)

Once in parliament, Conaf and Conaf's union unsuccessfully lobbied for changes to the bill. Evaluation reports are critical in explaining why this lobby was unsuccessful. Existing evaluations of the Conaf's concession programme showed very limited results and therefore Conaf did not have arguments to support its negotiation for changes (Bau; Galaz; Zúñiga, 2010). This was acknowledged by a Conaf representative:

It was impossible to defend the concession programme... We did as much as we could. (Galaz, 2010)

This unsuccessful lobby may also be explained by a policy factor. As explained in Chapter V, the debate of the tourism bill occurred in parallel with the debate of the conservation bill that created the new Ministry of Environment. This last bill contained a section that would create a Service of Biodiversity in charge of the SNASPE, which implied transferring the administration of the SNASPE from Conaf to the Service of Biodiversity. This was not accepted by Conaf's union who lobbied the bill, achieved the elimination of that part and agreed with the government to study and negotiate maintaining the SNASPE in Conaf. As with the lobby conducted for the conservation bill, during the debate of the tourism bill in Parliament Conaf's union proposed to keep the concession programme in the agency. However, for the Members of Parliament this proposal seemed to be a strategy by Conaf to retain the SNASPE (Ferreiro; Recondo; Rebolledo; Rodríguez; Zúñiga, 2010) and the bill was debated and passed without changes. This was highlighted by a deputy who stated:

During the debate Conaf was very critical; there was some tension there between Conaf and Minecon/Sernatur... Conaf's union attended several meetings... It seems that Conaf did not want to share the hegemony of the parks. (Recondo, 2010) 


\subsubsection{ZOITs.}

Act 1224 contains the procedure to declare and implement ZOITs. This procedure makes provision for Sernatur to propose and declare ZOITs; but because the act did not identify the agency in charge of implementation, the declared ZOITs were never implemented. Act 20423 aims to address the problem of implementation and creates a new procedure to identify, declare, and implement ZOITs. Drawing on the new institutional system proposed in Act 20423, the new procedure considers that the Subsecretariat identifies and proposes ZOITs, the Committee of Ministers declares these zones and Sernatur supports the implementation. In order to guarantee implementation, Act 20423 aligns the process to declare and implement ZOITs to the general mechanisms of planning contained in DFL 485.

During the pre-legislative stage Sernatur proposed changing the procedures for implementing ZOITs. This proposal suggested that a management plan to implement ZOITs be formulated by Sernatur and implemented by municipalities. At this stage, Sernatur declared a dozen new ZOITs which were never implemented because of the lack of skills, power, and resources of the municipalities (Rivas, 2010). Even more importantly, these ZOITs were not implemented because the management plan contained in Act 1224 was not recognised by DFL 485 as an official mechanism of planning (Rebolledo, 2010). During the legislative stage, this situation led Sernatur to propose a new solution: changing the entire procedure to declare ZOITs by eliminating the management plan and aligning a new procedure to the official mechanisms of planning of DFL 485 (Rebolledo, 2010). This proposal was also suggested by the BCG report (Boston Consulting Group, 2007), which gave Sernatur a better position to push forward the creation of a new procedure. During the debate in Parliament this proposal was accepted without objection and the bill was passed without major changes.

Evaluation reports directly influenced and shaped the contents contained in Act 20423. As presented in Chapter VI, these reports concluded that ZOITs had a problem of implementation due to a problem of governance: DFL 485 did not recognise the ZOIT management plan as a mechanism of planning. To address this problem, during the formulation it was argued that any change required aligning the 
procedures of ZOITs to the procedures of DFL 485. Evaluation reports also concluded that the lack of implementation resulted because of a lack of political commitment to guarantee implementation. In order to address this lack of commitment, Act 20423 allocates the declaration to the highest political level (the Committee of Ministers). During the debate of the bill in Parliament this new procedure was broadly accepted. As described in Chapter V, during the consultation conducted in Parliament the private and academic sectors suggested some complementary proposals (i.e. the creation of the category of tourist municipalities). Because the main focus of this part of the bill was centred on ZOITs, the government and Parliament did not address these proposals on the grounds that the bill should focus only on critical aspects. The conflict, presented in Chapters V and VI, between declared ZOITs and Act 19300 was not addressed either. This occurred because Act 19300 was under review in the context of the conservation bill discussed in parallel in Parliament. Any modification, in this regard, should have been included in the conservation bill.

\subsection{The role of quality assurance}

Act 1224 contained the quality assurance system existing before Act 20423 was enacted. The system consisted of a classification and qualification scheme for tourism providers. As mentioned in Chapters IV and VI, though the system was compulsory for accommodation providers only $25 \%$ of these providers adopted it (Inter American Development Bank, 2007b; Sernatur, 2002, 2007b). Act 20423 creates a new system based on an ISO Standards certification scheme. The new system is voluntary with the exception of accommodation and adventure tourism providers. In those two cases registration and certification is compulsory and penalties exist in case providers are not certified or do not fulfil the standards.

During the pre-legislative stage several evaluations were conducted that illustrated the obsolescence of the quality assurance system contained in Act 1224. These evaluations highlighted the lack of skills in the NTA to control the implementation of the system and the lack of mechanisms for guarantee its implementation (C\&S Soluziona Servicios Profesionales, 2004; Sernatur, 2002, 2005, 2006b, 2006c). In this context, in 2002 Sernatur created a pilot programme of quality assurance based 
on ISO certification standards. Towards 2007 the pilot programme had been implemented with positive results (Sernatur, 2007b). During the legislative stage, in particular during the formulation of the bill, Sernatur suggested the adoption of the pilot programme as the new official quality assurance system. At this point MineconDipres agreed with the need to create a new system; however they disagreed with the idea of including the new system in the bill. The reason why Dipres/Minecon opposed the inclusion of the system was explained thus by a Dipres representative:

The system of quality was not necessary to be included in the bill... it stiffens the system because later on if you want to have another system you will need to change the bill. (Rodríguez, 2010)

As part of the negotiation, Dipres/Minecon accepted the Sernatur proposal and the ISO certification programme was included in the bill (Loader, Rebolledo, 2010). During the debate in Parliament there was agreement with this proposal and the bill was passed without objection. One minor change occurred as a result of the debate of the bill in the Chamber of Senators; the penalties for not being certified were increased and the two labels proposed in the submitted bill were reduced to just one. Evaluation reports are again useful in explaining the creation of the new quality assurance system. During the legislative stage several evaluation reports highlighted the obsolescence of the existing system and concluded that this system caused a problem of asymmetry of information affecting the competitiveness of the tourism industry (Boston Consulting Group, 2007; P4 \& Tourism Resource Consultants, 2008). Because these evaluation reports were commissioned by Minecon, during the formulation of the bill Sernatur had better arguments to negotiate with MineconDipres and include a new system as part of the bill.

Several factors also help explain why a new quality assurance system was included in the bill. The legally driven nature of the public sector implied that changes in the existing system or the creation of a new one required legal modifications. In this context, the formulation of the tourism bill gave Sernatur the opportunity to introduce these legal modifications, replace the obsolete scheme of quality assurance, and create a new one. The creation of the new system also emerged from a policy factor. As mentioned, during the last decade Sernatur had two quality assurance schemes operating in parallel (the official and the pilot programme). This situation created a problem of governance because neither of the schemes was 
tackling the problem of quality; while Sernatur did not have the mechanisms to control the implementation of the programme contained in Act 1224, the pilot certification programme was voluntary and Sernatur could not put forward its implementation.

The pilot ISO certification programme implemented by Sernatur also influenced and shaped the results of the process of change. In fact most of the elements contained in the bill emerged from the original design of the pilot programme. The exception is a clause regarding tourist rights. This clause was included during the formulation of the bill and emerged as a result of the process of negotiation between Sernatur, Minecon, and Dipres (Iglesias, 2010). These results were also influenced by Dipres' advocacy of the NPM approach. One of the core characteristics of the NPM approach is the market driven nature of the public sector (Peters \& Pierre, 2003). In this context, the characteristics of the ISO certification scheme addressed the problem of quality assurance from a market point of view: the scheme is voluntary in most of cases, the certification is granted by specialised private third parties, control only exists in cases when tourists' safety is at risk, and finally the scheme considers market incentives for its implementation. This market approach to tackling problems of quality suited Dipres' perspective and explains Dipres support for Sernatur's proposal of transforming the pilot certification programme into the new official quality assurance system. A Dipres representative stated:

Following the principles of the modern administration of the public sector (NPM), our approach has always been identifying market failures to address policy making...therefore, this programme tackles problems such as asymmetry of information. (Rodríguez, 2010)

Although the new system is driven by a market approach, it considers a greater involvement of the government in controlling the accommodation and adventure tourism sectors. Government control of the markets usually brings conflict between the public and private sectors, however in this case there was no conflict at all and the discussion in Parliament made the penalties even stronger. This is probably explained by the general understanding that the market was unregulated and a minimum regulation was required to increase international competitiveness of the tourism sector (Delmastro, De Urresti, Goic, Loader, Rebolledo, Recondo, 2010). 


\subsection{Discussion and conclusions}

This chapter investigated the results of the process of change contained in Act 20423. The chapter shows that three interrelated elements influenced the results contained in the act: the process of change, evaluation reports and environmental conditions underlying the process. An examination of the process of change shows the existence of two opposing proposals to address the changes to the tourism institutional framework. Sernatur proposed changing the structure of the institutional framework, while Minecon-Dipres proposed changing the roles. These opposing proposals triggered disagreement between Sernatur, Minecon, Dipres, and Conaf regarding the structure of the NTA and the roles of policy making and marketing (Iglesias, Rodríguez, Rebolledo, Santelices, Zúñiga, 2010). The other two roles (planning and quality assurance) were accepted by Dipres, arguing that they were technical matters.

In order to address their disagreements the organisations engaged in negotiations. However, by the end of the formulation of the bill and its debate in Parliament agreement was not achieved and power was used by Minecon-Dipres and Sernatur to influence the contents of the bill (Iglesias, Rodríguez, Rebolledo, Santelices, Zúñiga, 2010). During the formulation of the bill, the power Dipres had in the public sector emerged as a key political factor that allowed this organisation to put forward its proposals and influence the contents of the bill. Because Dipres advocated the adoption of the NPM approach in the public sector, the tourism bill gave Dipres the opportunity to redesign the tourism institutional framework and implement the NPM approach, in particular the principle of the disaggregation of the public sector in administrative units. As a consequence, Act 20423 allocates roles amongst different agencies leading to the creation of a new NTA and NTO. This was highlighted by a Dipres representative who stated:

With Minecon we agreed that any change must be drawn on separating roles... We wanted the Minister of Economy to become Minister of Tourism. A Subsecretariat led the tourism sector and Sernatur was only in charge of implementation. (Rodríguez, 2010)

The bill submitted to Parliament consisted of the same structure presented in this quote but differed in one aspect: the NTA proposed by Dipres was a technical 
secretariat rather than a subsecretariat. Once again, the power of Dipres was imposed to define the structure of the institutional framework proposed in the submitted bill. The same Dipres representative stated:

Bachelet's programme offered lots of ministries and subsecretariats. We did not want to create this subsecretariat (tourism) because if we did it, we needed to create the other agencies offered by Bachelet...we were strict in this position although we knew that in this particular case (the Subsecretariat of Tourism) it could have finished in what it finished... Bachelet liked the theme (tourism) too much. (Rodríguez, 2010)

While the bill was debated in Parliament, Sernatur challenged Dipres' power and successfully lobbied for the creation of the Subsecretariat of Tourism. Three political factors are critical to understanding how and why Sernatur challenged the power of Dipres. First, the political appointment of the Sernatur sub-director changed the allocation of power and allowed Sernatur to lobby for changes to the bill. Second, the general agreement in Parliament that the proposed structure was not appropriate prompted the request to create the subsecretariat. Finally, the power of the president to amend the bill - combined with her commitment to the bill and the creation of the subsecretariat - led to the creation of the Subsecretariat of Tourism. The lobby conducted in this case by Sernatur and the power of the Sernatur sub-director in his position of advisor clearly exemplifies how actors influenced decision making and what tactics they used to challenge Dipres' power. As mentioned by several interviewees, by challenging the power of Dipres Sernatur broke a trend underlying the four governments of "La Concertacion" over the preceding decades (Iglesias, Rebolledo, 2010).

There is no a similar legislative history over the last 20 years showing that a bill was submitted to Parliament considering one structure - even proposed by the same government - but that later on this structure was changed by the same government in order to create a Subsecretariat ... I mean, there is no history of a bill submitted with a technical secretariat and passed with a Subsecretariat... Dipres in this regard does not negotiate. (Iglesias, 2010)

Despite the fact that Sernatur successfully challenged the power of Dipres by having the Subsecretariat of Tourism created, most of the provisions of the act were strongly driven by Dipres and its proposal to change the roles of the framework. As noted in the act, the changes primarily focused on modifying the roles of policy making, marketing, planning, and quality assurance. The changes in these roles triggered changes in the structure of the entire institutional framework and the emergence of a 
new tourism institutional system for tourism. Also influenced by Dipres, the new institutional system reflects the dominant organisational structure of the Chilean public sector (Rivas, 2010). For example, the new tourism institutional system has a similar structure to the fisheries institutional framework: a Committee of Ministers in charge of policy approval, a Subsecretariat of Fisheries in charge of policy formulation, and Sernapesca (National Service of Fisheries) in charge of policy implementation. This shows the influence of Dipres on Act 20423 and suggests that the act sought to correct the concentration of roles in Sernatur, distribute these roles amongst different agencies, and align the structure of the new tourism institutional system to the general structure of the Chilean administrative sector.

As discussed in Chapter VI - and as also presented in this chapter - the results of Act 20423 were influenced and shaped by evaluation reports. For instance, the study of UChile (Universidad de Chile, 2007) directly influenced the role of policy making and the structure of the NTA submitted to Parliament; the role of marketing was influenced by the BCG study and the Dipres evaluation of Tourism Chile (Boston Consulting Group, 2007; Dipres, 2005a); and, finally, the roles of planning and quality assurance were shaped by several evaluation reports such as BCG (2007), C\&S (2004), Dipres (2005b), IADB (2007b) and Sernatur (2002, 2005, 2006d, 2007b, 2008b). As also noted in this chapter, evaluation reports were commissioned throughout the entire process of change (pre-legislative, policy window, and legislative stages) influencing the formulation of the bill and its discussion in Parliament. This confirms one of the key conclusions presented in Chapter VI, namely that evaluations were carried out throughout the entire policy process rather than at a particular phase.

The results of the process were also influenced by economic and political factors. The growth of the tourism industry, described in Chapter IV, emerges as a key economic factor. This growth raised the idea of tourism as a potential economic sector but one that was limited by lack of competitiveness. The BCG report (Boston Consulting Group, 2007) examined the competitiveness of the sector and identified problems in the roles of policy making, marketing, planning, and quality. As a consequence, these roles were explicitly addressed in the act. Amongst the political factors, the commitment of Bachelet to put the bill forward was critical. Bachelet 
used her power to overcome Dipres' opposition to the subsecretariat and move forward the debating of the bill in Parliament. Because of the presidential nature of the administrative system, any institutional change could not have been possible if Bachelet did not place the tourism bill as a priority for her administration. As suggested by several interviewees, Bachelet may have seen in the tourism sector a tool for social and economic development consistent with her idea of social welfare (Iglesias, Rodríguez, Santelices, 2010).

The involvement of the Ministers of Economy was also relevant. While Ferreiro put forward the formulation and submission of the bill to Parliament, the role of Lavados was critical in moving forward the debate of the bill in Parliament. These two ministers negotiated with Dipres and lobbied the president when disagreement emerged. The commitment of Bachelet and these ministers was also possible because of another political factor: the political appointment of the Sernatur sub-director. The sub-director was involved in the formulation of the programme of government of Bachelet in 2005 and strongly influenced the idea of including the formulation of the tourism bill as part of the programme. When the sub-director became advisor to the Minister, this new position gave him greater access to the Minister of Economy and Bachelet in order to push forward the bill, arguing that it was one of Bachelet's commitments during the presidential campaign.

The commitment of Bachelet to the bill and the political appointment of the Sernatur sub-director are, therefore, two factors that together explain the approval of the bill in Parliament. During the presidential campaign Bachelet proposed six institutional changes in the public sector: these included the creation of the Ministries of Environment and National Security and the Subsecretariats of Foreign Trade, Small Companies, Indigenous Affairs and Tourism (E1 Mercurio, 2006a). Towards the end of Bachelet's presidential term only two of these changes had been passed (the Ministry of Environment and the Subsecretariat of Tourism). The other five did not occur because of two reasons: the opposition of Dipres to conducting institutional change processes, and the slow debate of bills while they were in Parliament (Ferreiro, 2010). As explained, in the case of the tourism bill, Dipres' opposition to institutional changes was overcome by Bachelet's commitment and power to submit the bill and create the Subsecretariat. The slow discussion in Parliament was also 
overcome by Bachelet's power. The enactment of the tourism bill was fast and occurred within two years of being submitted. As explained in Chapter V, the President used her power to push forward the debate in Parliament by using "urgencies". In January 2010 Bachelet submitted an "urgency with immediate discussion", arguing that the bill was extremely important for her administration. After three days of debate the bill was passed. Once again, Sernatur's former subdirector in his position as advisor of the Minister influenced Bachelet's decision to submit these urgencies (Iglesias, Santelices, Szmulewicz, 2010).

Among the political factors presented above, power emerges as a critical one. The stakeholders used their power every time when agreement was not reached. The distribution of power changed depending on the stage and the theme under discussion (the structure or the roles). Dipres imposed its power during the formulation, while Minecon/Sernatur gained more power to influence the debate in Parliament. Power was also used to tackle the disagreement with Conaf. In that case Conaf was not able to challenge Minecon/Sernatur and no changes to the bill occurred. Power also allowed these organisations to create alliances to push forward their proposals. Who was included in these alliances and how they used power varied depending on the stage of the process and the theme under discussion (the structure or roles). During the formulation of the bill Dipres and Minecon agreed on the treatment of some roles. These organisations used their power to impose their proposals over Sernatur (e.g. the structure of the framework). In spite of this Minecon-Dipres alliance, the examination of other roles - such as tourism in the SNASPE - shows that Minecon was allied with Sernatur and together they imposed their proposals over that of Conaf. During the debate in Parliament the allocation of power changed and Minecon became an ally of Sernatur with regards to most of the roles. At this point Minecon/Sernatur imposed their combined power and changed the structure of the NTA originally proposed in the bill. However, in parallel, Dipres continued imposing its power, so triggering permanent disagreement which was finally tackled by the power of the President. The use of power was highlighted by a Dipres representative:

I would say that there were conflicts as pairs. Some fights were between Conaf and Sernatur, there were others between Minecon-Dipres against Sernatur, and others between Sernatur-Minecon against us. Then, during the debate in 
Parliament Minecon became an ally of Sernatur for most of the themes included in the bill and they were against us (Dipres). (Rodríguez, 2010)

In retrospect, representatives of Sernatur and Dipres highlighted the value of the process of change and its results. For a Sernatur's representative, the value of the process lay in the fact that Act 20423 was enacted in spite of the tourism sector not being a key economic sector in comparison to the copper or fruit industries and, therefore, a sector that had never gained enough political attention. This representative stated:

The value of this change rests on the political negotiations behind the process... I feel we gave the right arguments to convince the right people about the importance of the formulating the bill (the President, ministers and Dipres)... even considering that tourism is not a strong sector for the country and for the interests of politicians. (Iglesias, 2010)

For the representatives of Dipres and Minecon the value of the process and its results rested on a different aspect: public sector tourism was strengthened because of the adoption of the principles of the NPM approach, which align the sector to the general administration of the Chilean State (Rodríguez, Zúñiga, 2010). In particular, the Dipres' representative stated:

Dipres agreed that this change is relevant... Unlike changes over the last 20 years the government opted for a real change. It could have created the position of subsecretary and that's all... However in this case it opted to follow certain principles of modern administration even though it was more complex in term of design....changing the entire institutional framework is a big thing. However they achieved a real change. (Rodríguez, 2010)

Because of the legally driven nature of the Chilean administration, the enactment of Act 20423 implies political recognition of the tourism sector. In addition, due to the centralised nature of the public sector, the creation of the Subsecretariat strengthened the tourism sector by creating a new NTA placed at a higher hierarchical level. Despite these clear implications, the real effect of the act on tourism development in Chile is a matter to be evaluated after implementation. Because implementation exceeds the scope of this research, further investigation of the impact of the bill is needed. This suggests avenues for future research extension in order to have a more comprehensive understanding of processes of change in NTAs. 


\section{Chapter 8 Understanding processes of change in NTAs: How and why do these organisations change?}

\subsection{Introduction}

As discussed in Chapters I and II, NTAs are dynamic organisation whose structures and roles change over time. Research conducted over recent decades has investigated what these changes are but has not considered how and why changes in NTAs occur (Kerr, 2003; Pearce, 1992). Furthermore, research tends to lack a comprehensive perspective by failing to consider two critical aspects: these are the process that leads to the changes, and variations in the environmental conditions during the time over which the process occurs. As emphasised in this thesis, this last aspect is critical because variations in these conditions influence the process of change and, in turn, the process influences and shapes the outcomes. In order to adopt this comprehensive perspective, this thesis has examined three questions in the context of the Chilean experience:

1) What was the process that led to the creation of the new Chilean institutional framework for tourism?

2) What were the factors that influenced and shaped the process?

3) How and why did the process and the factors influence the outcomes of the process?

These questions have been investigated in earlier chapters. Chapter IV introduced the general context in which the process occurred, presented the environmental conditions underlying the process, and investigated changes in these conditions. Then, Chapter V presented the process of change, Chapter VI investigated the factors that triggered and shaped the process, and Chapter VII analysed the outcomes of the process. In Chapter VII, special consideration was given to the features of the policy process and the influence of the various factors that explain why particular outcomes resulted. The key findings presented in Chapters VI to VII are summarised in Section 8.1. Then, Section 8.2 provides a generalised conceptual framework to investigate processes of change in NTAs (Figure 8.1). This conceptual framework incorporates 
critical aspects not dealt with in the literature and aims to provide a generalised approach to address the broader question of how and why NTAs change over time. Section 8.3 discusses the implications of this case study, Section 8.4 presents some reflections of this thesis, and Section 8.5 introduces avenues for further research. Finally, in Section in 8.6 conclusions to this thesis are drawn.

\subsection{The lessons learnt from the process of change in Sernatur}

This section summarises the key findings that have emerged in the previous chapters in the following order: the process that led to the changes in Sernatur (Section 8.2.1), the factors that influenced and shaped the process (Section 8.2.2), and the influence of the process and the factors on the results of the process (Section 8.2.3).

\subsubsection{The processes of change in Sernatur.}

Drawing on Birkland (2007) and Kingdon (1995), Chapter V presented the process that led to the changes in Sernatur. The process was operationalised in three major stages: pre-legislative, policy window, and legislative. The pre-legislative stage (2000-2005) refers to general discussion in the industry about the need to strengthen the tourism sector. The legislative stage (2006-2010) relates to the legislative process by which the contents of the tourism bill were identified, the bill was formulated and later debated and passed in Parliament. Between these two stages there is the policy window stage (2005). This stage is defined as a window of policy opportunity (Kingdon, 1995; Scodanibbio, 2011) that triggers the movement from the prelegislative to the legislative stage.

As discussed in Chapters III and VI, milestones were identified to operationalise these three stages in Chile. Parsons (1995) suggests that pre-legislative stages start with critical events that create an issue or policy problem. In the Chilean case, a change of government in 2000 triggered the formulation of a document called the National Tourism Agenda and this marks the start of the pre-legislative stage. As suggested by Kingdon (1995), the policy window is opened when three different streams intersect: problem, policy and political. In the case study, the problem stream is represented by the increasing attention gained by the need to strengthen the tourism institutional framework (several media reports in 2005 highlighted this 
need); the policy stream is illustrated by the National Tourism Policy launched in 2005; and finally, the political stream is represented by Bachelet's programme of government launched during the presidential campaign in 2005. These three streams intersected when Bachelet was elected President in 2006. This election and the change of government led to the opening of the window and triggered the movement from the pre-legislative to the legislative stage. Finally, the legislative stage was initiated with the announcement of the tourism bill by Bachelet and a change of Minister of Economy (Minecon) in 2006. The change of minister prompted the creation of a committee between Sernatur, the Minecon, and Dipres (Budget Office) which, in turn, formulated the bill to be debated in Parliament (legislative stage).

As part of these stages, components of the policy process were also identified: these include evaluations, policy agendas, formulation, and decision making. Implementation was omitted because this component exceeds the scope of this research. As discussed in Chapter V, these components overlapped through the process and the clear division of phases suggested by the Policy Cycle Model was found to not exist. For example, there was no single agenda setting phase but, rather, multiple agendas which overlapped during the entire process. Because the bill was modified further during the debate in Parliament, the formulation and decision making phases also overlap. This confirms Sabatier's view (2007) that a clear division of these components into phases cannot be operationalised.

Based on Birkland (2007), Clark (2004), Howlett and Ramesh (2003), Parsons (1995), and Princen (2007), three different types of agendas were identified in the case: these are systemic, institutional and decision. The systemic agenda emerges during the pre-legislative stage and represents the priority issues identified by the industry in order to strengthen the tourism sector. The systemic agenda is mainly represented by the National Tourism Agenda (Sernatur, 2002). The institutional agenda arises from the policy windows and reflects the decision of the government to formulate the tourism bill. Bachelet's programme of government - which included some proposals to address tourism development - represents the institutional agenda. Finally, the decision agenda emerges during the legislative stage and contains the issues the government was to include in the tourism bill. As mentioned above, the establishment of the commission composed of Sernatur, Minecon, and Dipres 
prompted the decision agenda and the actual formulation of the bill (Iglesias, Rebolledo, Rodríguez, Zúñiga, 2010).

During the formulation of the bill - in particular during the identification of the decision agenda - Sernatur proposed a list of eleven issues (Sernatur, 2006c). Most of these issues emerged from the National Tourism Agenda. Dipres - which was not involved with the identification of these issues - asked for the issues to be revisited and negotiated with Sernatur. As a result, five of the eleven policy issues were accepted by Dipres: these were the structure of tourism institutional framework and the roles of policy making, marketing, planning (ZOITs and tourism in protected areas), and tourism quality (Iglesias, Rodríguez, 2010). In turn, some issues were omitted (examples are the creation of a programme of social tourism or a foundation for marketing). The selection or omission of issues was based on two criteria imposed by Dipres: the selected issues must require a legal body to be implemented (the tourism bill), and the implementation should not imply the creation of new public organisations (Iglesias, Rebolledo, Rodríguez, Zúñiga, 2010). Two key findings emerge in relation to the identification of the decision agenda. First, the final list of issues included in the bill emerged from the National Tourism Agenda. This suggests the influence of the systemic agenda on the decision agenda. Second, an understanding of the power held and imposed by Dipres explains how the decision agenda was negotiated and established.

Once the issues were agreed, Sernatur, Minecon and Dipres all suggested proposals for addressing these issues and proceeded with the actual formulation of the bill. At this point, however, each of these organisations had different proposals and so disagreement emerged. For example, Sernatur proposed transforming the NTA into a Subsecretariat of Tourism (Santelices, 2010), the Ministry of Economy suggested the creation of the position of Subsecretary of Tourism for Sernatur's director (Ferreiro, 2010), and Dipres proposed the creation of a Technical Secretariat of Tourism (Rodríguez, 2010). At the end of the formulation, Dipres imposed its power and strongly influenced the contents of the bill submitted to Parliament (i.e. the creation of a technical secretariat). Two key findings are identified in relation to the formulation of the bill. First, the proposals of Sernatur, Minecon, and Dipres reflect different agendas that overlap during formulation. While Sernatur's proposal reflects 
the systemic agenda, the proposals of Minecon and Dipres illustrate the institutional agenda and the agenda for adopting NPM respectively. Second, the clash of these different agendas triggered disagreement and, therefore, these organisations negotiated and used power to put their proposals forward. In this case, once again power emerges as a critical explanatory factor that helps explain why particular proposals were adopted and omitted.

Once in Parliament, the bill was debated in the context of the legislative process established by the Chilean Constitution. During this debate, the bill underwent a series of changes that led to a reformulation. Similarly, because decisions were also made before the debate of the bill in Parliament (i.e. to define the decision agenda), decision making also occurred during formulation. This confirms the idea suggested by Sabatier (2007) and Sidney (2007) that formulation and decision making may overlap to become a single component of a policy process.

In 2010 the bill was passed and Act 20423 was enacted. The act modified the structure and roles of the existing institutional framework and created a new tourism institutional framework. As presented in Chapter I (Figure 1.1), the new institutional framework is composed of a new NTA (Subsecretariat of Tourism), a new NTO (Advisory Council of Marketing), an Inter-Ministerial Committee of Ministers for Tourism Coordination, and Sernatur. In this new institutional framework the subsecretariat formulates and evaluates policies, the Committee of Ministers approves, and Sernatur implements. A similar distribution of roles is adopted with regards to marketing, planning, and quality assurance. The next section summarises the factors that caused the modifications to the structure and roles of the institutional framework.

\subsubsection{The factors that influenced and shaped the processes in Sernatur.}

The factors that influenced and shaped the process of change were identified in two interconnected sources: the general environmental conditions in Chile during the 2000s, and evaluation reports investigating the existing tourism institutional framework. 


\subsubsection{Environmental conditions underlying the process.}

Pearce (Pearce, 1990, 1992, 1996a, 1996b, 1997) suggests that the structures and roles of NTAs reflect the general environmental conditions within which these organisations exist. As discussed in Chapter VI, changes in these conditions in the Chilean tourism context prompted changes in the existing NTAs and also influence the process that leads to these changes.

Chapter IV identified these conditions and Chapter VI classified them into three major types of factors: economic, political and policy. Economic factors relate to the characteristics of the tourism industry (that is, rates of growth in inbound tourism and public expenditure in tourism). As discussed in Chapter VI, during the 2000s the tourism sector showed growth rates never seen before. This caught the attention of the political spheres and contributed to triggering the process of change in Sernatur. Political factors were also identified. For example, the process of change would have not occurred without the commitment of President Bachelet to the tourism bill (Iglesias, Ferreiro, Rebolledo, Rodríguez, Santelices, 2010). Bachelet included the formulation of the bill as part of her programme of government, instructed the formulation of the bill and used her Presidential power to accelerate the debate in Parliament. Finally, policy factors also existed. For example, the consensus about the weakness of the existing tourism institutional framework supported the idea that changes in the framework were required.

\subsubsection{Evaluation reports of the existing institutional framework.}

Evaluation reports also help identifying and explaining the factors that influence a policy process (Parsons, 1995; Pforr, 2001; Wollmann, 2007). More than 20 evaluation reports were identified in this case. This large number of reports occurred because evaluations were conducted by multiple agencies, in different contexts and with different goals. In order to systematise and investigate this large number of reports, Chapter VI classified them into three types based on the following criteria: the source of the evaluations, the context in which the evaluations were conducted, and the goal of the evaluations (see Figure 6.1). 
The first type of evaluation relates to who conducted or commissioned them (Wollmann, 2007). In the Chilean case, evaluations of the existing tourism institutional framework were conducted by Sernatur (internal evaluations) and also by other public and private agencies (external evaluations). A second type was defined based on the context in which evaluations were carried out. Some of them were conducted in the general environment (for example, Dipres' evaluation of Tourism Chile in 2005), while others were directly carried out as part of the process of change (for example, UChile report commissioned to support the formulation of the bill in 2006). Finally, a third group was identified based on the goals of the evaluations. Some reports evaluated the tourism framework with the ultimate goal of establishing a baseline for the tourism sector while others aimed to identify proposals to address changes in the institutional framework. This last type of report shows that evaluations "of policy" and "for policy", as defined by Hill (2005) and Sabatier (2007), also existed here.

Regardless of the type of evaluation report, evaluations were conducted during the entire process of change and played different roles during the process. For example, the National Tourism Agenda (Sernatur, 2002) gave public visibility to failures in the tourism framework and helped identify the pre-legislative stage and the systemic agenda. The National Tourism Policy, the Tourism Action Plan, and the BCG Report (Boston Consulting Group, 2007; Sernatur, 2005, 2006b) supported the discussion inside the government about the need to tackle these failures (institutional agenda). These reports strengthened the idea of formulating a tourism bill and helped identify the opening of the policy window (Ferreiro, Rodríguez, 2010). Evaluations were also commissioned during the legislative stage. For example, the UChile report (Universidad de Chile, 2007) was commissioned to support the formulation of the bill. The preparation of evaluation reports throughout the entire process of change challenges the Policy Cycle Model, in which evaluation occurs only as a single phase, and confirms the views of Parsons (1995), Jann and Wegrich (2007) and Sabatier (2007) that evaluations are conducted during the entire policy process.

Evaluation reports shaped the process of change. For example, the study of UChile (Universidad de Chile, 2007) influenced the role of policy making and the structure of the NTA; the role of marketing was influenced by the BCG study and the Dipres 
evaluation of Tourism Chile (Boston Consulting Group, 2007; Dipres, 2005a), while the roles of planning and quality assurance were shaped by evaluation reports conducted by C\&S (2004), IADB (2007b) and Sernatur (2002, 2005, 2006d, 2007b, 2008b).

As presented in Chapter III and VI, evaluation reports addressed four interconnected issues: funding, effectiveness, coordination, and accountability (Figure 3.4). Since these issues are incorporated under the broader notion of governance (Bevir, 2007, 2009), it is possible to conclude that governance of the institutional framework was a key aspect driving the process of change in Chile. As discussed in Chapter VI, differences occurred in the emphasis the various evaluation reports gave to these issues. For example, evaluations conducted by Sernatur focused on the issue of funding, while evaluations conducted by Dipres emphasised transparency and accountability. This suggests that the analysis of the issues varied depending on who commissioned or conducted the evaluation reports: therefore, identifying who commissions these reports is critical.

For the analysis of these four issues, Chapter VI investigated evaluation reports based on four aspects: the core problems, the causes of the problems, the background causes, and the proposed solutions (Table 3.2). Although both Sernatur and Minecon-Dipres agreed on the background cause (problems of governance), these organisations differed in interpreting what the particular problem of governance was. Sernatur argued that the problem of governance lay in an obsolete Act 1224 (C\&S Soluziona Servicios Profesionales, 2004; Inter American Development Bank, 2007b; Sernatur, 2002, 2005, 2006b), whereas Minecon-Dipres suggested that the problem occurred because of a failure of design of the entire public institutional framework for tourism (Boston Consulting Group, 2007; SCL Econometrics S.A, 2008; Universidad de Chile, 2007).

Because of these differences in interpreting governance, Sernatur and MineconDipres also differed in the solutions they proposed. On the one hand, Sernatur proposed transforming the NTA into a Subsecretariat (Sernatur, 2006c). This would allow Sernatur to reorganise the agency in order to address funding, effectiveness, and coordination. On the other hand, Minecon-Dipres suggested the creation of a 
technical secretariat as the new NTA (Universidad de Chile, 2007). The creation of a new NTA would allow the allocation of policy roles among different organisations and tackle the adoption of the NPM approach to address governance in the public sector. These different proposals illustrate and explain the disagreement existing during the formulation of the bill described in Section 8.2.1 and are used to investigate the results of the process in the next section.

The adoption of the NPM approach put forward by Dipres is a salient environmental condition that shows how the general environment may influence evaluations and, in turn, how these evaluations may shape a process of change. As explained in Chapters II and IV, during the 2000s Dipres implemented an administrative reform that advocated the adoption of the principles of the NPM approach in the public sector (that is, governance and disaggregation of the public sector into administrative units). This may explain why evaluations conducted or commissioned by Dipres put the emphasis on investigating governance, effectiveness, transparency, and accountability. In contrast, Sernatur had been created in 1975 under a political scheme that tended to concentrate policy roles (Plumer, 2010). Thus, Dipres may have seen in the process of change in Sernatur an opportunity to influence the process and align the institutional framework for tourism to the general trend of adopting the NPM approach in the public sector.

\subsubsection{The influence of the process and the factors on Act 20423.}

Chapter VII investigated the results of the process of change in Sernatur (Act 20423). Two interrelated elements were identified to explain why these particular outcomes resulted: these were the features of the policy process, and the factors triggering and shaping the process.

\subsubsection{The features of the policy process.}

Anastasiadou (2008), Bramwell and Meyer (2007), Reed (1997), and Thomas and Thomas $(2005,2006)$ suggest the examination of the features of a policy process in order to investigate and explain the results of the process. As discussed in Chapter VII, these features include consultation and participation, agreement, disagreement, negotiation, power, and acceptance. 
As described in Chapter VII, the entire process of change in Sernatur was characterised by the uneven participation and consultation of relevant stakeholders. During the first part of the pre-legislative stage, the private sector played a key role in defining the systemic agenda. However, towards the end of this stage this involvement tended to disappear and the systemic agenda was basically promoted by Sernatur. During the policy window and the legislative stages - in particular during the formulation of the bill - the involvement of the private sector ceased. In fact, no consultation meetings were identified at this point. During the debate of the bill in Parliament, the private sector was again actively involved as a result of the consultation meetings organised by the Chamber of Deputies. A similar situation occurred with the involvement of the public sector. The characteristics of the private and public sectors, described in Chapter IV, are critical to examining the participation of these stakeholders. For example, although the private sector was highly involved during the debate in Parliament, it was unable to influence changes in the bill. The fragmented character of the private sector, described in Chapter IV may have affected the sector's ability to influence and negotiate changes of the bill and push forward the proposal of maintaining Tourism Chile as the NTO.

During the pre-legislative and policy window stages there was general agreement in terms of strengthening the structure and roles of Sernatur. During the legislative stage - in particular during the formulation of the bill - partial agreement also existed regarding the roles of planning (ZOITs) and quality assurance. In spite of this partial agreement, disagreement also occurred. As described in Section 8.2.1, during the formulation of the bill Sernatur and Minecon-Dipres had opposing approaches to tackling the process of change. These different approaches caused disagreement, particularly in regards to the structure of the framework and the roles of policy making, marketing, and planning in protected areas (Iglesias, Rodríguez, Rebolledo, Santelices, Zúniga, 2010). To resolve this disagreement, Sernatur, Minecon and Dipres negotiated.

The emergence of the use of power and acceptance as key features of the policy process is central to understanding how this negotiation occurred. During the formulation of the bill, the power of Dipres in the public sector allowed this organisation to put forward its proposals and directly influence the contents of the 
bill. For example, the bill contained the creation of a technical secretariat in the same terms proposed by Dipres. Sernatur's representatives accepted Dipres' proposals on the grounds that any changes might be negotiated again during the debate in Parliament (Iglesias, Rodríguez, Rebolledo, Santelices, Zúñiga, 2010). During the debate of the bill in Parliament, Sernatur challenged Dipres' power and successfully lobbied for the creation of the Subsecretariat of Tourism. The reasons why this occurred are examined in detail in the next section. The stakeholders used their power to influence the bill and promote their proposals. The use of power as described here confirms Bramwell and Meyer (2007), Reed (1997), and Thomas and Thomas' $(2005,2006)$ view that power is a critical feature to explain how policy processes occur and why particular outcomes result from these processes.

As also noted in this case, the distribution of power changed during the process. During the pre-legislative stage Sernatur concentrated power because no other powerful public organisations were involved (for example, Dipres). This situation changed during the legislative stage. During the formulation of the bill, Dipres became involved in the process and imposed its power to influence the contents of the bill. In turn, during the debate of the bill in Parliament Sernatur gained more power and challenged Dipres. The distribution of power also changed depending on the theme under discussion (the structure or the roles of the NTA). For example, during the formulation of the bill Dipres imposed its power over Sernatur to tackle changes in the structure of the NTA. In parallel, Sernatur imposed its power over Conaf (Forest Service) to address the role of planning in protected areas. These changes in the distribution of power suggest that during a policy process power is not static, and in turn, changes in the distribution of power may directly influence the results of a policy process.

A key aspect to understanding power distribution relates to the tactics stakeholders use to influence a policy process (Reed, 1997). For example, Sernatur, Minecon, and Dipres created alliances in order to put forward their proposals. Which organisations formed these alliances and how they used power to influence the process of change also varied depending on the stage of the process and the theme under discussion (structure or roles). During the formulation of the bill, Dipres and Minecon agreed on the treatment of some roles (for example, the structure of the framework) and 
together used their power to impose their proposal over Sernatur. In spite of this alliance, during the formulation Minecon was also allied with Sernatur in order to impose Sernatur's proposal over Conaf (role of planning protected areas). During the debate in Parliament the focus of power changed and Minecon became an ally of Sernatur with regard to most of the roles. At this point, Minecon and Sernatur imposed their combined power and changed the structure of the NTA originally proposed in the bill.

As discussed in this section, the features of the policy process changed over time depending on the stage of the process and the theme under discussion. Changes in these features occurred because of several factors, including variations in the environmental conditions during the time in which the process of change occurred. These factors are examined next.

\subsubsection{The factors influencing the results of the process of change.}

As discussed in Chapter VII, the results of Act 20423 were also influenced and shaped by various factors. The process and its results were influenced by economic factors. The economic stability and economic welfare of the country might have provided favourable conditions to formulate the tourism bill and allocate public funds to a sector that, although having potential, was less of a priority in comparison with other industries (García, M, Szmulewicz, 2010). The steady growth of the tourism industry over the 2000s (see chapter IV) also explains the process and its results. This growth showed a sector with economic potential but one which was limited by lack of competitiveness (Boston Consulting Group, 2007; Universidad de Chile, 2007). The BCG report attributed this lack of competitiveness to market failures caused by the roles of policy making, marketing, planning, and quality (Boston Consulting Group, 2007). Thus, Minecon and Dipres suggested tackling these market failures and explicitly addressing these roles in the tourism bill (Rodríguez, Zúñiga, 2010).

Policy factors, in particular the adoption of the NPM approach in the public sector, also influenced the results of the process. During the pre-legislative and legislative stages Sernatur proposed strengthening the existing institutional framework. However, during the legislative stage Dipres suggested a new proposal based on a 
modification of the roles of the entire institutional framework. The analysis conducted in Chapter VII shows that much of the content of Act 20423 was strongly driven by Dipres and its proposal to change the roles of the framework (roles of policy making, marketing, planning, and quality assurance). In order to address these changes, a modification of the structure of the institutional framework was required. Therefore, in the case study the changes in the structure resulted from changes primarily focused on the roles.

As also discussed in Chapter VII, the new institutional framework reflects the organisational structure of the Chilean public sector and the adoption of NPM put forward by Dipres (Rivas, 2010). This shows the influence of Dipres on Act 20423 and suggests that the act aimed to align the tourism institutional framework to the general trend of NPM in the public sector. In this context, Act 20423 corrects the concentration of roles in Sernatur, distributes these roles amongst different agencies, and aligns the structure of the new tourism institutional system to the general structure of the Chilean administrative sector. This suggests that the process of change in Sernatur was not an isolated process and was influenced by the administrative reform to adopt NPM described in Chapters II and IV. This is also consistent with the studies conducted by Pearce (1990, 1992, 1996a, 1996b, 1997) that indicate that NTAs reflect the administrative context in which these organisations exist.

Political factors also influenced the process of change. Amongst these factors, political commitment emerges as a key one. Because of the presidential nature of the administrative system, any institutional change would not have been possible without the commitment of President Bachelet to formulate the bill. The involvement of the Ministers of Economy was also relevant. Minister Ferreiro put forward the formulation and submission of the bill to Parliament, while Minister Lavados moved the debate forward in the Chambers of Deputies and Senators. These two ministers negotiated with Dipres and lobbied with the President when disagreement emerged.

The results of the process were also influenced by political factors. For example, during the debate in Parliament the bill was modified and the proposed Technical 
Secretariat was replaced by a Subsecretariat of Tourism. Three political factors explain why this change occurred. First, there was general agreement in Parliament that the proposed structure (technical secretariat) was not going to tackle problems of coordination in tourism. This agreement existed across all the political parties, even amongst those Members of Parliament from the Right who do not usually favour the creation of public organisations (Recondo, 2010). Second, the political appointment of the former Sub-director of Sernatur as advisor of the Minister of Economy changed the features of power and allowed Sernatur to successfully lobby for the creation of a subsecretariat. This appointment gave the former Sernatur sub-director greater access to lobby the bill in Parliament and influence the President and the Minister of Economy in order to create the subsecretariat. Finally, the power of Bachelet and her commitment to the bill overcame Dipres' opposition to the creation of the subsecretariat and moved the debate in Parliament forward. The lobby conducted by Sernatur and the power of the former sub-director clearly exemplifies Bramwell and Meyer (2007), Reed (1997) and Thomas and Thomas's (2005, 2006) stance in terms of the tactics that actors use to influence a policy process.

The fast approval of the bill in Parliament (within two years) is also explained by the political factors mentioned above. Bachelet accelerated the debate of the bill for approval by putting Parliament under urgency (Iglesias, 2010), while the general agreement in Parliament also helped to pass the bill relatively quickly (Delmastro, De Urresti, Goic, Recondo, 2010).

Some of the political factors mentioned above directly emerged from changes in the environmental conditions (for example, a cabinet reshuffle that triggered the political appointment of the former Sub-Director of Sernatur). This confirms that these conditions vary during the process of change and that this variation shapes and influences the process and its results. This also confirms a key element contained in the integrated conceptual framework (Figure 2.4); that is, the value of a temporal perspective for the analysis of processes of change in NTAs. This temporal perspective enables the researcher to portray changes in the environmental conditions and to explain how changes in the environment may influence changes during the process of change. 
As discussed in this section, the commitment of President Bachelet emerged as a key factor to explain the process of change in Sernatur. This suggests that in countries, such as Chile, that have presidential systems - with highly centralised and hierarchical administrative systems - the commitment of the President is one of the most relevant aspects to address and explain processes of change. Bachelet proposed six institutional changes in the public sector when she came into office in 2006. However, by the end of her presidential term only two of these changes had taken place (the creation of the Ministry of Environment, and the creation of the Subsecretariat of Tourism). A third change occurred with the creation of the Ministry of Energy. However, this last change was not contained in Bachelet's programme of government and resulted as a consequence of an increasing energy crisis faced by the country. Bachelet used her power to accelerate the formulation and enactment of the tourism bill. She also used her power to tackle the disagreement between Sernatur, Minecon, and Dipres. Even more importantly, this commitment allowed Sernatur to propose the creation of the Subsecretariat of Tourism in Parliament by challenging the power of Dipres.

In Chile, there is no legislative history of a bill being submitted proposing the creation of a technical secretariat and being passed with the creation of a Subsecretariat (Iglesias; Rebolledo, 2010). The influence of the political factors mentioned above, and particularly the commitment of Bachelet, explains why this occurred. This commitment was commented on by most interviewees and explained by a Dipres' representative, who mentioned the genuine support that the President had for the tourism sector. According to this interviewee, Bachelet saw in the tourism sector a tool for economic, cultural, and recreational development that was coherent with the general idea of social welfare contained in her programme of government (Rodríguez, 2010).

\subsection{How and why NTAs change over time. A generalised conceptual framework to investigate processes of change in NTAs}

Pearce (2012) highlights the value of conceptual frameworks in integrating ideas, concepts, theories and methods to depict phenomena and formulate research problems. Based on Pearce's proposition about frameworks, the different streams of literature reviewed and the research findings from the Chilean case, this section 
presents a generalised conceptual framework to investigate how and why processes of change in NTAs occur (Figure 8.1).

Three key points illustrate why the conceptual framework might be applied beyond the Chilean case:

- The importance of contextual factors or the general environment for the analysis,

- The identification of key elements for the investigation of processes of change (stages, components and features),

- The relationships between the general environment and the key elements and their influence on how and why these processes occur.

Pearce (2012) suggests that taking contextual factors into account is a key aspect that helps generalisation and applicability of a framework to other cases. He suggests that explicitly incorporating contextual factors into a conceptual framework allows building a bridge from the specific aspects of a particular setting to a more general approach to investigate a research problem. While in this thesis the specific setting is given by the particular political, policy and economic factors in Chile during the 2000s, the general approach presented in the framework suggests that political, policy and economic factors, whatever they are, also exist in other settings and need to be taken into account if the process of change in an NTA is to be fully understood.

The framework also provides a guide to investigate how processes of change in NTAs occur and suggests the examination of three key elements: stages, components and features. The stages show how a policy process occurs and how the process unfolds. These stages are distinguished by components and features. The components show how the ideas discussed during a policy process evolve until final approval is gained, while the features illustrate the techniques stakeholders use to influence the process and its outcomes. Although this thesis has investigated the particular characteristics of the stages, components and features of the process of change in the Chilean NTA, the framework suggests the examination of these three elements are critical ones that would guide the investigation of processes of change in NTAs in countries where a legislative debate is required. This is not to suggest that the specifics of the Chilean case would be found elsewhere but rather that 
concepts such as consultation, negotiation, power and so forth would be relevant and need to be considered in other settings.

Finally, the generalised framework depicts the relationship between the environmental conditions and the elements of the process in order to explain how and why processes of change occur. As discussed later, changes in the environmental conditions may influence the key elements of a policy process and in turn changes in these processes may influence the results of the process of change. Thus, the dynamic nature of environments and their impact on policy processes need to be taken into account when investigating processes of change in NTAs.

Having addressed the generalisation issues of the conceptual framework, the particular details of Figure 8.1 are presented next. McCarthy (2012) defines a process of institutional change as a complex and dynamic development. Following this definition, a process of change in NTAs may also be understood as a complex and dynamic development. As emphasised in this thesis, the process of change in NTAs is complex because it occurs in the context of a dynamic environment. As suggested by Hall (2008), Jeffries (2001), Kerr et al (2001), Pearce (1990, 1992, 1996a, 1996b, 1997, 2000), and Stevenson (2008), this environment may change over time triggering changes in the structures and roles of NTAs. While this environment changes in the long term prompting changes in NTAs, the environment may also change during the time in which the process of change occurs (Pearce, 1992). Therefore, changes in the general environment may also impact on the process and directly influence the results.

This process is also complex. In a process of change there are multiple stakeholders with different interests and motivations (agendas) to influence the process and its outcomes. These stakeholders may use various mechanisms (features of the policy process) including consultation, participation, agreement, disagreement, negotiation, power, and acceptance (Anastasiadou, 2008; Bramwell \& Meyer, 2007; Reed, 1997; Thomas \& Thomas, 2005, 2006). 


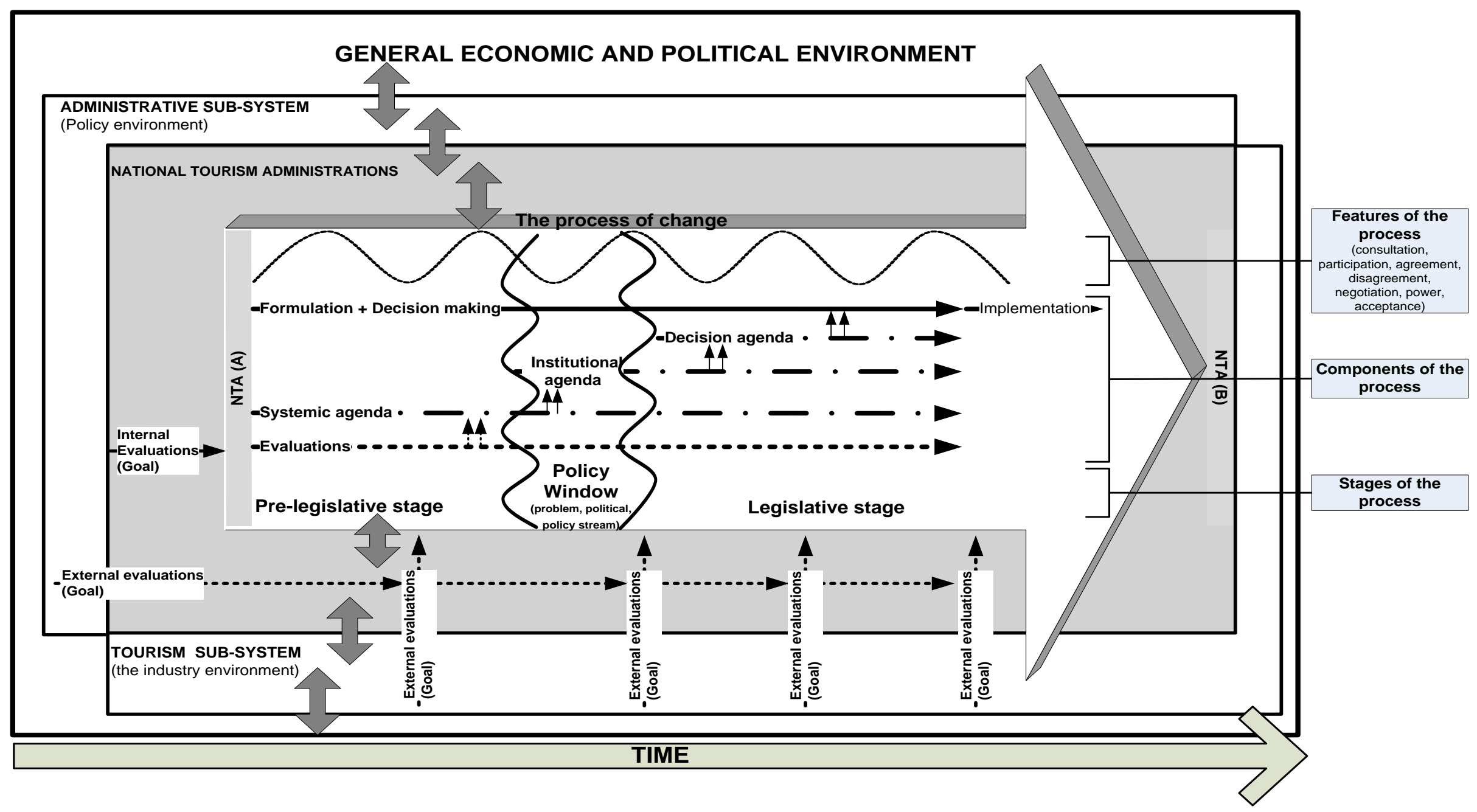

Figure 8.1: A generalised conceptual framework to investigate processes of change in NTAs 
These features of the policy process are also dynamic and may change during the period in which the process occurs. Once again, variations in the general environment may change the features of the policy process and in turn changes in these features may shape the outcomes of the process. This confirms the studies of Hall (2008), Jeffries (2001), Kerr et al (2001), Pearce (1990, 1992, 1996a, 1996b, 1997, 2000), and Stevenson (2008) that shows the general environment is a critical aspect to investigate changes in NTAs.

The dynamic and complex nature of the process of change is shown in Figure 8.1. The figure presents a generalised conceptual framework to investigate processes of change in NTAs and aims to provide a more general approach to tackle the broader question of how and why NTAs change. In this way, the conceptual framework seeks to contribute to the literature by providing a comprehensive approach to the analysis of NTAs. This perspective incorporates aspects not dealt with previously in the literature: the process that leads to changes in NTAs and the influence of a changing environment on the process and its outcomes.

There are two major aspects regarding the generalised framework with direct implications for the analysis of institutional change in tourism elsewhere. First, the framework presents the process of change in the context of a legislative process. This suggests that understanding the legislative context in which the process occurs is important and shows tourism researchers the need to consider this more closely. Second, the framework shows a process of change as it occurs in the context of countries with parliament and democracies. This may help explain some of the features of the policy process (consultation, participation, agreement, disagreement, negotiation, power, and acceptance) and suggests that particular attention must be given to these features in order to investigate how and why the process occurs.

Figure 8.1presents four key elements to investigate a process of change in NTAs. First, the process may occur as part of three policy stages: pre-legislative, policy window, and legislative. These stages show how the process moves from one set of events to another and helps operationalise a process of change in NTAs. Second, as part of these stages there are components of a policy process: evaluations, multiple agendas, formulation-decision making, and implementation. Inclusion of these 
components helps to investigate how policy issues are selected, omitted, debated, and modified during a process of change and also enables explanation of why a particular outcome results. Third, the stages and components might be influenced by the features of the process (consultation, participation, agreement, disagreement, power, and acceptance). These features are the mechanisms by which the process unfolds, in other words, the means used by stakeholders in order to influence and move the process forward. Finally, the influence of the environmental conditions on the process and its outcomes is also presented. These conditions may shape the stages and components of the process and influence the features of the process of change.

\subsubsection{Processes of change in NTAs: how do these processes occur?}

Figure 8.1 shows an arrow that presents the process of institutional change in NTAs. The process starts at $\operatorname{NTA}(a)$ and finishes with the implementation of NTA(b). NTA(a) is an existing tourism institutional framework with a particular structure and set of roles, while NTA(b) illustrates the outcomes of the process including any change in the structure and roles of the institutional framework. Although the changes resulting from the process may go beyond simple modifications to the NTA - for example, in Chile the process led to the creation of a new system for tourism the starting and end points are still called NTAs in order to simplify the nomenclature.

In order to operationalise the process, the figure shows three policy stages: prelegislative, policy window, and legislative (Clark, 2004; Howlett \& Ramesh, 2003; Kingdon, 1995). Critical events in the general environment usually trigger the prelegislative and legislative stages. For example, a change of government in 2006 triggered the legislative stage in the Chilean case. These critical events also support the opening of the policy window by intersecting the problem, policy, and political streams (Kingdon, 1995). The impact of the environmental conditions on these stages is shown in Figure 8.1 by arrows that connect the general environment with the sub-systems and the process of change. The figure also shows that these stages might overlap and that a clear division between them is not always possible. 
As part of these stages, the figure shows the components of a policy process: evaluation, multiple agendas, formulation-decision making and implementation. As mentioned in Chapter II, these components help identify what the issues discussed during a policy process are and help investigate how these issues were debated and modified through the different stages of the process. As suggested by Birkland (2007), these components overlap and occur in parallel, which confirms the complexity of the analysis of policy processes highlighted by Sabatier (2007). For example, in the Chilean case formulation and decision making overlap and a division into two separate components was not possible. In the figure, these three components are represented by differentiated arrows.

A first component presented in Figure 8.1 is evaluation. Multiple evaluations might exist during a process of change. These evaluations might be internal or external, they may be conducted as part of the process or in the general environment, and they also might be carried out in order to achieve different goals. As discussed later in section 8.3.1, evaluations may impact on the different stages of the process and influence the other two components (agendas and formulation-decision making).

The figure also shows three overlapping agendas: systemic, institutional, and decision (Birkland, 2007; Clark, 2004; Parsons, 1995). The systemic agenda represents different proposals emerging from the industry in order to initiate a process of change; the institutional agenda shows the proposals the government would consider in a legislative process; and, finally, the decision agenda relates to the proposals a government decides to include in a bill. The identification of these agendas helps investigate the policy issues discussed during the process of change and also to identify the stages of the process. As presented in Figure 8.1, the systemic agenda emerges during the pre-legislative stage, the institutional agenda arises from the policy window, and the decision agenda appears during the legislative stage. The interrelation between these agendas suggested by Parsons (1995) is a key aspect for the analysis of a process of change in NTAs. The systemic agenda may influence the institutional agenda and, in turn, both agendas may influence the decision agenda. This influence is presented in the figure by arrows that connect these three agendas. 
A third component is formulation, decision making, and implementation. As suggested by Sabatier (2007) and Sidney (2007), these components overlap and are closely related. Thus, in Figure 8.1 formulation and decision making are presented as a single component that extends to implementation once the legislative stage finishes. As also presented in the figure, formulation and decision making are ongoing components that exist through the entire process of change. Formulation and decision making may exist through the three policy stages in order to identify and select the issues contained in the systemic, institutional and decision agendas. Furthermore, formulation and decision making may also occur once the decision agenda is established. At that point, the issues of the decision agenda are transferred into particular proposals (that is, the formulation of a bill) and later on these proposals are debated and approved or rejected by Parliament (decision making in Parliament). This suggests that formulation does not finish with the submission of a bill for parliamentary debate and, in turn, decision making starts before the submission of a bill because decisions were made throughout the entire policy process.

Figure 8.1 also shows the features of a policy process (consultation, participation, agreement, disagreement, negotiation, power, and acceptance). These features illustrate the mechanisms that stakeholders may use to influence and move the process forward. As discussed later (section 8.3.3), these features may change during the policy process influencing both the components and the outcomes of the process. In order to show this changing condition, Figure 8.1 presents these features by an oscillating line placed above the component of formulation and decision making.

Finally, Figure 8.1 shows that a process of change in tourism does not occur in a vacuum. The figure shows that the process occurs in the context of a broader system in a particular country and over a particular period of time. Within this general environment are two sub-systems: the administrative sub-system and the tourism sub-system. Due to fact that NTAs are public organisations with specific roles in tourism, the figure shows an overlap between the two sub-systems in order to demonstrate that NTAs form part of both. For example, in the Chilean case the broader system is composed of the general economic, political and policy conditions during the decade of the 2000s. In that case, the first sub-system is composed of 
public organisations related to the administration of the government and the legislative framework, while the second sub-system is composed of organisations related to the tourism industry (i.e. Achet and Fedetur). Sernatur existed as part of these two sub-systems. The relationship between NTAs with both the general environment and other organisations confirms Pearce's model (1992) that NTAs are not isolated organisations and that they closely relate to and interact with multiple agencies at different scales. In figure 8.1, these relationships are presented by arrows that connect the broader system and sub-systems with the process of change.

The influence of the context in which the process occurs is particularly important because, in countries with parliamentary democracies, institutional change occurs as part of a legislative process carried out in the administrative sub-system. This suggests that processes of change in NTAs are not isolated developments and, in turn, they reflect the general policy making context in which the process occurs. Therefore, research investigating processes of change in NTAs should give more attention to the broader literature on public policy and legislative processes and situate the analysis in the context of the administrative sub-system and the legislative process in which the process of change occurs.

In order to show that environmental conditions may vary during the process of change, Figure 8.1 also shows an arrow at the lower part of the framework. The arrow represents the process of change in a temporal perspective and helps portray changes in the general environmental that may impact on the stages, components, and features of the process.

\subsubsection{Why do NTAs change? The factors shaping a process of change.}

Figure 8.1 shows that environmental conditions and evaluation reports may provide information about the factors that influence and shape a process of change. Pearce (1992, 1996a, 1996b, 1997) suggests that environmental conditions may provide information about why the process starts. For example, changes in the political environment (for example, a change of government) may trigger the process. Similarly, the characteristics of these environments may also influence the process and shape the debate during the different stages. For example, in the Chilean case the 
fragmentation of the private sector limited the ability of the sector to influence the formulation and debate of a bill in Parliament. The influence of these conditions is shown in Figure 8.1 by arrows that connect the broad system and sub-systems with the process of change.

Evaluation reports may also provide information about what triggers, influences, and shapes a process of change. As discussed in previous sections, different types of evaluation reports may be identified. A first type of evaluation might relate to who conducts them (internal/external). For example, in the Chilean case there were evaluations conducted by Sernatur (internal evaluations) and evaluations carried out by other organisations (external evaluations). In Figure 8.1 internal evaluations come from the NTA, whereas external evaluations come from the administrative and tourism sub-systems. A second group of evaluations might relate to the stage of the process when evaluations are carried. As noted in the figure, evaluations might be conducted throughout the entire process of change influencing the different stages of the process (Jann \& Wegrich, 2007; Parsons, 1995; Sabatier, 2007). This suggests that evaluations play a key role not only in providing information about the factors that trigger a process but also how these factors may influence the pre-legislative, policy window, and legislative stages. Finally, a third group of evaluations relates to the goals evaluations have and the role they play in a policy process: evaluation "of" and "for" policy (Hill, 2005; Sabatier, 2007). Evaluations "of policy" primarily exist during the pre-legislative stage in order to assess the existing institutional framework. In turn, evaluation "for policy" may emerge during the policy window and legislative stages in order to identify proposals to address the process of change. These different goals of evaluations are also illustrated in Figure 8.1.

Existing research has not given sufficient attention to these different types of evaluations and their impact on a process of change in NTAs. The identification and investigation of these evaluations is critical as it enables a better interpretation of the results of evaluations and helps explain their influence on a process of change. 


\subsubsection{Why particular outcomes result from a process of change? The influence of the process and the environmental conditions.}

The features of the policy process and various factors arising from the environmental conditions may help explain the outcomes of a process of change in tourism. The features of the process illustrate the mechanisms used by the stakeholders in order to influence the process and are presented in Figure 8.1 as consultation, participation, agreement, disagreement, negotiation, power, and acceptance. As emphasised in this thesis, these features may change during the time in which the process of change occurs and between the stages of the policy process. In order to show this changing condition, these features are represented by an oscillating line. For example, the features of consultation and participation might be uneven during the process of change and vary depending on the stage. In the Chilean case, these features mainly existed during the pre-legislative stage and tended to disappear during the policy window and the first part of the legislative stage (formulation of the bill).

Similarly, agreement, disagreement, negotiation, power, and acceptance may also vary. At the beginning of the process, there might be general agreement because the debate is centred on identifying general issues rather than particular proposals (systemic agenda). For example in Chile, at the beginning of the process the general issues contained in the National Tourism Agenda were generally agreed by the private and public sectors. Nevertheless, the movement from the systemic to the institutional and decision agendas might change the features of the process and cause disagreement during the policy window and/or legislative stages.

A key element to explain the emergence of disagreement might be the involvement of new organisations. For example, in the Chilean case disagreement emerged once Dipres was involved during the legislative stage. Representatives of these new organisations may not agree with the issues to be included in the institutional or decision agendas and, therefore, they propose new issues. This may occur for two reasons: these new stakeholders might have not been involved in the definition of the systemic agenda and they may have their own agendas during the process of change. 
Because of disagreement, stakeholders may have to negotiate. Negotiation may lead to agreement; however, disagreement may also persist. The features of power and acceptance may help explain how disagreement is resolved (Anastasiadou, 2008; Bramwell, 2006; Bramwell \& Meyer, 2007; Fallon, 2001; Reed, 1997; Thomas \& Thomas, 2005, 2006). Power may explain three key aspects of the process of change. First, power may enable some stakeholders to introduce their proposals into the decision agenda and directly influence the process of change. Second, the use of power may also explain why less powerful stakeholders have no option but to accept the inclusion or rejection of some issues (acceptance). Third, the results of the process of change might be directly influenced by the most powerful stakeholder. In some cases, less powerful stakeholders are able to put forward their agendas and successfully lobby for change. This successful lobby helps illustrate the fact that the features of the process (i.e. the allocation of power) may also change between the different stages of the process.

As this thesis emphasises, changes in these features may be explained by changes in the environmental conditions. Variations in the environmental conditions may change the features of the process and, in turn, changes in these features may directly impact on the debate in Parliament and the results of the process of change. In order to identify changes in these conditions, Figure 8.1 shows an arrow at the lower part of the framework. The arrow aims to present the process of change in a temporal perspective and helps portray changes in the general environmental that may modify the features of the process. For example, variations in the political conditions may change the allocation of power and explain why less powerful stakeholders gain more power at a particular stage (Bramwell \& Meyer, 2007; Reed, 1997; Thomas \& Thomas, 2005, 2006). The environmental conditions influence not only the features of the process but also the results (Pearce, 1992). For example, changes in the organisation of the public sector (e.g. the adoption of NPM) may influence the results of the process of change and explain why a particular structure and roles for the NTA results.

In the light of the generalised conceptual framework (Figure 8.1), the features of the process and the impact of the environmental conditions on these features are critical to understanding how and why NTAs change and why particular outcomes result. 
This shows that the process that leads to the changes is not isolated but is strongly influenced and shaped by the context in which it occurs. As a consequence, future research should give greater attention to the political, policy, and legislative contexts in which the process of change occurs.

\subsection{Implications and contributions of this research}

As presented in Chapters I and II, research investigating changes in NTAs tends to focus on what these changes are and how these changes reflect the general environment in which NTAs change. In spite of the value of that research, two critical aspects have been largely neglected. First, research to date has ignored the process that led to these changes in order to explain how and why these changes occur (Hall, 2008; Hall \& Jenkins, 1995; Kerr, 2003; Pearce, 1992, 1996a, 1996b, 1997); and second, research has not given sufficient attention to the changes in the environmental conditions during the time in which the process occur (Hall, 2008; Hall \& Jenkins, 1995; Kerr, 2003; Pearce, 1992). This last aspect is particularly important because - as emphasised in this thesis - changes in these conditions during the process may influence the features of the process and, in turn, these features may impact on the outcomes. In order to address these neglected aspects, this thesis has emphasised the analysis of three major issues in the case study of Sernatur: these included a) what the process that led to the changes was; b) what factors influenced and shaped this process; and, c) how the outcomes of the process were influenced by both the features of the process and the environmental conditions. By investigating these questions in the case study, this research aimed to provide a better understanding of processes of change in NTAs, especially of the broader issue of how and why NTAs change.

A conceptual framework was proposed to investigate the case study (Figure 2.3). During the analysis of data, some findings could not be explained by some features of the framework (for example, the use of the Policy Cycle Model). Thus, the framework was revisited and modified prompting the development of an integrated conceptual framework to conduct additional data analysis (Figure 2.4). The multiple revisions and changes introduced to the conceptual frameworks (Figure 2.3 and 2.4) 
allowed the researcher to strengthen the analysis and interpretation of data and have a better understanding of the process of change to Sernatur.

After data analysis and interpretation, a generalised conceptual framework to investigate processes of changes in NTAs was presented (Figure 8.1). The framework aims contributes to the literature by providing a generalised approach to investigate processes of change in NTAs. The generalised conceptual framework emphasises the investigation of multiple aspects of a process of change. This has methodological implications that should be considered during the analysis of processes like the one related to Sernatur. Because of the multiple elements of the framework, a wide range of data is required and multiple layers of analysis must be carried out to investigate the policy stages, the components of the process, the features of the process, and the influence of changing environmental conditions. This complexity may, in turn, require multiple phases of data analysis and the adoption of a systematic combining approach which enables the researcher to match findings with the theoretical foundations of the research and increase understanding of the case under investigation.

The generalised conceptual framework also contributes to the tourism literature in three major ways. First, the framework provides an approach to operationalise processes of change in NTAs in other countries. In order to operationalise the policy stages and the components of the policy process, this thesis suggests the use of milestones. These milestones are critical events that help both in identifying when the stages and components occur and in investigating what the characteristics of these stages and components are. For example, the submission of a bill to Parliament signals the start of the debate and decision making in Parliament, while the enactment of the bill shows the end of the legislative stage and the start of implementation. The operationalisation of the process of change based on these stages and components of the policy process may provide a more general approach to investigate processes of change in NTAs and tackle the limitations of the Policy Cycle Model described earlier. The operationalisation of the process as presented here also suggests that greater attention should be given to the literature on policy making and legislative processes. 
Second, the framework shows that evaluation reports play a key role during the entire process of change providing information on the factors that trigger, influence, and shape the process. Being aware of this helps provide a better understanding of how and why evaluations may influence the process and also how these evaluations shape the results of the process of change. Therefore, identifying and investigating these different types of evaluations is a key aspect to consider during the analysis of processes of change in other NTAs.

Third, the framework shows that investigating the outcomes of the process requires attention to two hitherto largely neglected aspects: the features of the process of change and the variation in the environmental conditions during the time in which the process occurs. Key features to consider are consultation, participation, agreement, disagreement, negotiation, power, and acceptance. These features show the mechanisms the stakeholders adopt to influence the process and help to explain how stakeholders mobilise and decide on the tactics they use during a process of change. Environmental conditions, particularly changes in these conditions during the period of change, should also be considered to explain how these features may change and why particular outcomes result from a process.

The generalised conceptual framework might also provide a structure to investigate processes of changes in other Chilean public organisations. Firstly, the characteristics of both the general environment in the country and the Chilean administrative sub-system are aspects that go beyond the analysis of the single case of Sernatur. These characteristics underlie any policy making process in Chile and therefore help investigate any other process of change in the Chilean public sector. Secondly, depicting the policy process in stages, components and features reflects some of the general aspects of the Chilean public administration (highly hierarchical, presidential and legally driven). For example, the framework suggests that the process of change in Sernatur unfolded in three policy stages (pre-legislative, policy window and legislative). Although the particularities and characteristics of these stages in the case might be unique, these stages may also to be identified with other sectors in Chile because the Constitution makes a legislative debate compulsory when conducting any change in the public sector (Chapter IV). 
This research also has several practical implications for the Chilean tourism industry. The process investigated in this thesis finished with the legislative stage; however its implementation is still being carried out. The findings presented in the previous chapters may allow the industry to have a better understanding of policy processes in Chile and to be able either to monitor and influence the implementation of Act 20423 or get involved in a new policy process.

There are several lessons learnt from this case in order to address the implementation of Act 20423 or be involved in a new policy process. As discussed in Chapter IV and VI, the industry played a key role during the pre-legislative stage by establishing the systemic agenda and moving this agenda forward. However, during the policy window and legislative stages the industry was far less involved. This affected the ability of the industry to influence the bill during the formulation and debate in Parliament. Three aspects are critical to understand why this may have occurred: the lack of official mechanisms for participation in Chilean policy making processes; the fragmentation of the industry; and the lack of understanding of policy making in the country by the industry. While the first one is a matter that can only to be addressed by legal modifications to the Constitution, the second and the third completely rest on the industry and its capacity to be organised.

Tackling the fragmentation of the industry and strengthening the organisation of the private sector seems to be critical. This may allow the industry to be better placed to monitor the implementation of Act 20423 or be involved in a new policy process. It has been demonstrated that important goals may be achieved when the industry is organised and works together with the academic sector. For example, when Dipres imposed its power to avoid the creation of a subsecretariat, the industry and academics (Societur) carried out a broad discussion of the bill. As described in Chapter IV and VI, these sectors organised a forum to debate the bill. As a result of this forum, the industry asked the Deputies to revise the bill, in particular in relation to the technical secretariat proposed by Dipres. The organisation of the industry described here - plus Bachelet's commitment to the bill, the power gained by Sernatur during the debate in Parliament and the agreement in the Chamber of Deputies - led to an amendment of the bill and the creation of the Subsecretariat. 
This research has also shown that participation of the industry through the entire policy process is a critical aspect. The industry cannot completely delegate policy processes to the State, such as occurred during the legislative stage (Chapter V and VII). If the industry wants to be involved and move its ideas forward, representatives of the industry need to be actively involved and play a key role in policy formulation, decision making and implementation.

The case examined here also shows the lack of understanding of the industry in both, policy processes and institutional arrangements of the public sector for conducting these processes. For example, the power and importance of Dipres in policy processes in Chile was hardly acknowledged by the industry. In this case, the involvement of Dipres triggered changes in the systemic and institutional agendas, affecting the proposals that industry suggested during the pre-legislative stage. Better understanding of policy processes and being aware of these institutional arrangements may allow the industry to debate and negotiate its agenda with the right organisation and in this way influence the process and its outcomes.

Finally, there were some key aspects suggested by the industry which were not addressed in the tourism bill (for example, the creation of the category of tourist municipalities). Bringing these aspects back to the debate about tourism development in the country may help to establish a new systemic agenda and start a new policy process. In order to move this new agenda forward, the industry needs to look for alliances inside the public sector and once again, address the fragmentation of the industry and improves its understanding of Chilean policy processes.

\subsection{Some reflections about this research}

Four major reflections are presented here for consideration in future research in this field. First, the process of change in Chile could not be operationalised based on the initial conceptual framework (Figure 2.3). This occurred because this framework rested on the Policy Cycle Model and did not address the broader literature on public policies and legislative processes. Thus, new literature reviews were required and an integrated framework was proposed (Figure 2.4). The integrated framework strengthened the theoretical foundations to investigate the case and improve 
understanding of the process but it was time-consuming and delayed the work on research questions two and three. Consequently, future research should give greater attention to the broader literature on public policies and legislative processes.

Second, some trade-off of detail against the broad perspective to investigate the process of change was required. Despite the wide range of data that was collected in the field, some details related to the case were addressed generally without detail. For example, the launch of the Strategy of Innovation might have indirectly supported the idea of strengthening the tourism sector and formulating the tourism bill. The strategy was reviewed and its relevance for the process was cross checked with interviewees' responses but - because the strategy did not directly impact on the process - an in-depth analysis of the Strategy of Innovation was not conducted.

A third aspect relates to the sample of stakeholders interviewed. The sample included a wide range of relevant stakeholders at the national level and two stakeholders at the regional and local levels. Although this group of interviewees provided rich and valuable information, a bigger group of stakeholders from the regional and local levels would have been desirable. The inclusion of more perspectives from these two levels could have helped with cross checking data and investigating, for example, if there were different interpretations between the national, regional, and local levels of the factors that triggered the process of change in Sernatur. Interviewing President Bachelet would have also been desirable. Bachelet played a critical role in the process and therefore getting access to her own interpretation of the case would have increased the understanding of the case. Unfortunately when fieldwork was conducted in Chile, Bachelet was in the New York in charge of the UN-Women agency. Moreover, even if she had been in Chile, getting access to a former President is not easy.

Finally, because of timing no attempt was made to examine the implementation of Act 20423. This omission has two implications. Firstly, according to the literature on public policy, the results of a process should relate to the actual implementation of a new institutional framework. Because Act 20423 was implemented two years after the research design and data collection, the implementation of the act could not be investigated. Secondly, omitting the implementation of Act 20423 may limit 
understanding of the entire process of change in the case. As emphasised in this thesis, variations in the environmental conditions shape the features of the process and its results. Since the actual result of the process is the implementation of Act 20423, possible changes in these conditions after 2011 may have also impacted on the implementation of the act. This suggests the importance of investigating the implementation of Act 20423 in the future and provides avenues for future research.

\subsection{Avenues for future research}

This thesis has emphasised that greater attention has to be given to the broader literature on public policy and legislative process. The thesis has embraced this literature and this has increased understanding of processes of change in NTAs. However, a number of issues emerging from the analysis of the Chilean case suggest that further investigation is still needed. Firstly, researchers could adopt the generalised conceptual framework (Figure 8.1) and use it to investigate processes of institutional change in other NTAs. Investigation of other cases may confirm the utility of the framework, add wider application, or suggest new elements to consider. Future research on NTAs could also give attention to particular aspects of the generalised framework, such as the policy window, with special attention to how the problem, policy, and political streams intersect and how the features of a policy process and the environmental conditions support and impact the opening of the window.

Some components of the policy process presented in Figure 8.1 might also be addressed in future research (e.g. policy agendas, evaluation and implementation). Research could pay more attention to the different types of policy agendas in a process of change (systemic, institutional, and decision). An in-depth investigation of these agendas may increase understanding of stakeholders' interaction and negotiation, how these agendas influence each other, and how these agendas may influence and shape the process of change and its outcomes. The component of evaluation could be also addressed in future research. This thesis has emphasised that different types of evaluations may exist. These evaluations play different roles and influence the process in different ways. Research focused on these types of evaluations may provide a better understanding of the role evaluations play in a 
process of change and how these different types of evaluations impact on the process. Future research addressing implementation would also be desirable. Research could investigate other processes of change in which the NTA resulting from the process has been implemented. As mentioned in the previous section, research could also investigate the implementation of Act 20423 in the Chilean case and provide a better understanding of the entire process of change in the case.

Finally, amongst the features of a process of change, power emerges as critical. In this thesis power was investigated as one of the multiple features of the process in Sernatur. Because of the importance of power to explain the results of a process of change in NTAs suggested in this thesis, future research could give greater attention to power and increase understanding about how stakeholders used power, how power impacts on the policy stages, and how this shapes the components of the process.

\subsection{Conclusions}

This thesis investigated the process of change in Sernatur in order to address the bigger question of how and why NTAs change over time. Three research questions were formulated to investigate the case study. Question one investigated the process of change in Sernatur. The findings in the Chilean case suggest that in countries with Parliamentary democracies processes of institutional change in NTAs occur in the context of legislative processes. This suggests that in future research special consideration should be given to the literature on public policies and legislative process. As also presented in this thesis, these processes are complex because there are multiple components of a policy process (evaluations, agendas, formulation, decision making, and implementation). Because these components were found to overlap in the case under study, this thesis challenges the Policy Cycle Model on the grounds that a clear division of these components in consecutive steps does not exist. The findings also suggest that processes of change in NTAs are not isolated developments. This confirms the position of Hall (2008), Hall and Jenkins (1995), Hall and Kearsley (2001), Jeffries (2001), Kerr, et al. (2001), Kerr (2003), Pearce (1990, 1992, 1996a, 1996b, 1997), and Stevenson, et al. (2008) that changes in NTAs directly reflect the general environment in which these organisations exist. 
The thesis also investigated the factors that trigger, influence, and shape the process of change (question two). Environmental conditions provide information about why a process starts and what triggers the different stages of the process. Similarly, evaluation reports provide insights about what factors trigger changes in NTAs and how these factors influence the proposals discussed over a process of change. As found in Chile, evaluations exist during the entire process of change, which also challenges the Policy Cycle Model which presents evaluation is a single phase of the process. Examination of evaluation reports reveals that they vary depending on who conducts them (internal, external); where they are conducted (as part of the process or in the general environment); and what the objectives of these reports are (of or for policy analysis). As emphasised in this thesis, identifying these types of evaluation reports helps with understanding the proposals contained in the reports and explains how these proposals may influence the process of change.

The thesis also investigated the results of the process of change in Sernatur. The following features of the policy process were investigated to explain these results: agreement, disagreement, negotiation, power, acceptance, consultation, and participation. The analysis of the case study shows that these features are dynamic and change during the process. For example, the allocation and implementation of power may change between the stages and also between the components of the policy process (for example, between formulation and decision making in Parliament). As discussed in this thesis, variation in the environmental conditions is key to explaining changes in these features. In turn, variation in these features may also explain the results of a process of change.

A major aspect emerging from the case study is the influence of the environmental conditions on the process of change. These conditions help to explain how the process occurred, why the process started, what factors influenced the process, and why a particular outcome resulted. The influence of the environmental conditions is even more important considering that the process of change in this case might have finished with a different structure and different roles. The proposal imposed by Dipres and submitted to Parliament considered the creation of a technical secretariat as the NTA. However, Sernatur challenged Dipres' power and push forward the creation of a Subsecretariat: a situation described in Chapter VI as unique in Chilean 
legislative history. The power of President Bachelet and her commitment to the bill, plus variations in the environmental conditions that changed the allocation of power enabled Sernatur to modify the bill and to create the subsecretariat. This suggests that the analysis of the environmental conditions and changes in these conditions might be even more important than the analysis purely focused on the process of change.

Finally, this thesis has emphasised the importance of taking a comprehensive approach to understanding how and why NTAs change over time. This approach should address key aspects already investigated in the literature (that is, why NTAs change or what these changes are) and also consider new aspects such as how these changes occur and how variations in the general environment may shape these changes. In order to develop such a desirable perspective, these key aspects were investigated in the case study of Sernatur. Although the findings presented in this thesis reflect the particularities of the Chilean case, and these findings may not be necessarily generalised, the key aspects investigated here could be used in the future to research other processes of change in NTAs. The adoption of this comprehensive approach will bring greater insights into processes of change in NTAs and in this way increase the understanding of how and why NTAs change over time. 


\section{REFERENCES}

Adamczyk, B. (2005). The national tourism organisations of Poland, the Czech Republic, Slovakia and Hungary - The organisation and activities. Tourism, 53(3), 247-258.

Airey, D. (1984). Tourism administration in the USA. Tourism Management, 5(4), 269-279.

Airey, D., \& Chong, K. (2010). National policy-makers for tourism in China. Annals of Tourism Research, 37(2), 295-314.

Alipour, H., \& Kilic, H. (2005). An institutional appraisal of tourism development and planning: The case of the Turkish Republic of North Cyprus (TRNC). Tourism Management, 26(1), 79-94.

Anastasiadou, C. (2008). Stakeholder perspectives on the European union tourism policy framework and their preferences on the type of involvement. International Journal of Tourism Research, 10(3), 221-235.

Bachelet, M. (2005). Programa de Gobierno Michelle Bachelet. Santiago.

Barzelay, M. (2001). The New Public Management: Improving research and policy dialogue. California: University of California Press, LTd.

Baum, T. (1994). The development and implementation of national tourism policies. Tourism Management, 15(3), 185-192.

Beaumont, N., \& Dredge, D. (2010). Local tourism governance: A comparison of three network approaches. Journal of Sustainable Tourism, 18(1), 7-28.

Bevir, M. (2007). Encyclopedia of Governance. Encyclopedia of Governance. SAGE Publications, Inc. Thousand Oaks, CA: SAGE Publications, Inc.

Bevir, M. (2009). Key Concepts in Governance (First ed.). London: SAGE Publications Ltd.

Birkland, T. (2007). Agenda setting in public policy. In F. Fisher, G. Miller \& M. Sidney (Eds.), Handbook of public policy analysis. Theory, politics and methods (pp. 63-78). New York: Taylor and Francis Group.

Blanco, H., Diaz, A., Marin, A., Victoria, A., Silva, C., \& Ludici, S. (2007). International trade and sustainable tourism in Chile (pp. 72). Winnipeg,: International Institute for Sustainable Development,. 
Blanke, J., \& Chiesa, T. (2008). The Travel \& Tourism Competitiveness Report 2008. Geneva: World Economic Forum.

Blomgren, L. (2011). Collaborative Governance. In M. Bevir (Ed.), The Sage handbook of Governance (pp. 386-401). California: Sage Publications.

Borkan, J. (Ed.). (1999). Immersion/Crystallization (2nd ed.). Thousand Oaks, CA: Sage Publications.

Boston Consulting Group. (2007). Estudio de Competitividad en Clusters de la Economía Chilena. Documento de referencia en turismo. Santiago: Corporacion de Fomento a la Produccion (Corfo).

Bramwell, B. (2006). Actors, power, and discourses of growth limits. Annals of Tourism Research, 33(4), 957-978.

Bramwell, B., \& Meyer, D. (2007). Power and tourism policy relations in transition. Annals of Tourism Research, 34(3), 766-788.

Brudney, J., O'Toole, L., \& Rainey, H. (2000). Advancing public management (1st ed.). Washington: Georgetown University Press.

Brugha, R., \& Varvasovszky, Z. (2000). Stakeholder analysis: A review. Health Policy and Planning, 15(3), 239-246.

C\&S Soluziona Servicios Profesionales. (2004). Servicio Nacional de Turismo: Rediseño Institucional, comprendiendo modificaciones a la Ley Orgánica y Reglamento del Servicio.

Cámara de Diputados de Chile. (2008a). Legislatura 355a, Sesión 125a , en martes 8 de enero de 2008.

Cámara de Diputados de Chile. (2008b). Legislatura 356a . Sesión 126a , en martes 20 de enero de 2009.

Cámara de Diputados de Chile. (2009a). Informe de la Comisión de Hacienda recaído en el proyecto que establece un Sistema Institucional para el Desarrollo del Turismo, modifica Decreto Ley 1224, que crea el Servicio Nacional de Turismo.

Cámara de Diputados de Chile. (2009b). Informe de la Comisión Especial de Turismo recaído en el proyecto que establece un Sistema Institucional para el Desarrollo del Turismo, modifica Decreto Ley 1224, que crea el Servicio Nacional de Turismo y otras normas legales.

Cámara de Diputados de Chile. (2009c). Oficio 7911, Comunica la aprobacion del proyecto de ley en la Camara de Diputados. 
Cámara de Diputados de Chile. (2010a). Como se Hace una Ley? Retrieved 23 of June, 2009, from http://camara.cl/camara/media/docs/formacion ley.pdf

Cámara de Diputados de Chile. (2010b). Oficio 8499: Oficio de Ley a la Presidenta de la República comunica texto aprobado por el Congreso Nacional.

Cámara de Diputados de Chile. (2010c). Tramitacion Boletin 5687-23, Establece un sistema institucional para el desarrollo del turismo, modifica el decreto ley N1224, que crea el Servicio Nacional de Turismo y otras normas legales Retrieved 02 of March, 2010, from http://camara.cl/pley/pley_detalle.aspx?prmID=6076\&prmBL=5687-23

Chacon, M. (2002). Turismo en Chile. Santiago de Chile: Congreso Nacional de Chile.

Choy, D. J. L. (1993). Alternative roles of national tourism organizations. Tourism Management, 14(5), 357-365.

Clark, B. T. (2004). Agenda setting and issue dynamics: Dam breaching on the lower snake river. Society and Natural Resources, 17(7), 599-609.

Conaf. (2004). Política para el desarrollo del ecoturismo en áreas silvestres protegidas del estado y su entorno. Documento de trabajo: Conaf.

Conaf. (2007a). Documento interno de trabajo con la evaluación del proceso de concesiones 2005: Conaf.

Conaf. (2007b). Política para concesiones turísticas al interior de las áreas silvestres protegidas del estado (SNASPE): Conaf.

Conaf. (2011). Estadísticas de visitación a Áreas Protegidas del estado (SNASPE). from http://www.conaf.cl/parques/seccion-estadisticas-de-visitacion.html

Corfo. (2010). Chile y Turismo: Oportunidad para la innovación y el emprendimiento.

Creswell, J. (2007). Qualitative inquiry and research design: choosing among five approaches (2nd ed.). California: Sage Publications Inc.

Cybertur. (2009). Se estan haciendo grandes esfuerzos para potenciar la industria turistica. $\quad$ Retrieved February 04, 2011, from http://www.cybertour.cl/modules.php?name=News\&file $=$ article $\&$ sid $=860$

Dinica, V. (2009). Governance for sustainable tourism: A comparison of international and Dutch visions. Journal of Sustainable Tourism, 17(5), 583603. 
Dipres. (2000). Ley de Presupuesto del Sector Público Año 2001. Retrieved 20 of May, 2011, from www.dipres.cl

Dipres. (2001). Ley de Presupuesto del Sector Público Año 2002. Retrieved 20 of May, 2011, from www.dipres.cl

Dipres. (2002). Ley de Presupuesto del Sector Público Año 2003. Retrieved 20 of May, 2011, from www.dipres.cl

Dipres. (2003). Ley de Presupuesto del Sector Público Año 2004. Retrieved 20 of May, 2011, from www.dipres.cl

Dipres. (2004). Ley de Presupuesto del Sector Público Año 2005. Retrieved 20 of May, 2011, from www.dipres.cl

Dipres. (2005a). Evaluacion comprehensiva Programa Aplicacion Ley N 19.255 $(C P T)$.

Dipres. (2005b). Evaluacion Comprehensiva Programa Nacional de Areas Silvestres Protegidas del Estado-SNASPE.

Dipres. (2005c). Ley de Presupuesto del Sector Público Año 2006. Retrieved 20 of May, 2011, from www.dipres.cl

Dipres. (2006). Ley de Presupuesto del Sector Público Año 2007. Retrieved 20 of May, 2011, from www.dipres.cl

Dipres. (2007). Ley de Presupuesto del Sector Público Año 2008. Retrieved 20 of May, 2011, from www.dipres.cl

Dipres. (2008). Ley de Presupuesto del Sector Público Año 2009. Retrieved 20 of May, 2011, from www.dipres.cl

Dipres. (2009). Ley de Presupuesto del Sector Público Año 2010. Retrieved 20 of May, 2011, from www.dipres.cl

Dipres. (2011). Programa de Mejoramiento de Gestión (PMG). Retrieved 12 of June, 2011, from http://www.dipres.gob.cl/572/propertyvalue-15230.html

Dredge, D. (2006a). Networks, conflict and collaborative communities. Journal of Sustainable Tourism, 14(6), 562-581.

Dredge, D. (2006b). Policy networks and the local organisation of tourism. Tourism Management, 27(2), 269-280.

Dredge, D., \& Jenkins, J. (2003). Federal-State relations and tourism public policy, New South Wales, Australia. Current Issues in Tourism, 6(5), 415-443.

Dredge, D., \& Whitford, M. (2011). Event tourism governance and the public sphere. Journal of Sustainable Tourism, 19(4-5), 479-499. 
Dubois, A., \& Gadde, L.-E. (2002). Systematic combining: an abductive approach to case research. Journal of Business Research, 55(7), 553-560.

El Mercurio. (2000a). Lagos promete desarrollo turistico. Emol Retrieved 15 of June 2010

El Mercurio. (2000b). Para solucionar los problemas del sector: Turismo pide voluntad politica. Emol Retrieved 15 of june, 2010

El Mercurio. (2000c). Politica de Turismo. Emol Retrieved 24 of June, 2010

El Mercurio. (2001a). Dentro de la reforma estatal evaluan una subsecretaria o viceministerio. Retrieved 15 of Julio, 2009

El Mercurio. (2001b). Elaboran propuesta para el turismo. Retrieved 15 of August, 2009

El Mercurio. (2005). Hay actualmente trabas al turismo? Emol Retrieved 08 of February, 2010

El Mercurio. (2006a). Bachelet mantiene equilibrio politico con nombramientos.

El Mercurio. (2006b). Bachelet remueve a Zaldivar, Zilic y Antonijevic en su primer cambio de gabinete. Retrieved 07 of February, 2011

El Mercurio. (2006c). El turismo busca una nueva organizacion gremial. Retrieved February 08, 2010

El Mercurio. (2006d). Gobierno alista plan para impulsar el turismo. Retrieved 08 of February, 2010

El Mercurio. (2006e). Gobierno define nueva agenda para el turismo. Emol Retrieved 08 of February, 2010

El Mercurio. (2007a). Bachelet envia proyecto al Congreso para crear subsecretaria de turismo. Retrieved 17 of April, 2009

El Mercurio. (2007b). Turismo Tendra Subsecretaria y Mayores Recursos. Retrieved 08 of February, 2010

El Mercurio. (2008). Bachelet realiza tercer cambio de gabinete para enfrentar nueva etapa de Gobierno. Retrieved 07 of February, 2011

El Mercurio. (2009). Turismo constituye federacion que reune a toda la industria. Retrieved February 04, 2011

Fallon, F. (2001). Conflict, power and tourism on Lombok. Current Issues in Tourism, 4(6), 481-502.

Farazmand, A., \& Pinkowski, J. (2007). Handbook of Globalization, Governance and Public Administration (1sr ed.): CRC Press. 
Gobierno de Chile. (1980). Constitución Política de Chile

Gobierno de Chile. (1986). Ley Orgánica Constitucional 18575 sobre de Bases de la Administración del Estado.

Gobierno de Chile. (1992). Ley Orgánica Constitucional 19175 sobre Gobierno y Administración Regional.

Gobierno de Chile. (2005a). Constitución Política de Chile Santiago de Chile.

Gobierno de Chile. (2005b). Ley Orgánica Constitucional del Congreso de Chile.

Gobierno de Chile, \& Congreso de Chile. (2003). Acuerdo Político-Legislativo para la modernización del estado, la transparencia y la promoción del crecimiento

Gobierno de Chile, \& Ministerio de Economia Fomento y Reconstruccion. (2007). Proyecto de ley que crea el sistema institucional para el desarrollo del turismo.

Guba, E. G., \& Lincoln, Y. S. (1994). Competing Paradigms in Qualitative Research. In N. K. Denzin \& Y. S. Lincoln (Eds.), Handbook of Qualitative Research. California: Sage Publications.

Hall, M. (2008). Tourism Planning: Policies, Processes and Relationships (2d ed. ed.).

Hall, M., \& Jenkins, J. (1995). Tourism and public policy (1st ed.). New York: Routledge.

Hall, M., \& Kearsley, G. (2001). Tourism in New Zealand: an introduction. South Melbourne: Oxford University Press.

Ham, C., \& Hill, M. (1984). The policy process in the modern capitalist state (1st ed.). New York: Harvest Wheatsheaf.

Hill, M. (Ed.). (2005). The public policy process (4th ed.). Harlow, England: Pearson Longman.

Howlett, M., \& Ramesh, M. (2003). Studying public policy: policy cycles and policy subsystems. Don Mills, Ont: Oxford University Press.

Hughes, O. (2003). Public Administration and Management (3rd ed.). New York: Palgrave Macmillan.

InnovaChile Corfo. (2007). Agendas de Innovacion en Destinos Turisticos: Corfo. Inter American Development Bank. (2007a). Loan proposal to strengthen Conaf. Inter American Development Bank. (2007b). Loan Proposal to Strengthen the Chilean tourism sector. 
Jann, W., \& Wegrich, K. (2007). Theories of the Policy Cycle. In F. Fisher, G. Miller \& M. Sidney (Eds.), Handbook of Policy Analysis

CRC Press.

Jansson, A., \& Parding, K. (2011). Changed governance of public sector organisations=challenged conditions for intra-professional relations? The International Journal of Public Sector Management, 24(3), 177-186.

Jeffries, D. (2001). Tourism and governments (1st ed.). Woburn: Reed educational and Professional Publishing Ltda.

Kerr, W. R. (2003). Tourism public policy and the strategic management of failure (1st ed.). Oxford: Elvesier Ltda.

Kerr, W. R., Barron, G., \& Wood, R. (2001). Politics, policy and regional tourism administration: A case examination of Scottish area tourist board funding. Tourism Management, 22(6), 649-657.

Kingdon, J. W. (1995). Agenda, Alternatives and Public Policies. New York: HarperCollings College Publishers.

La Estrella de Iquique. (2006). En Humberstone se celebro el dia mundial del turismo.

La Nación. (2006). Bachelet Asumió como presidenta de Chile. La Nación

Retrieved 15 of May, 2010, from http://www.lanacion.com.ar/787975-bacheletasumio-como-presidenta-de-chile

La Nación (2006a). Gabinete clave ya esta en marcha. Retrieved 29 of September, 2010

La Nación (2006b). Presidenta Bachelet anució plan para potenciar al país como destino turístico. Retrieved 07 of February, 2011

La Tercera. (2006). Gobierno define nueva agenda para el turismo. Latercera online Retrieved 02 February, 2010

Lahera, E., \& Cabezas, M. (2000). Governance and institutional development of the Chilean economy. Journal of International Development, 12(8), 1087-1109.

Marshall, C., \& Rossman, G. (2006). Designing qualitative research (4th ed.). California: Sage Publications Ltda.

McCarthy, B. (2012). From fishing and factories to cultural tourism: the role of social entrepreneurs in the construction of a new institutional field. Enterpreneurship and regional development, 24(3-4), 259-282. 
McLaverty, P. (2011). Participation. In M. Bevir (Ed.), The Sage handbook of Governance (pp. 402-418). California: Sage publications.

Meethan, K. (1998). New tourism for old? Policy developments in Cornwall and Devon. Tourism Management, 19(6), 583-593.

Mehmetoglu, M., \& Altinay, L. (2006). Examination of grounded theory analysis with an application to hospitality research. International Journal of Hospitality Management, 25(1), 12-33.

Ministerio de Economía Fomento y Reconstrucción. (1975). DL 1224 Crea el Servicio Nacional de Turismo. Retrieved from http://www.leychile.cl/Navegar?idNorma=6519\&tipoVersion=0.

Ministerio de Economía Fomento y Reconstrucción. (1987). DS 227: Aprueba el reglamento de clasificación, calificación y registro de establecimientos que presten servicios de alojamiento turístico; deroga el decreto 103 de 1986. Retrieved from http://www.leychile.cl/Navegar?idNorma=11264\&tipoVersion=0.

Ministerio de Economía Fomento y Reconstrucción. (1989). Decreto 118 Modifica Reglamento del Servicio Nacional de Turismo. Retrieved from http://www.leychile.cl/Navegar?idNorma=123918.

Ministerio de Economía Fomento y Reconstrucción. (1990). Adecua Plantas y Escalafones del Servicio Nacional de Turismo al Articulo 5 de la ley 18834,sobre; Estatudo Administrativo.

Ministerio de Economía Fomento y Reconstrucción. (1993). Ley 19255: Modifica Articulo 5 del Decreto Ley 1224, de; 1975, que crea el Servicio Nacional de Turismo. Retrieved from http://www.leychile.cl/Navegar?idNorma=30622\&buscar=19255.

Ministerio de Economía Fomento y Reconstrucción. (2003). Aprueba el reglamento de clasificación, calificación y registro de establecimientos que presten servicios de alojamiento turístico; deroga el decreto 103 de 1986.

Ministerio de Economía Fomento y Reconstrucción. (2004). DL 1224 Crea el Servicio Nacional de Turismo. Retrieved from http://www.leychile.cl/Navegar?idNorma=6519\&idParte=8784369\&idVersio $\mathrm{n}=2004-07-29$.

Ministerio de Economía Fomento y Reconstrucción. (2006). Aprueba reglamento para la aplicación del articulo 5, N22, del DL 1224 de 1975. 
Ministerio de Economía Fomento y Reconstrucción. (2007). Adecua Plantas y Escalafones del Servicio Nacional de Turismo al Articulo 5 de la ley 18834,sobre; Estatudo Administrativo. Retrieved from http://www.leychile.cl/Navegar?idNorma=3759.

Ministerio de Economía Fomento y Reconstrucción. (2010). Ley 20423 "Del Sistema Institucional para el Desarrollo del Turismo". Retrieved from http://www.leychile.cl/Navegar?idNorma=1010960\&buscar=20423.

Ministerio de Hacienda. (1980). DL 3477 "Establece normas de caracter presupuestario. de administracion financiera y de personal"

Moreno, C. (2008). Transferencia de políticas y construcción de lecciones para la modernización administrativa Revista Venezolana de Gerencia, 12(44), 531542.

Olavarría, M. (2007). Documento de Trabajo: Conceptos básicos en el análisis de políticas publicas: Universidad de Chile.

Olavarría, M., Navarrete, B., \& Figueroa, V. (2011). Cómo se formulan las políticas públicas en Chile? Política y Gobierno, 18(1), 109-154.

Organisation for Economic Co-operation and Development. (2010). OECD Tourism $\begin{array}{llll}\text { and } & \text { Trends } & 2010 & \text { Available }\end{array}$ http://books.google.co.nz/books?id=bQum9p3q6UYC\&pg=PA75\&dq=travel tand+tourism+competitiveness+report+2010\&hl=en\&ei=sMJITe30JJSksQO zrs35Cg\&sa=X\&oi=book_result\&ct=result\&resnum=4\&ved=0CFIQ6AEwA $\underline{\mathrm{w} \# \mathrm{v}=\text { onepage } \& \mathrm{q} \& \mathrm{f}=\text { false }}$

Organizaciones Sindicales de Conaf. (2008). Presentacion Organizaciones Sindicales de Conaf acerca de la ley de turismo.

P4, \& Tourism Resource Consultants. (2008). Consultoría para el diseño de Programas y Agendas estratégicas del clúster turismo.

Parsons, D. W. (1995). Public Policy: an introduction to the theory and practice of policy analysis: Aldershot Hants.

Pearce, D. (1990). Tourism in Ireland. Questions of scale and organization. Tourism Management, 11(2), 133-151.

Pearce, D. (1992). Tourism organisations (1st ed.). England: Longman Group UK Limited.

Pearce, D. (1996a). Federalism and the organization of tourism in Belgium. European Urban and Regional Studies, 3(3), 189-204. 
Pearce, D. (1996b). Tourist organizations in Sweden. Tourism Management, 17(6), 413-424.

Pearce, D. (1997). Tourism and the autonomous communities in Spain. Annals of Tourism Research, 24(1), 156-177.

Pearce, D. (2000). Tourism plan reviews: Methodological considerations and issues from Samoa. Tourism Management, 21(2), 191-203.

Pearce, D. (2012). Frameworks for Tourism Research (1st ed.). Oxfordshire: CABI.

Pedersen, R. A., Sehested, K., \& Sorensen, E. (2011). Emerging theoretical understanding of pluricentric coordination in public governance. American Review of Public Administration, 41(4), 375-394.

Peters, G., \& Pierre, J. (2003). Handbook of Public Administration (1st ed.). London: Sage Publications Ltd.

Pforr, C. (2001). Tourism policy Australia's Northern Territory: A policy process analysis of its tourism development masterplan. Current Issues in Tourism, 4(2-4), 275-307.

Pforr, C. (2005). Three lenses of analysis for the study of tourism public policy: A case from northern Australia. Current Issues in Tourism, 8(4), 323-343.

Pforr, C. (2006). Tourism policy in the making: An Australian network study. Annals of Tourism Research, 33(1), 87-108.

Pliscoff, C. (2008). Modernización de la Gestión Pública en el Primer Tiempo: Avances y retrocesos. Agenda Publica, Enero 2008.

Princen, S. (2007). Agenda-setting in the European Union: A theoretical exploration and agenda for research. Journal of European Public Policy, 14(1), 21-38.

Putnam, L., \& Pacanowsky, M. (1983). Comunication and Organizations, An Interpretive approach (First ed.). California: Sage Publications, Inc.

Quinn, M. (2002). Qualitative research and evaluation methods (3dr ed.). California: Sage publications Ltda.

Radio Cooperativa. (2007). Presidenta anunció envió de proyecto para crear la Subsecretaría de Turismo. Retrieved 01 of February, 2011

Reed, M. G. (1997). Power relations and community-based tourism planning. Annals of Tourism Research, 24(3), 566-591.

Richter, L. K. (1985). Fragmented politics of US tourism. Tourism Management, 6(3), 162-173. 
Sabatier, P. (1999). Theories of policy process (1st ed.). Boulder, Colorado: Westview Press.

Sabatier, P. (2007). Theories of policy process (2nd ed.). Boulder, Colorado: Westview Press.

SCL Econometrics S.A. (2008). Evaluación de Impacto Programa Aplicación Ley N19255, Promoción Turística de Chile en el extranjero (pp. 206).

Scodanibbio, L. (2011). Opening a policy window for organisational change and full-cost accounting: The creation of BC Hydro's water use planning program. [doi: 10.1016/j.ecolecon.2010.12.022]. Ecological Economics, 70(5), 1006-1015.

Scott, N., Cooper, C., \& Baggio, R. (2008). Destination Networks. Four Australian Cases. Annals of Tourism Research, 35(1), 169-188.

Senado de la República de Chile. (2005a). Senador José Garcia Ruminot propondrá la creación de un ministerio de turismo. Retrieved 15 of June, 2009

Senado de la República de Chile. (2005b). Senadores Gazmuri y Garcia pidieron al gobierno creación del ministerio de turismo. Retrieved 15 of June, 2009

Senado de la República de Chile. (2009a). Diario de Sesiones del Senado, Legislatura 357ª Sesión 77a , en lunes 21 de diciembre de 2009.

Senado de la República de Chile. (2009b). Diario de Sesiones del Senado, Legislatura 357ª Sesión 78a en martes 22 de diciembre de 2009.

Senado de la República de Chile. (2009c). Oficio 1058: Oficio de aprobación del proyecto con moficaciones.

Senado de la República de Chile. (2009d). Primer Informe de la Comisión de Economía

Senado de la República de Chile. (2009e). Primer Informe de la Comisión de Hacienda.

Senado de la República de Chile. (2009f). Segundo Informe de la Comisión de Economía

Sepulveda, C. (2001). La economia del turismo en Chile, politicas publicas y recursos humanos.

Sernatur. (2001). Comportamiento del turismo receptivo 2001. Santiago: Sernatur.

Sernatur. (2002). Chile País Turístico: Mesa Publico Privada, Agenda Nacional de Turismo 2002-2005.

Sernatur. (2005). Política Nacional de Turismo 
Sernatur. (2006a). Balance de Gestión Integral 2006.

Sernatur. (2006b). Plan de Acción en Turismo 2006-2010.

Sernatur. (2006c). Propuesta de Ley de Turismo.

Sernatur. (2006d). Zonas y Cetros de Interes Turístico: Procedimientos para Elaborar una Declaratoria. Santiago: Sernatur.

Sernatur. (2007a). Balance de Gestión Integral 2007.

Sernatur. (2007b). Sistema de Calidad para los Servicios Turísticos 2004-2007.

Sernatur. (2008a). Balance de Gestión Integral 2008. Retrieved from http://www.sernatur.cl/institucional/archivos/quienes/datos_historicos/Dipres 2008.pdf.

Sernatur. (2008b). Zonas y Centros de Interes Turístico: Antecedentes Basicos para una Estrategia de Ordenamiento Territorial. Santiago: Sernatur.

Sernatur. (2010). Una decada del Turismo en Chile: Balance de Gestión

Sernatur, \& INE. (2008). Informe Anual de Turismo 2007.

Sernatur, \& INE. (2009). Informe Anual de Turismo 2008.

Sernatur, \& INE. (2010). Informe Anual de Turismo 2009.

Shone, M. C., \& Memon, A. (2008). Tourism, public policy and regional development: A turn from neo-liberalism to the new regionalism. Local Economy, 23(4), 290-304.

Sidney, M. (2007). Policy Formulation: Design and Tools. In F. Fisher, G. Miller \& M. Sidney (Eds.), Handbook of Public Policy Analysis: Theories, Politics and Methods. 2007: Taylor and Francis Group.

Sociedad Chilena de Investigadores en Turismo. (2008). ler Foro Nacional de Turismo: Indicaciones y recomendaciones al proyecto de ley de turismo.

Stevenson, N., Airey, D., \& Miller, G. (2008). Tourism Policy Making: The Policymakers' Perspectives. Annals of Tourism Research, 35(3), 732-750.

Strauss, A., \& Corbin, J. (1998). Basics of Qualitative Research: Techniques and Procedures for Developing Grounded Theory (2nd ed.). California, USA: Sage Publications Inc.

Tamborini, C. (2005). The reinvented state in emerging industries: a comparison of tourism in Peru and Chile. University of Texas, Austin.

Tecklin, D., Bauer, C., \& Prieto, M. (2011). Making environmental law for the market: the emergence, character, and implications of Chile's environmental 
regime. [doi: 10.1080/09644016.2011.617172]. Environmental Politics, 20(6), 879-898.

Thomas, R., \& Thomas, H. (2005). Understanding tourism policy-making in urban areas, with particular reference to small firms. Tourism Geographies, 7(2), 121-137.

Thomas, R., \& Thomas, H. (2006). Micro politics and micro firms: A case study of tourism policy formation and change. Journal of Small Business and Enterprise Development, 13(1), 100-114.

Timur, S., \& Getz, D. (2008). A network perspective on managing stakeholders for sustainable urban tourism. International Journal of Contemporary Hospitality Management, 20(4), 445-461.

Tolish, M., \& Davidson, C. (1999). Starting Fieldwork: An introduction to Qualitative Research in New Zealand

(First ed.). Auckland, New Zealand: Oxford University Press.

Treuren, G., \& Lane, D. (2003). The tourism planning process in the context of organised interests, industry structure, state capacity, accumulation and sustainability. Current Issues in Tourism, 6(1), 1-22.

Turner, M., \& Hulme, D. (1997). Governance, Administration and Development: Making the state work (1st ed.). Conneticut: Macmillan Press Ltd.

Tyler, D., \& Dinan, C. (2001). The role of interested groups in England's emerging tourism policy network. Current Issues in Tourism, 4(2-4), 210-252.

United Nations World Tourism Organisation. (1996). NTAs budget standard monitoring.

United Nations World Tourism Organisation. (2005). Structures, spheres of competence and activities of National Tourism Administrations.

United Nations World Tourism Organisation. (2006). Structure and budgets of National Tourism Organisations.

Universidad Católica de Valparaíso. (2009). Estudio Diagnostico Institucional del Servicio Nacional de Turismo.

Universidad de Chile. (2007). Institucionalidad pública para el turismo.

Varvasovszky, Z., \& Brugha, R. (2000). How to do (or not to do)...: A stakeholder analysis. Health Policy and Planning, 15(3), 338-345.

Vernon, J., Essex, S., Pinder, D., \& Curry, K. (2005). Collaborative policymaking: Local sustainable projects. Annals of Tourism Research, 32(2), 325-345. 
Waissbluth, M. (2005). La reforma del Estado en Chile 1990-2005. Diagnostico y propuestas de futuro.

Waissbluth, M., \& Inostroza, J. (2007). Globalización y Reforma del Estado en Chile. Iberoamericana Nordic Journal of Latin American and Caribean Studies, 37(1), 25.

Waters, R. (2011). The mosaic of Govenance: Creating a picture with definitions, theories and debates. The Policy Studies Journal, 39(1).

Wesley, A., \& Pforr, C. (2010). The governance of coastal tourism: Unravelling the layers of complexity at Smiths Beach, Western Australia. Journal of Sustainable Tourism, 18(6), 773-792.

Wollmann, H. (2007). Policy evaluation and evaluation research In F. Fisher, G. Miller \& M. Sidney (Eds.), Handbook of public policy analysis. New York: Taylor and Francis Group.

Yin, R. (2003). Case study research: design and methods (3rd ed.). California: Sage publications.

Yüksel, F., Bramwell, B., \& Yüksel, A. (2005). Centralized and decentralized tourism governance in Turkey. Annals of Tourism Research, 32(4), 859-886.

Zhang, H. (2010). A study on the role of government in China's tourism development. Paper presented at the 2010 International Conference on Management and Service Science, Wuhan. 
Appendix A:

Secondary data investigated at Phase I (approaching the case) 


\begin{tabular}{|l|l|}
\hline \multicolumn{1}{|c|}{ Document name } & \multicolumn{1}{c|}{ Author } \\
\hline DL 1224 Crea el Servicio Nacional de Turismo & Sernatur \\
\hline $\begin{array}{l}\text { Chile País Turístico, Mesa publica privada y agenda de trabajo 2002- } \\
2005\end{array}$ & Sernatur \\
\hline $\begin{array}{l}\text { Servicio Nacional de Turismo: Rediseño Institucional, compendio } \\
\text { modificaciones a la Ley Orgánica y Reglamento del Servicio }\end{array}$ & C\&S Solution \\
\hline Política Nacional de Turismo & Sernatur \\
\hline Institucionalidad Pública para el Turismo & U Chile \\
\hline News reports from 2000-2010 & Different sources \\
\hline Bill submitted to Parliament & Ministry of Economy \\
\hline
\end{tabular}




\section{Appendix B:}

Comparative analysis to design the set of questions for the interviews - the case of the role of Marketing 


\begin{tabular}{|c|c|c|c|}
\hline Function & Overview & Role & Description \\
\hline \multirow[t]{3}{*}{ Marketing } & \multirow{3}{*}{$\begin{array}{l}\text { Despite the fact that marketing is } \\
\text { one of the main roles of Sernatur, } \\
\text { since the } 1990 \text { s' }^{\prime} \text { the international } \\
\text { marketing role has been basically } \\
\text { carried out by Tourism Chile. } \\
\text { Tourism Chile is a private public } \\
\text { joint venture focused on } \\
\text { international marketing. This } \\
\text { scheme of private and public } \\
\text { cooperation has its basis in a } \\
\text { modification to the Act 1224, } \\
\text { which allowed Sernatur to } \\
\text { provide funds to private } \\
\text { corporations to carry out } \\
\text { marketing actions. In spite of a } \\
\text { consultancy recommendation in } \\
\text { 2004 to keep this scheme, an } \\
\text { evaluation report suggested in } \\
\text { 2007 suggested a big change in } \\
\text { order to bring back international } \\
\text { marketing to Sernatur as part of } \\
\text { its main role. This suggestion } \\
\text { was considered in the bill before } \\
\text { Parliament, and the enacted act } \\
\text { considers that Sernatur must be } \\
\text { completely responsible for } \\
\text { international marketing. This } \\
\text { change means leaving the idea of } \\
\text { a public and private funding } \\
\text { scheme for tourism marketing, } \\
\text { which is justified by the idea that } \\
\text { international marketing is a } \\
\text { public good. }\end{array}$} & Propose & $\begin{array}{l}\text { 1) Currently Sernatur and Tourism Chile defines annual tourism marketing actions } \\
\text { 2) The consultancies suggest: } \\
\text { - Keep the current scheme of collaboration with tourism Chile. Thus, Tourism Chile propose the actions } \\
\text { (Consultancy 2004) } \\
\text { - The technical secretariat suggests the formulation of a national marketing in charge of proposing actions } \\
\text { (Consultancy 2007) } \\
\text { 3) The bill considers: } \\
\text { - The Council of Ministers for Tourism defines general features of marketing policy } \\
\text { - A National Committee for Tourism is created. This committee proposes a plan with marketing actions } \\
\text { - The technical secretariat proposes the plan for its approval } \\
\text { 4) The enacted act considers: } \\
\text { - The Committee of Ministers for Tourism defines general features of marketing policy } \\
\text { - A National Council for Marketing is created to propose a marketing plan } \\
\text { - The sub secretariat of tourism proposes the plan for its approval }\end{array}$ \\
\hline & & Approve & $\begin{array}{l}\text { 1) Currently Sernatur and Tourism Chile approve marketing actions proposed by themselves } \\
\text { 2) The consultancies suggest: } \\
\text { - Keep the current scheme of collaboration with Tourism Chile. Tourism Chile directory approves marketing } \\
\text { actions (Consultancy 2004) } \\
\text { - The Council of Ministers for Tourism approved a marketing plan (Consultancy 2007) } \\
\text { 3) The bill considers that the Council of Ministers approves marketing actions } \\
\text { 4) The enacted act considers that the Committee of Ministers for Tourism approves marketing actions }\end{array}$ \\
\hline & & Implement & $\begin{array}{l}\text { 1) Currently Tourism Chile implements international marketing actions. Sernatur provides } 50 \% \text { of the total } \\
\text { international marketing actions budget. National Marketing is implemented by Sernatur } \\
\text { 2) The consultancies suggest: } \\
\text { - The joint venture scheme implemented between Sernatur and Tourism Chile should be kept. Then, Tourism } \\
\text { Chile is in charge of implementing marketing actions (Consultancy 2004) } \\
\text { - The joint venture between Sernatur and the private sector must be replaced with a new scheme. The new } \\
\text { scheme considers Sernatur is in charge of implementing international marketing actions. This proposal is } \\
\text { based on the idea that international marketing is a public good which must be provided by the State } \\
\text { (Consultancy 2007) } \\
\text { 3) The bill considers that Sernatur must implement marketing actions. The bill also proposes that Sernatur } \\
\text { provide funds to Tourism Chile. However, one year after the bill is enacted, Sernatur is no longer to be able to } \\
\text { provide more funds and since then Sernatur is completely responsible for implementing international tourism } \\
\text { marketing } \\
\text { 4) The enacted act considers that Sernatur must implement marketing actions. The act also proposes that } \\
\text { Sernatur can provide funds to Tourism Chile up for the period of two years. After two years, Sernatur must not } \\
\text { provide more funds to Tourism Chile and since then Sernatur is completely responsible of implementing } \\
\text { international marketing }\end{array}$ \\
\hline
\end{tabular}




\section{CONCLUSIONS}

In 2004 a consultancy suggested keeping the current private and public cooperation for international marketing. However in 2007 a new consultancy proposed leaving the private public cooperation scheme and suggested implementing a new scheme completely led by the public sector. Then, exploring the consultancies carried out in 2004 and 2007 may provide important clues to understand the changes in tourism marketing perspectives and help to understand why a change between the two consultancies occurs. In addition, because major changes in the consultancies' proposals may be explained by changes in the environmental conditions and people involved during the consultancies, it is relevant to look for the political and economic conditions at the time the consultancies were commissioned and formulated, as well as who commissioned each consultancy. It is known that Sernatur directly commissioned the consultancy in 2004, while in 2007 it was the Ministry of Economy. Therefore, it is important to understand if there is there some relation between who commissioned the consultancy and changes in the marketing scheme proposed by both consultancies? How these changes may be explained? What was different among Sernatur and the Ministry of economy perspectives to trigger the change in the marketing approach?

Whereas the act passed in Parliament considers U Chile marketing proposal, it is necessary to explore the process by which this particular consultancy was carried out. In particular, What was the process to formulate the proposal of marketing? How was this proposal discussed and approved with Sernatur and the Ministry of Economy? What was the private sector involvement in discussing the marketing proposal in the consultancy? What was the private sector position about a change in the marketing scheme? Did the private sector have a different proposal? Was the private sector's proposal considered in the consultancy? Was Tourism Chile involved in this discussion and what was its opinion?

After U Chile consultancy was carried out, its main marketing suggestions were considered in the bill before Parliament. Therefore, it is also important to explore the process by which the marketing aspects were included in the bill and then discussed in Parliament. In the bill formulation process, as well as the decision making process in the Parliament, it is relevant to explore what the process was to formulate the marketing proposals in the bill? Who was in charge of formulating it? Was the private sector involved in the bill formulation and decision making processes and how was the private sector involved? Did the private sector propose changes to the marketing scheme proposed in the bill and if changes were proposed, why were these changes not considered? Who led the formulation process of the marketing aspect of the bill and who led the discussion of these aspects in Parliament? Who led the process in the private sector? What was Tourism Chile's position about this change and how was Tourism Chile involved in the bill formulation and decision making discussion?

In relation to the particular roles in marketing, the enacted act considers important changes in defining, approving and implementing marketing policy and plans. In particular, the act considers that the Committee of Ministers defines the general marketing policy, a national marketing council proposes a plan, the sub secretariat of tourism presents the plan to be approved by the Committee of Ministers and Sernatur implements the plan. The creation of a marketing council is probably one of the most relevant changes. While nowadays marketing actions are proposed by Tourism Chile, the enacted act considers that the marketing plan will be proposed by a marketing council composed of private and public stakeholders. The argument to trigger this change is provided by U Chile consultancy (2007). The consultancy highlights that the current scheme tends to privilege only Tourism Chile members. Since not all of the tourism industry is represented in Tourism Chile (i.e. smaller tourism operators) UChile's proposal suggests transferring the marketing role to the State. This change would ensure the promotion of the country as a destination and seek greater impact on those who are not members of Tourism Chile. Based on a change in the role of proposing the marketing plan, it is relevant to understand who proposed this change and why it was proposed. It is clear that Tourism Chile loses power in the new scheme. In the new scheme, Tourism Chile has both less influence in defining marketing actions and budget to carry out its own actions. Thus it is relevant to explore What is Tourism Chile position about the new scheme? How is Tourism Chile going to be engaged in the new structure? How is Tourism Chile going to face international marketing after Sernatur leaves transferring funds?

In regards to the role of approving marketing plans there is another big difference. While the current approval is taken by Tourism Chile (Sernatur and private sector which integrates Tourism Chile), the passed bill considers that the Committee of Ministers for Tourism is completely responsible for approving marketing plans. It means that the private sector does not have any involvement in the marketing policy approval and loses participation in strategic marketing decisions. Thus, again What is Tourism Chile's position in relation to 
this change? Why was this particular structure proposed? Who proposed this structure? In relation to the implementation, the enacted act also indicates that an international marketing plan must be completely funded and directly implemented by Sernatur. U Chile consultancy (2007) highlights that the main argument to transfer implementation from Tourism Chile to Sernatur is that marketing must be a public good, and thus it needs to be provided by the State. In addition, the consultancy also highlights that current marketing actions, carried out by Tourism Chile, do not represent the whole tourism sector. Because of this argument, the act considers that Sernatur must be completely in charge of implementing marketing actions. Considering this change an important question emerges. If nowadays the total marketing budget is provided by Sernatur and the private sector (each one provides 50\%), in this the new scheme will the State be able to provide the remaining $\mathbf{5 0 \%}$ that the private sector will not provide? This is a good question, because the current public funding for tourism marketing is one of the lowest in comparison with most South American countries. Considering changes in the roles of proposing, approving and implementing marketing plans, the research needs to explore who proposed these changes, why these changes were proposed; what are the ideas underlying this change; what is Tourism Chile's position about the changes in the whole public marketing approach, what is the opinion of those members who are not part of Tourism Chile, how was the private sector involved in the formulation of this proposal during the consultancy, the formulation of the bill and the decision making process in the congress.

Finally, the public institutional framework highlights that there are at least two organisations related to the image of the country overseas: Country Image Foundation and Prochile. These organisations carry out international marketing plans for promoting the image of the country, including Chilean attractions and general tourism services. A main question arises in this regard which is how these organisations and their plans are related to the new tourism marketing scheme? In summary, in the new scheme the private sector seems to be involved just as a collaborator in formulating marketing policy through the marketing council. However, strategic roles of marketing plans approval and implementation are going to be part of the State responsibility. The practical implication of this change is a change in the marketing framework for tourism. In particular, tourism marketing is moving from a system where the private sector led marketing actions in collaboration with the public sector, towards one where marketing is led by the public sector in collaboration with the private one. 
Appendix C:

Checklist of Questions 


\section{"Institutional Change in National Tourism Administrations (NTAs): The case of Sernatur"}

Good morning (afternoon):

This interview is part of my PhD research at Victoria University of Wellington, entitled "Institutional Change in National Tourism Administrations (NTAs): The case of the Chilean Tourism National Board - Sernatur". In order to investigate the institutional change process, this study addresses the factors that triggered the institutional change, the process that led to the creation of the new Chilean NTA and the influence of contextual factors on both the process and the new NTA. Due to the involvement of your organisation in the recently enacted Tourism Act, your perspective about the process that led to the institutional change would be a relevant contribution to achieve the objectives above mentioned. The interview consists of six sections. Sections one and two relate to your professional and organisational background. Section three is focused on the process that led to the formulation of the tourism bill, while section four seeks to explore the political and economic conditions during the time the bill was formulated and discussed in Parliament. Section five analyses the new institutional framework in tourism and, finally section six analyses the roles of the new tourism institutional framework approved by the tourism bill in 2010.

\section{SECTION A: Respondent}

1. What is your position and role in this agency?

2. How long have you been in this position?

3. How long have you worked in this agency?

4. If you have worked in any other agency during the last 10 years, what was this agency and what was your position?

\section{SECTION B: Organisational background}

5. Please describe the type of organisation where you currently work and its roles

6. Please describe the internal structure of your organisation

7. If your agency is not exclusively focused on the tourism sector, what is the organisation's role in tourism and how is it structured to carry out this role?

\section{SECTION C: Tourism Act}

This set of questions seeks to identify the perspective of your organisation in relation to the process that to led the creation and approval of the Tourism Act.

8. What are the most relevant aspects of the Tourism Act in terms of the new structure and roles of the public tourism sector?

9. When did the initiative of creating a bill for tourism start? How was this idea developed?

10. What factors triggered the formulation of the tourism bill? And how are these factors expressed in the Act?

11. When was the tourism bill formulated? How was it formulated? And how was your organisation involved in the formulation?

12. How was the bill discussed in Parliament? And how was your organisation involved in this discussion?

13. The Institutional change in the Chilean tourism sector could have been achieved without creating a bill, Why was it necessary to create the bill to undertake the institutional change?

14. Did other options exist? If so, what were these options and why were they not adopted? 


\section{SECTION D: Institutional framework of the Chilean tourism sector.}

The next questions explore changes in the Chilean public institutional framework over the last ten years. The section is divided into three parts: the institutional framework before the bill was enacted, the institutional framework proposed in the tourism bill and the institutional framework approved by the Act.

\section{d.1. Before the Tourism Act was approved}

15. What was the tourism institutional framework in the country? And how was your organisation involved with this institutional framework?

16. Please describe the organisations included in this institutional framework in terms of functions, hierarchy, budget, and staff composition.

17. One of the components of the institutional framework was a council of ministers for tourism created in 2002. What can you tell me about this council?

\section{d.2 Tourism Bill (2007)}

18. How was your organisation involved in the formulation of the bill?

19. What were the most relevant elements of the institutional framework proposed in the bill? Who proposed this institutional framework and how was it proposed?

20. Was this institutional framework agreed on by all the stakeholders? If not, who had other ideas and what did they propose?

21. The tourism bill considered the creation of a Council of Ministers for Tourism, what are the differences between the council proposed in the bill and the council created in 2002?

22. Did your organisation agree with the institutional framework proposed in the tourism bill? If not, why not?

23. In 2004 and 2007 the government commissioned two consultants to analyse the structure and roles of the public tourism sector in Chile. What do you know about these projects? Was your organisation involved in them? How was your organisation involved? If your organisation was not involved, why was it not involved?

24. What are the main differences between these two consultancy projects? What factors may explain these differences?

25. What is the relationship between these consultancy projects and the tourism bill presented to Parliament in 2007?

d.3 Tourism Act (2010)

26. What are the most relevant aspects of the new institutional framework considered in the Tourism Act 2010?

27. Does your organisation agree with the institutional framework? If not, why not?

28. Are there differences between the bill before Parliament and the enacted act in terms of the institutional framework? If there are, what are these differences? And why were these differences produced?

29. How is your organisation involved with this new institutional framework?

30. What reasons may explain the particular structure approved by the Act?

\section{SECTION E: Political and economic conditions in the country}

The next set of questions focuses on identifying the political and economic conditions during the institutional change process in Sernatur. Diagram one (Annex 1) shows you a timeline with some relevant milestones previously identified. Based on this timeline, please identify the most important milestones for your organisation.

31. What milestones would you add to describe the political and economic conditions over this timeline? Why do you consider these particular milestones?

32. Can you show me in the diagram when the discussion to modify Sernatur started? When did the idea of creating the bill start? And when was the bill formulated? 


\section{SECTION F: New roles in the public tourism sector}

This section seeks to explore the new roles of the institutional framework post the Tourism Act 2010. Questions 33 to 35 are general for all interviewees, while questions included in sub sections f.1 to f.5 (Annex 2) will be used selectively depending on the background of the interviewee. For instance, sub section f.3 relates to private sector representatives, while sub section $f .4$ will be used with local government representatives.

33. The Tourism Act considers different areas related to the roles of the tourism public sector. What can you tell me about these areas?

34. How were these areas identified and prioritised to be included in the tourism bill?

35. Apart of the areas included in the bill/act, were there other areas which were not included in the bill/act? What are these areas? Why were they not adopted?

\section{SECCION G: Final considerations}

36. Apart from the points I have raised, are there any important ideas or themes that you would like to discuss?

37. Are there any important documents or reports that may be useful for my research?

38. Are there some other relevant stakeholders that you can suggest who might be helpful to interview for my research? 


\section{Political and economic conditions during the institutional change process}

\section{Institutional change process in Sernatur}

March 2000 - January 2010

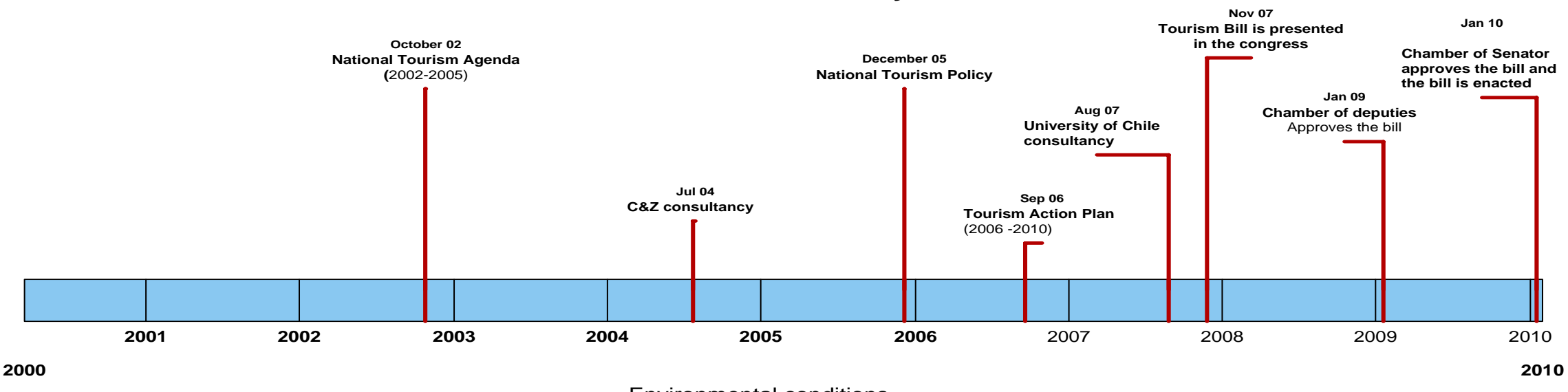

Environmental conditions

Political conditions

Economic conditions

Others 


\section{Questions based on the new institutional framework areas - roles}

\section{f.1. Tourism national policy}

39. Before the act was enacted, what was the process to formulate, approve and implement the tourism national policy? How was your organisation involved in this process? How does your organisation assess this process?

40. After the act was enacted, what is the new process to formulate, approve and implement the tourism national policy? How will your organisation be involved in this process? What are the most relevant changes?

41. Why was it necessary to bring about a change in the tourism policy arena?

42. Are there any differences between the bill presented in 2007 and the act enacted in 2010 in relation to the tourism policy arena? What are these differences?

43. How was your agency involved in the discussion of the policy arena during the formulation of the bill and its discussion in the Parliament?

44. Was there any proposal in the policy arena which were different to those proposed in the bill in 2007? What were these proposals? Who proposed them? Why were these proposals not adopted?

45. What are the implications of the change of roles in the tourism policies arena for the tourism sector and Sernatur?

46. Why was this particular structure for formulating, approving and implementing tourism policies adopted in the act?

\section{f.2. Zones of Interest for Tourism Development (ZOITs)}

47. Before the act was enacted, what was the process to formulate, approve and implement areas of tourist importance? How was your organisation involved in this process? How does your organisation assess this process?

48. After the act was enacted, what is the new process to formulate, approve and implement the areas of touristic importance? How will your organisation be involved in this process? What are the most relevant changes?

49. Why was it necessary to bring about a change in the arena of ZOITs?

50. Is there some difference between the bill presented in 2007 and the act enacted in 2010 in the arena of ZOITs? What are these differences?

51. How was your agency involved in the discussion of this arena during the formulation of the bill and its discussion in the Parliament?

52. Was there any proposal in this arena which was different to that proposed in the bill in 2007 ? What was this proposal? Who proposed it?

53. What are the implications of the change of roles in the arena of ZOITs for the tourism sector and Sernatur?

54. Why was this particular structure for formulating, approving and implementing ZOITs adopted in the act?

\section{f.3 Tourism international marketing}

55. Before the act was enacted, what was the process to formulate, approve and implement tourism international marketing plans and actions? How was your organisation involved in this process? How does your organisation assess this process?

56. After the act was enacted, what is the new process related to the scope of tourism international marketing? How will your organisation be involved in this process? What are the most relevant changes?

57. Why was it necessary to bring about a change in the international marketing arena?

58. Are there any differences between the bill presented in 2007 and the act enacted in 2010 in the arena of international marketing? What are these differences?

59. How was your agency involved in the discussion of the tourism marketing aspect during the formulation of the bill and its discussion in Parliament?

60. Were there any proposals in this arena which were different to those proposed in the bill in 2007 ? What were these proposals? Who proposed them?

61. The act considers the creation of a public-private council of marketing, When was this council proposed? Why was this particular structure proposed?

62. What are the implications of the change of roles in the arena of international marketing for the private tourism sector and Sernatur? 


\section{f.4 Tourism in national protected areas}

63. Before the act was enacted, what was the process to promote tourism in national protected areas? Who was involved in this process? How was your organisation involved in this process? How does your organisation assess this process?

64. After the act was enacted, what is the new process to promote tourism in national protected areas? What organisations will be involved? How will your organisation be involved in this process? What are the most relevant changes?

65. Were there any differences between the bill presented in 2007 and the act enacted in 2010 in this arena? What are these differences?

66. Why was this particular structure for promoting tourism in protected areas adopted in the act?

67. Why was it necessary to bring about a change in the arena of tourism in national protected areas?

68. When did the idea of promoting tourism in national protected areas emerge? How and why did the idea emerge?

69. How was your agency involved in the discussion of this arena during the formulation of the bill and its discussion in the Parliament?

70. Were there any proposals in this area which were different to those proposed in the bill in 2007 ? What were these proposals? Who proposed them?

71. What are the implications of the change of roles in the arena of tourism in protected areas for the tourism sector and Sernatur?

\section{f.5 System of tourism quality assurance}

72. Before the act was enacted, what was the system of quality assurance for tourism services? How was your organisation involved in this process? How does your organisation assess this system?

73. After the act was enacted, what is the new system? What organisations will be involved? How will your organisation be involved in this system? What are the most relevant changes?

74. What is the relationship between the system of quality assurance proposed in the Act and the tourism quality programme currently implemented by Sernatur?

75. Why was it necessary to bring about a change on the system of quality assurance?

76. In particular, the act considers the certification scheme as part of the new system of quality assurance, what are the implications of the certification scheme adopted by the act? And why was this particular scheme adopted by the act?

77. Are there any differences between the bill presented in 2007 and the act enacted in 2010 in this respect? What are these differences?

78. How was your agency involved in the discussion of this issue during the formulation of the bill and its discussion in the Parliament?

79. Were there any proposals which were different to those proposed in the bill in 2007? What were these proposals? Who proposed them?

80. What are the implications of the change of roles regarding the tourism quality system for the tourism sector and Sernatur? 
Appendix D:

List of documents collected in the field 


\begin{tabular}{|c|c|}
\hline Document title & Author \\
\hline Ley de Presupuestos al sector público & DIPRES \\
\hline $\begin{array}{l}\text { Chile País Turístico, Mesa publica privada y agenda de } \\
\text { trabajo 2002-2005 }\end{array}$ & Sernatur \\
\hline $\begin{array}{l}\text { Sistema de Calidad para los servicios turísticos 2004- } \\
2007\end{array}$ & Sernatur \\
\hline $\begin{array}{l}\text { Servicio Nacional de Turismo: Rediseño Institucional, } \\
\text { compendio modificaciones a la Ley Orgánica y } \\
\text { Reglamento del Servicio }\end{array}$ & Sernatur \\
\hline Política Nacional de Turismo & Sernatur \\
\hline $\begin{array}{l}\text { Evaluación Comprehensiva Programa Aplicación Ley } \\
19.255 \text { (CPR) }\end{array}$ & DIPRES \\
\hline $\begin{array}{l}\text { Evaluación Comprehensiva Sistema Nacional de Áreas } \\
\text { Silvestres Protegidas - SNASPE }\end{array}$ & DIPRES \\
\hline Propuesta Ley de Turismo & Sernatur \\
\hline Lineamientos para la Estrategia Nacional de Innovación & $\begin{array}{l}\text { Consejo de } \\
\text { Innovación }\end{array}$ \\
\hline Plan de Acción en Turismo 2006-2010 & Sernatur \\
\hline Estrategia Nacional de Innovación Volumen I & $\begin{array}{l}\text { Consejo de } \\
\text { Innovación }\end{array}$ \\
\hline Establece Régimen especial para trabajadores de turismo & $\begin{array}{l}\text { Cámara de } \\
\text { Diputados }\end{array}$ \\
\hline $\begin{array}{l}\text { Estudios de competitividad en clúster de la economía } \\
\text { Chilena. Doc. referencia en Turismo }\end{array}$ & $\begin{array}{l}\text { Boston Consulting } \\
\text { Group }\end{array}$ \\
\hline Institucionalidad pública para el turismo & Universidad de Chile \\
\hline Estrategia Nacional de Innovación Volumen II & $\begin{array}{l}\text { Consejo de } \\
\text { Innovación }\end{array}$ \\
\hline $\begin{array}{l}\text { Consultoría para el diseño de Programas y Agendas } \\
\text { estratégicas del clúster turismo }\end{array}$ & P4 and T.R.C \\
\hline $\begin{array}{l}\text { 1er Foro Nacional de Turismo: Indicaciones y } \\
\text { recomendaciones al proyecto de ley de turismo }\end{array}$ & $\begin{array}{l}\text { Sociedad Chilena de } \\
\text { investigadores en } \\
\text { Turismo }\end{array}$ \\
\hline Presentación de Organizaciones Sindicales de Conaf & Conaf's Union \\
\hline Travel \& Tourism Competitiveness Report 2009 & WEF \\
\hline Estudio Diagnostico Institucional del Sernatur & $\begin{array}{l}\text { Universidad Católica } \\
\text { de Valparaíso }\end{array}$ \\
\hline Tourism Development Programme & IADB \\
\hline Programme to Strengthen Conaf's Management Capacity & IADB \\
\hline $\begin{array}{l}\text { Proceso de Convocatoria Conaf Sernatur para el } \\
\text { desarrollo de inversiones sustentables en el SNASPE } \\
2005\end{array}$ & Conaf \\
\hline $\begin{array}{l}\text { Política para el desarrollo del ecoturismo en áreas } \\
\text { silvestres protegidas del estado y su entorno }\end{array}$ & Conaf \\
\hline $\begin{array}{l}\text { Política para concesiones turísticas al interior de las áreas } \\
\text { silvestres protegidas del estado }\end{array}$ & Conaf \\
\hline $\begin{array}{l}\text { Zonas y Centros de Interés Turístico. Procedimientos para } \\
\text { elaborar una declaratoria }\end{array}$ & Sernatur \\
\hline
\end{tabular}




\begin{tabular}{|l|l|}
\hline \multicolumn{1}{|c|}{ Document title } & \multicolumn{1}{|c|}{ Author } \\
\hline Manual Operativo relación de Conaf con terceros & Conaf \\
\hline $\begin{array}{l}\text { Zonas y Centros de Interés Antecedentes básicos para una } \\
\text { estrategia de ordenamiento territorial }\end{array}$ & Sernatur \\
\hline $\begin{array}{l}\text { Manual de procedimientos para el control de de } \\
\text { cumplimiento de concesiones }\end{array}$ & Conaf \\
\hline Bases para la gestión del turismo en SNASPE & Conaf \\
\hline $\begin{array}{l}\text { Experiencia de la convocatoria pública para el desarrollo del } \\
\text { ecoturismo en el SNASPE }\end{array}$ & Conaf \\
\hline El sistema de concesiones ecoturísticas de Conaf & Conaf \\
\hline $\begin{array}{l}\text { Turismo y Sistema Nacional de SNASPE para beneficio } \\
\text { local y Global }\end{array}$ & Conaf \\
\hline $\begin{array}{l}\text { Ley de turismo y Sistema Nacional de Áreas Protegidas del } \\
\text { Estado SNASPE }\end{array}$ & Conaf \\
\hline Agendas de Innovación de destinos turísticos & Corfo \\
\hline Balances de gestión integral Sernatur 2000-2010 & Sernatur \\
\hline $\begin{array}{l}\text { Chile y turismo, oportunidades para la innovación y el } \\
\text { emprendimiento }\end{array}$ & Corfo \\
\hline
\end{tabular}

\begin{tabular}{|l|l|}
\hline \multicolumn{1}{|c|}{ Act title } & \multicolumn{1}{c|}{ Content } \\
\hline DL 1224 Crea el Servicio Nacional de Turismo & Creates Sernatur \\
\hline D 188 Modifica el Reglamento de Sernatur & Modifies Sernatur roles \\
\hline $\begin{array}{l}\text { DL 1224 Crea el Sernatur e incluye } \\
\text { modificaciones }\end{array}$ & Modifications to DL 1224 \\
\hline $\begin{array}{l}\text { DL 1224 Crea el Sernatur e incluye } \\
\text { modificaciones derivadas de la ley 20423 }\end{array}$ & Modifications to DL 1224 \\
\hline DFL 7 Modifica la planta de Sernatur & Modifies Sernatur's staffing \\
\hline $\begin{array}{l}\text { Ley 19255 Permite a Sernatur formar parte de } \\
\text { corporaciones privadas para la promoción }\end{array}$ & $\begin{array}{l}\text { Allows Sernatur integrate } \\
\text { Private Corporations for } \\
\text { Marketing (CPT) }\end{array}$ \\
\hline $\begin{array}{l}\text { D 227 Aprueba reglamentos de calificación y } \\
\text { clasificación de alojamiento turístico }\end{array}$ & $\begin{array}{l}\text { Approves system for hotel's } \\
\text { classification based on stars }\end{array}$ \\
\hline D148 Modifica D227 & $\begin{array}{l}\text { Modifies D227 about } \\
\text { classification }\end{array}$ \\
\hline $\begin{array}{l}\text { Ley 20417 Crea el Ministerio de Medio } \\
\text { Ambiente }\end{array}$ & $\begin{array}{l}\text { Creates the Ministry of } \\
\text { Environment }\end{array}$ \\
\hline Ley 20283 de Bosque Nativo & Act about Native forest \\
\hline $\begin{array}{l}\text { Ley 20423 del Sistema institucional para el } \\
\text { desarrollo del turismo }\end{array}$ & $\begin{array}{l}\text { About the institutional system } \\
\text { for tourism development }\end{array}$ \\
\hline DFL 485 Ley de vivienda y Urbanismo & Act of Housing and Urbanism \\
\hline
\end{tabular}




\begin{tabular}{|l|l|}
\hline \multicolumn{1}{|c|}{ History of the act: document title } & \multicolumn{1}{c|}{ Chamber } \\
\hline Bill deposited in the Chamber of Deputies & Deputies \\
\hline $\begin{array}{l}\text { Summary of sessions (Commission of Tourism and } \\
\text { Economy) }\end{array}$ & Deputies \\
\hline $\begin{array}{l}\text { Summary of sessions (Commission of Economy and } \\
\text { Treasury) }\end{array}$ & Senators \\
\hline Report of the Commission of Tourism & Deputies \\
\hline Report of the Commission of Economy & Deputies \\
\hline Procedures with the debate during the second reading & Deputies \\
\hline Version of the bill sent to the Chamber of Senators & Deputies \\
\hline First Report of Economy Commission & Senators \\
\hline Procedures with the debate during the first reading & Senators \\
\hline Amendments to the bill & Senators \\
\hline Amendments to the bill & Senators \\
\hline Second Report of the Commission of Economy & Senators \\
\hline First Report of Commission of Treasury & Senators \\
\hline Procedures of debate during the second reading & Senators \\
\hline Procedures of debate during the second reading & Senators \\
\hline Bill with modifications sent to the Chamber of Deputies & Senators \\
\hline Memo with approval of amendments & Deputies \\
\hline Bill sent to be enacted & Deputies \\
\hline & \\
\hline
\end{tabular}


Appendix E:

List of interviewees 


\begin{tabular}{|c|c|c|}
\hline Interviewee & Organisation & Position \\
\hline Alcayaga, Juan & $\begin{array}{l}\text { Association of } \\
\text { Municipalities }\end{array}$ & President \\
\hline Arriagada, Lorena & Achet & Main Manager \\
\hline Bau, Catalina & Conaf & Former Conaf Director \\
\hline Cadiz, Trinidad & Corfo & Tourism programme officer \\
\hline Délano, Gabriel & Hotelga & Former Director of Consetur \\
\hline Delmastro, Roberto & $\begin{array}{l}\text { Treasury commission, } \\
\text { Chamber of Deputies }\end{array}$ & Deputy \\
\hline De la Fuente, Fernando & Achiga & Achiga \\
\hline De Urresti, Alfonso & Chamber of Deputies & Deputy \\
\hline Díaz, Miguel & Conaf & $\begin{array}{l}\text { Former Head of the Unit of } \\
\text { Protected Areas }\end{array}$ \\
\hline Ferreiro, Alejandro & Ministry of Economy & $\begin{array}{l}\text { Former Minister of } \\
\text { Economy }\end{array}$ \\
\hline Figueroa, Felipe & $\begin{array}{l}\text { Chamber of Tourism of } \\
\text { Valdivia }\end{array}$ & Main Director \\
\hline Galaz, José Luis & Conaf & $\begin{array}{l}\text { Former programme officer } \\
\text { of the Department of } \\
\text { Wildlife Heritage }\end{array}$ \\
\hline García (a), Rodolfo & Consetur & President \\
\hline García (b), Miguel & Eurochile & Former programme manager \\
\hline Goic, Carolina & Chamber of Deputies & Deputy \\
\hline Gonzalez, Ricardo & Sernatur & $\begin{array}{l}\text { Head of Programme of } \\
\text { Planning }\end{array}$ \\
\hline Iglesias, Sebastian & Sernatur & Ex Sernatur sub-director \\
\hline Lazo, Angel & Conaf & $\begin{array}{l}\text { Head of the programme of } \\
\text { ecotourism }\end{array}$ \\
\hline Loader, Claudio & Sernatur & $\begin{array}{l}\text { Head the Programme of } \\
\text { Quality }\end{array}$ \\
\hline Magnani, Mauro & Hoteleros de Chile & Director \\
\hline Martinez, Jorge & Conaf & President of Conaf's union \\
\hline Martinez, Luis & Indap & $\begin{array}{l}\text { Head of the Programme of } \\
\text { Rural Tourism }\end{array}$ \\
\hline Meliboski, Miguel & Hotelga & Director \\
\hline Moll, Pablo & Tourism Chile & Former Manager \\
\hline Monte, Javiera s & Sernatur & Sub Director of Sernatur \\
\hline Plumer, Marie Claude & Sernatur & Fiscal Sernatur \\
\hline Rebolledo, Pablo & Sernatur & $\begin{array}{l}\text { Fomer Fiscal lawyer \& } \\
\text { coordinator of the IADB } \\
\text { project }\end{array}$ \\
\hline Recondo, Carlos & Chamber of Deputies & Deputy \\
\hline Retamal, Pablo & Corfo & $\begin{array}{l}\text { Former Director Cluster of } \\
\text { Tourism }\end{array}$ \\
\hline Reyes, Jose & Sernatur & President Sernatur's Union \\
\hline Rivas, Humberto & Sernatur & $\begin{array}{l}\text { Former Head of planning } \\
\text { programme }\end{array}$ \\
\hline Rodríguez, Jorge & Dipres & Former programme officer \\
\hline
\end{tabular}




\begin{tabular}{|c|c|c|}
\hline Interviewee & Organisation & Position \\
\hline Santelices, Oscar & Sernatur & Nacional Director 2001- \\
& Societur & President \\
\hline Szmulewicz, Pablo & Fedetur & Main Director \\
\hline Yunis, Eugenio & Sernatur & Department of Planning \\
\hline Zamorano, Natacha & Ministry of Economy & $\begin{array}{c}\text { Assessor of the Minister of } \\
\text { Economy }\end{array}$ \\
\hline Zuñiga, Isabel & & \\
\end{tabular}


Appendix F:

List of themes, categories and subcategories 


\begin{tabular}{|c|c|c|}
\hline \multicolumn{3}{|c|}{ Theme 1 : THE INSTITUTIONAL CHANGE PROCESS } \\
\hline Category & Sub-Category & Issues \\
\hline $\begin{array}{l}\text { - Evaluation } \\
\text { - Consultation } \\
\text { - Participation } \\
\text { - Agreement } \\
\text { - Disagreement } \\
\text { - Negotiation } \\
\text { - Power } \\
\text { - Acceptance } \\
\text { - Environmental } \\
\text { conditions }\end{array}$ & 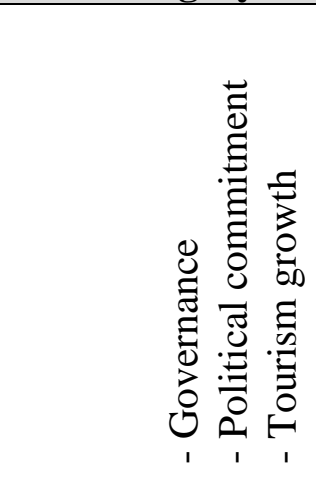 & \\
\hline
\end{tabular}

Theme 2 and 3: STRUCTURE OF THE NTA AND POLICY MAKING

\begin{tabular}{|c|c|c|}
\hline Category & Sub-Category & Issues \\
\hline $\begin{array}{l}\text { - Evaluation } \\
\text { - Consultation } \\
\text { - Participation } \\
\text { - Agreement } \\
\text { - Disagreement } \\
\text { - Negotiation } \\
\text { - Power } \\
\text { - Acceptance } \\
\text { - Environmental } \\
\text { conditions }\end{array}$ & 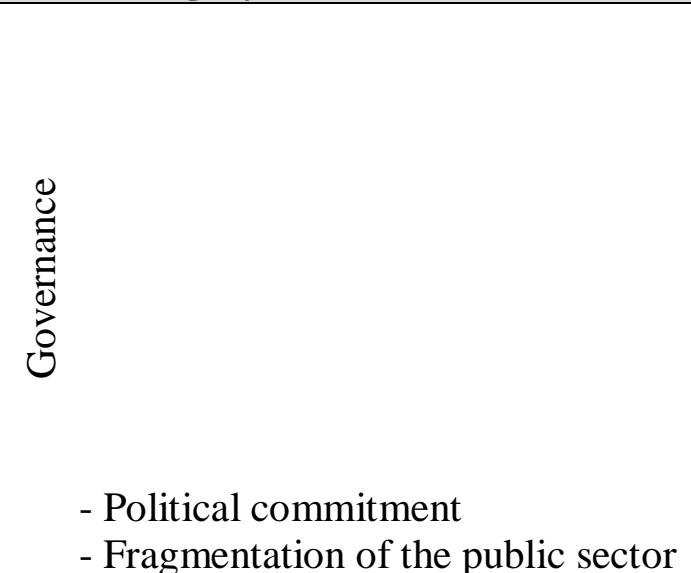 & $\begin{array}{l}\text { Funding } \\
\text { Effectiveness } \\
\text { Coordination } \\
\text { Transparency and } \\
\text { accountability }\end{array}$ \\
\hline
\end{tabular}

\begin{tabular}{|c|c|c|}
\hline \multicolumn{3}{|c|}{ Theme 4: MARKETING } \\
\hline Category & Sub-Category & Issues \\
\hline $\begin{array}{l}\text { - Evaluation } \\
\text { - Consultation } \\
\text { - Participation } \\
\text { - Agreement } \\
\text { - Disagreement } \\
\text { - Negotiation } \\
\text { - Power } \\
\text { - Acceptance }\end{array}$ & 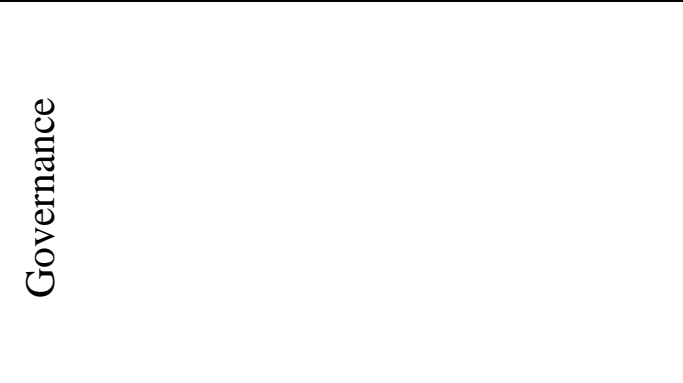 & $\begin{array}{l}\text { - Funding } \\
\text { - Effectiveness } \\
\text { - Coordination } \\
\text { - Transparency and } \\
\text { accountability }\end{array}$ \\
\hline $\begin{array}{l}\text { - Environmental } \\
\text { conditions }\end{array}$ & $\begin{array}{l}\text { - Political commitment } \\
\text { - Fragmentation of the public sector }\end{array}$ & \\
\hline
\end{tabular}




\begin{tabular}{|c|c|c|}
\hline \multicolumn{3}{|c|}{ Theme 5: PLANNING (TOURISM IN THE SNASPE) } \\
\hline Category & Sub-Category & Issues \\
\hline $\begin{array}{l}\text { - Evaluation } \\
\text { - Consultation } \\
\text { - Participation } \\
\text { - Agreement } \\
\text { - Disagreement } \\
\text { - Negotiation } \\
\text { - Power } \\
\text { - Acceptance } \\
\text { - Environmental } \\
\text { conditions }\end{array}$ & $\begin{array}{l}\text { - Tourism growth in the } \\
\text { SNASPE } \\
\text { - Political commitment } \\
\text { - Fragmentation of the public } \\
\text { sector } \\
\text { - Tourism growth }\end{array}$ & $\begin{array}{l}\text { - Funding } \\
\text { - Effectiveness } \\
\text { - Coordination }\end{array}$ \\
\hline
\end{tabular}

\begin{tabular}{|l|l|l|}
\hline \multicolumn{3}{|c|}{ Theme 5: PLANNING (ZOITs) } \\
\hline Category & Sub-Category & Issues \\
\hline - Evaluation & - Tourism growth & \\
- Agreement & & \\
& 0 & - Funding \\
& E & - Effectiveness \\
& - Coordination \\
- Environmental & - Political commitment & \\
conditions & - Fragmentation of the public & \\
& sector & \\
& - Tourism growth & \\
\hline
\end{tabular}

Theme 6: TOURISM QUALITY ASSURANCE

\begin{tabular}{|c|c|c|}
\hline Category & Sub-Category & Issues \\
\hline $\begin{array}{l}\text { - Evaluation } \\
\text { - Agreement } \\
\text { - Environmental } \\
\text { conditions }\end{array}$ & 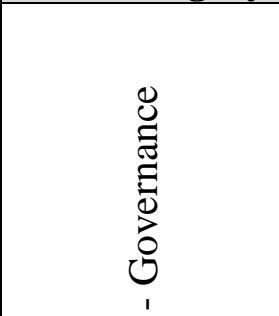 & - Effectiveness \\
\hline
\end{tabular}

